ORNL/TM-2014/464

\title{
Reactor Fuel Isotopics and Code Validation for Nuclear Applications
}

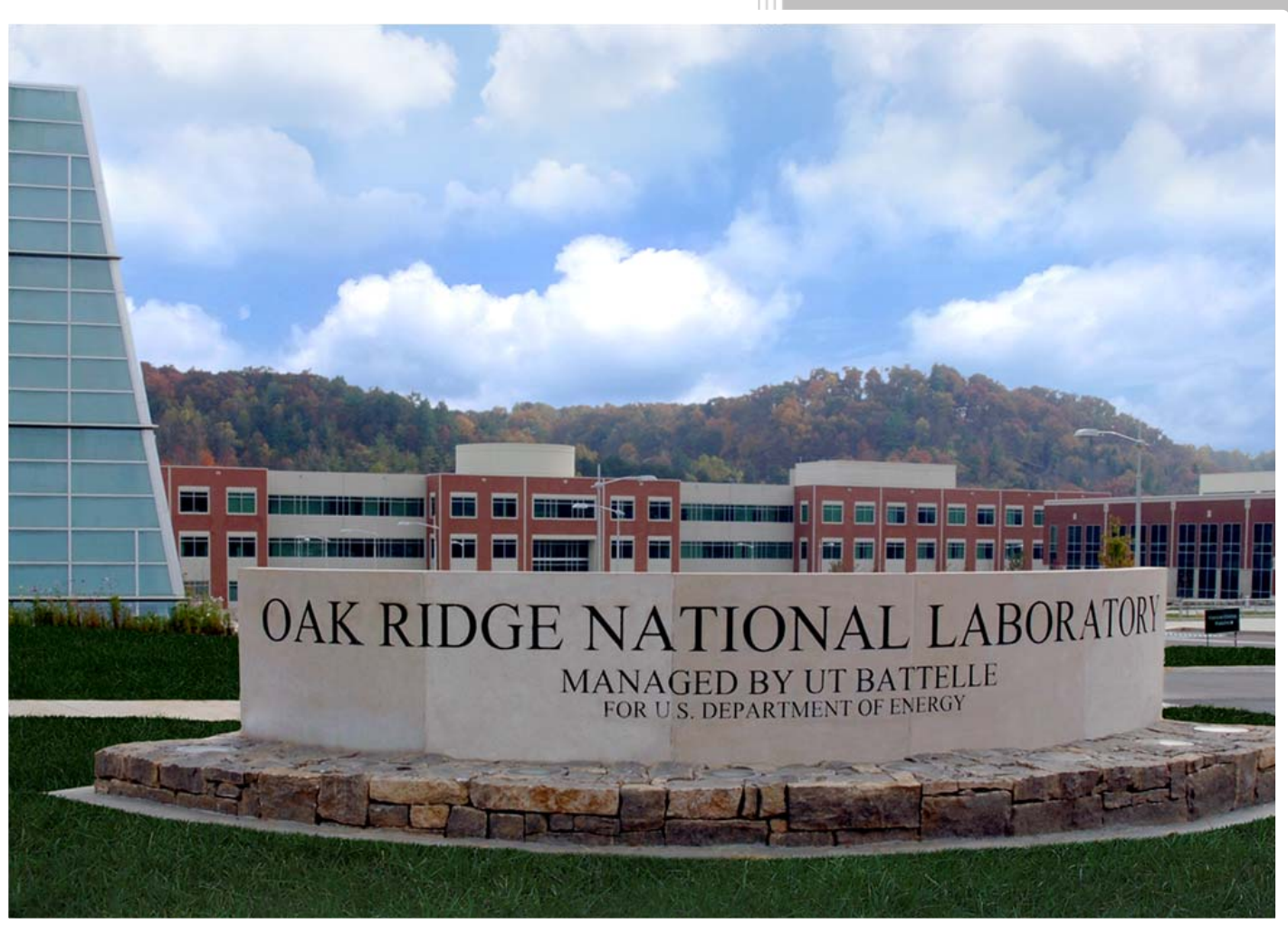

Approved for public release; distribution is unlimited.
Matthew W. Francis Charles F. Weber Marco T. Pigni Ian C. Gauld

\section{September 2014}




\section{DOCUMENT AVAILABILITY}

Reports produced after January 1, 1996, are generally available free via US Department of Energy (DOE) SciTech Connect.

Website http://www.osti.gov/scitech/

Reports produced before January 1, 1996, may be purchased by members of the public from the following source:

National Technical Information Service

5285 Port Royal Road

Springfield, VA 22161

Telephone 703-605-6000 (1-800-553-6847)

TDD 703-487-4639

Fax 703-605-6900

E-mail info@ntis.gov

Website http://www.ntis.gov/help/ordermethods.aspx

Reports are available to DOE employees, DOE contractors, Energy Technology Data Exchange representatives, and International Nuclear Information System representatives from the following source:

Office of Scientific and Technical Information

PO Box 62

Oak Ridge, TN 37831

Telephone 865-576-8401

Fax 865-576-5728

E-mail reports@osti.gov

Website http://www.osti.gov/contact.html

This report was prepared as an account of work sponsored by an agency of the United States Government. Neither the United States Government nor any agency thereof, nor any of their employees, makes any warranty, express or implied, or assumes any legal liability or responsibility for the accuracy, completeness, or usefulness of any information, apparatus, product, or process disclosed, or represents that its use would not infringe privately owned rights. Reference herein to any specific commercial product, process, or service by trade name, trademark, manufacturer, or otherwise, does not necessarily constitute or imply its endorsement, recommendation, or favoring by the United States Government or any agency thereof. The views and opinions of authors expressed herein do not necessarily state or reflect those of the United States Government or any agency thereof. 
Reactor and Nuclear Systems Division

\title{
REACTOR FUEL ISOTOPICS AND CODE VALIDATION FOR NUCLEAR APPLICATIONS
}

\author{
Matthew W. Francis \\ Charles F. Weber \\ Marco T. Pigni \\ Ian C. Gauld
}

Date Published:

September 2014

$$
\text { Prepared by }
$$

OAK RIDGE NATIONAL LABORATORY

Oak Ridge, Tennessee 37831-6283

managed by

UT-BATTELLE, LLC

for the

US DEPARTMENT OF ENERGY

under contract DE-AC05-00OR22725 



\section{CONTENTS}

LIST OF FIGURES

Page

LIST OF TABLES

$\mathrm{V}$

ACRONYMS AND UNITS

ix

ACKNOWLEDGMENTS

xi

ABSTRACT.

xiii

1. INTRODUCTION

$\mathrm{XV}$

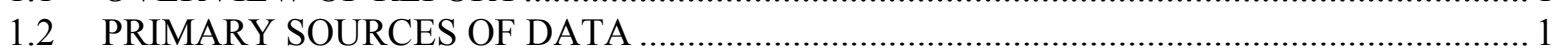

1.3 STANDARDIZATION OF FIGURES …................................................................ 2

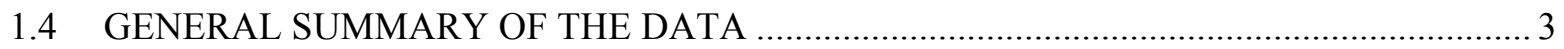

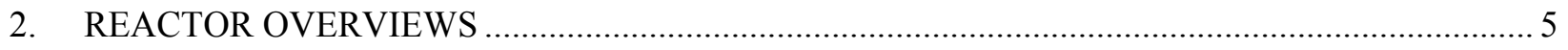

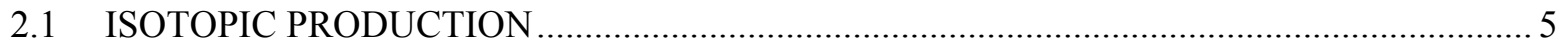

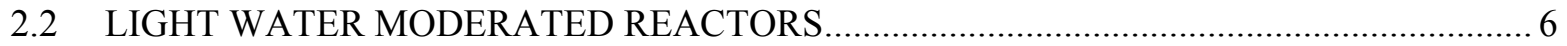

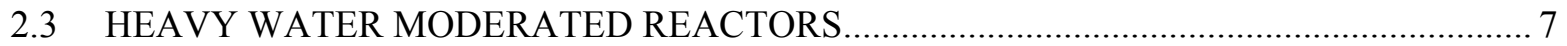

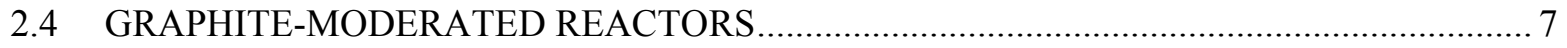

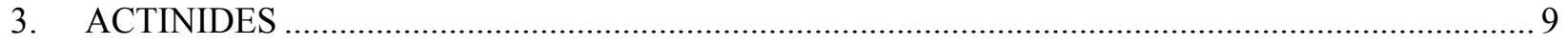

3.1 OVERVIEW OF ACTINIDE PRODUCTION ................................................................ 9

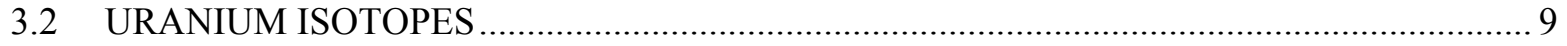

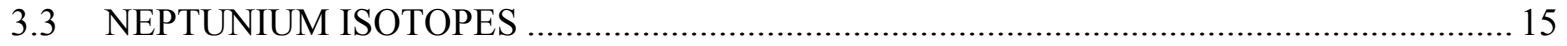

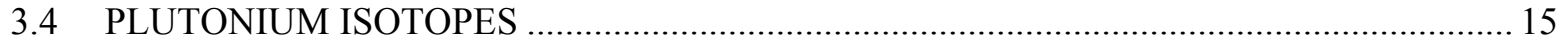

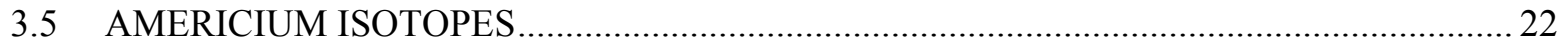

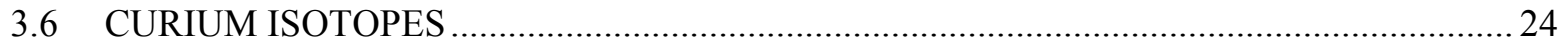

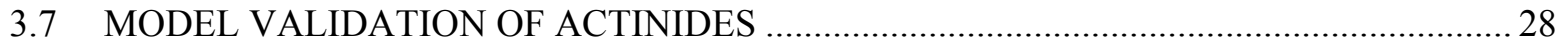

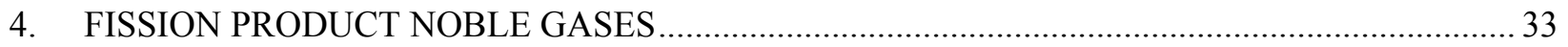

4.1 OVERVIEW OF FISSION PRODUCT NOBLE GAS PRODUCTION .................................. 33

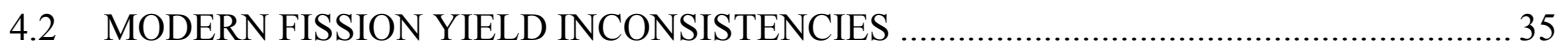

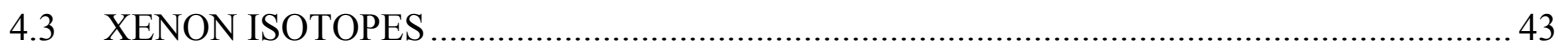

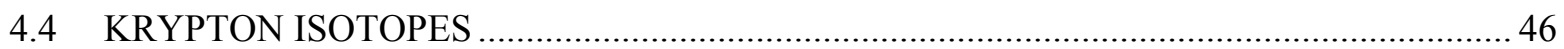

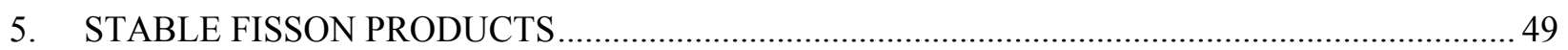

5.1 OVERVIEW OF STABLE FISSION PRODUCT PRODUCTION ...................................... 49

5.2 NEODYMIUM ISOTOPES

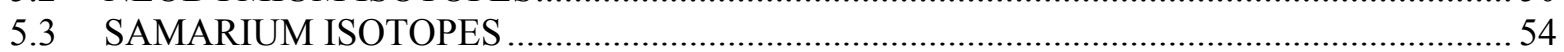

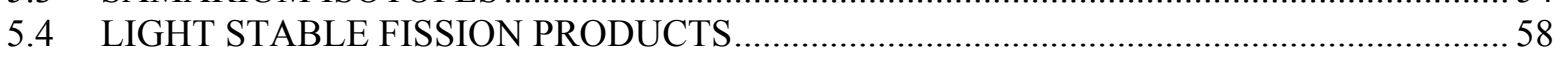

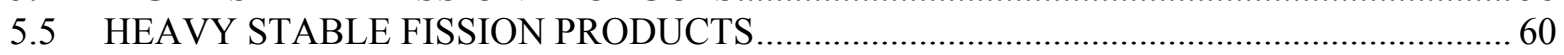

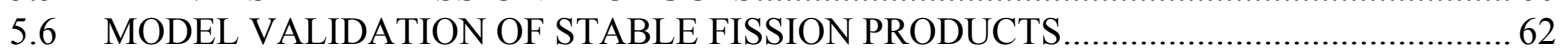

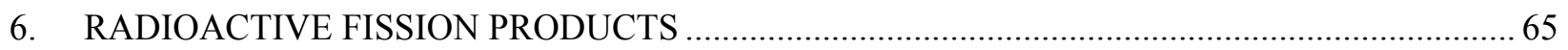

6.1 OVERVIEW OF RADIOACTIVE FISSION PRODUCT PRODUCTION ................................65

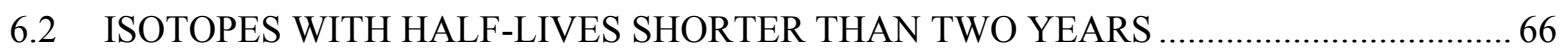

6.3 ISOTOPES WITH HALF-LIVES BETWEEN TWO AND TEN YEARS ............................... 68

6.4 ISOTOPES WITH HALF-LIVES BETWEEN TEN AND ONE HUNDRED YEARS .......... 72

6.5 ISOTOPES WITH HALF-LIVES GREATER THAN ONE HUNDRED YEARS ................ 74

6.6 MODEL VALIDATION OF RADIOACTIVE FISSION PRODUCTS .............................. 76

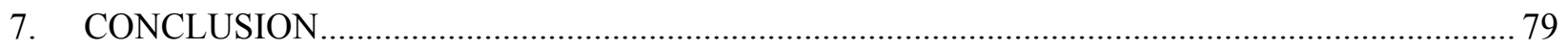

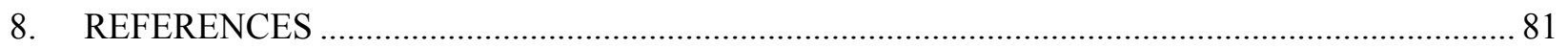

APPENDIX A. CORRECTING FISSION YIELD INCONSISTENCIES ......................................... A-1

A.1 FORMALIZED FISSION YIELD DEFINITIONS ……..................................................... A

A.2 CORRECTION UTILIZING A BAYESIAN METHOD …............................................. A-5 



\section{LIST OF FIGURES}

Figure

Page

1. Normalized flux as a function of energy for different moderators. .................................................... 6

2. Relative fission rates for four primary fissionable isotopes for a generic PWR with $4 \mathrm{wt} \% \mathrm{U}-235 \ldots \ldots 10$

3. Relative fission rates for four primary fissionable isotopes for a generic CANDU with natural

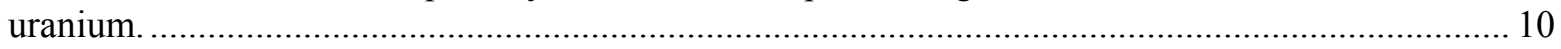

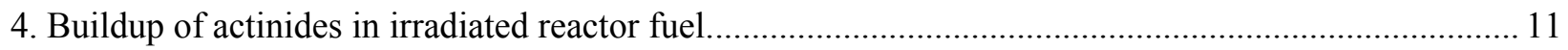

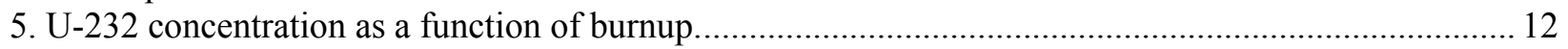

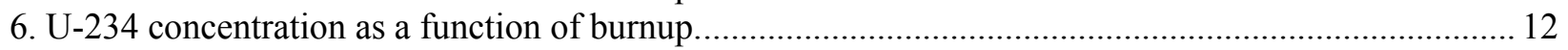

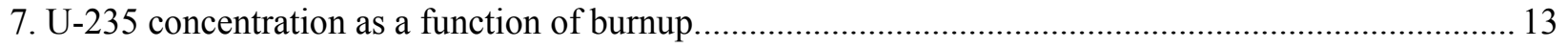

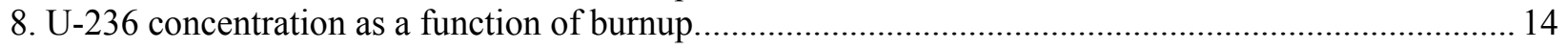

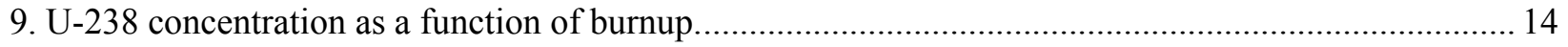

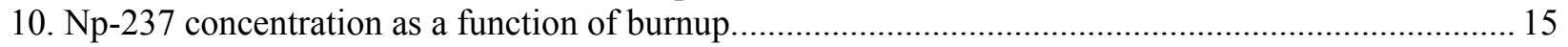

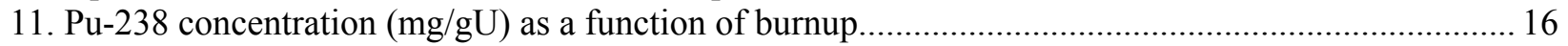

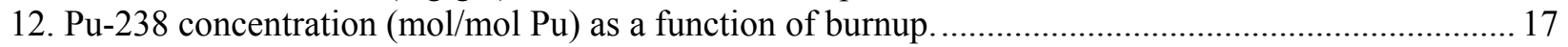

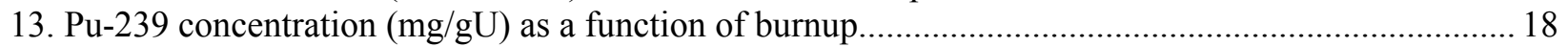

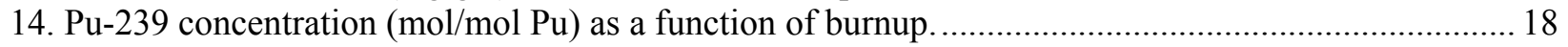

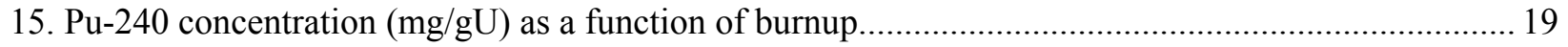

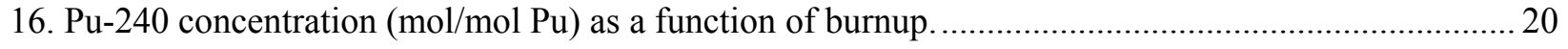

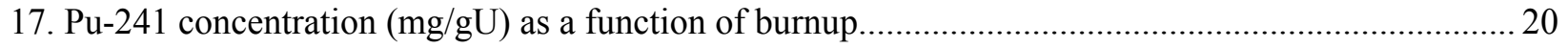

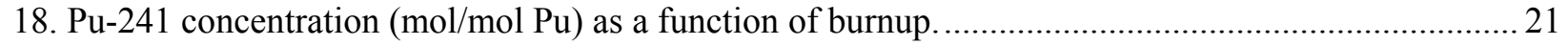

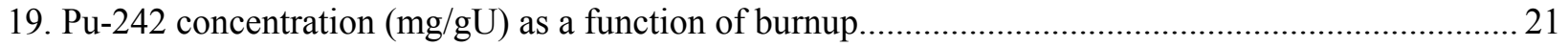

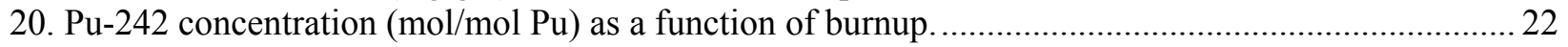

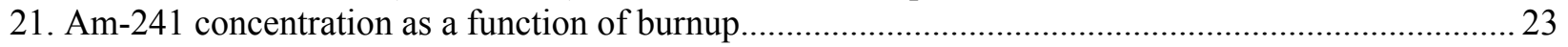

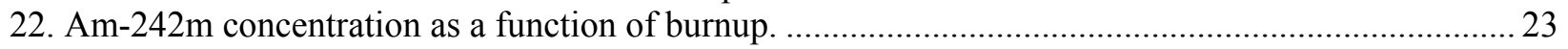

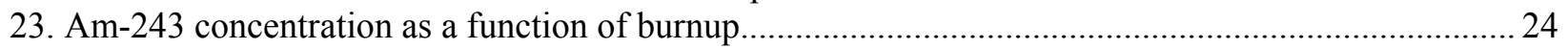

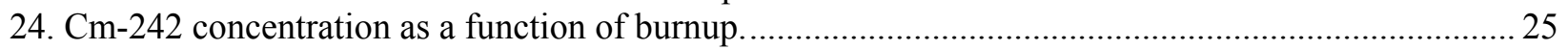

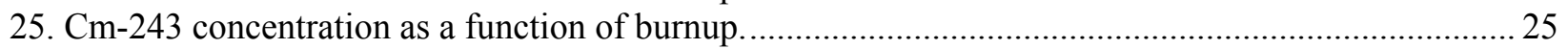

26. Cm-244 concentration as a function of burnup......................................................................... 26

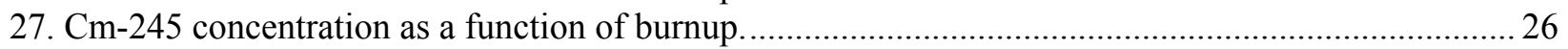

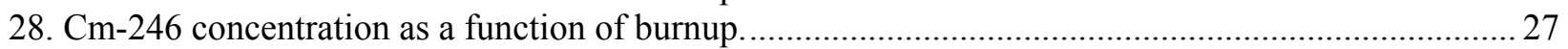

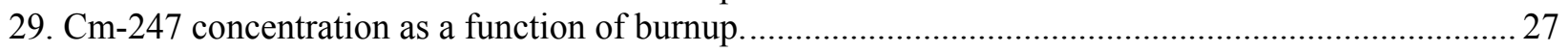

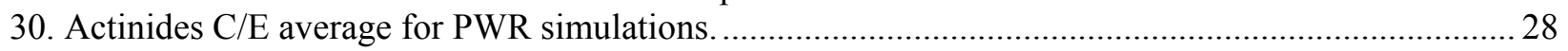

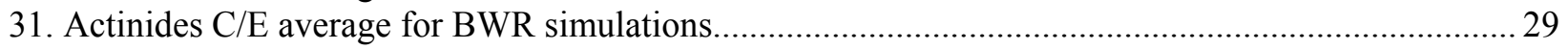

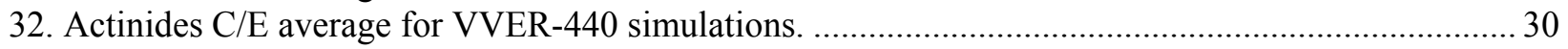

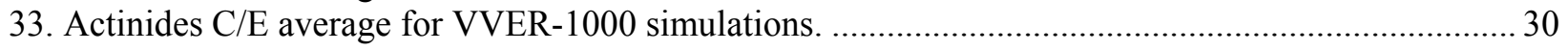

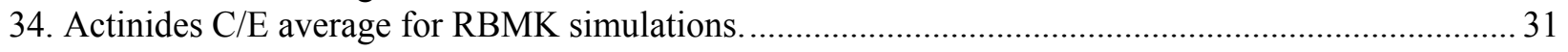

35. Actinides $\mathrm{C} / \mathrm{E}$ average for Hanford $\mathrm{B}$ reactor (graphite pile) simulations....................................... 31

36. Mass distribution of fission product noble gases from thermal fission of U-235 and Pu-239............. 33

37. Measured xenon concentrations as a function of relative fuel radius compared to theoretical

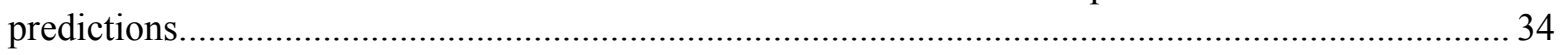

38. Ratio of calculated-to-reported ENDF/B-VII.1 cumulative yields for the ends of the mass chains for U-235 fissioned with thermal neutrons.

39. Ratio of calculated-to-reported ENDF/B-VII.1 cumulative yields for the ends of the mass chains for U-235 fissioned with thermal neutrons (zoomed view of Fig. 38).

40. Ratio of calculated-to-reported ENDF/B-VII.1 cumulative yields for the ends of the mass chains for $\mathrm{Pu}-239$ fissioned with thermal neutrons. 
41. Ratio of calculated-to-reported ENDF/B-VII.1 cumulative yields for the ends of the mass chains for $\mathrm{U}-238$ fissioned with fast neutrons.

42. Ratio of calculated-to-reported ENDF/B-VII.1 cumulative yields for the ends of the mass chains for $\mathrm{Pu}-241$ fissioned with thermal neutrons.

43. Mole fraction Xe-131/total xenon.

44. Mole fraction Xe-132/total xenon.

45. Mole fraction Xe-134/total xenon......

46. Mole fraction Xe-136/total xenon...

47. Mole fraction $\mathrm{Kr}-83 /$ total krypton...

48. Mole fraction $\mathrm{Kr}-84 /$ total krypton...

49. Mole fraction $\mathrm{Kr}-86 /$ total krypton...

50. Mole fraction $\mathrm{Kr}-85 / \mathrm{Kr}-86$.

51. Mass distribution of stable fission products from thermal fission of $\mathrm{U}-235$ and $\mathrm{Pu}-239$ covered in this section.

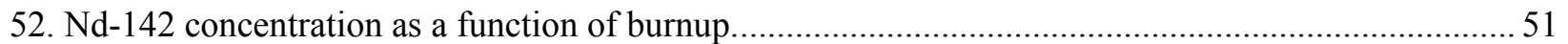

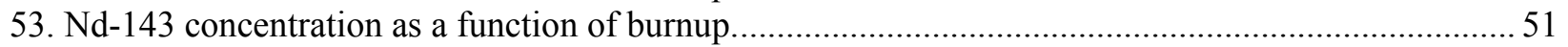

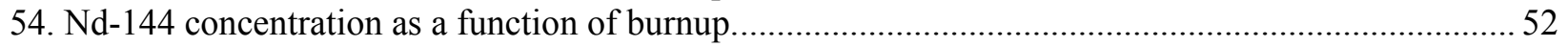

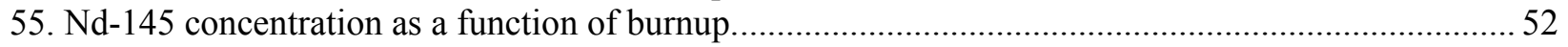

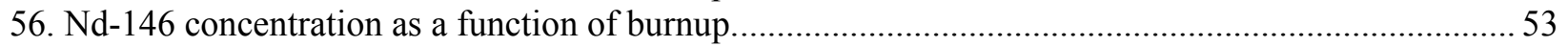

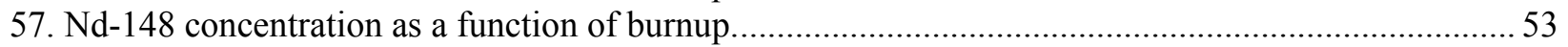

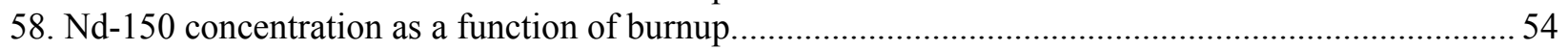

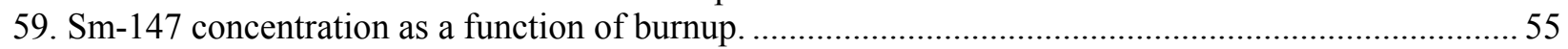

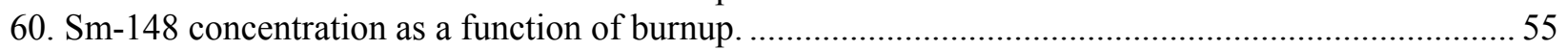

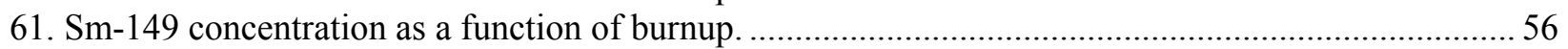

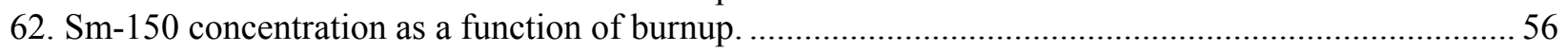

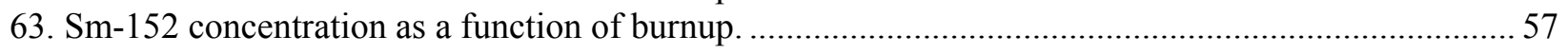

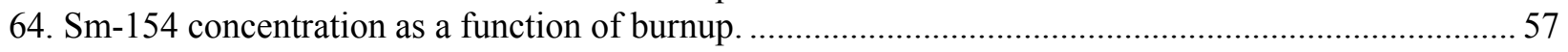

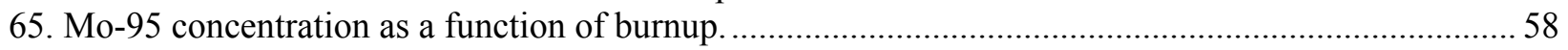

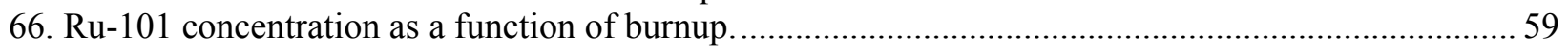

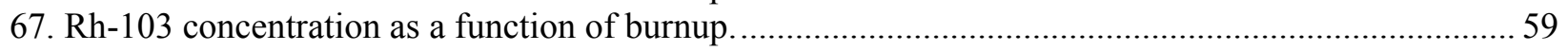

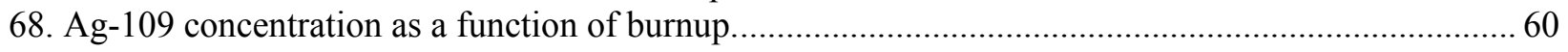

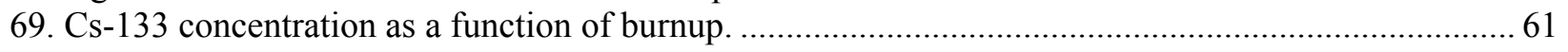

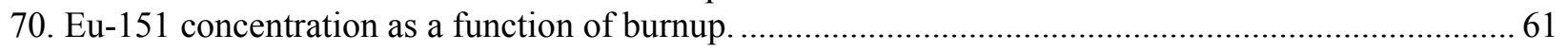

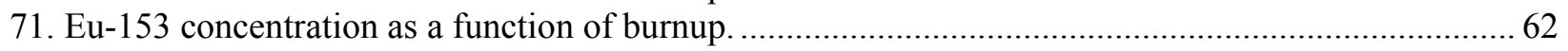

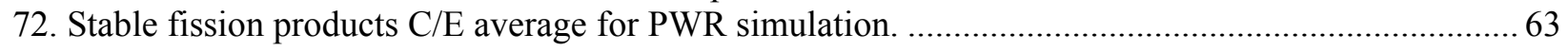

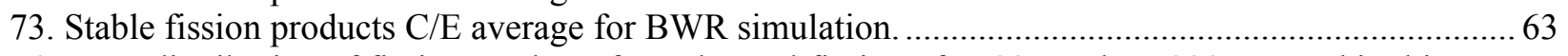

74. Mass distribution of fission products from thermal fission of $\mathrm{U}-235$ and $\mathrm{Pu}-239$ covered in this

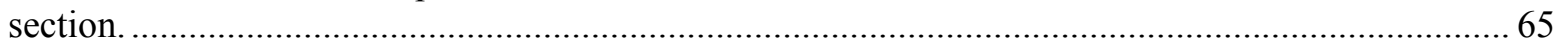

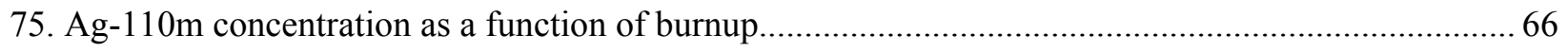

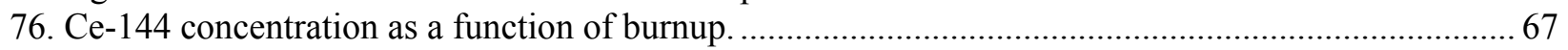

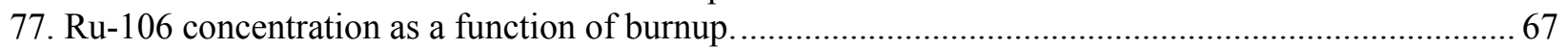

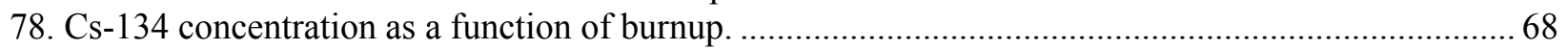

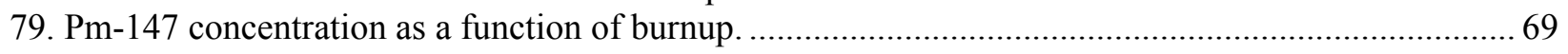

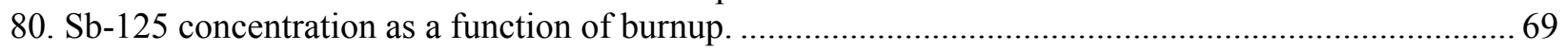

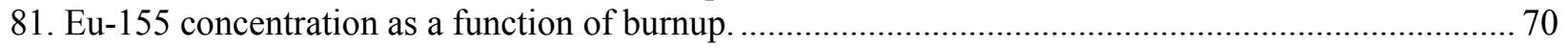

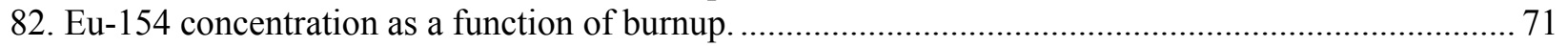

83. The effect of a hardened spectrum on Eu-154 concentration in a BWR .......................................... 71

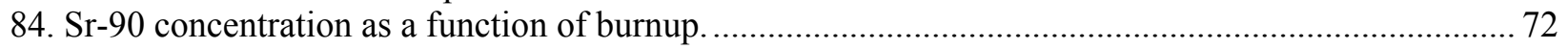

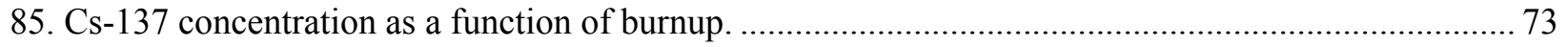

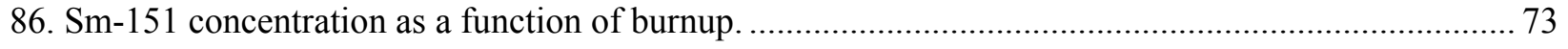

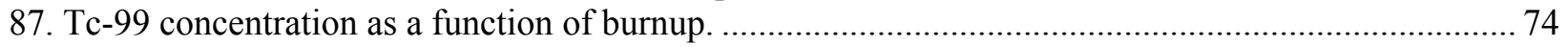




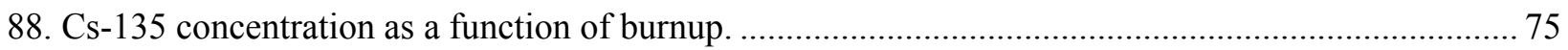

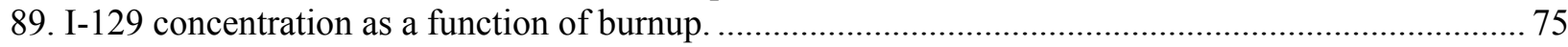

90. Radioactive fission products $\mathrm{C} / \mathrm{E}$ average for PWR simulation. .................................................... 76

91. Radioactive fission products $\mathrm{C} / \mathrm{E}$ average for BWR simulation....................................................... 77 


\section{LIST OF TABLES}

\section{Table}

Page

Table 1. Number of samples for each isotope and reactor type plotted in this report............................... 4

Table 2. Thermal and fast flux-averaged absorption plutonium isotope cross sections............................. 19

Table 3. Comparison of England and Rider (1993) and ENDF/B-VII.1 (2011) branching ratios

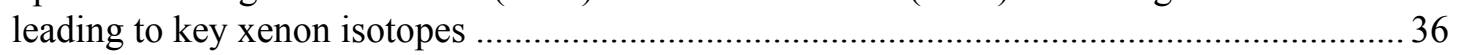

Table 4. Calculated cumulative yields using 2011 branching ratios and reported cumulative yields for the chains leading to key xenon isotopes (U-235 thermal)........................................... 37

Table 5. Comparison of England and Rider (1993) and ENDF/B-VII.1 (2011) branching ratios leading to key krypton isotopes...

Table 6. Calculated cumulative yields using 2011 branching ratios and reported cumulative yields for the chains leading to key krypton isotopes (U-235 thermal). 



\section{ACRONYMS AND UNITS}

$\begin{array}{ll}\text { AGR } & \text { advanced gas-cooled reactor } \\ \text { BWR } & \text { boiling water reactor } \\ \text { CANDU } & \text { CANada Deuterium Uranium reactor } \\ \text { ENDF } & \text { evaluated nuclear data file } \\ \text { g } & \text { gram } \\ \text { GKN } & \text { Gemeinschaftskraftwerk Neckar } \\ \text { GWd } & \text { Gigawatt-days } \\ \text { gU } & \text { gram of uranium } \\ \text { IFPE } & \text { International Fuel Performance Experiments database } \\ \text { LWR } & \text { light water reactor } \\ \text { mg } & \text { milligram } \\ \text { mol } & \text { mole } \\ \text { MAGNOX } & \text { magnesium non-oxidizing fuel cladding } \\ \text { MTU } & \text { metric ton of uranium } \\ \text { NEA } & \text { Nuclear Energy Agency } \\ \text { NPD } & \text { Nuclear Power Demonstration } \\ \text { OECD } & \text { Organization for Economic Co-operation and Development } \\ \text { ORIGEN } & \text { Oak Ridge Isotope GENeration code } \\ \text { ORNL } & \text { Oak Ridge National Laboratory } \\ \text { PWR } & \text { pressurized water reactor } \\ \text { RBMK } & \text { Reaktor Bolshoy Moschnosti Kanalnyy (high power channel-type reactor) } \\ \text { SFCOMPO } & \text { Spent Fuel Isotopic Composition database } \\ \text { SNF } & \text { spent nuclear fuel } \\ \text { TIHM } & \text { ton of initial heavy metal } \\ \text { VVER } & \text { Voda Voda Energo Reactor (Water Water Power Reactor) } \\ & \end{array}$





\section{ACKNOWLEDGMENTS}

This work was funded by the Office of Defense Nuclear Nonproliferation Research and Development (NA-22) within the US Department of Energy's National Nuclear Security Administration. The authors are grateful to Germina Ilas and Vince Jodoin, Oak Ridge National Laboratory staff members, for their technical review. 


\begin{abstract}
Experimentally measured isotopic concentrations of well characterized spent nuclear fuel (SNF) samples have been collected and analyzed by previous researchers. These sets of experimental data have been used extensively to validate the accuracy of depletion code predictions for given sets of burnups, initial enrichments, and varying power histories for different reactor types. The purpose of this report is to present the diversity of data in a concise manner and summarize the current accuracy of depletion modeling. All calculations performed for this report were done using the Oak Ridge Isotope GENeration (ORIGEN) code, an internationally used irradiation and decay code solver within the SCALE comprehensive modeling and simulation code. The diversity of data given in this report includes key actinides, stable fission products, and radioactive fission products.

In general, when using the current ENDF/B-VII.0 nuclear data libraries in SCALE, the major actinides are predicted to within 5\% of the measured values. Large improvements were seen for several of the curium isotopes when using improved cross section data found in evaluated nuclear data file ENDF/B-VII.0 as compared to ENDF/B-V-based results. The impact of the flux spectrum on the plutonium isotope concentrations as a function of burnup was also shown. The general accuracy noted for the actinide samples for reactor types with burnups greater than 5,000 MWd/MTU was not observed for the low-burnup Hanford B samples. More work is needed in understanding these large discrepancies.

The stable neodymium and samarium isotopes were predicted to within a few percent of the measured values. Large improvements were seen in prediction for a few of the samarium isotopes when using the ENDF/B-VII.0 libraries compared to results obtained with ENDF/B-V libraries. Very accurate predictions were obtained for ${ }^{133} \mathrm{Cs}$ and ${ }^{153} \mathrm{Eu}$. However, the predicted values for the stable ruthenium and rhodium isotopes varied as much as $10 \%$ of the measured values, and ${ }^{109} \mathrm{Ag}$ was consistently over-predicted by as much as $170 \%$.

In general, there is a larger uncertainty for modeling radioactive fission products when compared to either the actinides or the stable fission products in SNF. The relative $\mathrm{C} / \mathrm{E}$ ratios ranged from a few percent for ${ }^{137} \mathrm{Cs}$ up to $60 \%$ and $100 \%$ for ${ }^{106} \mathrm{Ru}$ and ${ }^{125} \mathrm{Sb}$, respectively. Limited or no radioactive fission products data exist in the current data sets for reactor types other than PWRs and BWRs. More work is needed in obtaining a greater diversity of radioactive fission product data.

While performing this survey, issues leading to inconsistencies in nuclear fission yield data were discovered that specifically impacted the fission product noble gases. Emphasis was given to this legacy data, and corrective actions were taken as described in this report. After the fission yield data were corrected, the stable xenon and krypton fission products were predicted to within $5 \%$ of their measurements. However, preliminary results not explicitly given in this report indicate that the relative $\mathrm{C} / \mathrm{E}$ ratio for the radioactive isotope ${ }^{85} \mathrm{Kr}$ varied as much as $10 \%$. Due to the complex migration and the difficulty in measuring noble gases in the fuel, a more thorough investigation is needed to understand how accurately depletion codes can calculate these gas concentrations.
\end{abstract}





\section{INTRODUCTION}

\subsection{OVERVIEW OF REPORT}

Experimentally determined isotopic concentrations of well characterized spent nuclear fuel (SNF) samples have been collected and analyzed by previous researchers and included in databases for use in validation studies. ${ }^{1-7}$ These databases have been used extensively to validate the accuracy of depletion code predictions for given burnups, initial enrichments, and varying power histories and for different reactor types. ${ }^{8-28}$ The purpose of this report is to present the diversity of data in a concise manner and summarize the current accuracy of depletion modeling. Special focus is given to SCALE, Oak Ridge National Laboratory's (ORNL) nuclear systems modeling and simulation code, and Oak Ridge Isotope GENeration (ORIGEN), an internationally used irradiation and decay code solver within SCALE, due to their extensive validation against measured SNF composition data. ${ }^{8-13,16-21,23-28}$ During this survey, issues with current evaluated nuclear data files were discovered, specifically impacting fission product noble gas production. Additional emphasis was given to this legacy data, and the corrective actions that were taken are described herein.

The remainder of this introductory section describes the primary sources of measurement data, provides an overview of how the data will be presented, and presents a general summary of the data.

Section 2 is an overview on the governing equations of isotopic concentrations during irradiation and decay. Based on the large impact of the moderator on the neutron flux spectrum (as further discussed), the reactor types addressed within this report are grouped with respect to the moderator type.

Section 3 covers the actinide data, along with the associated validation work.

Section 4 focuses on fission product noble gases. The noble gases are discussed separately from other fission products because (1) the noble gases are rarely used for validation of depletion codes due to the measurement challenge presented by their high migratory nature, and (2) the issues with legacy nuclear data became evident while performing validation calculations on these fission products.

Section 5 reports on the data and validation of stable fission products other than the stable noble gases. Neodymium and samarium are discussed in their own subsections due to the large number of stable isotopes. The remaining stable fission products are divided into the light fission products $(<110$ mass number) and heavy fission products ( $>125$ mass number).

The radioactive fission product data and past validation work are covered in Section 6 . These fission products are grouped by half-life: (1) less than two years, (2) between two and 10 years, (3) between 10 and 100 years, and (4) greater than 100 years.

Finally, Section 7 provides the conclusions of the report.

\subsection{PRIMARY SOURCES OF DATA}

The primary source of data discussed in this report is the Spent Fuel Isotopic Composition database (SFCOMPO) maintained by the Nuclear Energy Agency (NEA) within the Organization for Economic Co-operation and Development (OECD). ${ }^{6}$ The SFCOMPO was originally developed at the Japan Atomic Energy Research Institute (JAERI) Department of Fuel Cycle Safety Research in the Fuel Cycle Safety Evaluation Laboratory. ${ }^{2-5}$ Available through the internet, this database provides measured isotopic composition data that can be used for the validation of burnup codes.

In 2011, the OECD/NEA initiated a major development effort to restructure the SFCOMPO database. ${ }^{6}$ The new SFCOMPO is being developed under the guidance of the Expert Group on Assay Data of Spent Nuclear Fuel (EGADSNF). The primary goal of the restructured database is to provide access to open experimental SNF data to ensure preservation and to "facilitate their qualification as evaluated assay data suitable for the validation of methodologies used to predict the composition of irradiated nuclear fuel." The data are drawn from a large variety of references spanning several decades. 
Historically, SFCOMPO did not report the noble fission gas results found in the same reports from which other isotopic data were gleaned. Therefore, by returning to the original measurement reports, the noble fission gas data were extracted and are included within the current report. The OECD/NEA International Fuel Performance Experiments (IFPE) database was also utilized to extract further fissionproduct noble gas data. The aim of the IFPE database was to provide in the public domain, "a comprehensive and well-qualified database on $\mathrm{Zr}$ clad $\mathrm{UO}_{2}$ fuel for model development and code validation., 29

\subsection{STANDARDIZATION OF FIGURES}

This section describes how the data are presented. Much of the data in this report are presented in standardized figures to allow for comparisons. While all trends for a single isotopic concentration could not easily be presented in a single figure, as much information is presented as possible while still allowing for clear interpretation. Some trends and observations not depicted here may be examined in the future.

Measured data are reported by different laboratories in a wide variety of units. To the extent possible, this report plots isotopic data in concentration units of milligrams per gram of initial uranium. Data were not used if they were not originally reported in this unit or if they could not be easily converted. This unit was chosen because the large majority of available data are reported in this or a similar unit.

Much of the data that were reported in units of milligrams per gram of final uranium or were given in mass or atom ratios were not included in this report. The one exception to this rule was for the plutonium isotopes, for which atom ratios were plotted in a second figure, along with the standard concentration plot. It was decided to plot all concentrations of individual isotopes as a function of burnup reported in units of Gigawatt-days per ton of initial heavy metal (GWd/TIHM). For most cases, the initial heavy metal is only uranium; therefore, TIHM is equivalent to the more familiar unit of metric ton of uranium (MTU).

A different color was selected for each sample data point taken from a specific reactor type (see Section 2 for a description of the reactor types included in this report). The following color coding was used:

\begin{tabular}{ll}
\hline Pressurized Water Reactor (PWR): & red \\
Boiling Water Reactor (BWR): & blue \\
CANDU: & purple \\
MAGNOX: & light blue \\
\hline RBMK: & black \\
\hline Russian Water-Water Power Reactor (VVER): & green \\
Advanced Gas-Cooled Reactor (AGR): & orange \\
Graphite Pile: & light purple \\
\hline
\end{tabular}

The differences in initial uranium enrichment were also differentiated by the shape of the data point. The following shapes were used to represent their corresponding initial enrichment:

$$
\begin{aligned}
& \text { Circle = natural uranium }(\sim 0.71 \mathrm{wt} \%) \\
& \text { Square }=1 \text { to } 2 \mathrm{wt} \%{ }^{235} \mathrm{U} \\
& \text { Triangle }=2 \text { to } 3 \mathrm{wt}^{235}{ }^{235} \mathrm{U} \\
& \text { Diamond }=3 \text { to } 4 \mathrm{wt} \%{ }^{235} \mathrm{U} \\
& \times=4 \text { to } 5 \mathrm{wt} \%{ }^{235} \mathrm{U}
\end{aligned}
$$

A shape not filled in with a color represents a sample from a reactor that also uses gadolinium as a burnable poison.

In addition to single points that correspond to measurement data, each plot contains a generic PWR ORIGEN simulation curve to help the reader observe a general expected trend with a particular isotope as 
a function of burnup. For isotopes that either have noticeable decay or buildup changes within a typical decay time (from fuel discharge to time of measurements) of 3 to 10 years, generic ORIGEN simulation curves were generated for varying decay times. ORIGEN results for various initial enrichments can be seen on the uranium isotope figures, and generic ORIGEN results for various reactor types can be seen on the plutonium isotope figures. These figures should not be used to deduce a quantitative uncertainty in modeling results as compared to measured values since the detailed modeling of each fuel sample was not performed. Utilizing actual reactor parameters with respect to specific sample points, true average quantitative validation results can be obtained and are reported in Sections 3.7, 5.6, and 6.6 for select isotopes.

\subsection{GENERAL SUMMARY OF THE DATA}

Table 1 presents the number of samples for each isotope and for each reactor type. While more actinide data could be included in this report if units normalized to final concentrations were used, the majority of the reported fission products are captured in this report. Well characterized samples with fission product data are not currently included in OECD databases for reactors other than PWRs, BWRs, VVERs, and CANDUs. 
Table 1. Number of samples for each isotope and reactor type plotted in this report

\begin{tabular}{|c|c|c|c|c|c|c|c|c|}
\hline Isotope & PWR & BWR & VVER & CANDU & RBMK & MAGNOX & AGR & Hanford \\
\hline${ }^{232} \mathrm{U}$ & 16 & & & & & & & \\
\hline${ }^{234} \mathrm{U}$ & 55 & 18 & & 1 & & & & \\
\hline${ }^{235} \mathrm{U}$ & 135 & 30 & 6 & 1 & & & & \\
\hline${ }^{236} U$ & 113 & 30 & 6 & 1 & & & & \\
\hline${ }^{238} \mathrm{U}$ & 105 & 30 & 6 & 1 & & & & \\
\hline${ }^{237} \mathrm{~Np}$ & 50 & 18 & & & & & & \\
\hline${ }^{238} \mathrm{Pu}^{a}$ & $122 / 138$ & $30 / 30$ & $6 / 34$ & $1 / 2$ & $/ 41$ & $/ 4$ & $/ 62$ & $17 / 17$ \\
\hline${ }^{239} \mathrm{Pu}^{a}$ & $131 / 153$ & $30 / 30$ & $6 / 34$ & $1 / 7$ & / 41 & $/ 4$ & $/ 68$ & $19 / 19$ \\
\hline${ }^{240} \mathrm{Pu}^{a}$ & $137 / 153$ & $30 / 30$ & $6 / 34$ & $1 / 7$ & $/ 41$ & $/ 4$ & 169 & $19 / 19$ \\
\hline${ }^{241} \mathrm{Pu}^{a}$ & $137 / 153$ & $30 / 30$ & $6 / 34$ & $1 / 7$ & / 41 & $/ 4$ & 169 & $19 / 19$ \\
\hline${ }^{242} \mathrm{Pu}^{a}$ & $136 / 152$ & $30 / 30$ & $6 / 34$ & $1 / 7$ & $/ 41$ & $/ 4$ & $/ 61$ & $17 / 17$ \\
\hline${ }^{241} \mathrm{Am}$ & 103 & 30 & 6 & & & & & \\
\hline${ }^{242 \mathrm{~m}} \mathrm{Am}$ & 63 & 18 & & & & & & \\
\hline${ }^{243} \mathrm{Am}$ & 88 & 18 & 6 & & & & & \\
\hline${ }^{242} \mathrm{Cm}$ & 81 & 30 & 4 & & & & & \\
\hline${ }^{243} \mathrm{Cm}$ & 20 & 17 & & & & & & \\
\hline${ }^{244} \mathrm{Cm}$ & 89 & 30 & 6 & & & & & \\
\hline${ }^{245} \mathrm{Cm}$ & 22 & 17 & & & & & & \\
\hline${ }^{246} \mathrm{Cm}$ & 19 & 14 & & & & & & \\
\hline${ }^{247} \mathrm{Cm}$ & 10 & 6 & & & & & & \\
\hline${ }^{131} \mathrm{Xe}^{b}$ & 44 & 8 & & & & & & \\
\hline${ }^{132} \mathrm{Xe}^{b}$ & 44 & 8 & & & & & & \\
\hline${ }^{134} \mathrm{Xe}^{b}$ & 44 & 8 & & & & & & \\
\hline${ }^{136} \mathrm{Xe}^{b}$ & 44 & 8 & & & & & & \\
\hline${ }^{83} \mathrm{Kr}^{b}$ & 32 & 2 & & & & & & \\
\hline${ }^{84} \mathrm{Kr}^{b}$ & 32 & 2 & & & & & & \\
\hline${ }^{85} \mathrm{Kr}^{b}$ & 28 & 2 & & & & & & \\
\hline${ }^{86} \mathrm{Kr}^{b}$ & 32 & 2 & & & & & & \\
\hline${ }^{142} \mathrm{Nd}$ & 16 & & 6 & & & & & \\
\hline${ }^{143} \mathrm{Nd}$ & 59 & 18 & 6 & & & & & \\
\hline${ }^{144} \mathrm{Nd}$ & 40 & 18 & 6 & & & & & \\
\hline${ }^{145} \mathrm{Nd}$ & 59 & 18 & 6 & & & & & \\
\hline${ }^{146} \mathrm{Nd}$ & 48 & 18 & 6 & & & & & \\
\hline${ }^{148} \mathrm{Nd}$ & 110 & 30 & & & & & & \\
\hline${ }^{150} \mathrm{Nd}$ & 48 & 18 & & & & & & \\
\hline${ }^{147} \mathrm{Sm}$ & 30 & 15 & & & & & & \\
\hline${ }^{148} \mathrm{Sm}$ & 11 & 14 & & & & & & \\
\hline${ }^{149} \mathrm{Sm}$ & 30 & 14 & & & & & & \\
\hline${ }^{150} \mathrm{Sm}$ & 30 & 14 & & & & & & \\
\hline${ }^{152} \mathrm{Sm}$ & 30 & 14 & & & & & & \\
\hline${ }^{154} \mathrm{Sm}$ & 11 & 14 & & & & & & \\
\hline${ }^{95} \mathrm{Mo}$ & 16 & & & & & & & \\
\hline${ }^{101} \mathrm{Ru}$ & 16 & & & & & & & \\
\hline${ }^{103} \mathrm{Rh}$ & 16 & & & & & & & \\
\hline${ }^{109} \mathrm{Ag}$ & 14 & & & & & & & \\
\hline${ }^{133} \mathrm{Cs}$ & 5 & & & & & & & \\
\hline${ }^{151} \mathrm{Eu}$ & 21 & & & & & & & \\
\hline${ }^{153} \mathrm{Eu}$ & 24 & & & & & & & \\
\hline${ }^{110 \mathrm{~m}} \mathrm{Ag}$ & 5 & & & & & & & \\
\hline${ }^{144} \mathrm{Ce}$ & 39 & 15 & & & & & & \\
\hline${ }^{106} \mathrm{Ru}$ & 44 & 18 & & & & & & \\
\hline${ }^{134} \mathrm{Cs}$ & 85 & 28 & & & & & & \\
\hline${ }^{147} \mathrm{Pm}$ & 4 & & & & & & & \\
\hline${ }^{125} \mathrm{Sb}$ & 32 & 11 & & & & & & \\
\hline${ }^{155} \mathrm{Eu}$ & 16 & & & & & & & \\
\hline${ }^{154} \mathrm{Eu}$ & 65 & 28 & & & & & & \\
\hline${ }^{90} \mathrm{Sr}$ & 4 & & & & & & & \\
\hline${ }^{137} \mathrm{Cs}$ & 100 & 30 & & & & & & \\
\hline${ }^{151} \mathrm{Sm}$ & 30 & 14 & & & & & & \\
\hline${ }^{99} \mathrm{Tc}$ & 20 & & & & & & & \\
\hline${ }^{135} \mathrm{Cs}$ & 4 & & & & & & & \\
\hline${ }^{129} \mathrm{I}$ & 3 & & & & & & & \\
\hline
\end{tabular}

\footnotetext{
${ }^{a}$ Number of samples reported as (1) normalized to initial uranium concentration (first number) and (2) final atom ratio (second number).

${ }^{b}$ Ratio to an isotope of the same element.
} 


\section{REACTOR OVERVIEWS}

\subsection{ISOTOPIC PRODUCTION}

Familiarity with the time rate of change of the concentration of a nuclide is important in understanding the trends in isotopic concentrations in a reactor. The following relationship describes the time rate of change in concentrations for an individual nuclide: ${ }^{30}$

$$
\frac{d N_{i}}{d t}=\sum_{j=1}^{m} l_{i j} \lambda_{j} N_{j}+\bar{\Phi} \sum_{k=1}^{m} f_{i k} \sigma_{k} N_{k}-\left(\lambda_{i}+\bar{\Phi} \sigma_{i}\right) N_{i}, \quad(\mathrm{i}=1,2, \ldots, \mathrm{m}) \quad \text { Eq. (1) }
$$

where

$$
\begin{array}{ll}
\mathrm{N}_{\mathrm{i}} & \text { atom density of nuclide } i, \\
\lambda_{\mathrm{i}} & \text { radioactive disintegration constant of nuclide } i, \\
\sigma_{\mathrm{i}} & \text { spectrum-averaged neutron absorption cross section of nuclide } i, \\
\bar{\Phi} & \text { space- and energy-averaged neutron flux, } \\
\mathrm{l}_{\mathrm{ij}} & \begin{array}{l}
\text { branching fraction of radioactive disintegrations from nuclide } j \\
\text { to nuclide } i,
\end{array} \\
\mathrm{f}_{\mathrm{ik}} & \begin{array}{l}
\text { branching fraction for neutron absorption by nuclide } k \text { that leads } \\
\text { to the formation of nuclide } i .
\end{array}
\end{array}
$$

As seen in the above expression, the production of nuclide $i$ is found by a coupled set of linear, homogeneous, first-order differential equations with constant coefficients. The first two terms on the right-hand side of the equation deal with (1) the production of isotope $i$ by means of radioactive decay from other isotopes and (2) the production of isotope $i$ from neutron-induced reactions such as neutron capture or fission, respectively. The last term deals with the loss of isotope $i$ by its own radioactive decay and loss from absorbing a neutron.

The above expression is written for a homogeneous medium containing a space and energy-averaged neutron flux with one-group, flux-weighted average cross sections representing the reaction probabilities. This model is satisfactory for reactor samples if the size of the sample is small enough to assume a locally constant neutron flux or if the average values are representative of the sample. Depletion codes such as ORIGEN that use the above equations also update the average flux and cross section values for each successive time step in a depletion simulation. ${ }^{30}$

The impact of the energy dependence of the neutron flux on isotopic buildup is seen throughout this report. The moderator has a large effect on the hardness of the spectrum. ${ }^{31}$ As seen in Fig. 1, which illustrates the effect of the moderator on the neutron spectrum in a reactor, graphite-moderated reactors tend to have normalized fluxes with smaller values in the thermal region as compared to heavy water and light water moderated reactors. The peak values are also shifted toward higher energies. This phenomenon is very well understood in the reactor physics community. ${ }^{31}$ The impact of spectrum changes on isotope concentrations such as plutonium production is discussed in a later section. Changes in moderator temperatures, fuel enrichment and fuel design will also have spectrum effects to varying degrees.

The following sections summarize the various reactor types discussed in this report. These sections are organized by the type of moderator used in each reactor. 


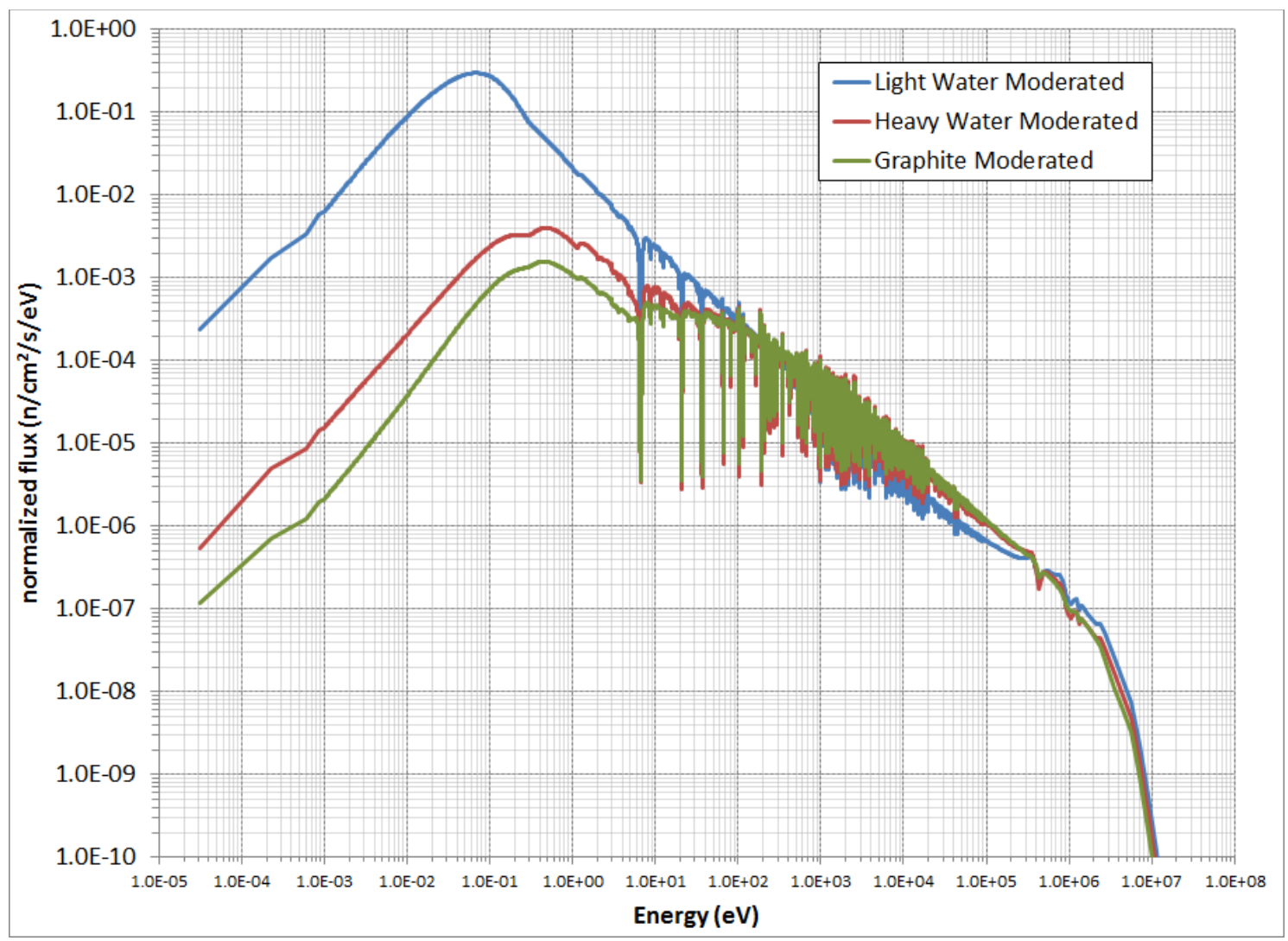

Fig. 1. Normalized flux as a function of energy for different moderators.

\subsection{LIGHT WATER MODERATED REACTORS}

The two primary commercial light water reactor (LWR) concepts that exist around the world for power production are the PWR and the BWR. All LWRs use ordinary water as coolant and neutron moderator. However, the PWR and BWR fuel elements come in various designs. Variations occur in fuel rod diameters, number, and enrichment; location of water tubes or instrument tubes; spacer grid locations; cladding material; and overall assembly shape (rectangular, hexagonal, cruciform, etc.). All of these variations affect the spatial and energy variation of the neutron flux.

Due to the abundance of PWRs around the world, a large amount of isotopic data exists for these types of reactors. This report uses data of various quality from 17 PWRs operated in six countries:

- Beznau Unit 1 and Gösgen Unit 1 in Switzerland;

- Gemeinschaftskraftwerk Neckar Unit 2 (GKN II), Biblis Unit 1 and Obrigheim Unit 1 in Germany;

- Genkai Unit 1, Mihama Unit 3, Ohi Unit 1, Ohi Unit 2, and Takahama Unit 3 in Japan;

- Vandellos Unit 2 in Spain;

- Trino Vercellese Unit 1 in Italy; and

- H.B. Robinson Unit 2, Three Mile Island Unit 1, Turkey Point Unit 3, Calvert Cliffs Unit 1, and Yankee Unit 1 in the US. ${ }^{6}$

The design of the Russian water-water power reactor (VVER) is similar to that of the PWR. Three VVER designs have been or are being constructed: VVER-440, VVER-1000, and VVER-1200. VVERs have historically had hexagonal fuel assemblies. SFCOMPO reports data for both the VVER-440 and VVER-1000. Within this report, the data from the VVER-440 Novo-Voronezh Unit 1 that is found in SFCOMPO are not included because the units used to report the measured isotopic concentrations are not consistent with those used for the large amount of other data found for the other types of reactors (see 
section 1.3). However, the VVER-1000 reactors-Balakovo Unit 2 and Unit 3 and Kalinin Unit 1-report their data normalized to beginning of irradiation masses in $\mathrm{mg} / \mathrm{g}$ and are therefore included in this report. ${ }^{6}$

BWRs are also very abundant around the world. However, only two reactors - Fukushima Daini Unit 2 in Japan and Gundremmingen in Germany-had data reported in initial loading units and are therefore included in this report. ${ }^{4}$ In the future, unit conversions for the other 9 BWRs for which data are included within SFCOMPO will be performed, and more BWR data could be included. Noble gas data are also included for Cooper in the US.

\subsection{HEAVY WATER MODERATED REACTORS}

Reactors that use heavy water moderators have historically used either light water or heavy water as a coolant. The first heavy water moderated design in Canada was the Zero Energy Experimental Pile (ZEEP). This pile was followed up by the NRX and National Research Universal (NRU) reactors, which were both heavy water-moderated but light-water-cooled. These early research efforts led to the first CANada Deuterium Uranium (CANDU) reactor, the Nuclear Power Demonstration (NPD), which was cooled by heavy water. Data for the NPD exists in SFCOMPO but is not included in this report because the units used to report the measured isotopic concentrations are not consistent with those used for the large amount of other data found for the other types of reactors (see section 1.3). ${ }^{6}$ The NPD led to the Douglas Point CANDU commercial prototype, which then ultimately led to Pickering A and B, the first CANDU 600 MWe class multi-unit stations. Data for Pickering A Unit 1 are found within this report, ${ }^{7}$ as are data from Bruce A Unit 1, a later 900 MWe CANDU reactor.

Heavy water reactors allow the use of natural or very low-enriched uranium. Historically, the fuel bundles consist of fuel elements arranged in concentric rings. Unlike LWRs, CANDU fuel assemblies are loaded into the core during normal operation with the reactor at power.

\subsection{GRAPHITE-MODERATED REACTORS}

As with heavy water moderated reactors, graphite moderated reactors can use a variety of coolants. Originally, the first graphite moderated piles were cooled only by air, as was the ORNL X-10 pile. Later, plutonium producing reactors like Hanford B used light water as the coolant. Recently declassified experimental data from the Hanford B reactor are included within this report. ${ }^{28}$

The High Power Channel-type Reactor, or Reaktor Bolshoy Moshchnosti Kanalnyy (RBMK), is a Russian graphite-moderated reactor that uses uranium oxide fuel and is cooled by light water. A total of 11 RBMK reactors currently operate in Russia, and the units in the Ukraine and Lithuania have been shut down. Experimental data for the Leningrad-I reactor fuel are given in this report. ${ }^{7}$

The MAGNOX reactor is a gas-cooled and graphite-moderated design that uses natural uranium metal fuel rods. The MAGNOX reactor design was developed in the United Kingdom and is similar to the French uranium natural graphite gas (UNGG) graphite-moderated and carbon dioxide-gas-cooled design. The name "MAGNOX" comes from the fuel cladding, which is a non-oxidizing alloy of magnesium. Experimental data for this reactor type that are found within this report come from Bradwell Unit 1 and Hunterston A Unit $1 .^{7}$

The United Kingdom later designed the advanced gas-cooled reactor (AGR), a second generation gascooled reactor. The cladding is made of stainless steel instead of a magnesium alloy. The uranium dioxide fuel is enriched and operated at higher temperature. Data from the AGR design are found within this report for Hinkley Unit 3 and Unit 4 and for Hunterston B Unit 3. ${ }^{7}$ 


\section{ACTINIDES}

This section provides an overview on the depletion, buildup, and measured concentrations of uranium, neptunium, plutonium, americium, and curium isotopes following the irradiation of nuclear fuel. At the end of this section, a summary of the current validation results for a subset of the actinides presented will be given.

\subsection{OVERVIEW OF ACTINIDE PRODUCTION}

Uranium is the main starting material currently used for nuclear energy production. Following irradiation of uranium isotopes, other actinides are produced by various combinations of neutron interactions and decay processes. ${ }^{32,33}$ Furthermore, ${ }^{235} \mathrm{U}$ is the primary source for all the fission products, as well. As seen in Fig. $2,{ }^{235} \mathrm{U}$ is the source of more than $90 \%$ of all fissions in a typical LWR at the beginning of irradiation. This value decreases as ${ }^{235} \mathrm{U}$ is depleted; however, it remains the primary source of fission products until ${ }^{239} \mathrm{Pu}$ surpasses it at around $30 \mathrm{GWd} / \mathrm{TIHM}$. This typically occurs in the second operational cycle of a PWR. The ${ }^{235} \mathrm{U}$ isotope is also the primary source of fission products for reactors operating with natural uranium, such as a CANDU, as illustrated in Fig. 3. As seen in the legends of Fig. 2 and Fig. 3, four isotopes $-{ }^{235} \mathrm{U},{ }^{239} \mathrm{Pu}$, and ${ }^{241} \mathrm{Pu}$ from thermal neutrons interactions and ${ }^{238} \mathrm{U}$ from fast neutrons interactions - contribute to over $99 \%$ of all fission events occurring in reactor fuel.

The buildup of the actinides in irradiated reactor fuel is complex, as seen in Fig. $4 .^{32}$ The neutron capture reactions - $(\mathrm{n}, \gamma)$ and $(\mathrm{n}, 2 \mathrm{n})$ reactions in Fig. 4, along with neutron-induced fissioning - only take place when a neutron flux exists. However, the $\alpha$ and $\beta$ decays shown in the same figure take place during and after irradiation. Therefore, even after irradiation has ceased, significant buildup of some of the actinides can continue.

\subsection{URANIUM ISOTOPES}

Data are reported in this section for the following isotopes of uranium: ${ }^{232} \mathrm{U},{ }^{234} \mathrm{U},{ }^{235} \mathrm{U},{ }^{236} \mathrm{U}$, and ${ }^{238} \mathrm{U}$. Natural uranium is made up of ${ }^{238} \mathrm{U}(99.2745 \mathrm{wt} \%),{ }^{235} \mathrm{U}(0.72 \mathrm{wt} \%)$, and ${ }^{234} \mathrm{U}(0.0055 \mathrm{wt} \%)$. ${ }^{32,33}$ The isotope ${ }^{236} \mathrm{U}$ is primarily produced by the neutron capture in ${ }^{235} \mathrm{U}$ during irradiation. The isotope ${ }^{232} \mathrm{U}$ is produced by the decay of ${ }^{236} \mathrm{Pu}$, as seen in Fig. $4 .{ }^{32}$ Due to the half-life of ${ }^{236} \mathrm{Pu}$ (2.85 years), the buildup of ${ }^{232} \mathrm{U}$ depends on both the fuel burnup and decay time. This dependency can be seen in Fig. 5 by the generic PWR ORIGEN simulations. The solid red line predicts the concentration of ${ }^{232} \mathrm{U}$ at the time of shutdown, when the reactor has achieved a certain burnup. The dashed red line shows predicted concentrations for the same irradiation scenario as they correspond to the solid red line, but after five years of decay after discharge. Due to its low concentration, ${ }^{232} \mathrm{U}$ is often not measured. Limited PWR samples in a limited enrichment range are seen in Fig. 5.

The isotope enrichment process not only leads to an increase in the ${ }^{235} \mathrm{U}$ concentration in the fuel, but it also results in an increase in the ${ }^{234} U$ concentration, as seen in Fig. $6 .{ }^{32}$ Natural uranium has a concentration of approximately $0.055 \mathrm{mg}$ of ${ }^{234} \mathrm{U}$ per gram of initial total uranium and $7.2 \mathrm{mg}$ of ${ }^{235} \mathrm{U}$ per gram of initial total uranium. ${ }^{32}$ As seen in Fig. 6 and Fig. 7, an increase from natural uranium to $3.5 \mathrm{wt} \%$ ${ }^{235} \mathrm{U}$ leads to $35 \mathrm{mg}$ of ${ }^{235} \mathrm{U}$ per gram of initial total uranium (4.9 times higher than its natural concentration) and to $0.31 \mathrm{mg}$ of ${ }^{234} \mathrm{U}$ per gram of initial total uranium (5.6 times higher than its respective natural concentration). 


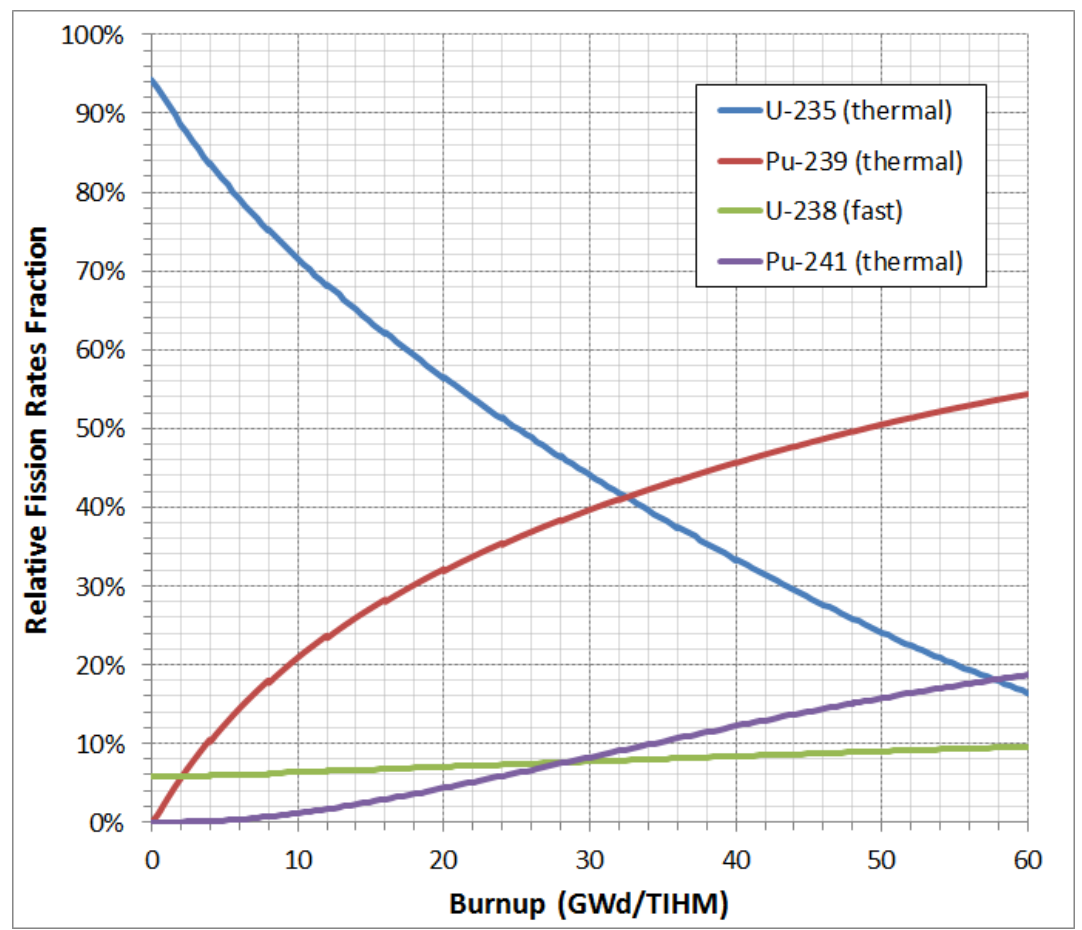

Fig. 2. Relative fission rates for four primary fissionable isotopes for a generic PWR with $4 \mathrm{wt} \% \mathrm{U}-235$.

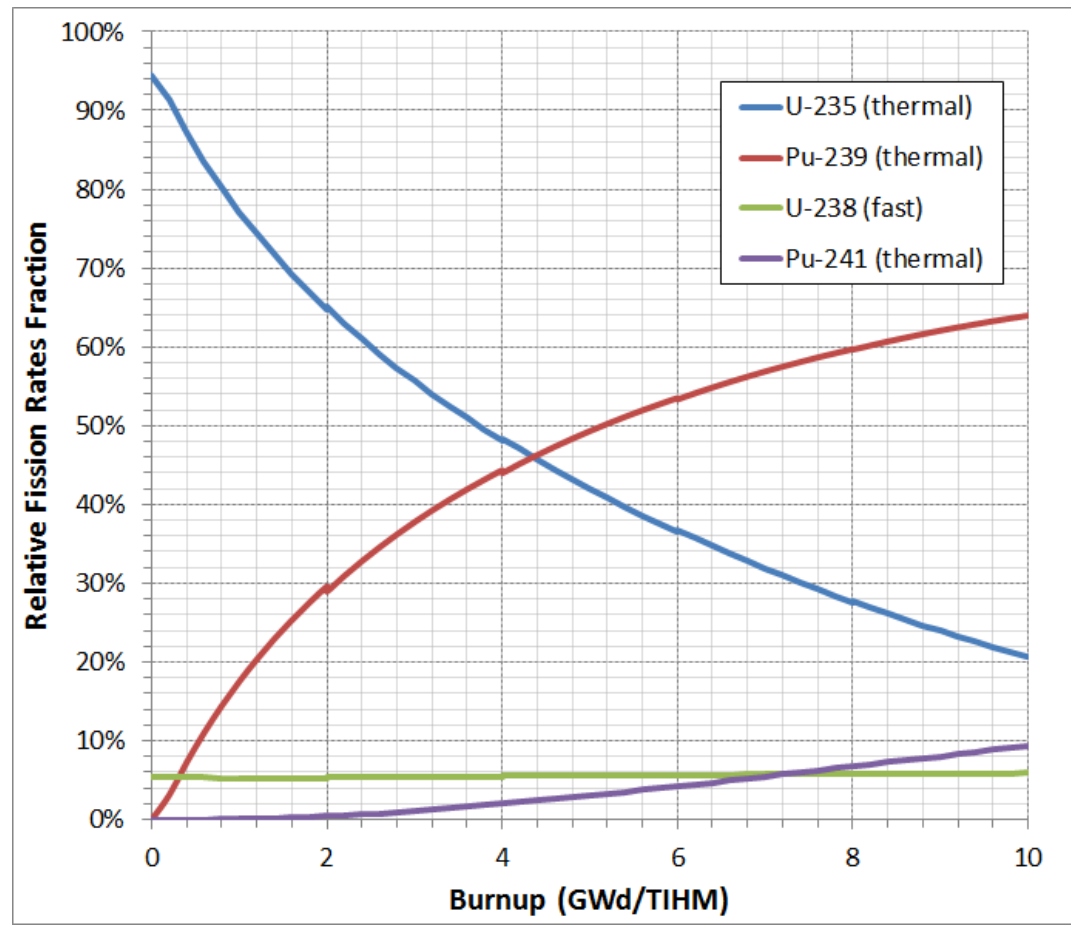

Fig. 3. Relative fission rates for four primary fissionable isotopes for a generic CANDU with natural uranium. 


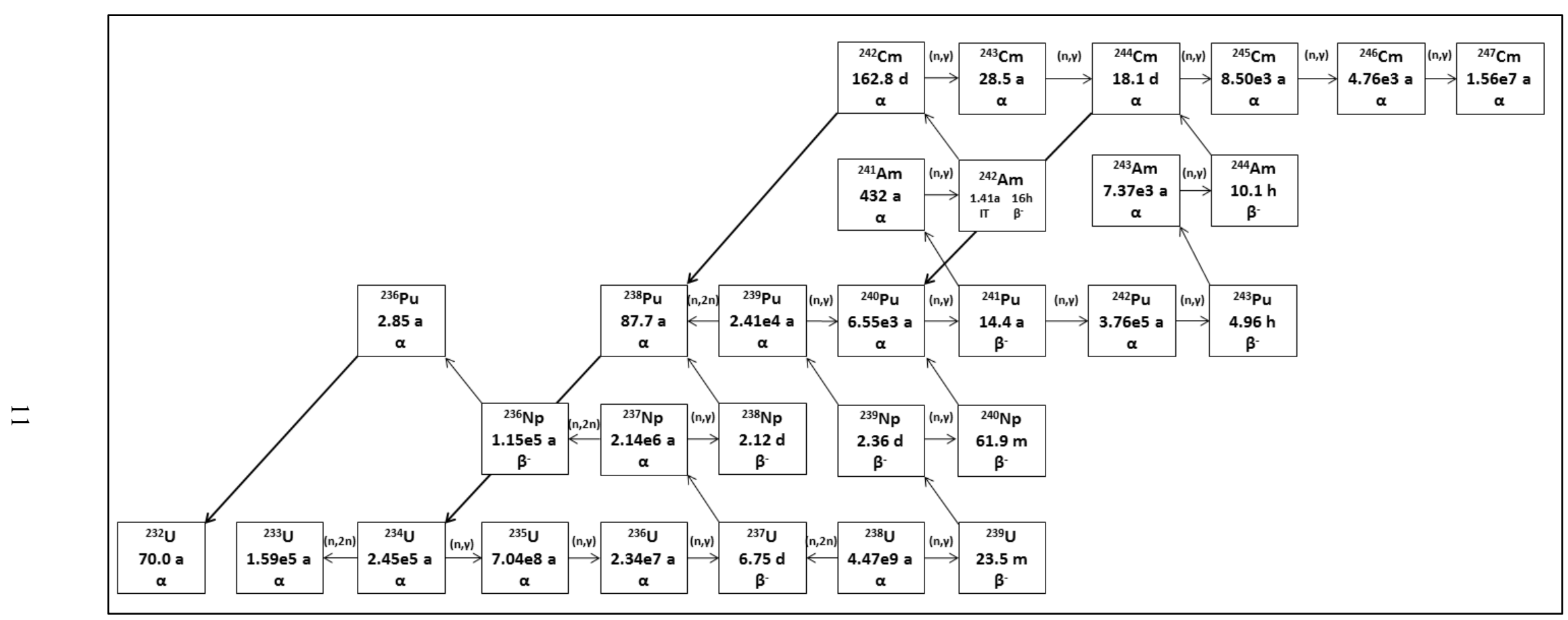

Fig. 4. Buildup of actinides in irradiated reactor fuel. 


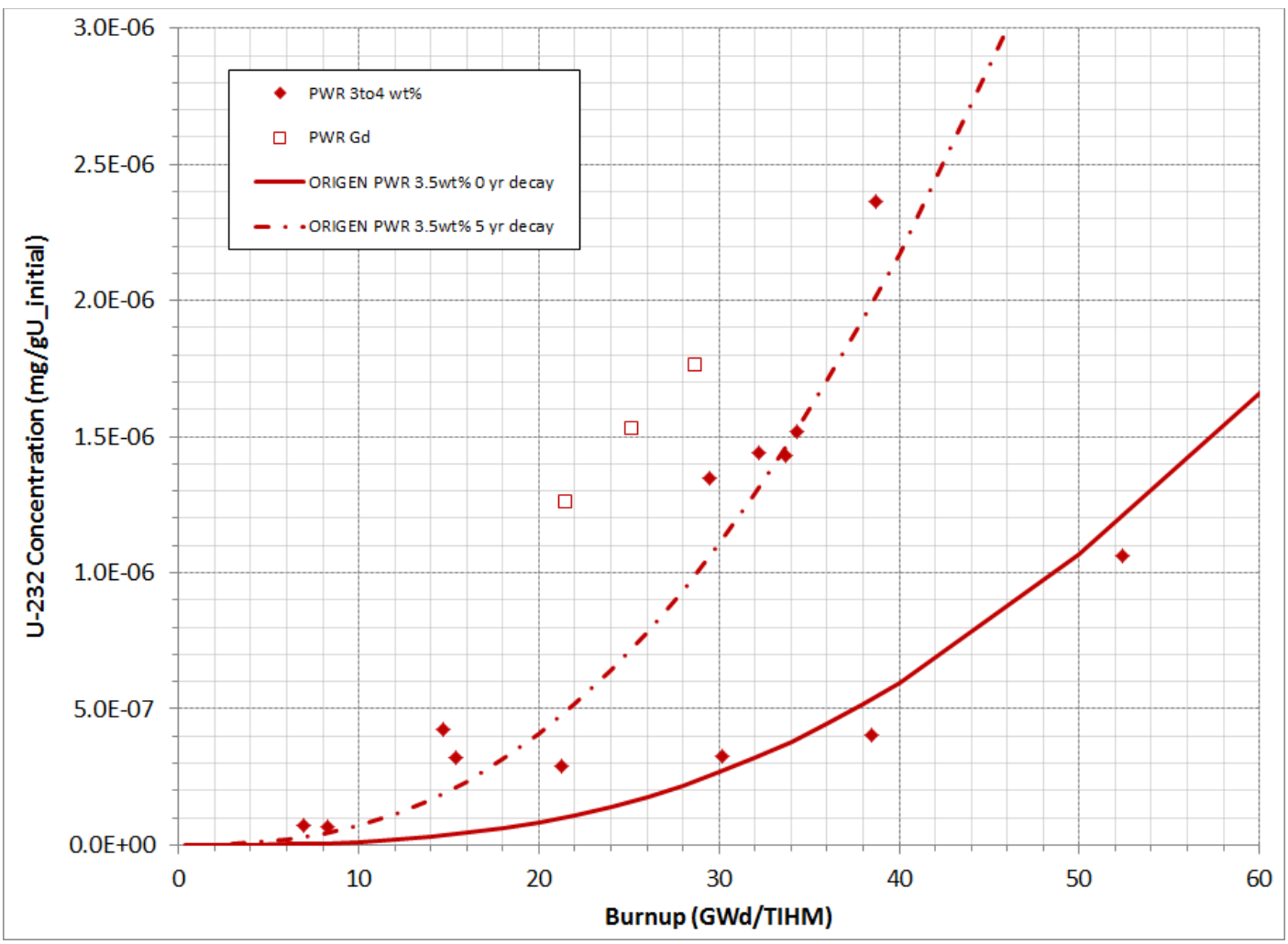

Fig. 5. U-232 concentration as a function of burnup.

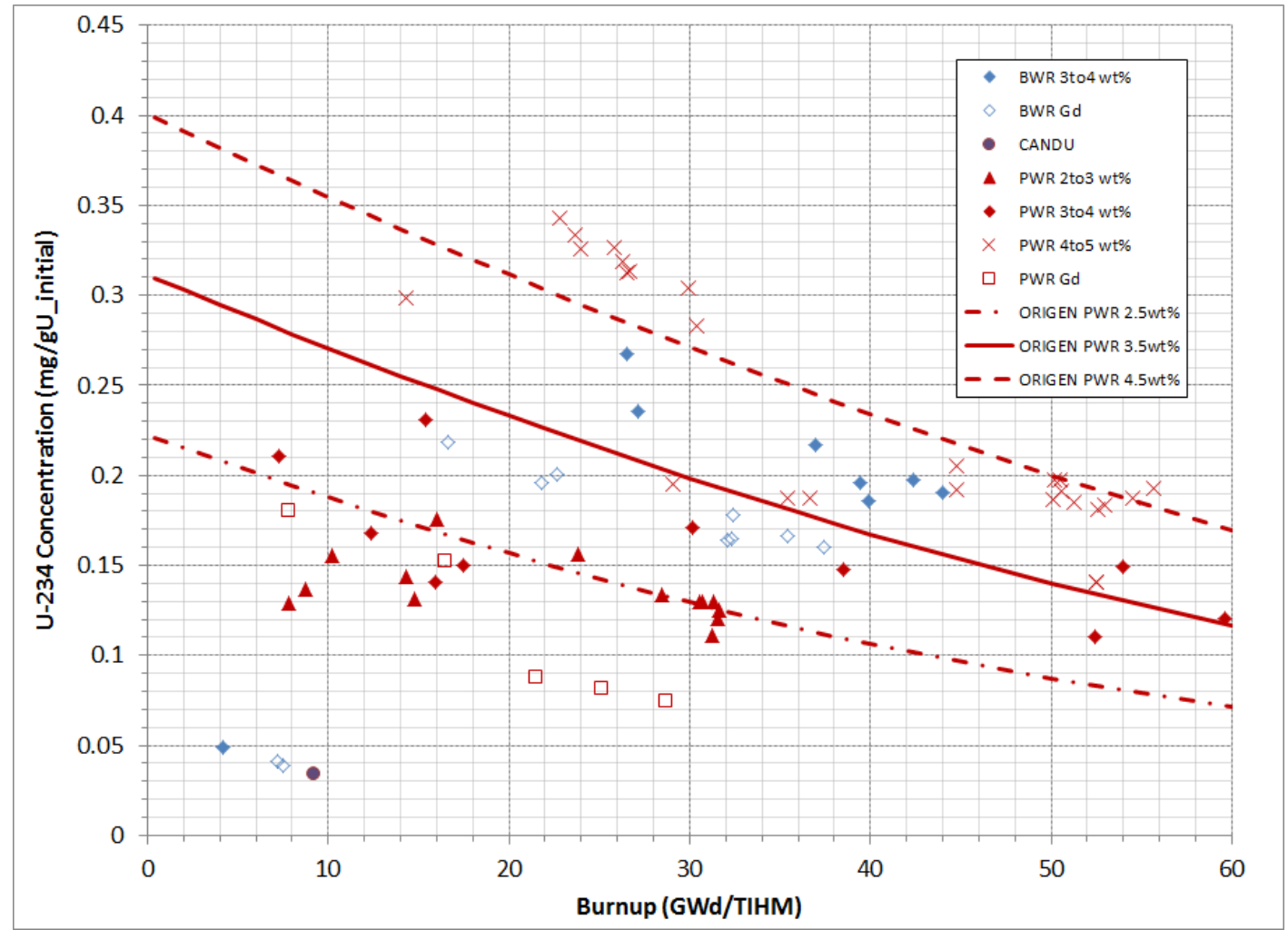

Fig. 6. U-234 concentration as a function of burnup. 
Fig. 6 through Fig. 9 show a few points at burnups less than $10 \mathrm{GWd} / \mathrm{TIHM}$ that correspond to a higher enrichment in the legend but deviate significantly from similar samples in the same burnup range. After further exploration, it was determined that while these samples correspond to fuel rods with a certain enrichment, they are actually samples found in natural uranium pellets placed at the end of the enriched LWR fuel rods to help with power shaping in the assembly. Therefore, they align with trends expected for natural uranium fuel such as the CANDU data shown in Fig. 7 through Fig. 9, but not with the overall enrichment of the rod.

As mentioned above, ${ }^{235} \mathrm{U}$ is the primary fission source in many nuclear reactors. Therefore, the enrichment as related to its natural concentration determines the grade of the uranium as a whole. The following five grades of uranium are commonly recognized: ${ }^{34}$

1. Depleted uranium (containing less than $0.72 \mathrm{wt} \%{ }^{235} \mathrm{U}$ )

2. Natural uranium (containing $0.72 \mathrm{wt} \%{ }^{235} \mathrm{U}$ )

3. Low-enriched uranium (containing more than $0.72 \mathrm{wt} \%$ and less than $20 \mathrm{wt} \%{ }^{235} \mathrm{U}$ )

4. Highly enriched uranium (containing more than $20 \mathrm{wt} \%{ }^{235} \mathrm{U}$ )

5. Weapon-grade uranium (containing more than $90 \mathrm{wt} \%{ }^{235} \mathrm{U}$ )

The ${ }^{235} \mathrm{U}$ enrichment in fuel for use in current operating commercial LWRs ranges from 3 to 5 per cent in the most prevalent power reactors around the world. ${ }^{32}$ The abundance of data in this enrichment range is very clear in Fig. 7.

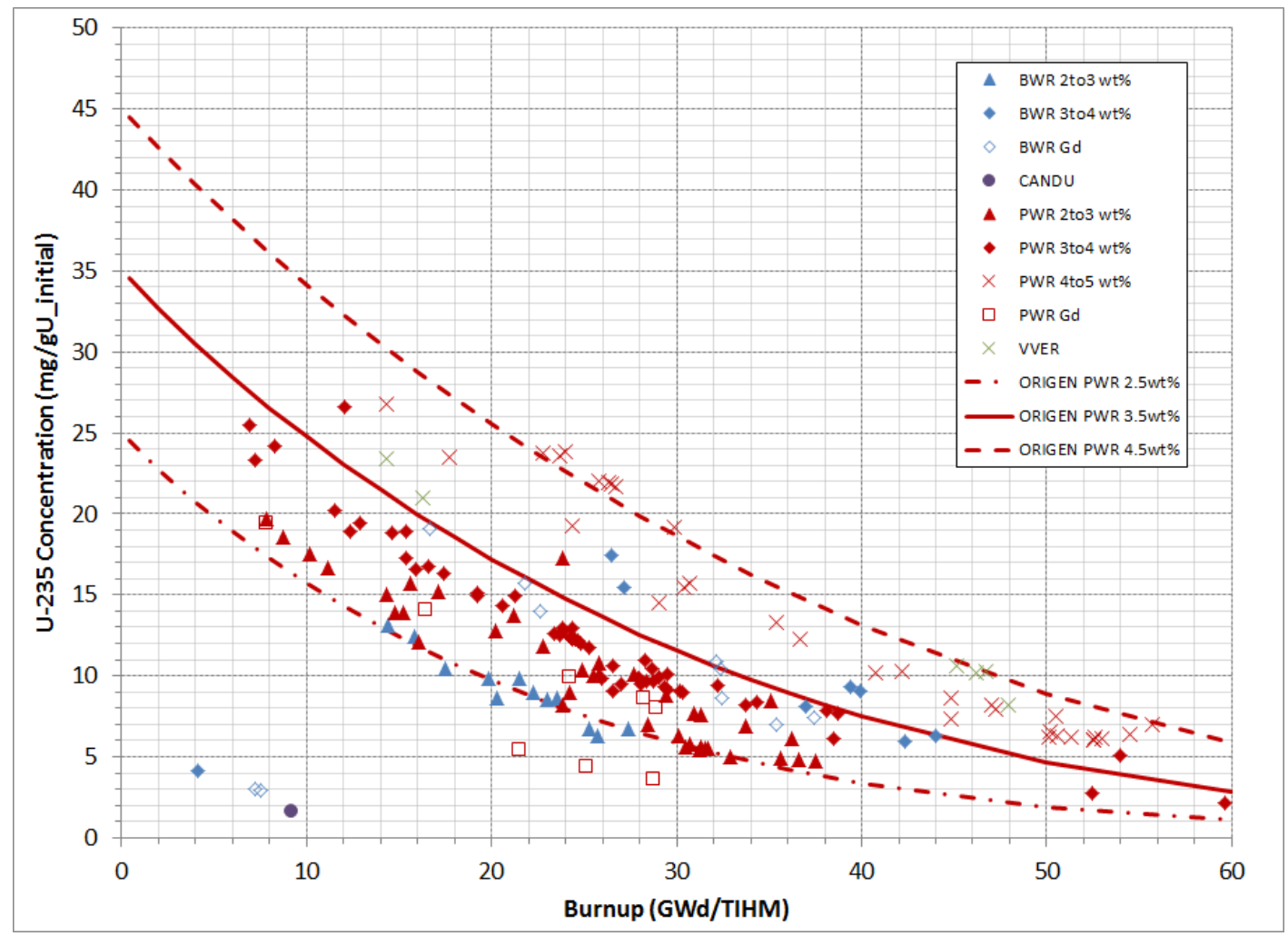

Fig. 7. U-235 concentration as a function of burnup. 


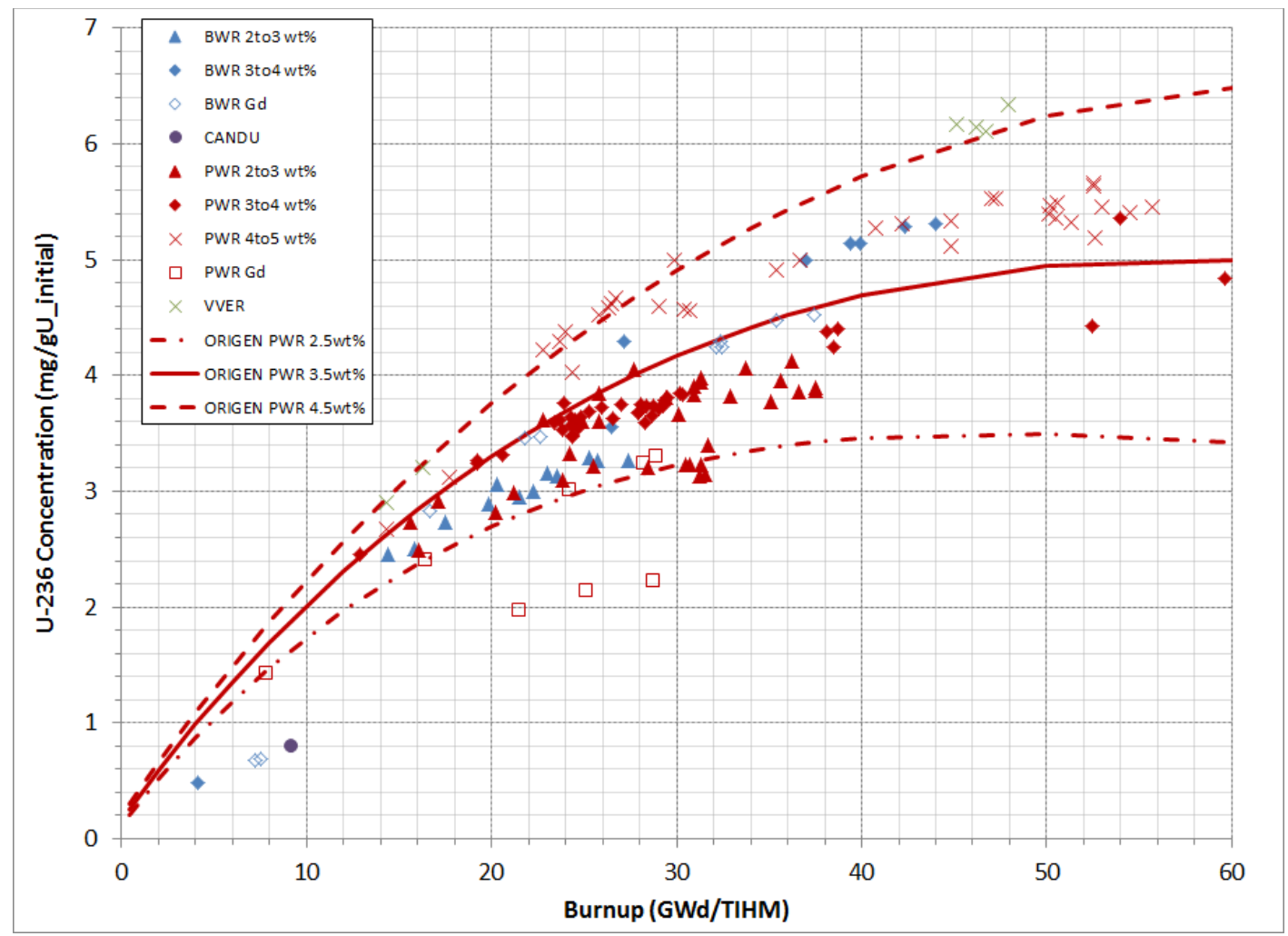

Fig. 8. U-236 concentration as a function of burnup.

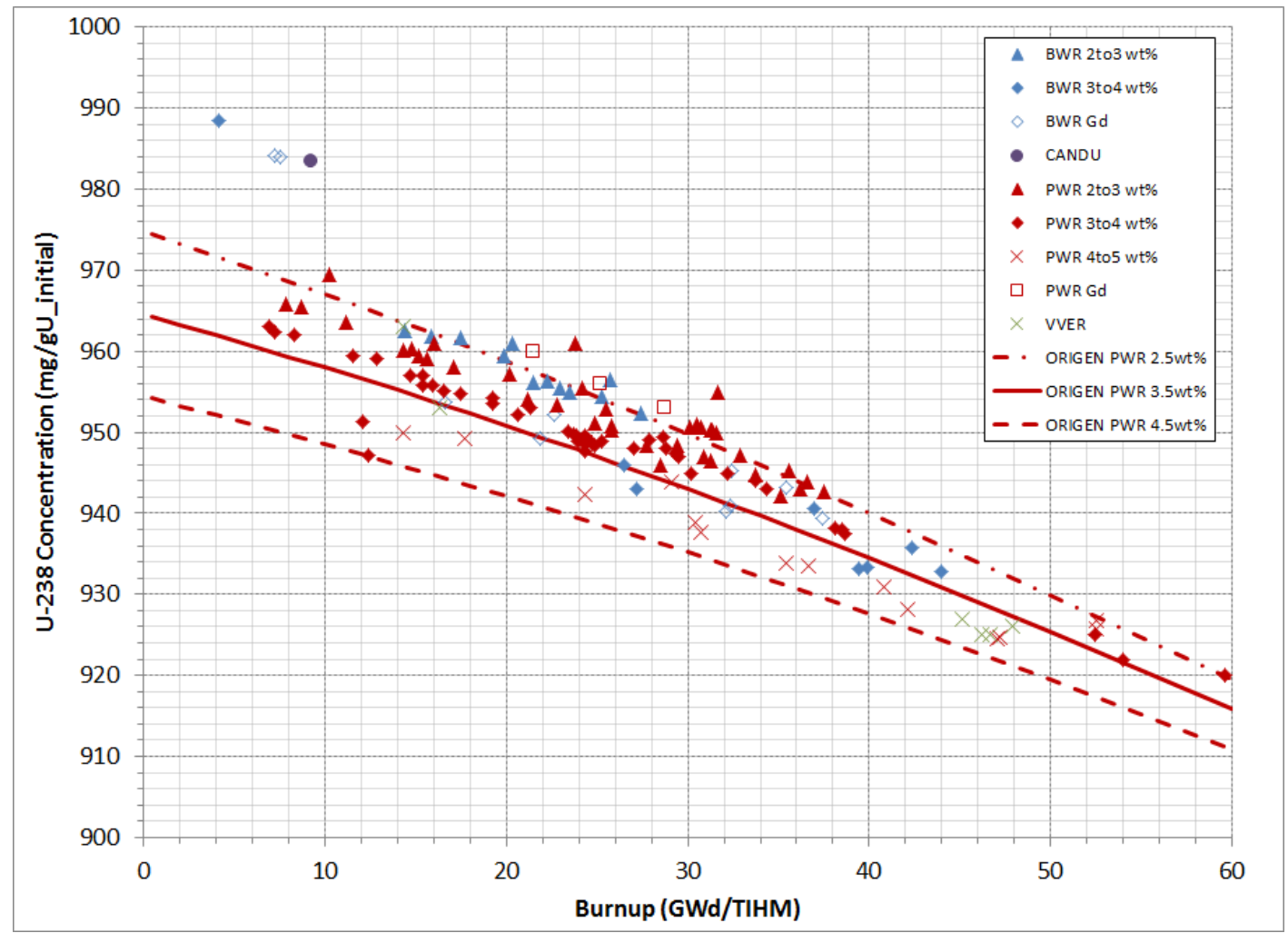

Fig. 9. U-238 concentration as a function of burnup. 


\subsection{NEPTUNIUM ISOTOPES}

A recent study at ORNL has shown the importance of correctly modeling the neutron capture of ${ }^{239} \mathrm{~Np}$ to accurately obtain ${ }^{240} \mathrm{Pu}$ concentrations for low burnups typically found in plutonium producing reactors. ${ }^{28}$ The main route for production of ${ }^{240} \mathrm{Pu}$ from low enriched uranium for commercial fuel exposures is ${ }^{238} \mathrm{U} \rightarrow{ }^{239} \mathrm{U} \rightarrow{ }^{239} \mathrm{~Np} \rightarrow{ }^{239} \mathrm{Pu} \rightarrow{ }^{240} \mathrm{Pu}$. However, at very low exposures, the production of ${ }^{240} \mathrm{Pu}$ from neutron capture in ${ }^{239} \mathrm{~Np}$ is an important path. Unfortunately the two primary neptunium isotopes leading to key plutonium isotopes $-{ }^{239} \mathrm{~Np}$ and ${ }^{238} \mathrm{~Np}$ - have relatively short half-lives and are not typically measured in SNF. Therefore, to assess the ability to accurately calculate these isotopes, one must examine how well the longer lived plutonium isotopes are calculated. ${ }^{237} \mathrm{~Np}$, on the other hand, has a long half-life, and various measured data points have been reported, as seen in Fig. 10.

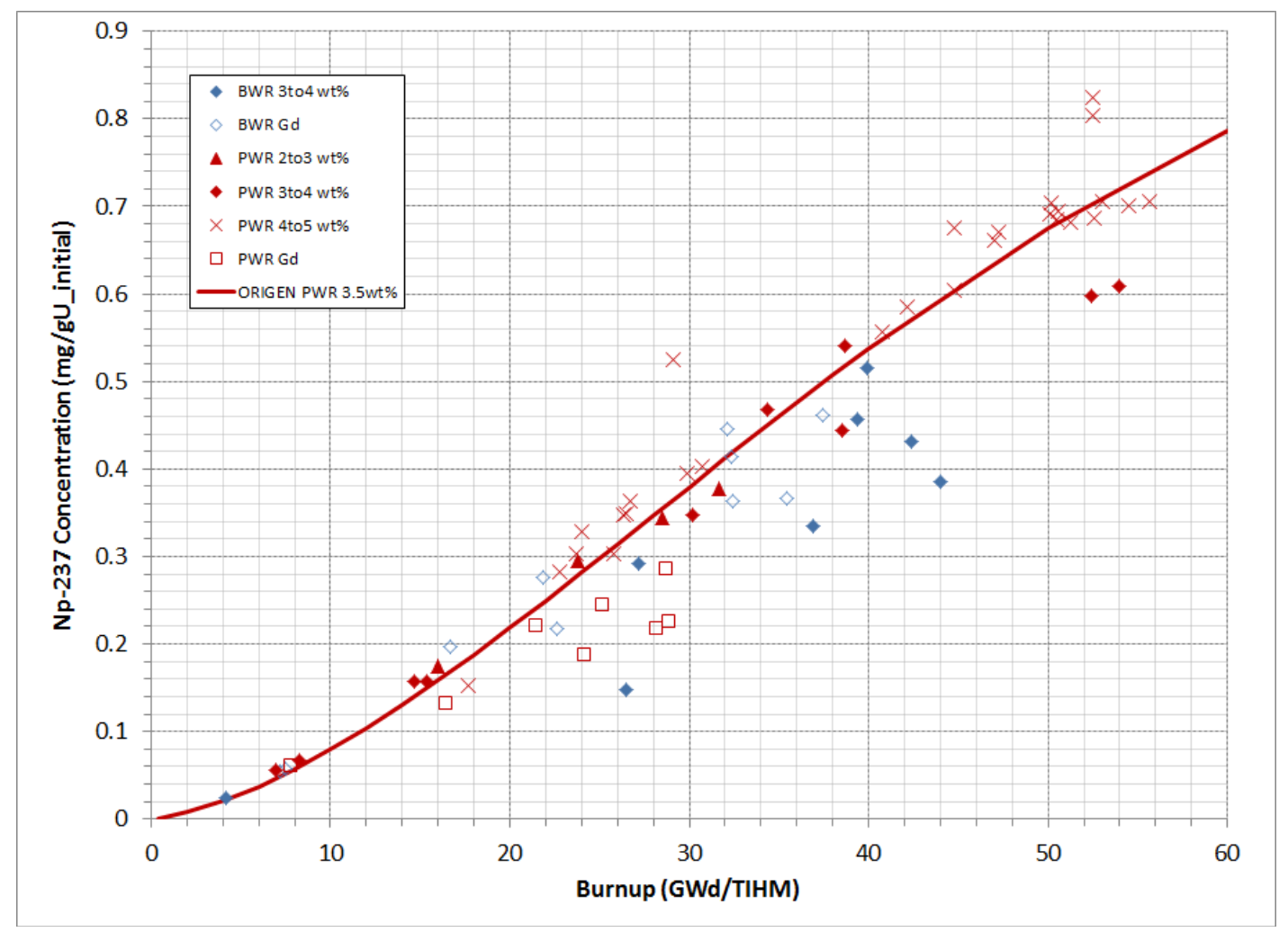

Fig. 10. Np-237 concentration as a function of burnup.

\subsection{PLUTONIUM ISOTOPES}

Due to plutonium's neutronic properties — especially ${ }^{239} \mathrm{Pu}$ - it has become synonymous with nuclear proliferation. However, plutonium, like uranium, is defined by its grade. Plutonium is typically defined by the following three grades with respect to the total plutonium inventory: ${ }^{34}$

1. Weapon-grade plutonium (containing less than 7 per cent ${ }^{240} \mathrm{Pu}$ )

2. Fuel-grade plutonium (containing 7 to 18 per $\operatorname{cent}^{240} \mathrm{Pu}$ )

3. Reactor-grade plutonium (containing over 18 per cent ${ }^{240} \mathrm{Pu}$ )

${ }^{240} \mathrm{Pu}$ has historically defined the grade of plutonium because it is the second most abundant plutonium isotope (after ${ }^{239} \mathrm{Pu}$ ), and it spontaneously fissions, generating energetic neutrons which can challenge the desirable environments wanted in weapon design. 
Because of the importance of plutonium to nuclear proliferation, two figures are given for each plutonium isotope to include all the data that have been obtained. The first figure for each isotope shows the quantity of the plutonium, with its concentration in units of mg per $\mathrm{g}$ of initially loaded uranium, and the second figure shows the grade of the plutonium, with its concentration in units of atoms (moles) of the relevant isotope per total moles of plutonium present at the corresponding burnup. Including both figures shows the additional information gained by presenting the same results in different ways. Additional generic ORIGEN models beyond the PWR models were run for a BWR, an RBMK, and a CANDU to show how the neutron spectra have an impact on the final concentration of each plutonium isotope.

The complexity of actinide buildup can be seen clearly with the buildup of ${ }^{238} \mathrm{Pu}$. This isotope is produced from (1) the $(\mathrm{n}, 2 \mathrm{n})$ reaction on ${ }^{239} \mathrm{Pu},(2)$ the beta-decay of ${ }^{238} \mathrm{~Np}$ that is ultimately produced by multiple stages of neutron captures originating with ${ }^{235} \mathrm{U}$, and (3) the alpha-decay of ${ }^{242} \mathrm{Cm} .{ }^{238} \mathrm{Pu}$ decays itself with a half-life of 87.7 years. The overall buildup of this isotope of plutonium can be seen in Fig. 11 ; likewise, ${ }^{238} \mathrm{Pu}$ increases in its overall contribution to the total amount of plutonium as the reactor fuel is irradiated (Fig. 12).

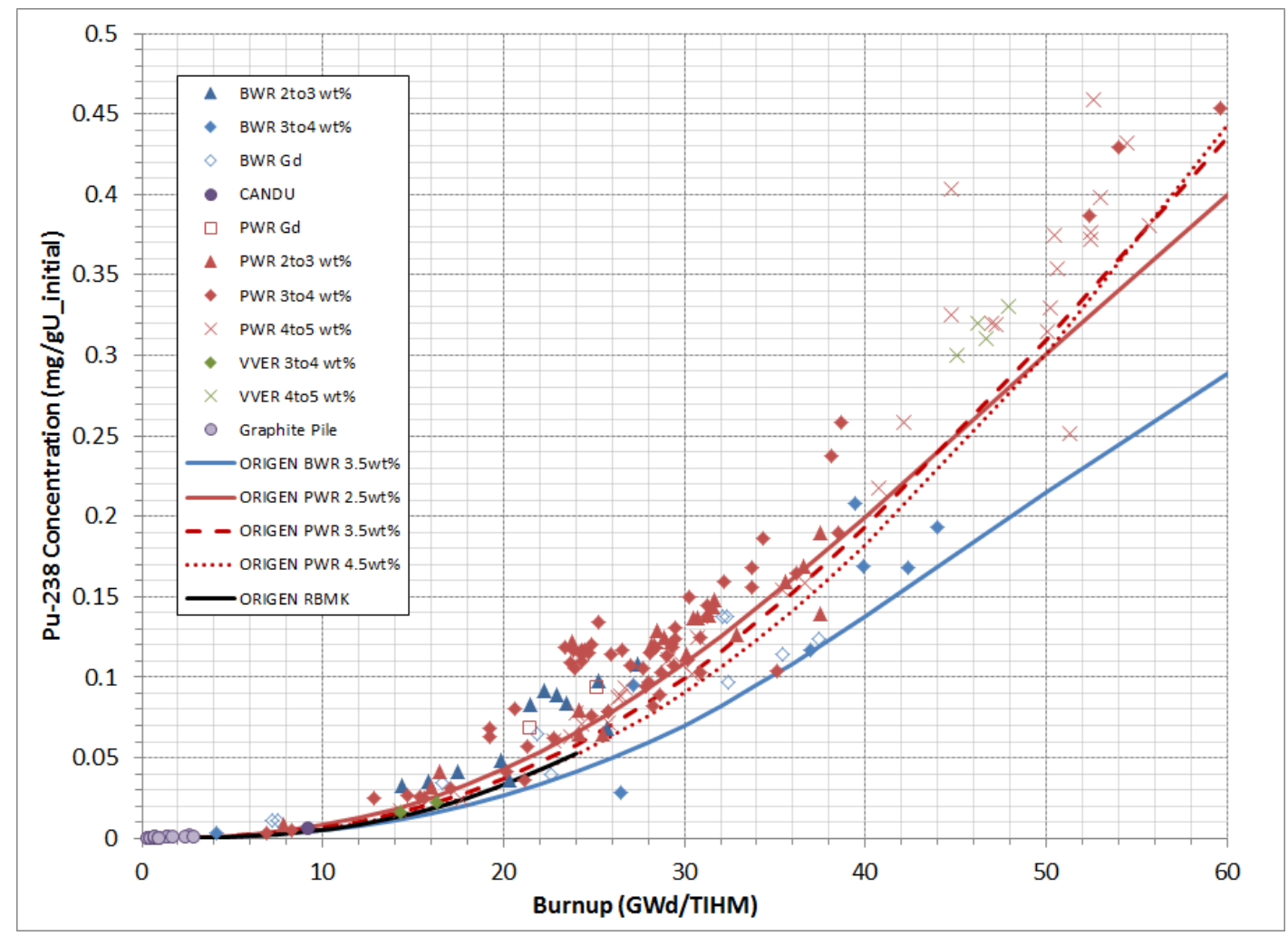

Fig. 11. Pu-238 concentration (mg/gU) as a function of burnup. 


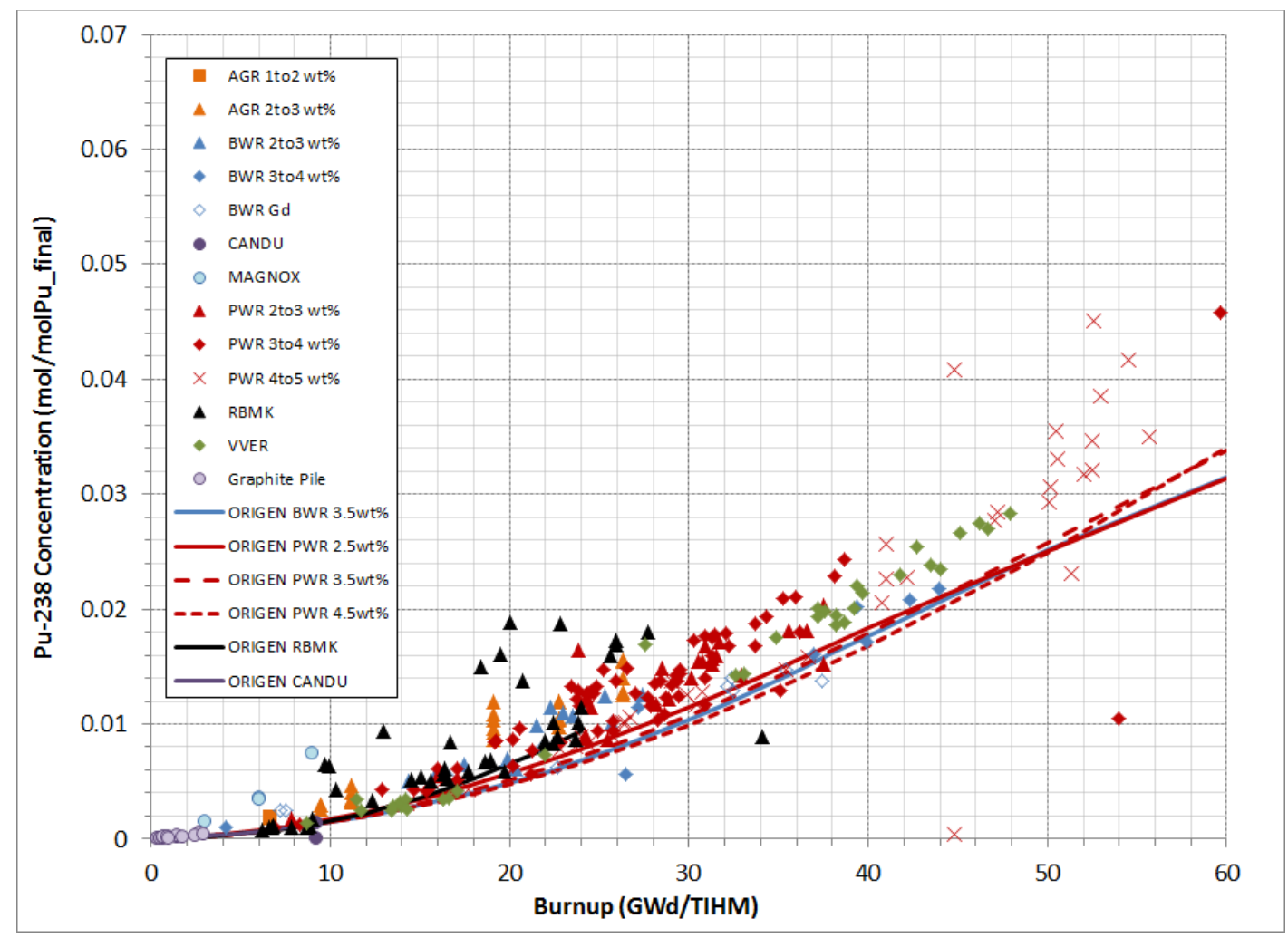

Fig. 12. Pu-238 concentration (mol/mol Pu) as a function of burnup.

${ }^{239} \mathrm{Pu}$ has a large fission cross section and one of the highest average neutron production rates per fission; therefore, this isotope has received a lot of focus in reactor operation, criticality, and safeguards. As shown in Fig. 2 and Fig. $3,{ }^{239} \mathrm{Pu}$ is the most significant producer of fission products after ${ }^{235} \mathrm{U}$ for the initial part of the fuel's irradiation history; ${ }^{239} \mathrm{Pu}$ surpasses ${ }^{235} \mathrm{U}$ in contribution to fission product generation with higher irradiated fuel. ${ }^{239} \mathrm{Pu}$ steadily increases with increasing burnup before reaching a temporary plateau, as seen in Fig. 13. At very high burnups, the ${ }^{239} \mathrm{Pu}$ concentration slowly declines as the ${ }^{238} \mathrm{U}$ concentration reduces because more ${ }^{239} \mathrm{Pu}$ is being consumed by neutron capture and fissioning than is being generated.

The peak in ${ }^{239} \mathrm{Pu}$ concentration as a function of burnup is approximately proportional to the initial concentration of ${ }^{238} \mathrm{U}$ and inversely proportional to the ${ }^{239} \mathrm{Pu}$ total average reaction rate (i.e., product of thermal flux and total average neutron cross section). The effect of the hardening of the flux spectrum due to the increase in initial uranium enrichment - and, therefore, the reduction in the total flux-weighted neutron cross section - on the ${ }^{239} \mathrm{Pu}$ concentration at higher burnups dominates over the effect from the reduction in initial ${ }^{238} \mathrm{U}$ concentration, also due to an increase in ${ }^{235} \mathrm{U}$ enrichment. This result explains why higher enriched fuel has a higher ${ }^{239} \mathrm{Pu}$ plateau concentration. This trend is an example of how the neutron flux spectrum has a significant impact on the isotopic concentrations. There are no RBMK and AGR data currently available in SFCOMPO in units normalized to initial uranium concentrations, so these data are not included in Fig. 13; however, the dominance of the flux spectrum is even more evident in Fig. 13 when comparing the RBMK curve, which was modeled with an enrichment of $2 \mathrm{wt} \%{ }^{235} \mathrm{U}$, as compared to the equivalent enrichment PWR and BWR models. 


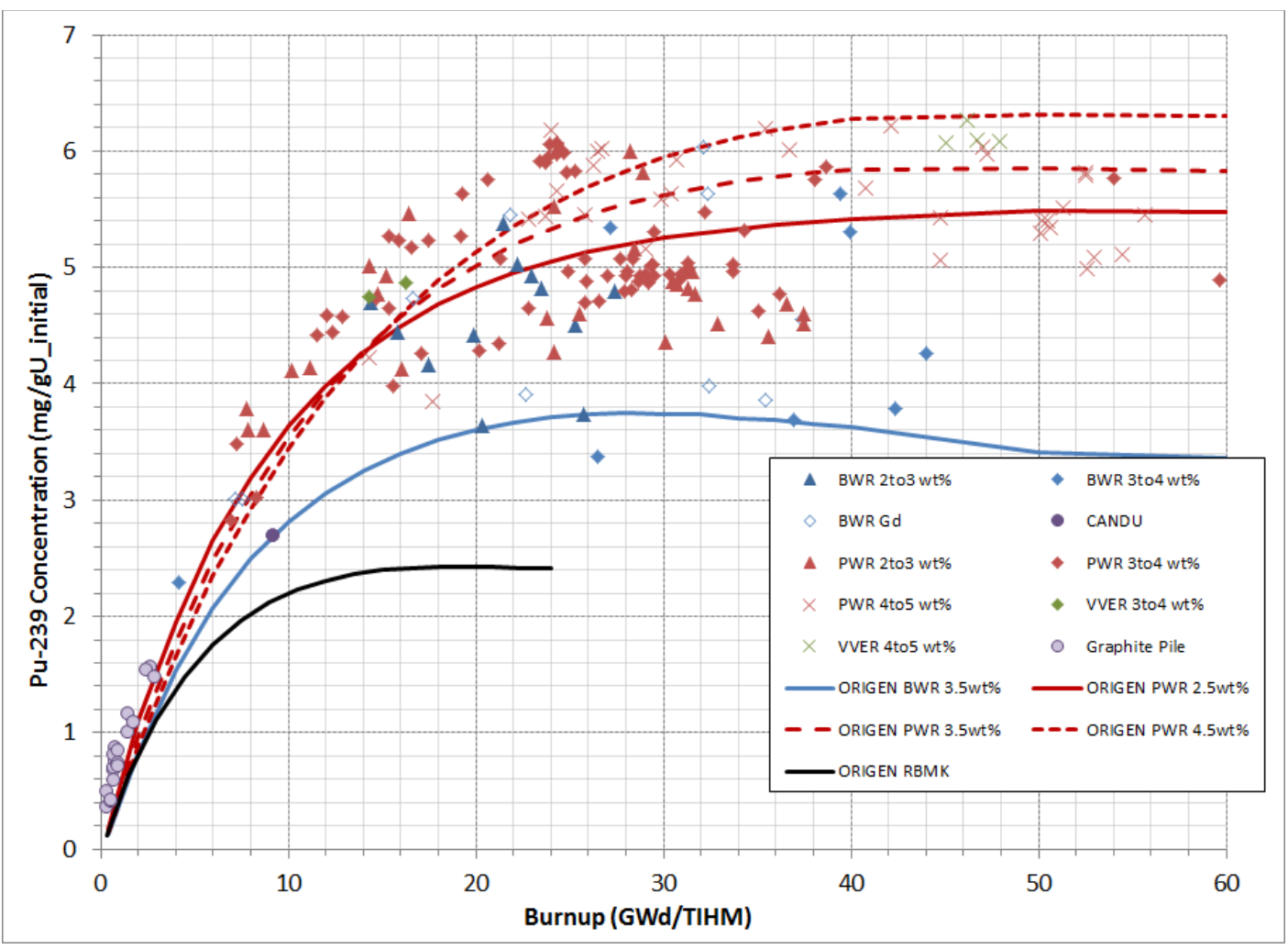

Fig. 13. Pu-239 concentration (mg/gU) as a function of burnup.

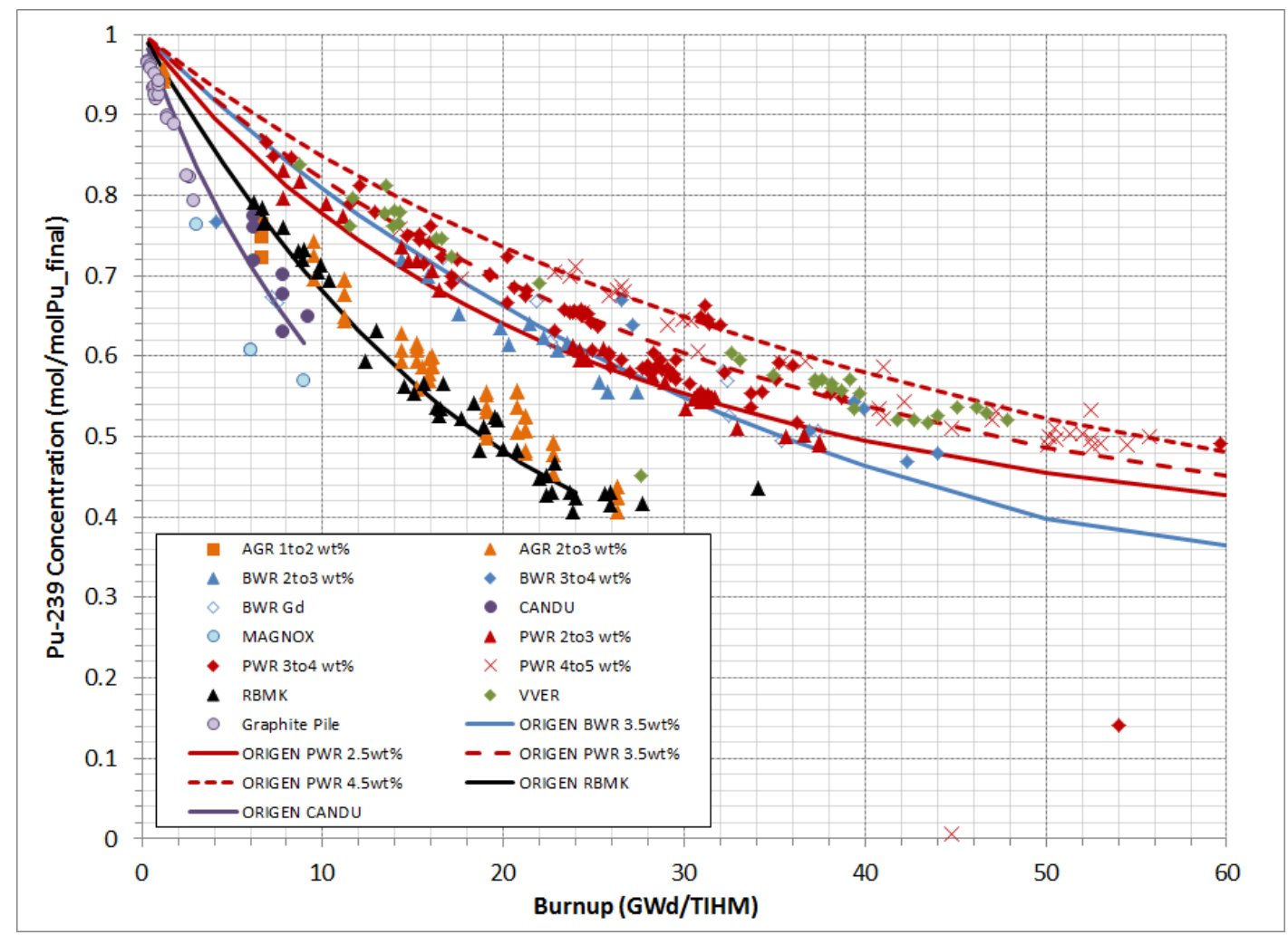

Fig. 14. Pu-239 concentration ( $\mathrm{mol} / \mathrm{mol} \mathrm{Pu})$ as a function of burnup. 
${ }^{240} \mathrm{Pu},{ }^{241} \mathrm{Pu}$, and ${ }^{242} \mathrm{Pu}$ steadily increase in quantity as a function of burnup, as seen in Fig. 15, Fig. 17, and Fig. 19. ${ }^{240} \mathrm{Pu}$ and ${ }^{242} \mathrm{Pu}$ quantities are relatively insensitive to the hardening of the neutron spectrum due to the different moderators. ${ }^{241} \mathrm{Pu}$ shows some sensitivity to the change in neutron spectrum. These effects are explained by the magnitude of the absorption cross sections as the spectrum is hardened toward the higher energies (see Table 2). ${ }^{239} \mathrm{Pu}$ and ${ }^{241} \mathrm{Pu}$ concentrations experience a greater effect with the change of the neutron spectrum due to their relatively large cross sections. ${ }^{241} \mathrm{Pu}$ does not show as significant an impact on the change of the neutron spectrum on the cross section because it has a short half-life-14.4 years - as compared to the other isotopes. This short half-life competes in the loss rate of ${ }^{241} \mathrm{Pu}$, reducing the impact on the neutron absorption loss rate.

Table 2. Thermal and fast flux-averaged absorption plutonium isotope cross sections

\begin{tabular}{|l|c|c|c|c|}
\hline & $\begin{array}{c}\text { Average thermal } \\
\text { fission cross } \\
\text { section (b) }\end{array}$ & $\begin{array}{c}\text { Average thermal } \\
\text { capture cross } \\
\text { section }_{(\mathbf{b})^{\mathbf{3 6}}}\end{array}$ & $\begin{array}{c}\text { Average fast } \\
\text { fission cross } \\
\text { section (b) }\end{array}$ & $\begin{array}{c}\text { Average fast } \\
\text { capture cross } \\
\text { section (b) }^{\mathbf{3 6}}\end{array}$ \\
\hline${ }^{239} \mathrm{Pu}$ & 788 & 310 & 1.8 & $0.04-0.05$ \\
\hline${ }^{240} \mathrm{Pu}$ & 0.06 & 287 & 1.3 & 0.08 \\
\hline${ }^{241} \mathrm{Pu}$ & 1059 & 373 & 1.6 & 0.09 \\
\hline${ }^{242} \mathrm{Pu}$ & 0.01 & 21 & 1.1 & 0.08 \\
\hline
\end{tabular}

The impacts on mole fraction (i.e., quality) for each of the plutonium isotopes beyond ${ }^{239} \mathrm{Pu}$ can be seen in Fig. 16, Fig. 18, and Fig. 20.

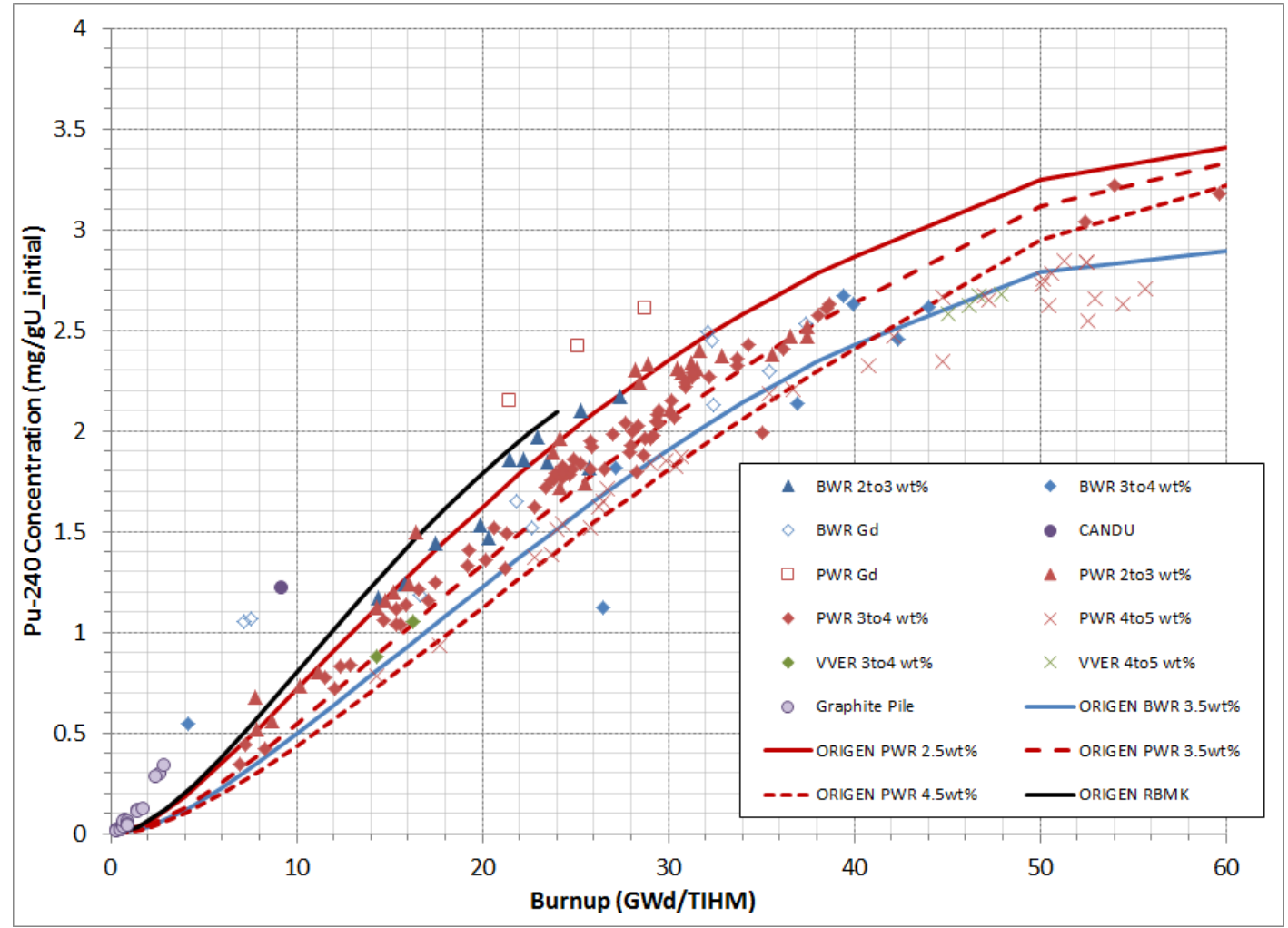

Fig. 15. Pu-240 concentration ( $\mathrm{mg} / \mathrm{gU})$ as a function of burnup. 


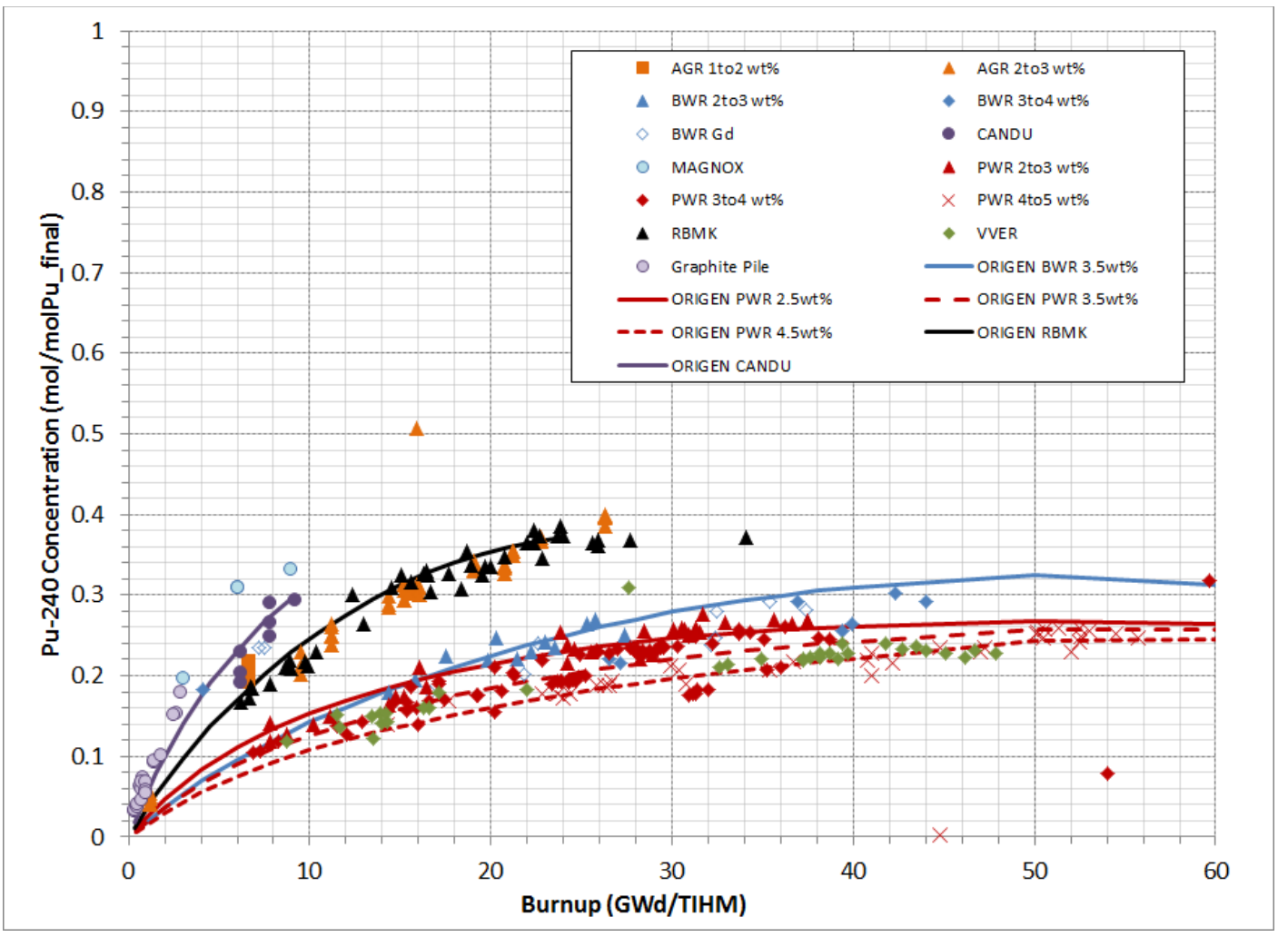

Fig. 16. Pu-240 concentration ( $\mathrm{mol} / \mathrm{mol} \mathrm{Pu})$ as a function of burnup.

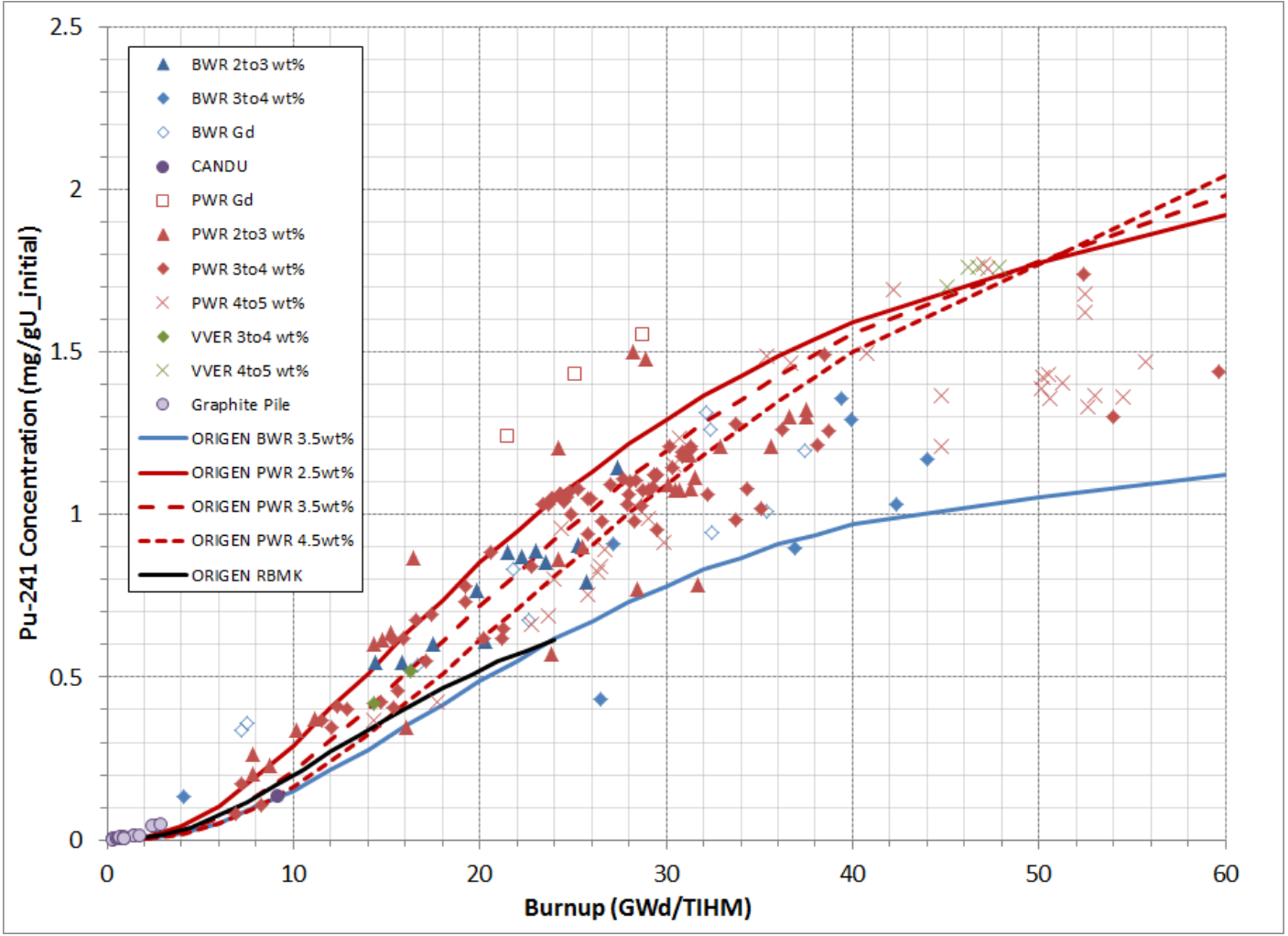

Fig. 17. Pu-241 concentration (mg/gU) as a function of burnup. 


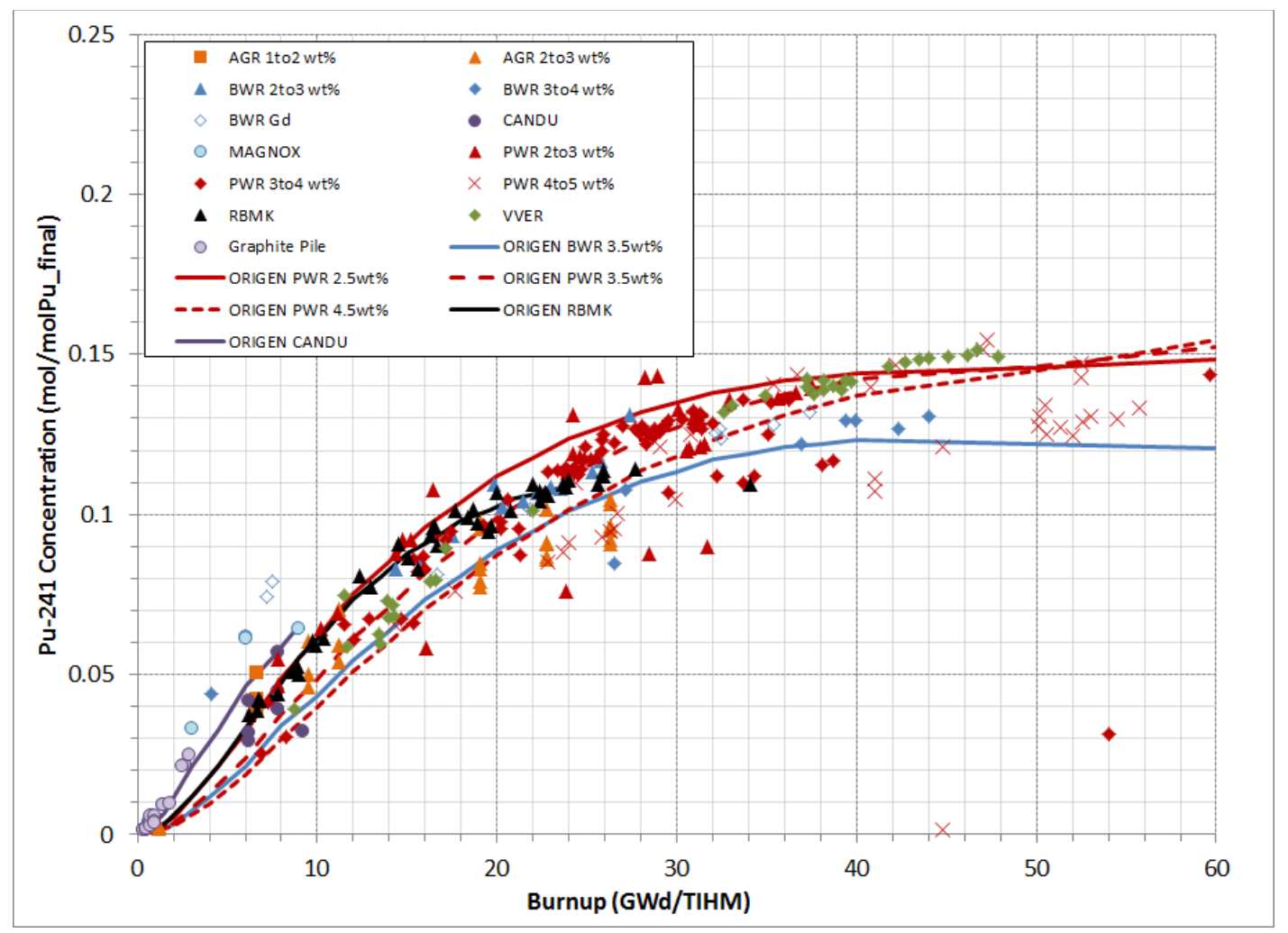

Fig. 18. Pu-241 concentration (mol/mol Pu) as a function of burnup.

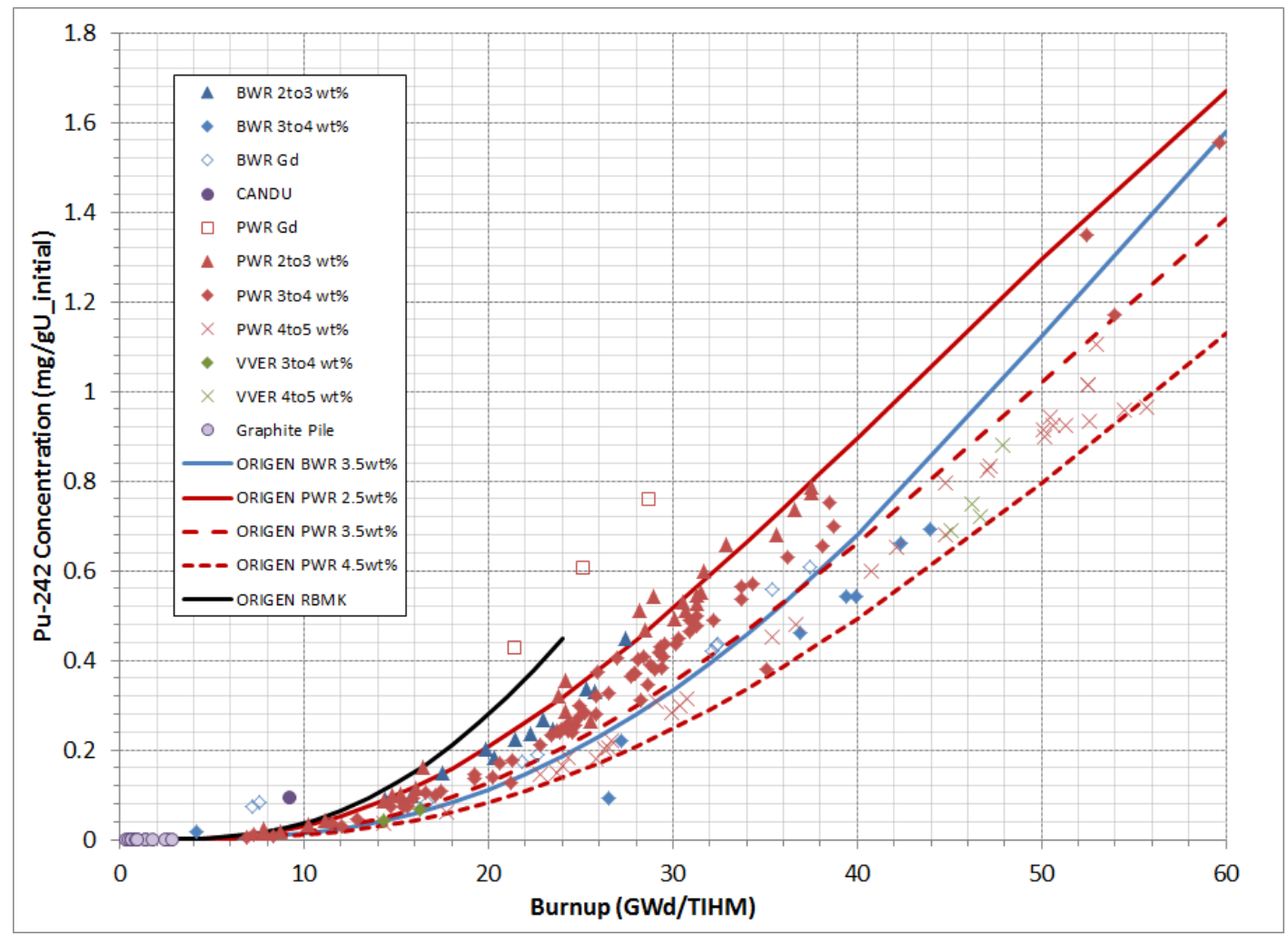

Fig. 19. Pu-242 concentration (mg/gU) as a function of burnup. 


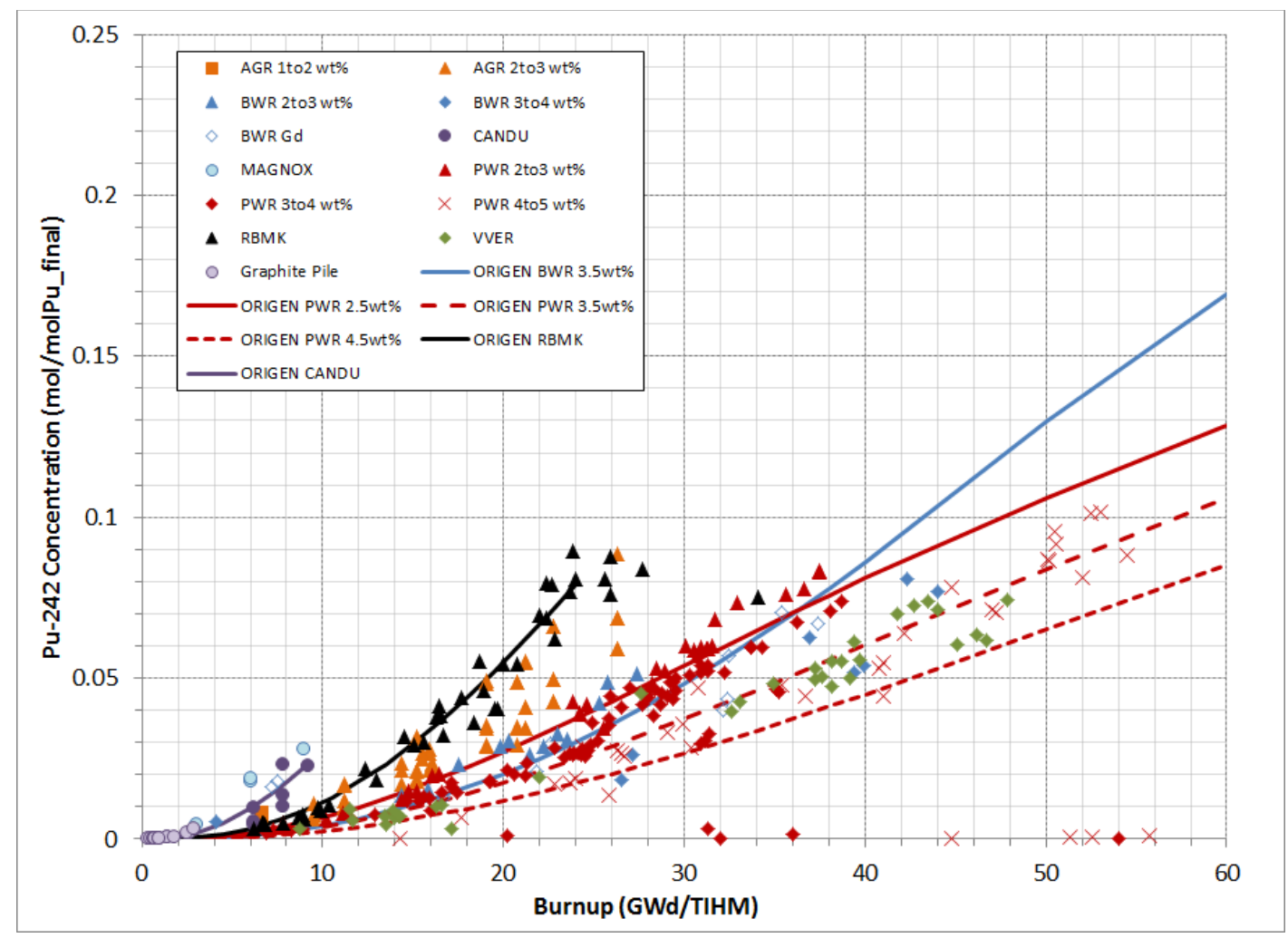

Fig. 20. Pu-242 concentration (mol/mol Pu) as a function of burnup.

\subsection{AMERICIUM ISOTOPES}

The three americium isotopes typically measured in used fuel are ${ }^{241} \mathrm{Am},{ }^{242} \mathrm{Am}$, and ${ }^{243} \mathrm{Am}$. More specifically, the metastable form of ${ }^{242} \mathrm{Am}$ is measured because it has a half-life of 141 years compared to the 16 hour half-life of the ground state of ${ }^{242} \mathrm{Am}$. Because ${ }^{241} \mathrm{Am}$ has a relatively long half-life (432 years) and is generated mainly from the decay of ${ }^{241} \mathrm{Pu}$ (14.4 years half-life), ${ }^{241} \mathrm{Am}$ continues to slowly build up after the fuel has been discharged from the reactor. This buildup is illustrated in Fig. 21 (i.e., the ORIGEN curves at different cooling times after discharge). The plotted data come from a variety of sources that are presented through a variety of reporting strategies. The data correspond to different cooling times after fuel discharge from the reactor. ${ }^{6,7}$ Some references adjust their measurements to the end of irradiation, while others simply report the concentration at time of measurement. The curves represent a generic PWR model that has been cooled to various times after irradiation. The scatter in the data seen in Fig. 21 is due to the different measurement times that were not considered in the calculations and is not an indication of modeling issues.

When a thermal neutron interacts with ${ }^{241} \mathrm{Am}, 79 \%$ of the time the interaction leads to ${ }^{242} \mathrm{Am}$ production, $10 \%$ of the time leads to ${ }^{242 \mathrm{~m}}$ Am production, and $\sim 11 \%$ of the time to a fission event. ${ }^{36}$ This example once again reiterates the complexity of actinide buildup. Measured values for ${ }^{242 \mathrm{~m}} \mathrm{Am}$ can be seen in Fig. 22.

The buildup of ${ }^{243} \mathrm{Am}$, on the other hand, resembles the buildup of ${ }^{242} \mathrm{Pu}$ (Fig. 19) with increasing burnup, as seen in Fig. 23. 


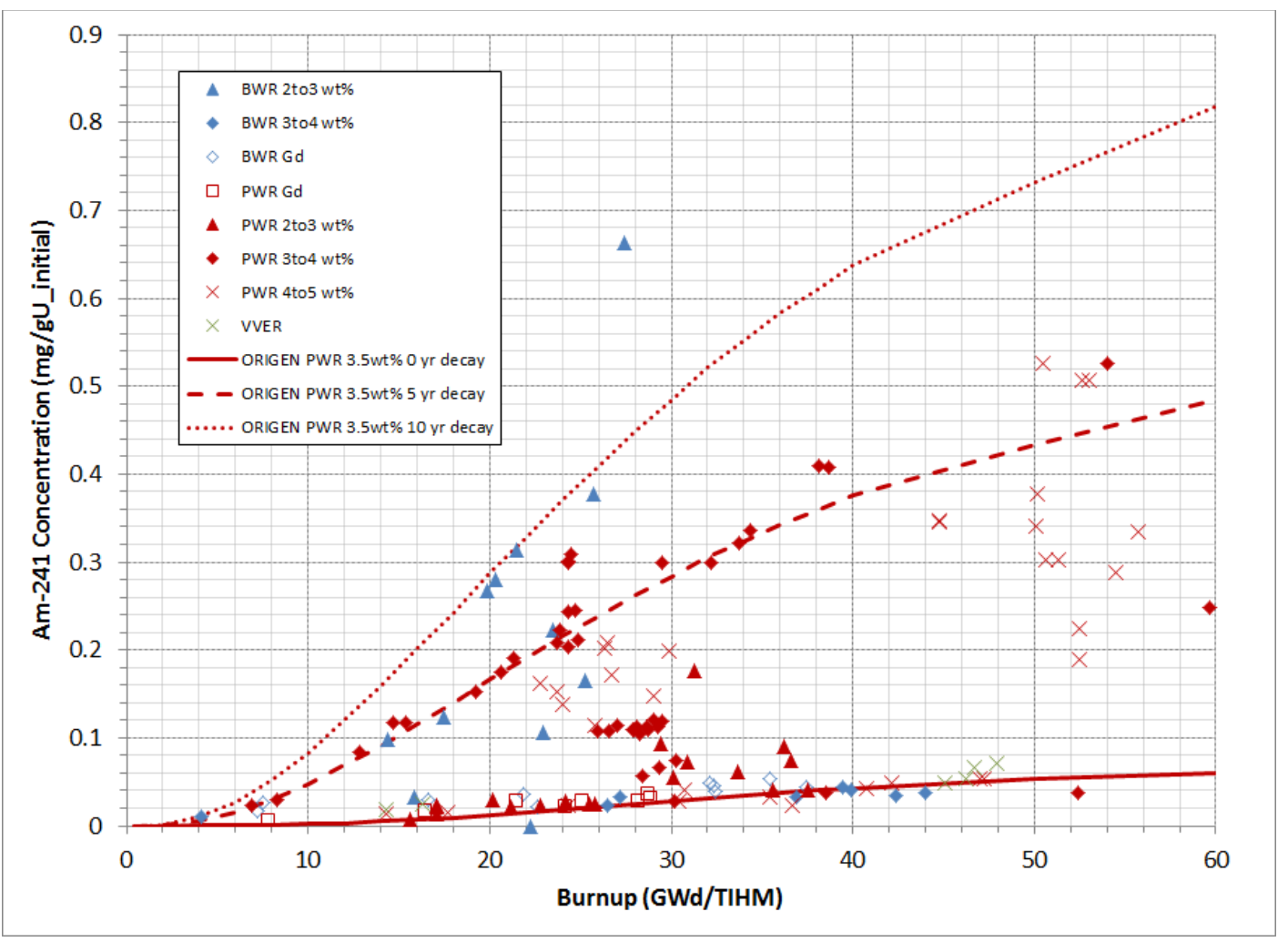

Fig. 21. Am-241 concentration as a function of burnup.

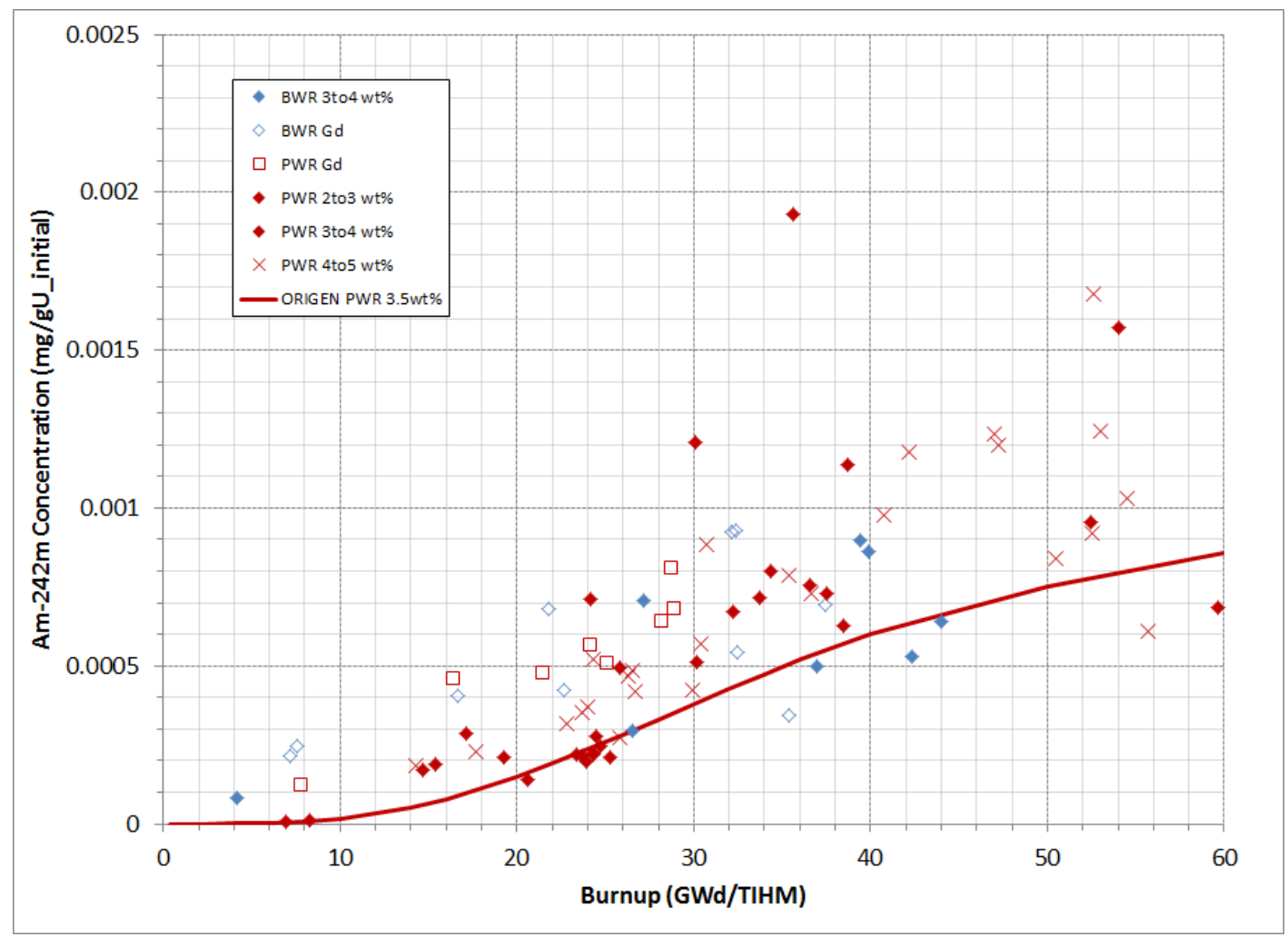

Fig. 22. Am-242m concentration as a function of burnup. 


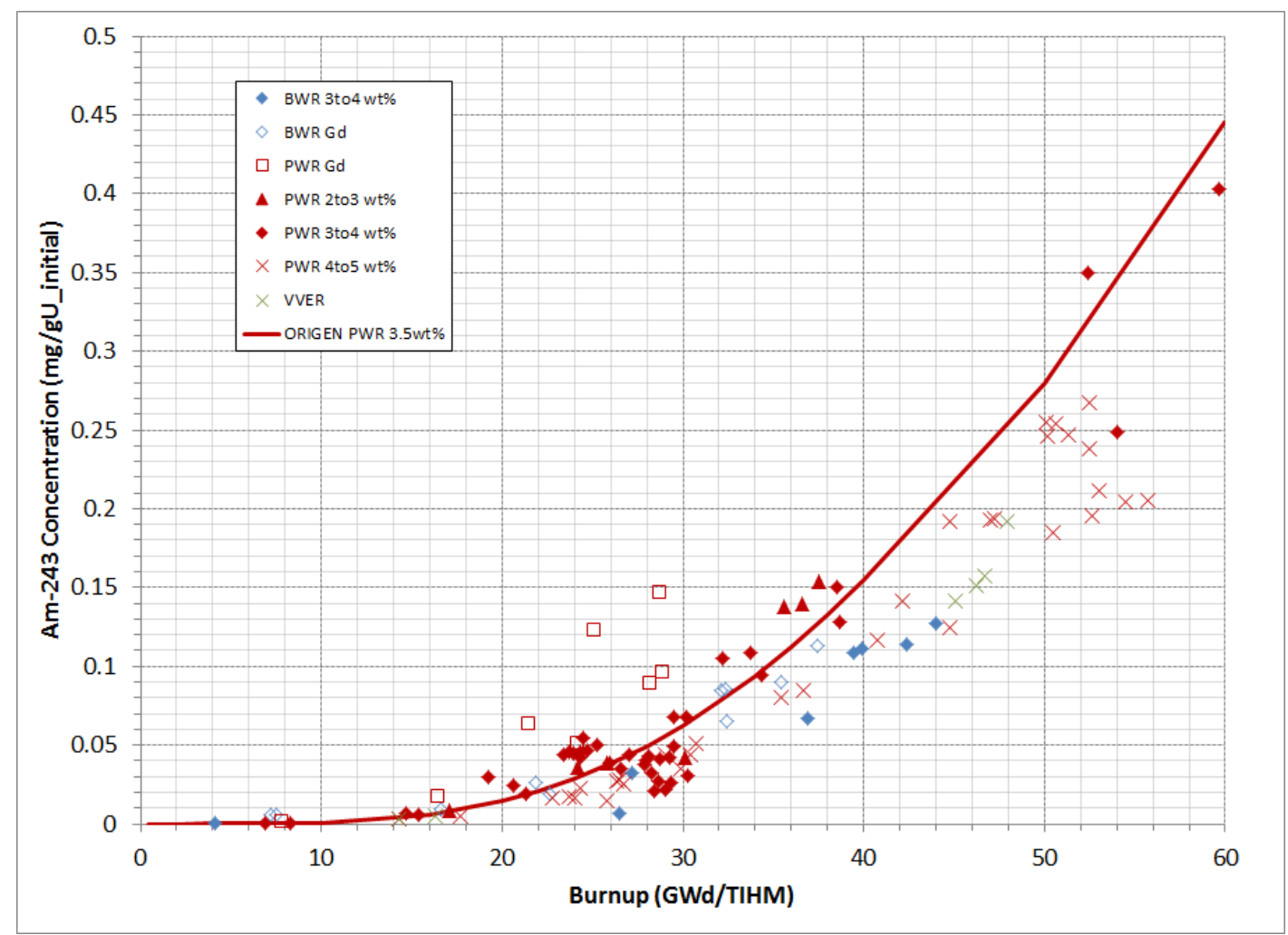

Fig. 23. Am-243 concentration as a function of burnup.

\subsection{CURIUM ISOTOPES}

Irradiated fuels typically have a relatively high neutron emission rate after discharge from the reactor. The primary contributors to these neutrons are spontaneous fission of ${ }^{242} \mathrm{Cm}$ and ${ }^{244} \mathrm{Cm} .{ }^{32}$ At short cooling times after discharge, most of the neutrons originate from ${ }^{242} \mathrm{Cm}$. Two years after discharge, most of the neutrons originate from ${ }^{244} \mathrm{Cm}$. Among the actinides, ${ }^{242} \mathrm{Cm}$ and ${ }^{244} \mathrm{Cm}$ are also predominant $\alpha$-emitters. Therefore, while the concentrations of the curium isotopes are small, they play a large role in the $\alpha$ and neutron signatures of the fuel after irradiation.

After irradiation, the concentration of ${ }^{242} \mathrm{Cm}$ decreases (half-life 163 days). Further analysis is needed to investigate the current discrepancies in modeling ${ }^{242} \mathrm{Cm}$, as seen in Fig. 24. The remaining curium isotopes trend very similarly, as seen in Fig. 25 through Fig. 29. 


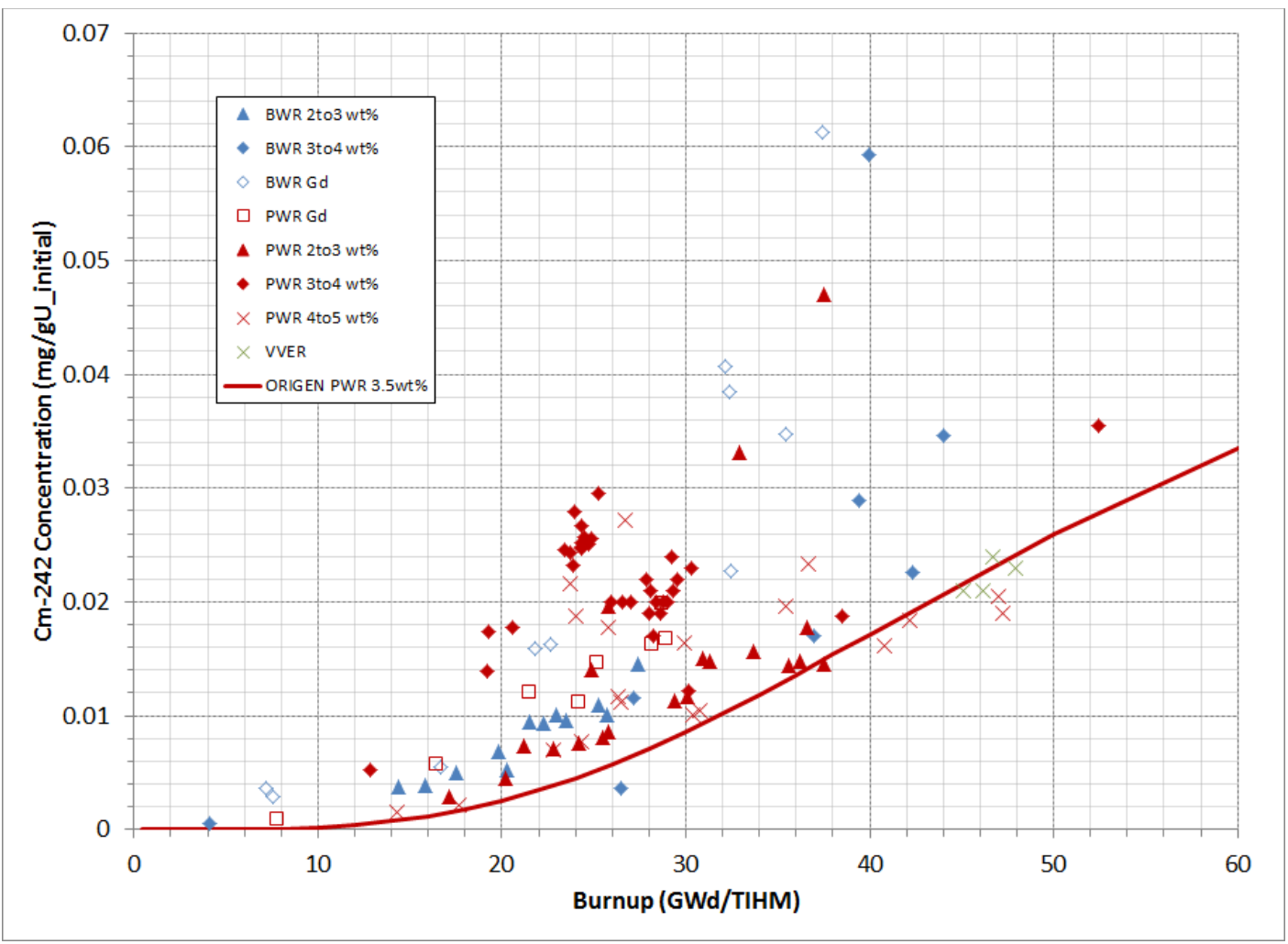

Fig. 24. Cm-242 concentration as a function of burnup.

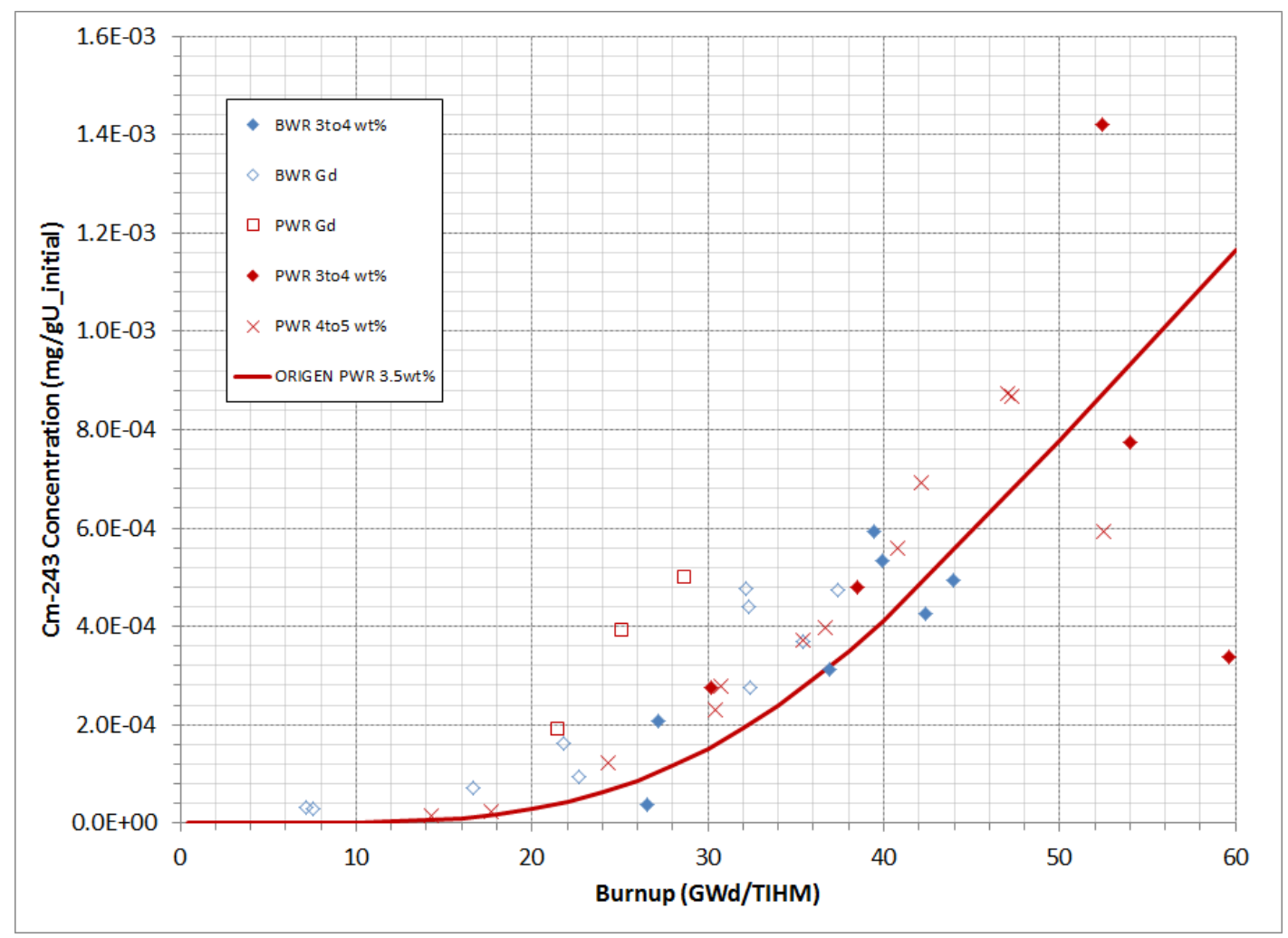

Fig. 25. Cm-243 concentration as a function of burnup. 


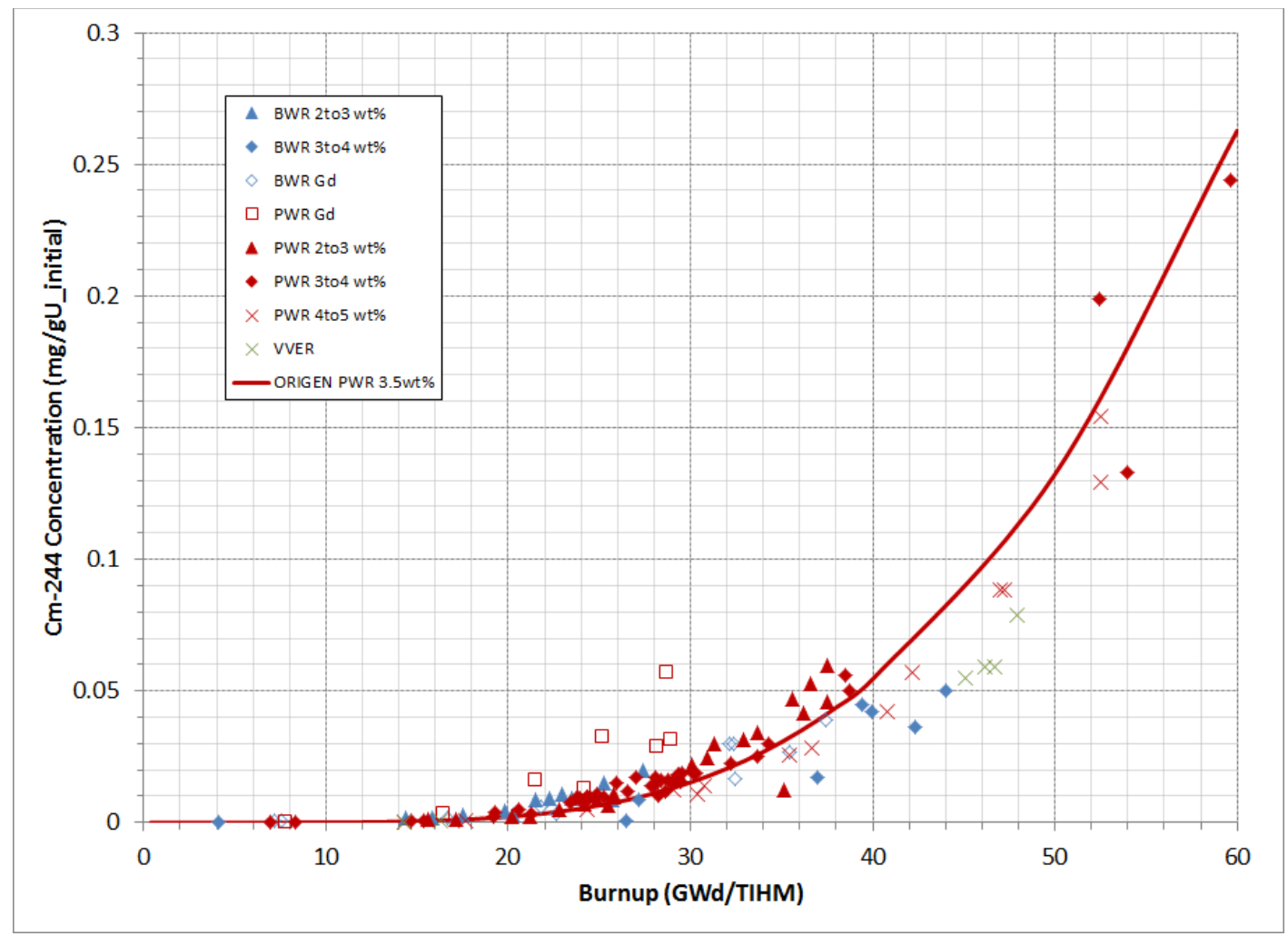

Fig. 26. Cm-244 concentration as a function of burnup.

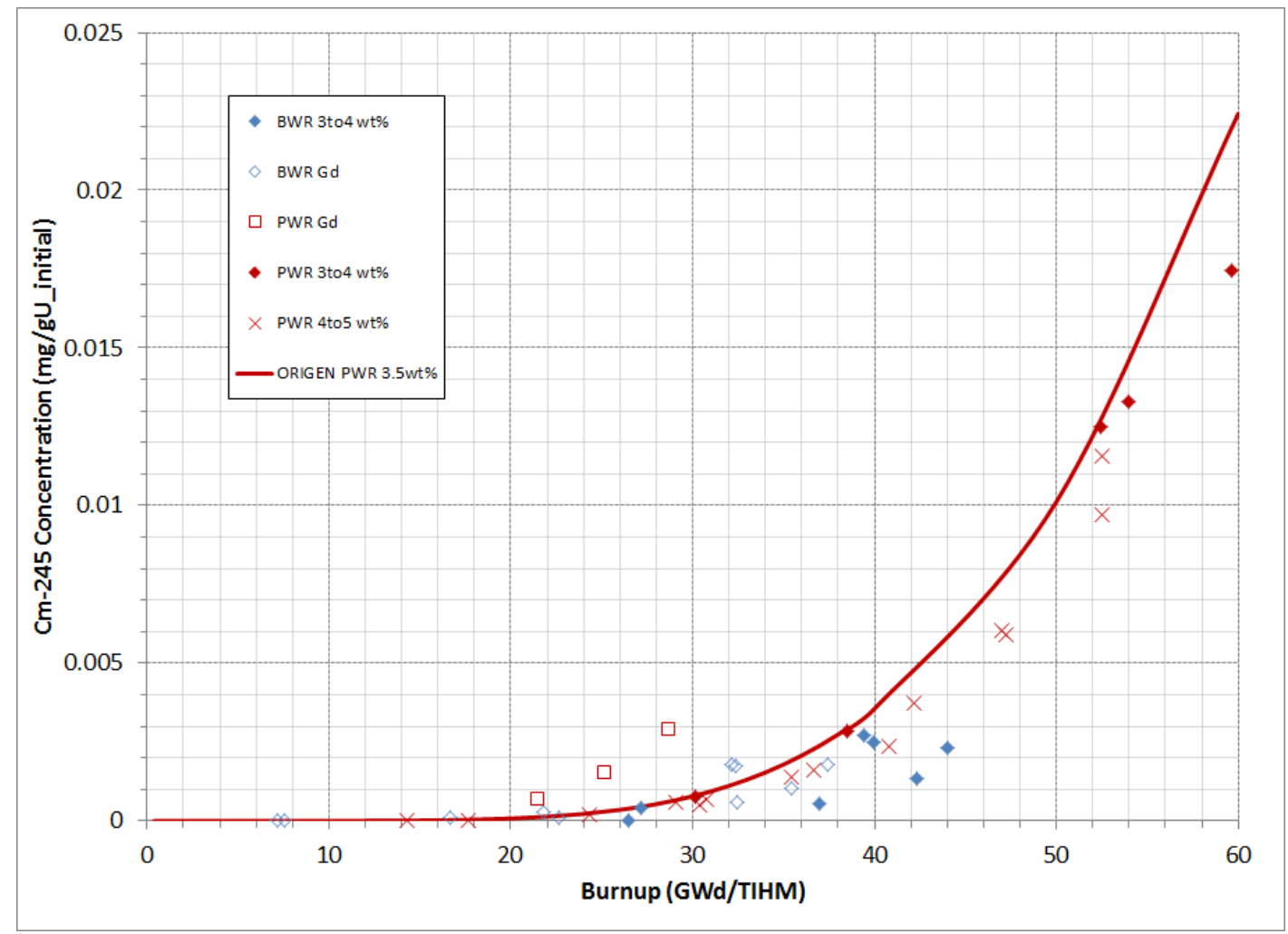

Fig. 27. Cm-245 concentration as a function of burnup. 


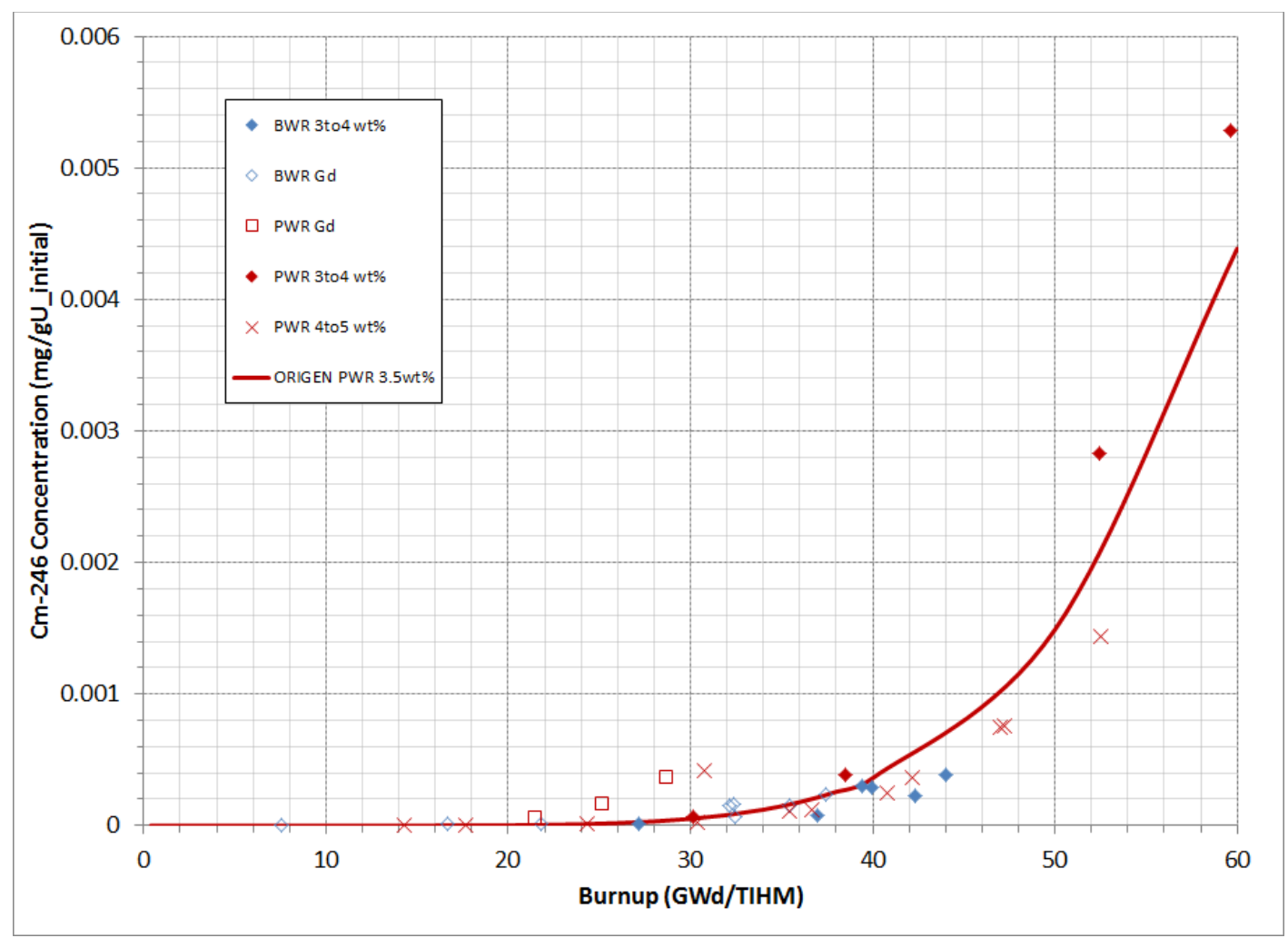

Fig. 28. Cm-246 concentration as a function of burnup.

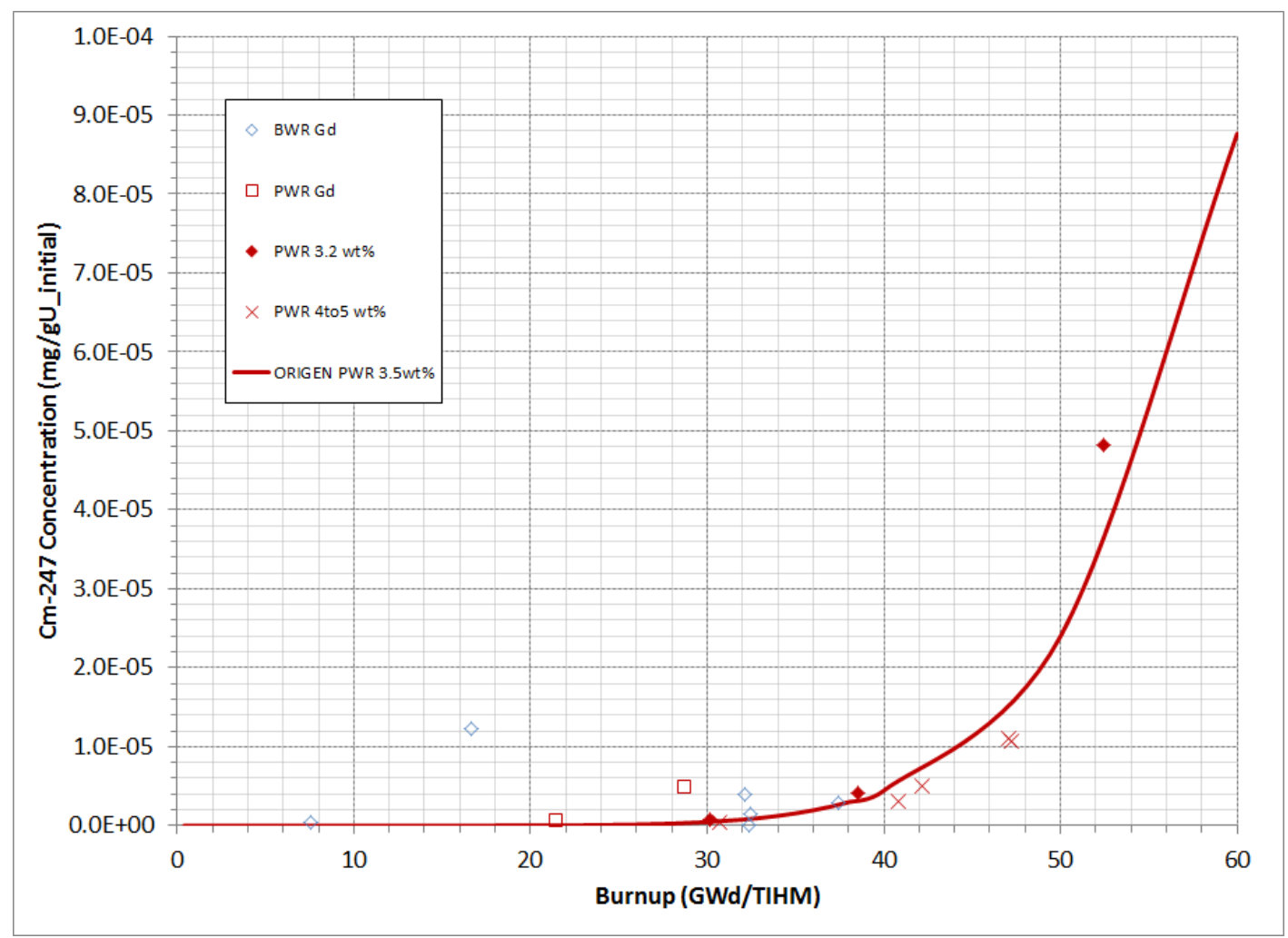

Fig. 29. Cm-247 concentration as a function of burnup. 


\subsection{MODEL VALIDATION OF ACTINIDES}

A series of validation reports have been previously published using the ORNL SCALE code with the data in this section. Due to the quality and quantity of PWR data, most of the focus has been on validation of samples from PWRs. ${ }^{10,13,16,18,20,21,23,24,25}$ However, varying degrees of validation work have been published on BWR ${ }^{19}, \mathrm{VVER}^{12}, \mathrm{RBMK}^{12}$, and Hanford $\mathrm{B}$ data ${ }^{28}$, as well.

The SCALE depletion models for validation have historically consisted of a two-dimensional representation of a specific fuel element. These models rely on various nuclear data libraries. ${ }^{23}$ The nuclear data are then processed - specifically the cross section data - and used in a neutron transport analysis. The typical 2-D transport code within the SCALE package is NEWT. ${ }^{38}$ Following the transport calculation, an updated cross section library is coupled to the ORIGEN depletion code. ${ }^{30}$ Following the depletion analysis, the newly calculated concentrations are used to recalculate needed cross section values to determine the next time step in the neutron transport analysis. This cyclic pattern is continued until the simulation has proceeded to the final time step. The coupling of all these steps is performed by the TRITON module within SCALE. ${ }^{39}$

The effect of nuclear data can be seen explicitly in Fig. $30 .{ }^{27}$ The calculated-to-experimental ratio $(\mathrm{C} / \mathrm{E})$ is an average over all fuel samples for which measured data for that nuclide were available. A 20 to 30 percent improvement in ${ }^{245} \mathrm{Cm}$ and ${ }^{246} \mathrm{Cm}$ prediction was seen due to improvements made from the ENDF/B-V library to the ENDF/B-VII library. The effect of changes in nuclear data, as well as the change in the cross section resonance processing method, were also assessed. ${ }^{27}$ The general $\mathrm{C} / \mathrm{E}$ trend seen in Fig. 30 for the PWR data using ENDF/B-V is very similar to the C/E trend seen in Fig. 31 for the BWR data that also used ENDF/B-V. ${ }^{19}$ A re-evaluation of the BWR data using ENDF/B-VII has not been performed; however, it is anticipated that the changes seen for the PWR samples would be seen for the BWR samples.

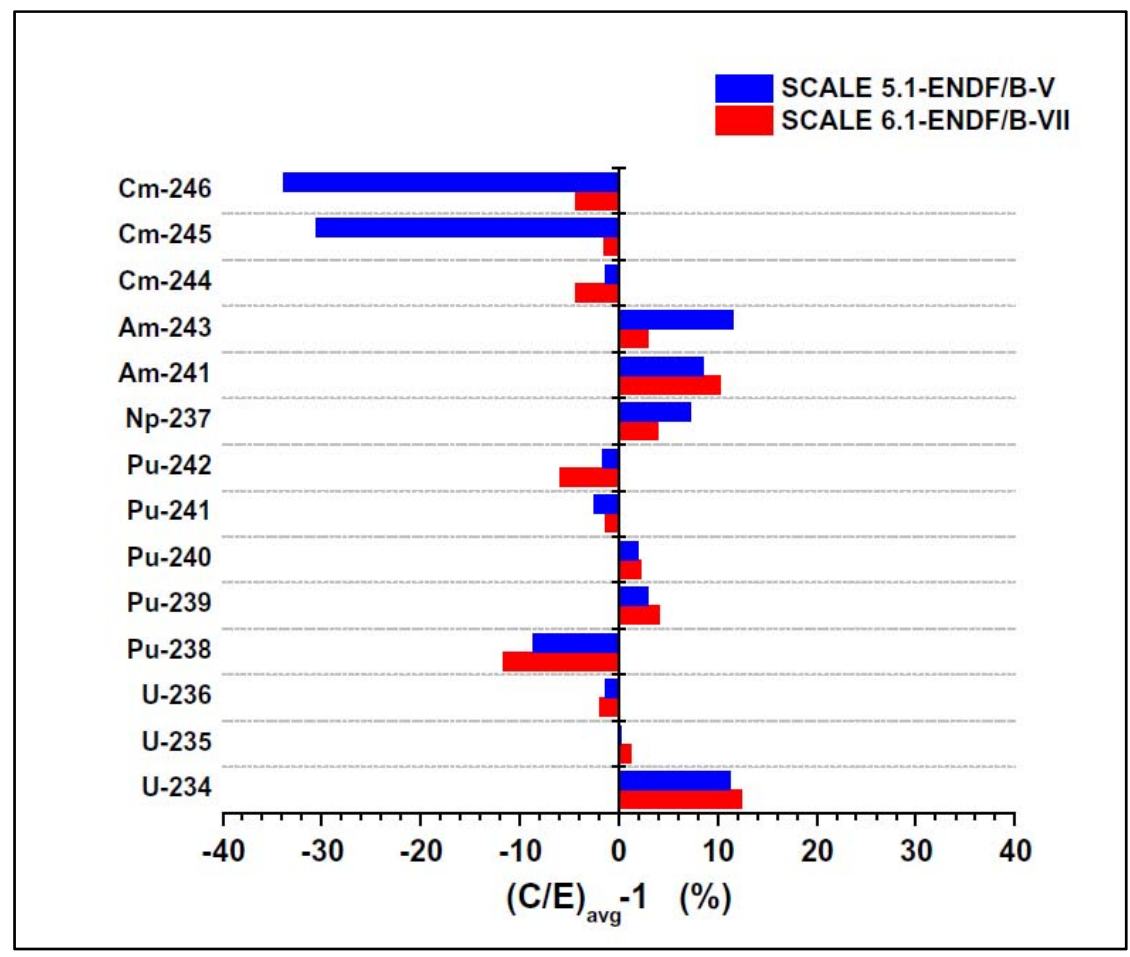

Fig. 30. Actinides C/E average for PWR simulations. ${ }^{27}$ 


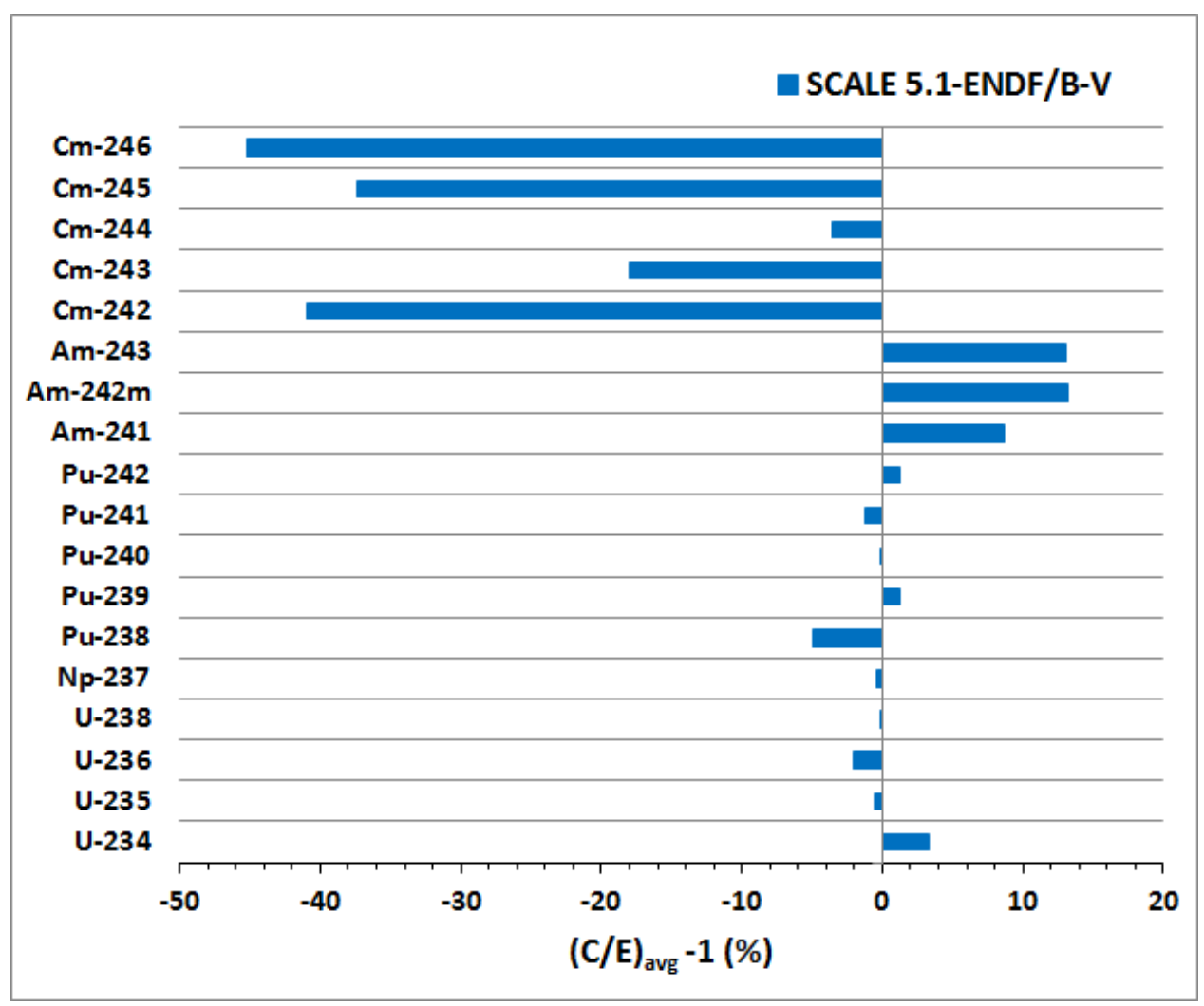

Fig. 31. Actinides C/E average for BWR simulations. ${ }^{19}$

On average, when using SCALE 5.1-ENDF/B-V, the major actinides ${ }^{235} \mathrm{U}$ and ${ }^{239} \mathrm{Pu}$ are overestimated by $0.3 \%$ and $3 \%$, respectively, for the PWR data. ${ }^{27}$ For the BWR data using the same library, the ${ }^{235} \mathrm{U}$ is underestimated by $0.5 \%$ and the ${ }^{239} \mathrm{Pu}$ is overestimated by $1.2 \%$. When using SCALE 6.1-ENDF/B-VII, the major actinides ${ }^{235} \mathrm{U}$ and ${ }^{239} \mathrm{Pu}$ are overestimated by $1 \%$ and $4 \%$, respectively, for the PWR data. The $\mathrm{C} / \mathrm{E}$ values for these major actinides as well as the other actinides are similar with the validation results for the VVER-440 (Fig. 32), VVER-1000 (Fig. 33), and the RBMK (Fig. 34), which were all performed using SCALE/TRITON and ENDF-B/V libraries. ${ }^{12}$

${ }^{238} \mathrm{Pu}$ is a noteworthy actinide. This isotope is consistently under-predicted by 10 to 20 percent. This under-estimation is not only seen in SCALE validation studies but by other codes as well. ${ }^{22,26}$ Future efforts need to examine the quality of the nuclear data that may be causing the codes to under-predict this isotopic concentration by so much.

The general agreement seen between the predicted and measured actinides for PWR, BWR, VVER, and RBMK samples, on the other hand, are not seen in the most recent study looking at the Hanford B sample using SCALE 6.1-ENDF/B-VII. ${ }^{28}$ As seen in Fig. 35, the ${ }^{239} \mathrm{Pu}$ concentration is predicted within $3.5 \%$, but the ${ }^{240} \mathrm{Pu}$ is under-predicted by $38 \%$. Such a discrepancy indicated a potentially serious nuclear data deficiency that is important to low exposure plutonium production scenarios. The impact was potentially due to large uncertainties in ${ }^{239} \mathrm{~Np}$ neutron capture cross sections. ${ }^{28}$ It was concluded that the use of different sources of currently available nuclear data evaluations did not resolve the large differences in predicted ${ }^{240} \mathrm{Pu}$, and these discrepancies are observed for many different codes. Further investigation of these discrepancies in the low exposure scenarios such as those seen for Hanford B is required to resolve the cause of the error and recommend improvements to current evaluated nuclear data. 


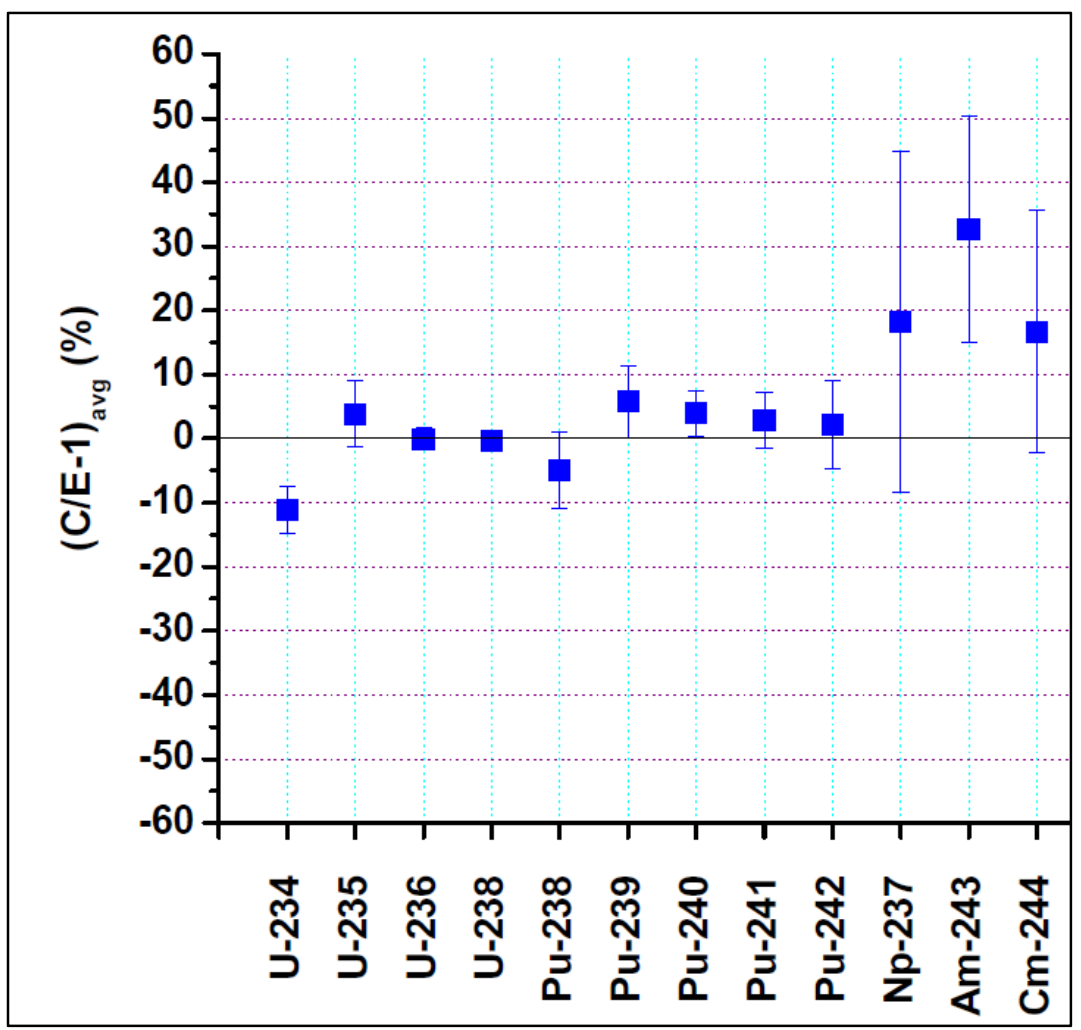

Fig. 32. Actinides C/E average for VVER-440 simulations. ${ }^{12}$

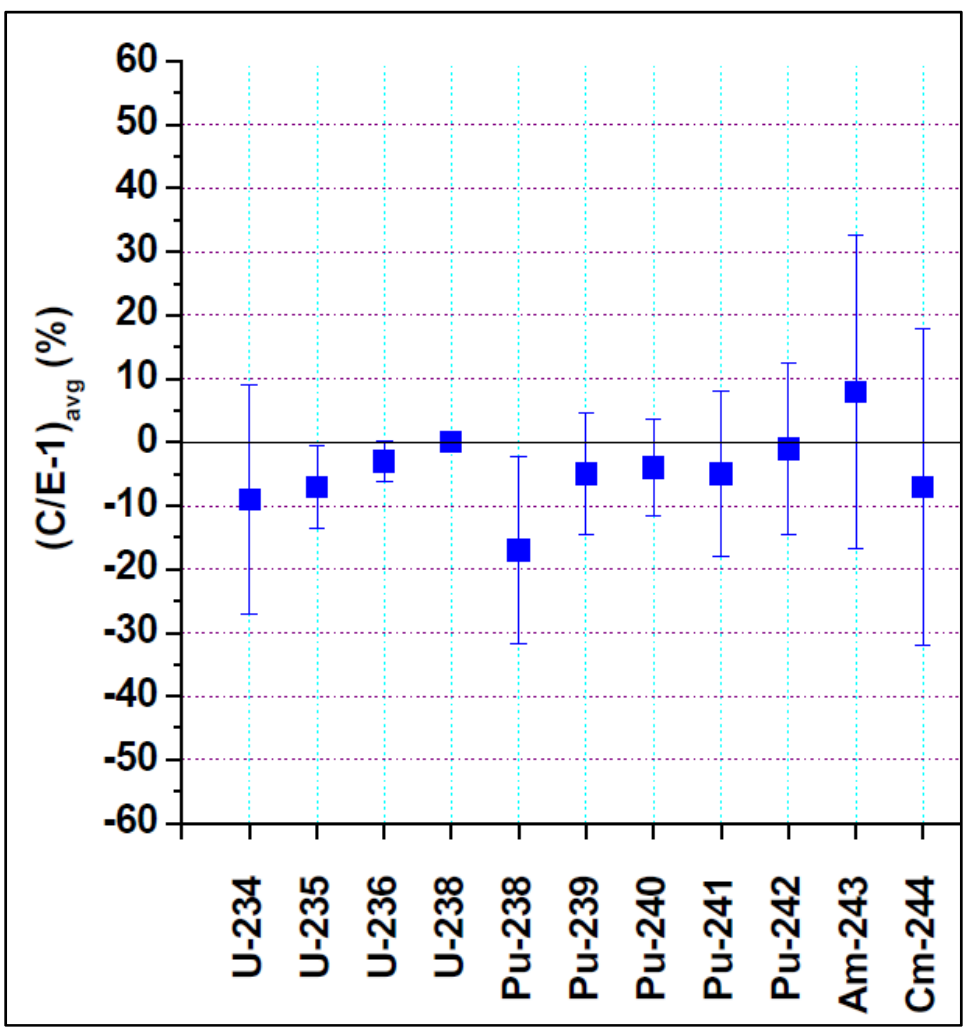

Fig. 33. Actinides C/E average for VVER-1000 simulations. ${ }^{12}$ 


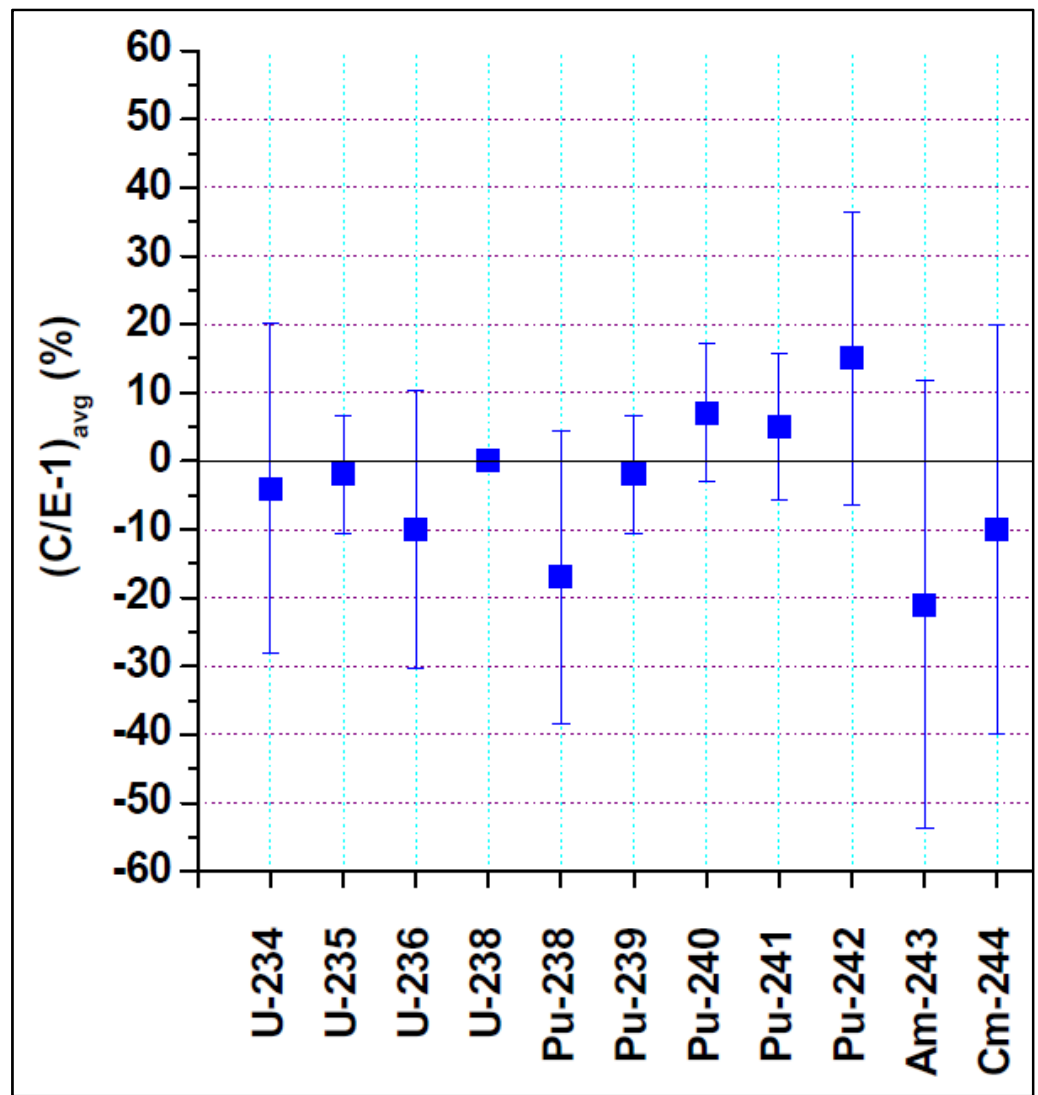

Fig. 34. Actinides C/E average for RBMK simulations. ${ }^{12}$

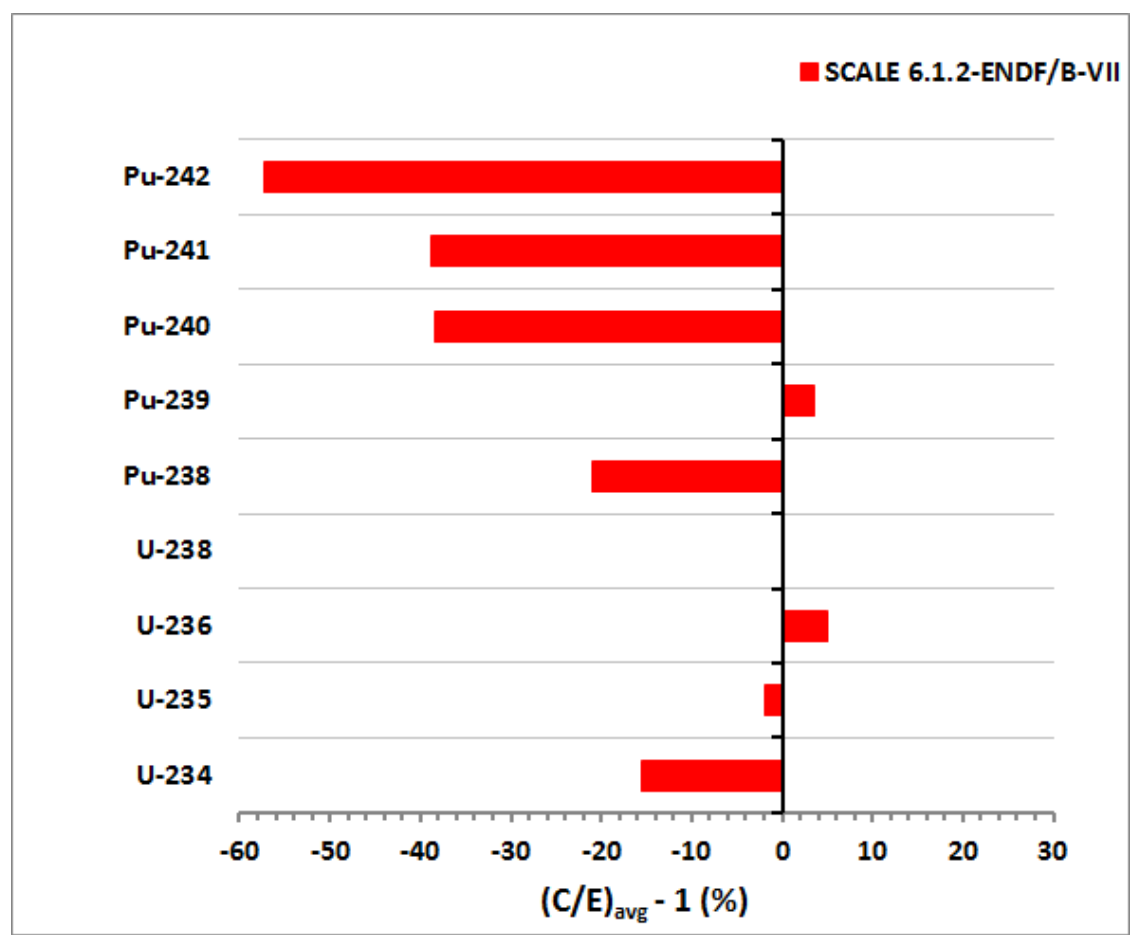

Fig. 35. Actinides C/E average for Hanford B reactor (graphite pile) simulations. ${ }^{28}$ 


\section{FISSION PRODUCT NOBLE GASES}

This section provides an overview of the buildup, decay, and migration of xenon and krypton isotopes following the irradiation of nuclear fuel. Noble gas measurements are commonly taken several years after fuel irradiation; therefore, the majority of the radioactive fission products have decayed away. With the exception of ${ }^{85} \mathrm{Kr}$, which has a half-life of 10.8 years, only the measurable stable noble gases are reported in this section. While collecting fission product noble gas data and comparing to modeled predictions, an inconsistency was discovered in reported data of independent yields, cumulative yields, and branching ratios. While this inconsistency affects all fission products, it was more noticeable for the fission product noble gases, as will be shown in this section.

\subsection{OVERVIEW OF FISSION PRODUCT NOBLE GAS PRODUCTION}

The fission product noble gases krypton and xenon can account for approximately $15 \%$ of the total amount of fission products. ${ }^{32}$ The xenon isotopes are relatively insensitive to the source of fissioning (i.e., ${ }^{235} \mathrm{U}$ or ${ }^{239} \mathrm{Pu}$ ), while the krypton isotopes do show a slight difference between fissioning from ${ }^{235} \mathrm{U}$ or ${ }^{239} \mathrm{Pu}$, as seen in Fig. 36. Because of the significance of the noble gases for the design of the fuel rods, numerous investigations have been devoted to their behavior in the fuel, resulting in fission gas behavior models which describe the processes occurring under reactor operating conditions. ${ }^{32,35,41-51}$

For locations in the fuel rod where the average thermal flux is highest, more fission products will be produced. Therefore, a higher concentration of fission products is found within a volume near the rod perimeter than within an equal volume in the center of the rod. ${ }^{35}$

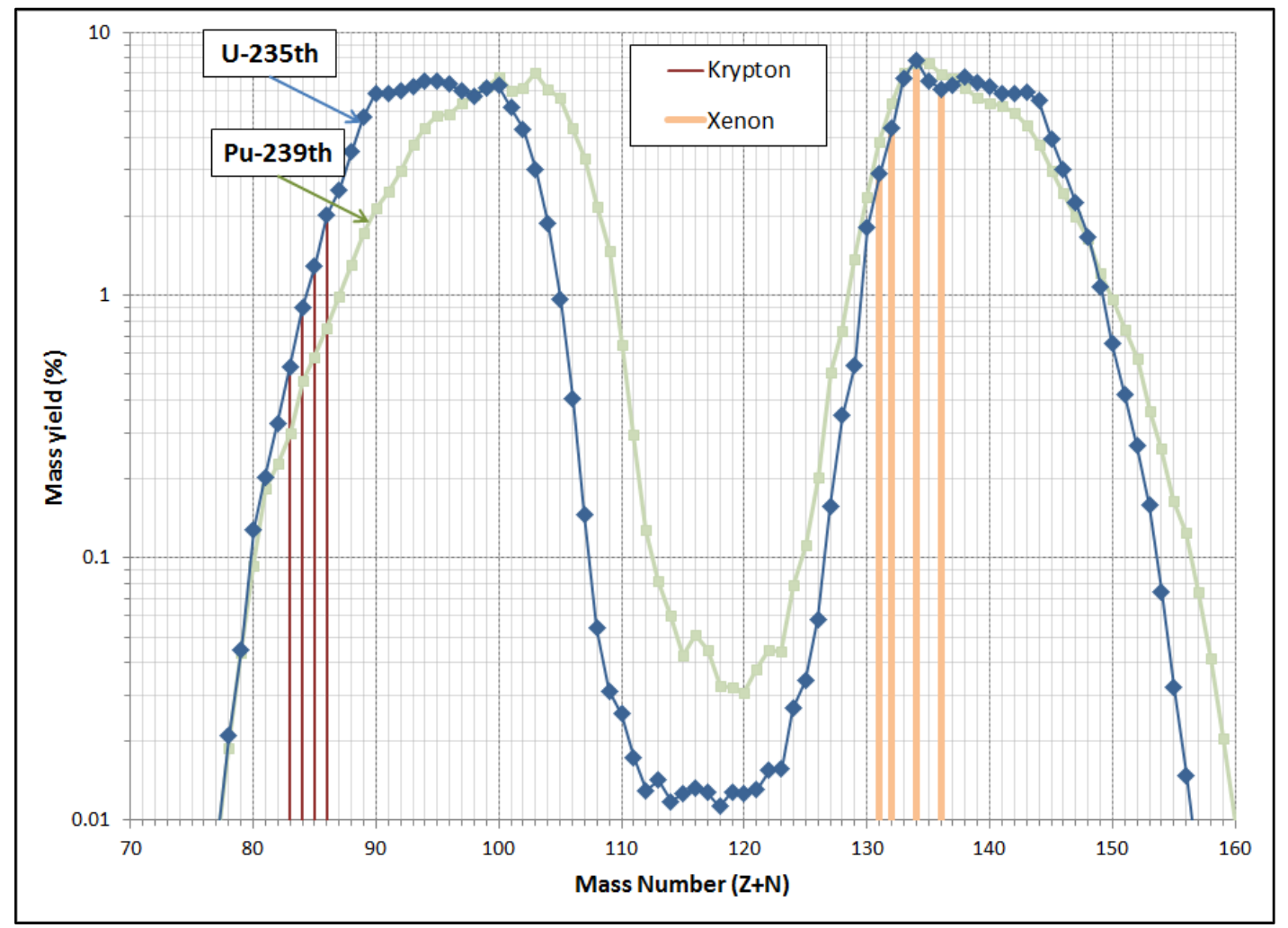

Fig. 36. Mass distribution of fission product noble gases from thermal fission of U-235 and Pu-239. 
The concentration of the fission products as a function of pellet radius can be determined by microanalysis across the fuel pellet. Microanalysis was performed by Goll et al. to determine the radial distribution of xenon in a fuel pellet. ${ }^{44}$ As seen in Fig. 37, the theoretically determined radial distribution of xenon (taking into account the spatially varying neutron flux) over-predicts the concentrations near the center of the fuel.

The significant deviation of xenon near the center of the fuel pin to the theoretical value as seen in Fig. 37 is due to fission gas release as a function of temperature. Typical temperature distributions within a solid fuel pin are parabolic, with the center of the fuel having the maximum temperature. Lewis et al. measured fission product xenon concentrations within small samples of $\mathrm{UO}_{2} \cdot{ }^{45}$ The mean temperatures were established for each sample location within the reactor. It was determined that at higher temperatures, more xenon is released from the fuel matrix into grain boundaries, imperfections, and bubbles. Therefore, more xenon is released from the fuel matrix at the center of the rod than from the fuel on the perimeter of the rod.

Fission product noble gases are released at varying linear heat rates (or temperatures). The linear heat rate varies spatially across a fuel rod; likewise, the linear heat rate changes throughout a cycle. Various parameters play a role in the physics of fission gas release as a function of irradiation time. ${ }^{40} \mathrm{Up}$ to this point, the term "release" does not mean release to the free voids of the fuel element, but that the gas has released from the fuel matrix and has collected in the interstitial spaces in the hot inner regions of the fuel. When the fuel is rapidly cooled in a decrease in power, thermal stresses cause the central region to crack along bubble-enriched grain boundaries. The trapped fission gas is released to the void spaces in the fuel element. The internal gas pressure will then increase during the next return to higher power. During the majority of the periods when the fuel is operated at constant power, the internal gas pressure is constant, indicating no release from the fuel to the void area in the fuel element.

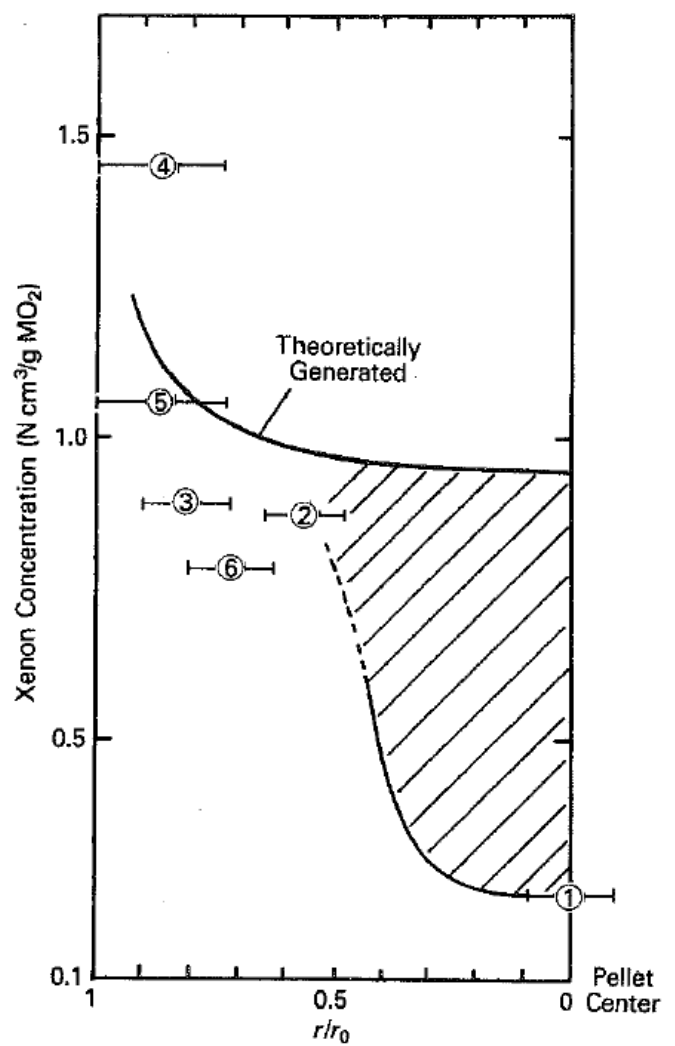

Fig. 37. Measured xenon concentrations as a function of relative fuel radius compared to theoretical predictions. $^{44}$ 


\subsection{MODERN FISSION YIELD INCONSISTENCIES}

As seen in Eq. (1), branching ratios are needed to calculate isotopic concentrations. It is important to distinguish independent fission yields (the formation of a nuclide directly from fission) from cumulative yields (the net formation from direct fission and the radioactive decay of precursors). In 1993, England and Rider produced a recommended set of independent and cumulative yields with their corresponding branching ratios for the fission products. This was based on a compiled list of open literature measurements and calculated charge distributions. ${ }^{52}$ This set was the basis for the evaluation of yields used with ENDF/B-VI and released in 1993. These yields are still used in ENDF/B-VII.1, which was released in $2011 .^{53}$ However, since the initial release of England and Rider's yield data, improved branching ratios have been released in ENDF/B evaluations. This has created inconsistencies between modern decay schemes and legacy fission product yields still in use today.

In England and Rider's original report, they stated, "The weighted average experimental independent yields, the weighted average experimental cumulative yields, and the calculated cumulative yields (where no data were available) were combined statistically to form a single, self-consistent recommended value." ${ }^{, 52}$ England and Rider go on to describe their very methodical approach to ensure consistency in the reported independent and cumulative yields and the branching ratios. For a more mathematically formalized definition of fission yields and branching ratios, see Appendix A.1.

During validation of ORIGEN, which uses the most recent nuclear data release, against measured fission product noble gases, the current predictions were not able to replicate the experimental values as accurately as they had in the past when ORIGEN was used with previous nuclear data releases. ORIGEN currently uses the ENDF/B-VII.1 yield and decay libraries. ${ }^{30}$ After further exploration, it was determined that the update in branching ratios in ENDF/B-VII.1 - more specifically the update in delayed neutron emissions - created an inconsistency between the reported independent yields and the reported cumulative yields. This inconsistency was evident due to the inability to predict cumulative mass chain yields consistent with experiments for the xenon and krypton isotopes.

The original branching ratios produced by England and Rider as compared to the modern recognized branching ratios in ENDF/B-VII.1 for xenon and krypton can be seen in Table 3 and Table 5, respectively. For many of the isotopes, the ratios have remained fairly similar.

Cumulative yields were calculated using the independent yields reported by England and Rider and the modern branching ratios. These newly calculated yields were compared to the cumulative yields as reported by England and Rider and included in ENDF/B-VII.1. The branching ratios assumed in 1993 and the declared independent yields were also used to confirm consistency in generating the original cumulative yields. The inconsistencies created by using legacy independent fission yields with modern decay schemes can be seen in Table 4 and Table 6 for xenon and krypton, respectively. 
Table 3. Comparison of England and Rider (1993) and ENDF/B-VII.1 (2011) branching ratios leading to key xenon isotopes

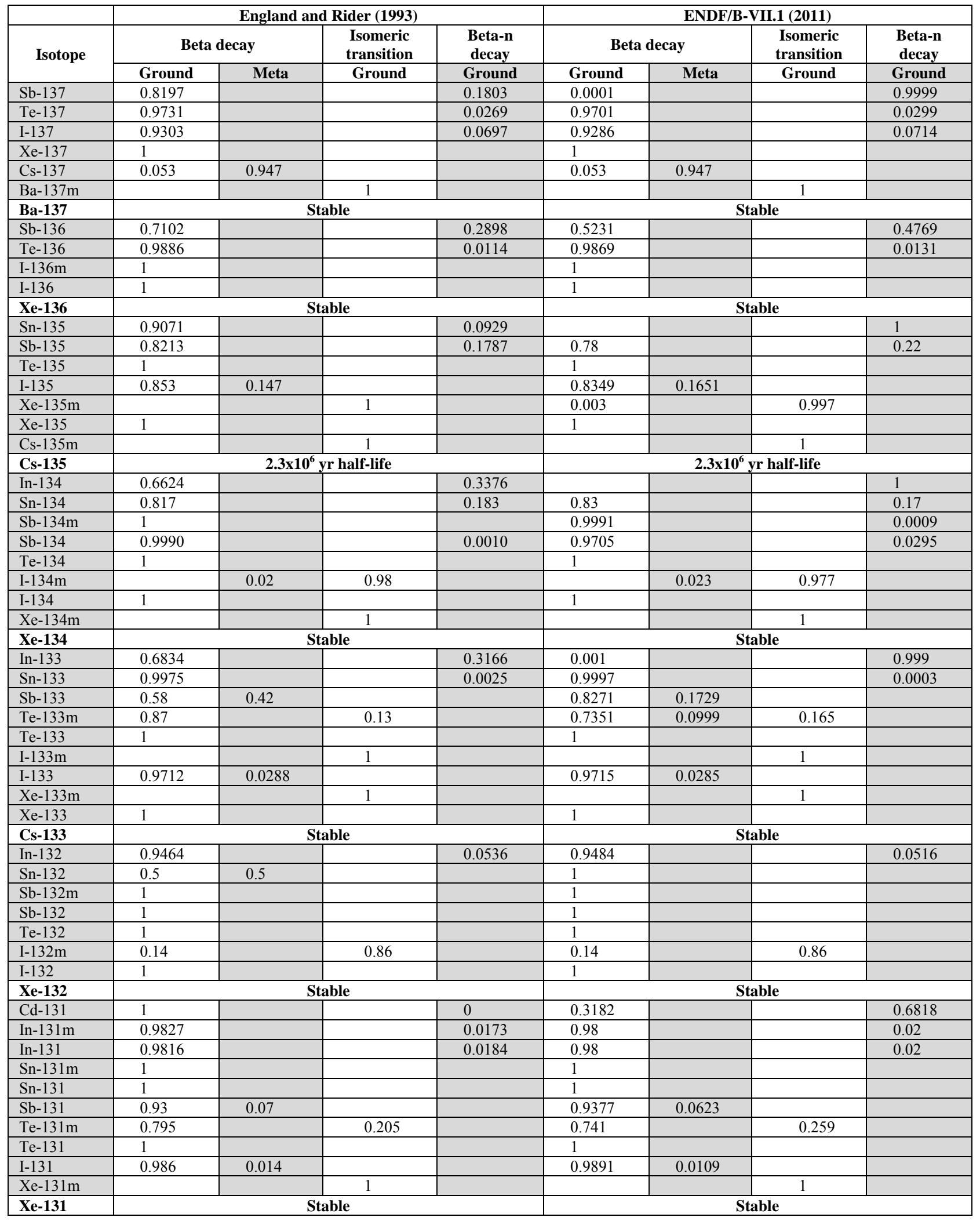


Table 4. Calculated cumulative yields using 2011 branching ratios and reported cumulative yields for the chains leading to key xenon isotopes (U-235 thermal).

\begin{tabular}{|c|c|c|c|c|}
\hline Isotope & $\begin{array}{c}\text { England et al. and } \\
\text { ENDF/B-VII.1 reported } \\
\text { direct yield } \\
\end{array}$ & $\begin{array}{c}\text { England et al. and ENDF/B- } \\
\text { VII.1 reported cumulative } \\
\text { yield }\end{array}$ & $\begin{array}{c}\text { Calculated cumulative } \\
\text { yield using } 2011 \\
\text { branching ratios } \\
\end{array}$ & $\begin{array}{c}\text { Calculated cumulative } \\
\text { yield (2011) over reported } \\
\text { cumulative yield }\end{array}$ \\
\hline Sb-137 & $7.43 \mathrm{E}-04$ & $7.43 \mathrm{E}-04$ & $7.43 \mathrm{E}-04$ & 1.00 \\
\hline Te-137 & 3.92E-03 & $4.53 \mathrm{E}-03$ & 3.92E-03 & 0.87 \\
\hline $\mathrm{I}-137$ & $2.62 \mathrm{E}-02$ & $3.07 \mathrm{E}-02$ & $3.01 \mathrm{E}-02$ & 0.98 \\
\hline $\mathrm{Xe}-137$ & $3.19 \mathrm{E}-02$ & $6.13 \mathrm{E}-02$ & $6.07 \mathrm{E}-02$ & 0.99 \\
\hline Cs-137 & $6.00 \mathrm{E}-04$ & $6.19 \mathrm{E}-02$ & $6.13 \mathrm{E}-02$ & 0.99 \\
\hline Ba-137m & $1.33 \mathrm{E}-06$ & $5.85 \mathrm{E}-02$ & $5.80 \mathrm{E}-02$ & 0.99 \\
\hline Ba-137 (stable) & 5.43E-07 & 6.19E-02 & 6.13E-02 & 0.99 \\
\hline $\mathrm{Sb}-136$ & $1.15 \mathrm{E}-04$ & $1.15 \mathrm{E}-04$ & $1.15 \mathrm{E}-04$ & 1.00 \\
\hline Te-136 & $1.32 \mathrm{E}-02$ & $1.34 \mathrm{E}-02$ & $1.40 \mathrm{E}-02$ & 1.04 \\
\hline $\mathrm{I}-136 \mathrm{~m}$ & $1.25 \mathrm{E}-02$ & $1.26 \mathrm{E}-02$ & $1.25 \mathrm{E}-02$ & 0.99 \\
\hline $\mathrm{I}-136$ & $1.32 \mathrm{E}-02$ & 2.64E-02 & 2.71E-02 & 1.03 \\
\hline Xe-136 (stable) & 2.19E-02 & 6.31E-02 & 6.37E-02 & 1.01 \\
\hline Sn-135 & $6.27 \mathrm{E}-06$ & $6.27 \mathrm{E}-06$ & $6.27 \mathrm{E}-06$ & 1.00 \\
\hline Sb-135 & $1.45 \mathrm{E}-03$ & $1.46 \mathrm{E}-03$ & $1.45 \mathrm{E}-03$ & 1.00 \\
\hline Te-135 & $3.22 \mathrm{E}-02$ & 3.34E-02 & 3.33E-02 & 1.00 \\
\hline $\mathrm{I}-135$ & $2.93 \mathrm{E}-02$ & $6.28 \mathrm{E}-02$ & $6.28 \mathrm{E}-02$ & 1.00 \\
\hline $\mathrm{Xe}-135 \mathrm{~m}$ & $1.78 \mathrm{E}-03$ & $1.10 \mathrm{E}-02$ & $1.22 \mathrm{E}-02$ & 1.10 \\
\hline Xe-135 & $7.85 \mathrm{E}-04$ & 6.54E-02 & $6.53 \mathrm{E}-02$ & 1.00 \\
\hline Cs-135m & $2.45 \mathrm{E}-06$ & $2.45 \mathrm{E}-06$ & $2.45 \mathrm{E}-06$ & 1.00 \\
\hline Cs-135 (long-lived) & 2.45E-06 & 6.54E-02 & 6.54E-02 & 1.00 \\
\hline In-134 & $3.47 \mathrm{E}-08$ & $3.47 \mathrm{E}-08$ & $3.47 \mathrm{E}-08$ & 1.00 \\
\hline Sn-134 & $1.77 \mathrm{E}-04$ & $1.77 \mathrm{E}-04$ & $1.77 \mathrm{E}-04$ & 1.00 \\
\hline Sb-134m & $3.58 \mathrm{E}-03$ & $3.58 \mathrm{E}-03$ & $3.58 \mathrm{E}-03$ & 1.00 \\
\hline $\mathrm{Sb}-134$ & $3.58 \mathrm{E}-03$ & 3.73E-03 & $3.74 \mathrm{E}-03$ & 1.00 \\
\hline Te-134 & $6.22 \mathrm{E}-02$ & 6.97E-02 & 6.97E-02 & 1.00 \\
\hline $\mathrm{I}-134 \mathrm{~m}$ & $3.64 \mathrm{E}-03$ & 3.64E-03 & $3.64 \mathrm{E}-03$ & 1.00 \\
\hline $\mathrm{I}-134$ & $5.00 \mathrm{E}-03$ & 7.83E-02 & 7.82E-02 & 1.00 \\
\hline Xe-134m & $2.46 \mathrm{E}-04$ & 3.19E-04 & $3.30 \mathrm{E}-04$ & 1.03 \\
\hline Xe-134 (stable) & 1.05E-04 & 7.87E-02 & 7.87E-02 & 1.00 \\
\hline In-133 & $1.71 \mathrm{E}-06$ & $1.71 \mathrm{E}-06$ & $1.71 \mathrm{E}-06$ & 1.00 \\
\hline $\mathrm{Sn}-133$ & $1.38 \mathrm{E}-03$ & $1.38 \mathrm{E}-03$ & $1.38 \mathrm{E}-03$ & 1.00 \\
\hline Sb-133 & $2.26 \mathrm{E}-02$ & $2.40 \mathrm{E}-02$ & $2.40 \mathrm{E}-02$ & 1.00 \\
\hline Te-133m & 2.99E-02 & 3.99E-02 & $3.40 \mathrm{E}-02$ & 0.85 \\
\hline Te-133 & $1.15 \mathrm{E}-02$ & $3.06 \mathrm{E}-02$ & $3.70 \mathrm{E}-02$ & 1.21 \\
\hline $\mathrm{I}-133 \mathrm{~m}$ & $8.25 \mathrm{E}-04$ & $8.25 \mathrm{E}-04$ & 4.22E-03 & 5.12 \\
\hline $\mathrm{I}-133$ & $8.25 \mathrm{E}-04$ & $6.70 \mathrm{E}-02$ & $6.71 \mathrm{E}-02$ & 1.00 \\
\hline $\mathrm{Xe}-133 \mathrm{~m}$ & $1.89 \mathrm{E}-05$ & $1.95 \mathrm{E}-03$ & $1.93 \mathrm{E}-03$ & 0.99 \\
\hline Xe-133 & $6.66 \mathrm{E}-06$ & $6.70 \mathrm{E}-02$ & $6.71 \mathrm{E}-02$ & 1.00 \\
\hline Cs-133 (stable) & 7.92E-09 & 6.70E-02 & 6.71E-02 & 1.00 \\
\hline In-132 & $6.23 \mathrm{E}-05$ & $6.23 \mathrm{E}-05$ & $6.23 \mathrm{E}-05$ & 1.00 \\
\hline $\mathrm{Sn}-132$ & $5.92 \mathrm{E}-03$ & $5.98 \mathrm{E}-03$ & $5.98 \mathrm{E}-03$ & 1.00 \\
\hline $\mathrm{Sb}-132 \mathrm{~m}$ & 8.63E-03 & $1.16 \mathrm{E}-02$ & 8.63E-03 & 0.74 \\
\hline Sb-132 & $1.30 \mathrm{E}-02$ & $1.60 \mathrm{E}-02$ & $1.90 \mathrm{E}-02$ & 1.19 \\
\hline Te-132 & $1.53 \mathrm{E}-02$ & 4.29E-02 & 4.30E-02 & 1.00 \\
\hline $\mathrm{I}-132 \mathrm{~m}$ & $9.13 \mathrm{E}-05$ & $9.13 \mathrm{E}-05$ & $9.13 \mathrm{E}-05$ & 1.00 \\
\hline $\mathrm{I}-132$ & $9.13 \mathrm{E}-05$ & 4.31E-02 & 4.31E-02 & 1.00 \\
\hline Xe-132 (stable) & 4.22E-07 & 4.31E-02 & 4.31E-02 & 1.00 \\
\hline Cd-131 & $1.38 \mathrm{E}-04$ & $1.38 \mathrm{E}-04$ & $1.38 \mathrm{E}-04$ & 1.00 \\
\hline In-131m & 0 & 0 & $5.56 \mathrm{E}-05$ & -- \\
\hline In-131 & $1.11 \mathrm{E}-04$ & $2.49 \mathrm{E}-04$ & $9.94 \mathrm{E}-05$ & 0.40 \\
\hline $\mathrm{Sn}-131 \mathrm{~m}$ & $4.41 \mathrm{E}-03$ & $4.42 \mathrm{E}-03$ & $4.41 \mathrm{E}-03$ & 1.00 \\
\hline Sn-131 & 4.41E-03 & 4.64E-03 & $4.56 \mathrm{E}-03$ & 0.98 \\
\hline Sb-131 & $1.65 \mathrm{E}-02$ & $2.56 \mathrm{E}-02$ & $2.55 \mathrm{E}-02$ & 1.00 \\
\hline $\mathrm{Te}-131 \mathrm{~m}$ & 2.33E-03 & 4.12E-03 & 3.92E-03 & 0.95 \\
\hline Te-131 & 9.70E-04 & $2.55 \mathrm{E}-02$ & $2.59 \mathrm{E}-02$ & 1.02 \\
\hline $\mathrm{I}-131$ & $3.92 \mathrm{E}-05$ & $2.89 \mathrm{E}-02$ & $2.88 \mathrm{E}-02$ & 1.00 \\
\hline $\mathrm{Xe}-131 \mathrm{~m}$ & $3.48 \mathrm{E}-09$ & $4.05 \mathrm{E}-04$ & $3.14 \mathrm{E}-04$ & 0.78 \\
\hline Xe-131 (stable) & 1.42E-09 & 2.89E-02 & 2.88E-02 & 1.00 \\
\hline
\end{tabular}


Table 5. Comparison of England and Rider (1993) and ENDF/B-VII.1 (2011) branching ratios leading to key krypton isotopes

\begin{tabular}{|c|c|c|c|c|c|c|c|c|}
\hline \multirow{3}{*}{ Isotope } & \multicolumn{4}{|c|}{ England and Rider (1993) } & \multicolumn{4}{|c|}{ ENDF/B-VII.1 (2011) } \\
\hline & \multicolumn{2}{|c|}{ Beta decay } & \multirow{2}{*}{$\begin{array}{c}\begin{array}{c}\text { Isomeric } \\
\text { transition }\end{array} \\
\text { Ground } \\
\end{array}$} & \multirow{2}{*}{$\begin{array}{c}\text { Beta-n decay } \\
\text { Ground }\end{array}$} & \multicolumn{2}{|c|}{ Beta decay } & \multirow{2}{*}{\begin{tabular}{|c|}
$\begin{array}{c}\text { Isomeric } \\
\text { transition }\end{array}$ \\
Ground \\
\end{tabular}} & \multirow{2}{*}{$\begin{array}{c}\begin{array}{c}\text { Beta-n } \\
\text { decay }\end{array} \\
\text { Ground }\end{array}$} \\
\hline & Ground & Meta & & & Ground & Meta & & \\
\hline $\mathrm{Ge}-87^{b}$ & 0.8487 & & & 0.1513 & 0.9588 & & & 0.0412 \\
\hline As- $87^{b}$ & 0.5564 & & & 0.4436 & 0.6033 & & & 0.3967 \\
\hline $\mathrm{Se}-87^{b}$ & 0.9981 & & & 0.0019 & 0.998 & & & 0.002 \\
\hline $\mathrm{Br}-87^{b}$ & 0.9746 & & & 0.0254 & 0.974 & & & 0.026 \\
\hline Ga-86 & 1 & & & & 0.2375 & & & 0.7625 \\
\hline Ge-86 & 0.8479 & & & 0.1521 & 0.948 & & & 0.052 \\
\hline As- 86 & 0.9150 & & & 0.0850 & 0.8751 & & & 0.1249 \\
\hline Se-86 & 1 & & & & 1 & & & \\
\hline $\mathrm{Br}-86^{a}$ & 1 & & & & 1 & & & \\
\hline Kr-86 & \multicolumn{4}{|c|}{ Stable } & \multicolumn{4}{|c|}{ Stable } \\
\hline Ga-85 & 0.5503 & & & 0.4497 & & & & 1.0 \\
\hline Ge- 85 & 0.8355 & & & 0.1645 & 0.9859 & & & 0.0141 \\
\hline As- 85 & 0.5 & & & 0.5 & 0.406 & & & 0.594 \\
\hline $\mathrm{Se}-85^{a}$ & 1 & & & & 1 & & & \\
\hline $\mathrm{Br}-85$ & 0.0018 & 0.9982 & & & 0.0016 & 0.9984 & & \\
\hline Kr-85m & 0.8 & & 0.2 & & 0.786 & & 0.214 & \\
\hline $\mathrm{Kr}-85$ & 1 & & & & 1 & & & \\
\hline Rb-85 & \multicolumn{4}{|c|}{ Stable } & \multicolumn{4}{|c|}{ Stable } \\
\hline Ga-84 & 1 & & & & 0.8402 & & & 0.1598 \\
\hline Ge-84 & 0.9479 & & & 0.0521 & 0.898 & & & 0.102 \\
\hline As- 84 & 0.9999 & & & 0.0001 & 0.9982 & & & 0.0018 \\
\hline Se-84 & 1 & & & & 1 & & & \\
\hline $\mathrm{Br}-84 \mathrm{~m}$ & 1 & & & & 1 & & & \\
\hline $\mathrm{Br}-84$ & 1 & & & & 1 & & & \\
\hline Kr-84 & \multicolumn{4}{|c|}{ Stable } & \multicolumn{4}{|c|}{ Stable } \\
\hline $\mathrm{Zn}-83$ & 0.7713 & & & 0.2287 & 0.9186 & & & 0.0814 \\
\hline Ga-83 & 0.438 & & & 0.562 & 0.2567 & & & 0.7433 \\
\hline Ge-83 & 0.9998 & & & 0.0002 & 0.9989 & & & 0.0011 \\
\hline As- 83 & 0.36 & 0.64 & & & 1 & & & \\
\hline Se- $83 m$ & 1 & & & & 1 & & & \\
\hline Se-83 & 1 & & & & 1 & & & \\
\hline $\mathrm{Br}-83$ & 0.0002 & 0.9998 & & & 0.0002 & 0.9998 & & \\
\hline $\mathrm{Kr}-83 \mathrm{~m}$ & & & 1 & & & & 1 & \\
\hline Kr-83 & \multicolumn{4}{|c|}{ Stable } & \multicolumn{4}{|c|}{ Stable } \\
\hline $\mathrm{Br}-82 \mathrm{~m}$ & 0.024 & & 0.976 & & 0.024 & & 0.976 & \\
\hline $\mathrm{Br}-82$ & 1 & & & & 1 & & & \\
\hline Kr-82 & \multicolumn{4}{|c|}{ Stable } & \multicolumn{4}{|c|}{ Stable } \\
\hline
\end{tabular}

${ }^{a}$ Metastable isotopes were assumed in 1993 but are assumed not to exist currently.

${ }^{b}$ Isotopes included from mass chain 87 that impact mass chain 86 by delayed neutrons. 
Table 6. Calculated cumulative yields using 2011 branching ratios and reported cumulative yields for the chains leading to key krypton isotopes (U-235 thermal).

\begin{tabular}{|c|c|c|c|c|}
\hline Isotope & $\begin{array}{l}\text { England et al. } \\
\text { and ENDF/B- } \\
\text { VII.1 reported } \\
\text { direct yield }\end{array}$ & $\begin{array}{c}\text { England et al. and } \\
\text { ENDF/B-VII.1 } \\
\text { reported cumulative } \\
\text { yield }\end{array}$ & $\begin{array}{c}\text { Calculated } \\
\text { cumulative yield } \\
\text { using } 2011 \\
\text { branching ratios }\end{array}$ & $\begin{array}{c}\text { Calculated } \\
\text { cumulative yield } \\
\text { (2011) over reported } \\
\text { cumulative yield }\end{array}$ \\
\hline $\mathrm{Ge}-87^{b}$ & $2.20 \mathrm{E}-05$ & $2.20 \mathrm{E}-05$ & $2.20 \mathrm{E}-05$ & 1.00 \\
\hline As $-87^{b}$ & $5.05 \mathrm{E}-04$ & $5.27 \mathrm{E}-04$ & $5.26 \mathrm{E}-04$ & 1.00 \\
\hline $\mathrm{Se}-87^{b}$ & $7.31 \mathrm{E}-03$ & $7.60 \mathrm{E}-03$ & $7.63 \mathrm{E}-03$ & 1.00 \\
\hline $\mathrm{Br}-87^{b}$ & $1.27 \mathrm{E}-02$ & $2.03 \mathrm{E}-02$ & $2.03 \mathrm{E}-02$ & 1.00 \\
\hline Ga-86 & $3.28 \mathrm{E}-07$ & $3.28 \mathrm{E}-07$ & $3.28 \mathrm{E}-07$ & 1.00 \\
\hline Ge-86 & $6.29 \mathrm{E}-03$ & $6.29 \mathrm{E}-03$ & $6.29 \mathrm{E}-03$ & 1.00 \\
\hline As- 86 & $1.99 \mathrm{E}-04$ & $5.53 \mathrm{E}-03$ & $6.16 \mathrm{E}-03$ & 1.11 \\
\hline Se-86 & $8.36 \mathrm{E}-03$ & $1.37 \mathrm{E}-02$ & $1.40 \mathrm{E}-02$ & 1.02 \\
\hline $\mathrm{Br}-86^{a}$ & $4.60 \mathrm{E}-03$ & $1.83 \mathrm{E}-02$ & $1.86 \mathrm{E}-02$ & 0.94 \\
\hline Kr-86 (stable) & 8.72E-04 & 1.96E-02 & 2.00E-02 & 1.02 \\
\hline Ga-85 & $5.88 \mathrm{E}-09$ & $5.88 \mathrm{E}-09$ & $5.88 \mathrm{E}-09$ & 1.00 \\
\hline $\mathrm{Ge}-85$ & $2.13 \mathrm{E}-05$ & $2.13 \mathrm{E}-05$ & $2.15 \mathrm{E}-05$ & 1.01 \\
\hline As- 85 & $1.21 \mathrm{E}-03$ & $2.19 \mathrm{E}-03$ & $1.56 \mathrm{E}-03$ & 0.71 \\
\hline $\mathrm{Se}-85^{a}$ & $8.94 \mathrm{E}-03$ & $1.05 \mathrm{E}-02$ & $1.03 \mathrm{E}-02$ & 0.98 \\
\hline $\mathrm{Br}-85$ & $2.35 \mathrm{E}-03$ & $1.28 \mathrm{E}-02$ & $1.27 \mathrm{E}-02$ & 0.99 \\
\hline $\mathrm{Kr}-85 \mathrm{~m}$ & $5.89 \mathrm{E}-05$ & $1.29 \mathrm{E}-02$ & $1.27 \mathrm{E}-02$ & 0.99 \\
\hline $\mathrm{Kr}-85$ & $2.55 \mathrm{E}-04$ & $2.83 \mathrm{E}-03$ & $3.00 \mathrm{E}-03$ & 1.06 \\
\hline Rb-85 (stable) & 2.37E-05 & 1.32E-02 & 1.30E-02 & 0.99 \\
\hline Ga-84 & $1.11 \mathrm{E}-04$ & $1.11 \mathrm{E}-04$ & $1.11 \mathrm{E}-04$ & 1.00 \\
\hline $\mathrm{Ge}-84$ & $1.90 \mathrm{E}-04$ & $3.01 \mathrm{E}-04$ & $2.83 \mathrm{E}-04$ & 0.94 \\
\hline As- 84 & $1.97 \mathrm{E}-03$ & $2.26 \mathrm{E}-03$ & $2.23 \mathrm{E}-03$ & 0.98 \\
\hline Se-84 & $6.31 \mathrm{E}-03$ & $9.66 \mathrm{E}-03$ & $9.46 \mathrm{E}-03$ & 0.98 \\
\hline $\mathrm{Br}-84 \mathrm{~m}$ & $1.67 \mathrm{E}-04$ & $1.67 \mathrm{E}-04$ & $1.67 \mathrm{E}-04$ & 1.00 \\
\hline $\mathrm{Br}-84$ & $1.86 \mathrm{E}-04$ & $9.85 \mathrm{E}-03$ & $9.65 \mathrm{E}-03$ & 0.98 \\
\hline Kr-84 (stable) & $3.25 \mathrm{E}-06$ & $1.00 \mathrm{E}-02$ & 9.82E-03 & 0.98 \\
\hline $\mathrm{Zn}-83$ & $6.32 \mathrm{E}-10$ & $6.32 \mathrm{E}-10$ & $6.32 \mathrm{E}-10$ & 1.00 \\
\hline Ga-83 & $1.92 \mathrm{E}-06$ & $1.92 \mathrm{E}-06$ & $1.92 \mathrm{E}-06$ & 1.00 \\
\hline $\mathrm{Ge}-83$ & 4.79E-04 & 4.80E-04 & 4.97E-04 & 1.04 \\
\hline As- 83 & $2.91 \mathrm{E}-03$ & $3.40 \mathrm{E}-03$ & $3.43 \mathrm{E}-03$ & 1.01 \\
\hline Se- $83 \mathrm{~m}$ & $3.35 \mathrm{E}-04$ & $2.51 \mathrm{E}-03$ & $3.35 \mathrm{E}-04$ & 0.13 \\
\hline Se-83 & $1.43 \mathrm{E}-03$ & $2.65 \mathrm{E}-03$ & $4.87 \mathrm{E}-03$ & 1.83 \\
\hline $\mathrm{Br}-83$ & $1.95 \mathrm{E}-04$ & $5.36 \mathrm{E}-03$ & $5.40 \mathrm{E}-03$ & 1.01 \\
\hline $\mathrm{Kr}-83 \mathrm{~m}$ & $1.55 \mathrm{E}-08$ & $5.36 \mathrm{E}-03$ & $5.40 \mathrm{E}-03$ & 1.01 \\
\hline Kr-83 (stable) & 6.63E-08 & 5.36E-03 & $5.40 \mathrm{E}-03$ & 1.01 \\
\hline $\mathrm{Br}-82 \mathrm{~m}$ & $1.63 \mathrm{E}-07$ & $1.63 \mathrm{E}-07$ & $1.63 \mathrm{E}-07$ & 1.00 \\
\hline $\mathrm{Br}-82$ & $3.83 \mathrm{E}-07$ & $5.42 \mathrm{E}-07$ & $5.42 \mathrm{E}-07$ & 1.00 \\
\hline Kr-82 (stable) & 3.35E-10 & 5.47E-07 & $5.46 \mathrm{E}-07$ & 1.00 \\
\hline
\end{tabular}

${ }^{a}$ Metastable isotopes were assumed in 1993 but are assumed not to exist currently.

${ }^{b}$ Isotopes included from mass chain 87 that impact mass chain 86 by delayed neutrons. 
Many of the differences in branching ratios for the mass chains ending with stable xenon isotopes seen in Table 3 have little impact on the total mass chain cumulative yields as seen in Table 4 . The differences are seen more in the intermediate isotopes. For example, ${ }^{133 \mathrm{~m}} \mathrm{Te}$, ${ }^{133} \mathrm{Te}$, and ${ }^{133 \mathrm{~m}} \mathrm{I}$ obtain significantly different cumulative yields than those originally reported; however, the cumulative yield for the stable isotope for the mass chain ${ }^{133} \mathrm{Cs}$ has remained fairly consistent. Also of note are the intermediate isotopes ${ }^{131 \mathrm{~m}} \mathrm{Xe}$ and ${ }^{135 \mathrm{~m}} \mathrm{Xe}$, whose ENDF/B-VII.1 cumulative yields deviate significantly from England and Rider. This is important since ${ }^{131 \mathrm{~m}} \mathrm{Xe}$ is one of the four xenon isotopes monitored by the Comprehensive Nuclear Test Ban Treaty. ${ }^{63,64}$

The impact is greater for the mass chains ending with stable krypton isotopes, in which two percent more ${ }^{86} \mathrm{Kr}$ is obtained, while two percent less ${ }^{84} \mathrm{Kr}$ is obtained. Smaller but still noticeable differences can also be seen with the one percent increase in ${ }^{83} \mathrm{Kr}$ and the one percent decrease in ${ }^{85} \mathrm{Rb}$. However, a significant difference can be seen in the intermediate isotope ${ }^{85} \mathrm{Kr}$. Using the current decay scheme and the legacy fission yields, the calculated cumulative yield for this isotope is 6 percent greater than the reported cumulative yield.

The significant changes in delayed neutron emissions for the mass chains leading to these relevant krypton isotopes lead to the noticeable differences in cumulative yields. The changes in delayed neutron emissions for the mass chains ending with stable xenon isotopes are not as large, and therefore have a smaller impact.

To correct these issues, new independent fission yields were determined through a Bayesian method that resembles the original brute force method of England and Rider. In this new method, the reported mass-chain cumulative yields and modern branching ratios were not changed but were accepted as the best values. A detailed description of the exact method can be seen in Appendix A.2. The method was implemented on the decay data for the fissioning of ${ }^{235} \mathrm{U}$ (see Fig. 38 and Fig. 39) and ${ }^{241} \mathrm{Pu}$ (see Fig. 42) by thermal neutrons and ${ }^{238} \mathrm{U}$ (see Fig. 41) by fast neutrons, as these isotopes are most significant for reactor modeling as seen in Fig. 2 and Fig. 3. No changes were deemed necessary for the yield data from the fissioning of ${ }^{239} \mathrm{Pu}$ from thermal neutrons because minimal changes were noted from the legacy data, as seen in Fig. 40.

Within these figures, the black triangles are the calculated-to-reported cumulative yields for a full mass chain before the correction. The red circles are the same ratio after the correction. The gray bars show the measured uncertainty on cumulative yield for each mass chain. The corrected values are used throughout the remainder of this report and are currently implemented in the most recent beta release of SCALE. 


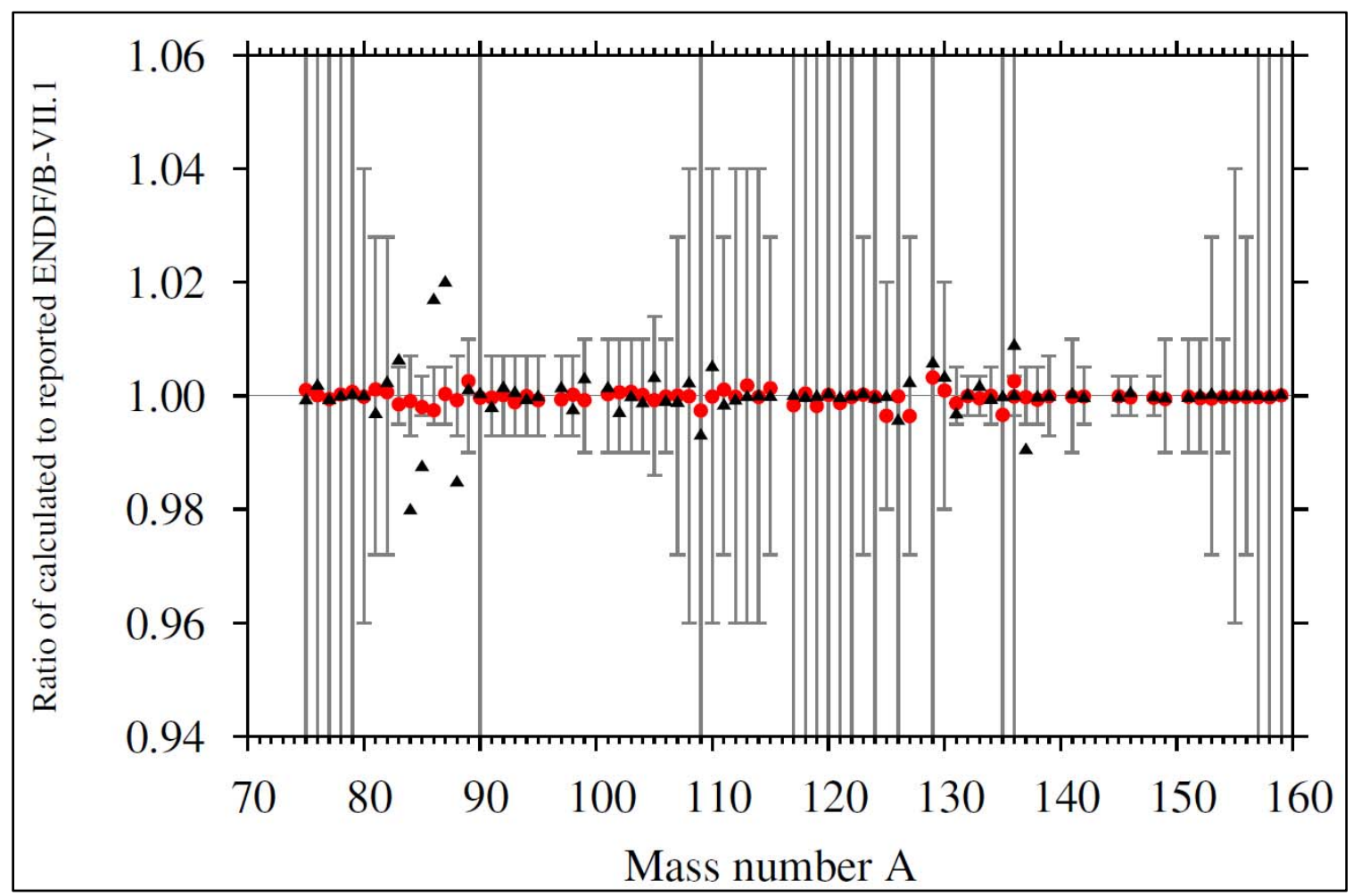

Fig. 38. Ratio of calculated-to-reported ENDF/B-VII.1 cumulative yields for the ends of the mass chains for U-235 fissioned with thermal neutrons.

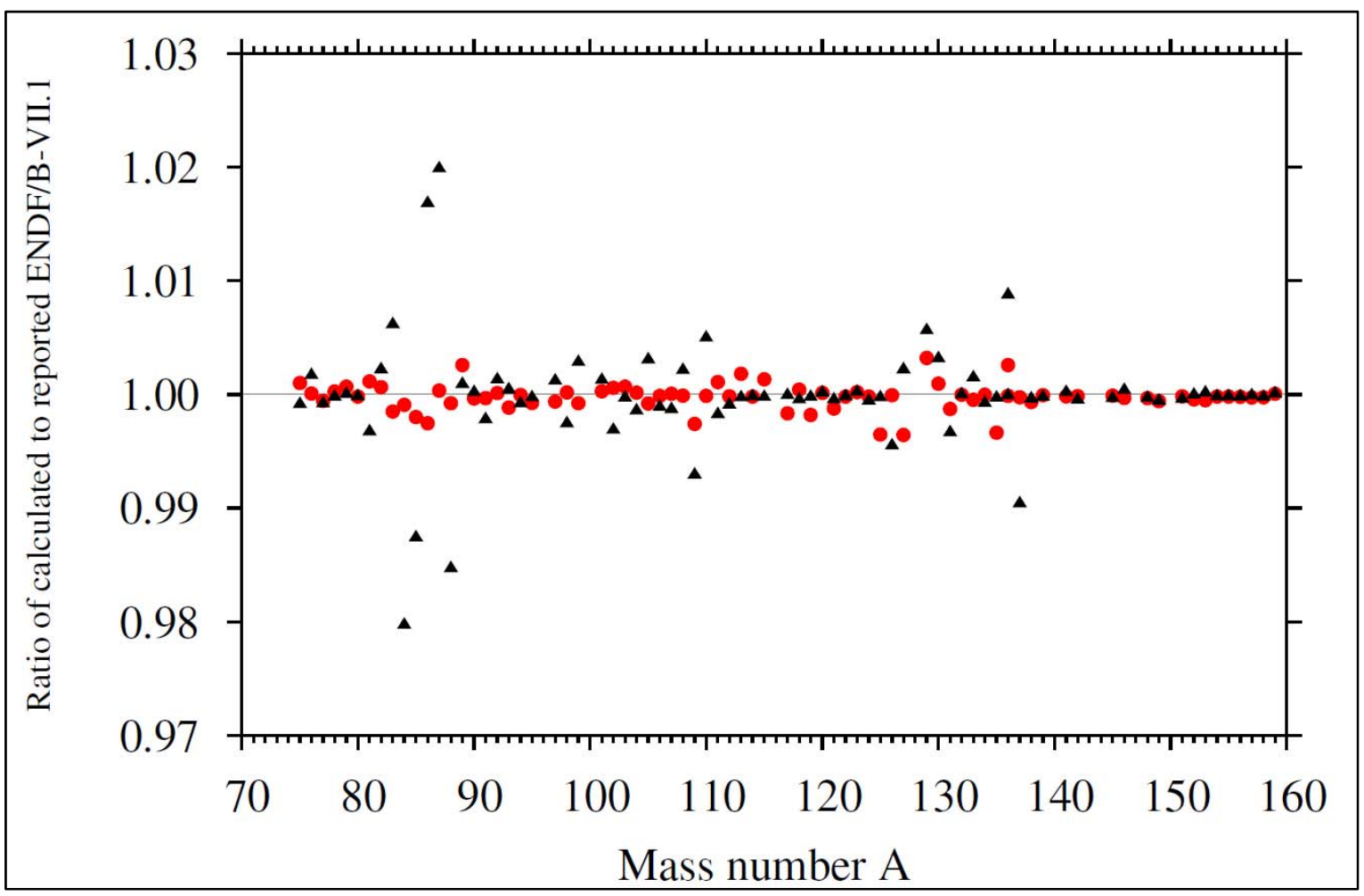

Fig. 39. Ratio of calculated-to-reported ENDF/B-VII.1 cumulative yields for the ends of the mass chains for U-235 fissioned with thermal neutrons (zoomed view of Fig. 38). 


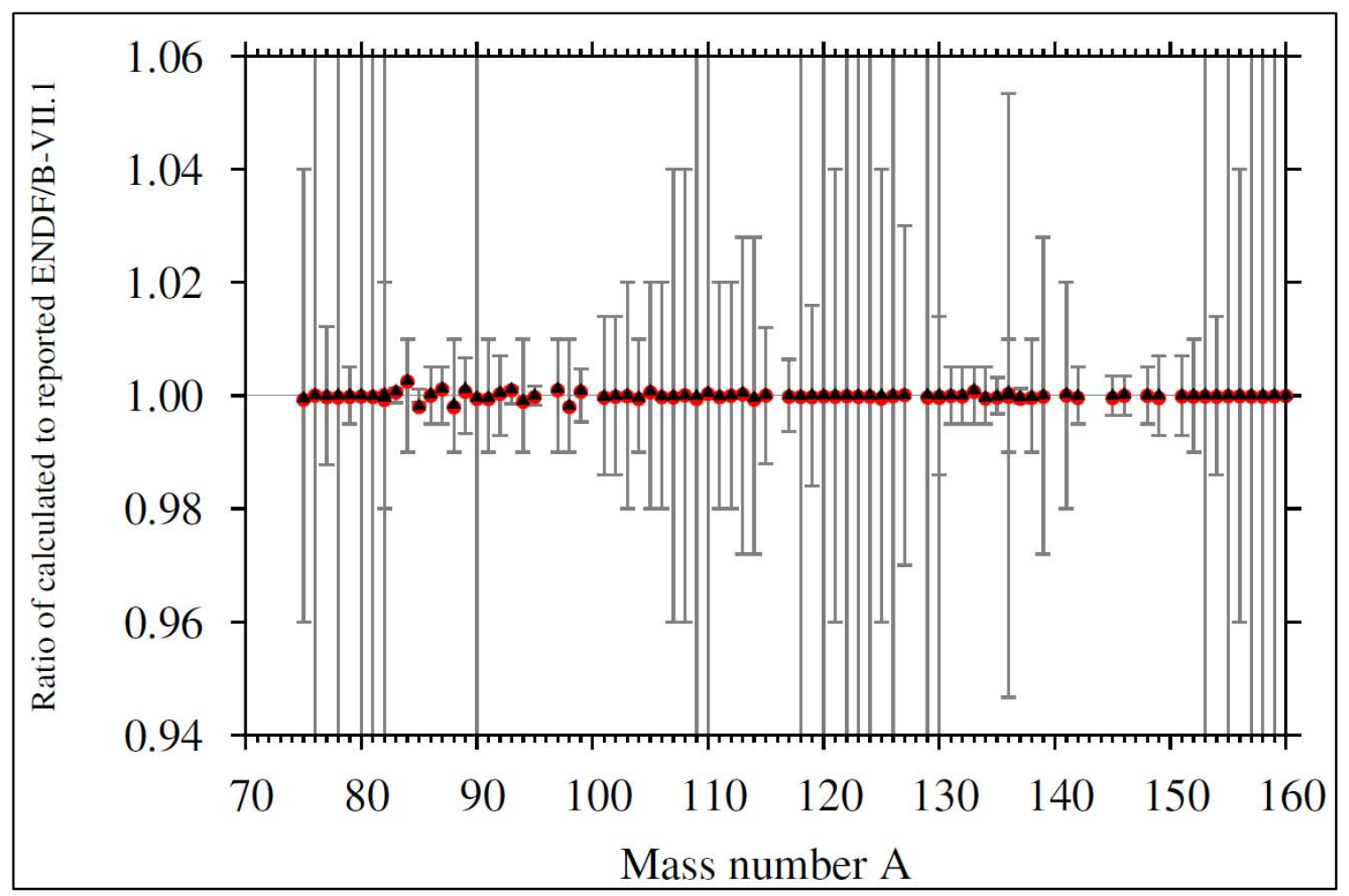

Fig. 40. Ratio of calculated-to-reported ENDF/B-VII.1 cumulative yields for the ends of the mass chains for Pu-239 fissioned with thermal neutrons.

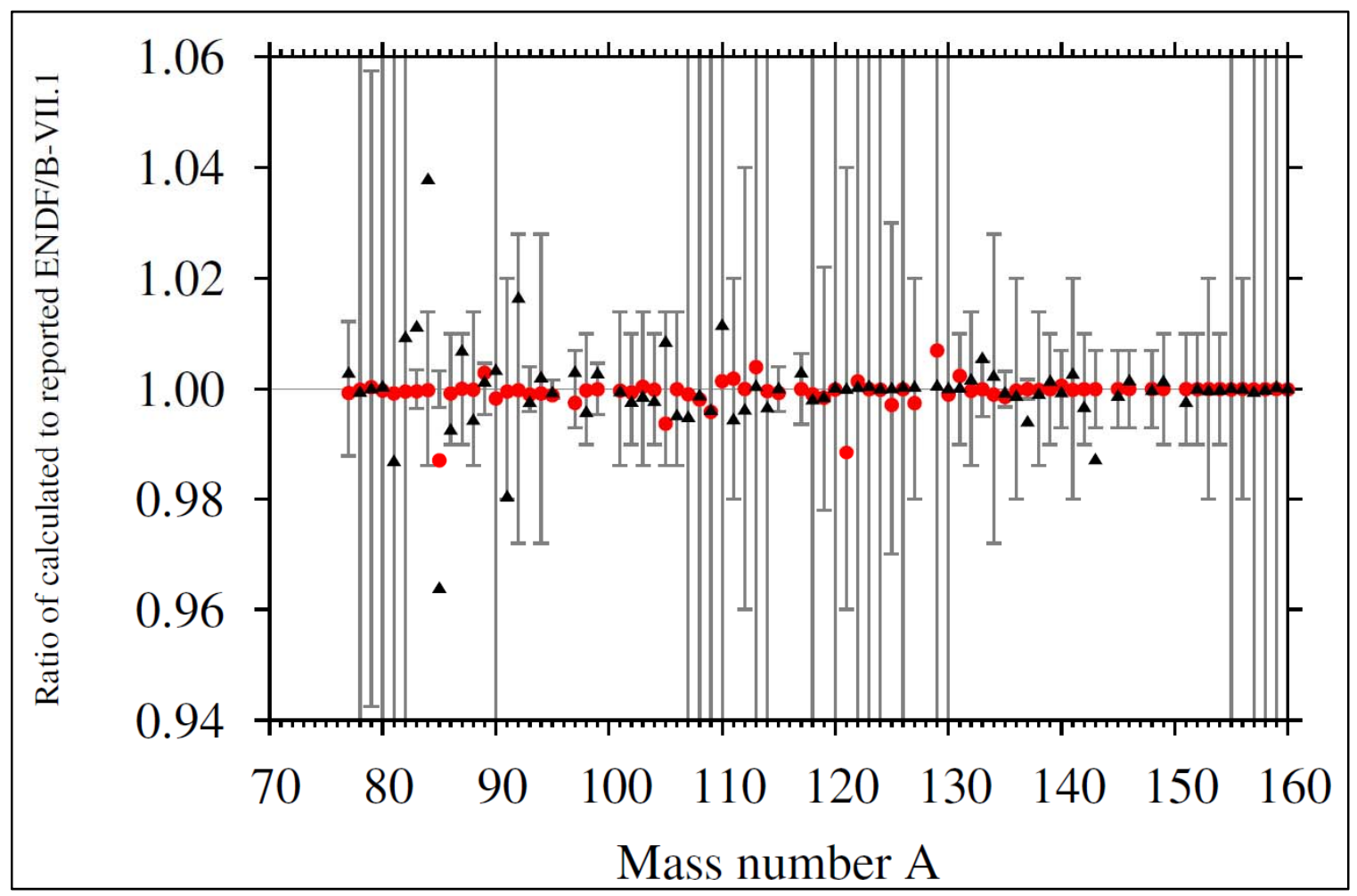

Fig. 41. Ratio of calculated-to-reported ENDF/B-VII.1 cumulative yields for the ends of the mass chains for U-238 fissioned with fast neutrons. 


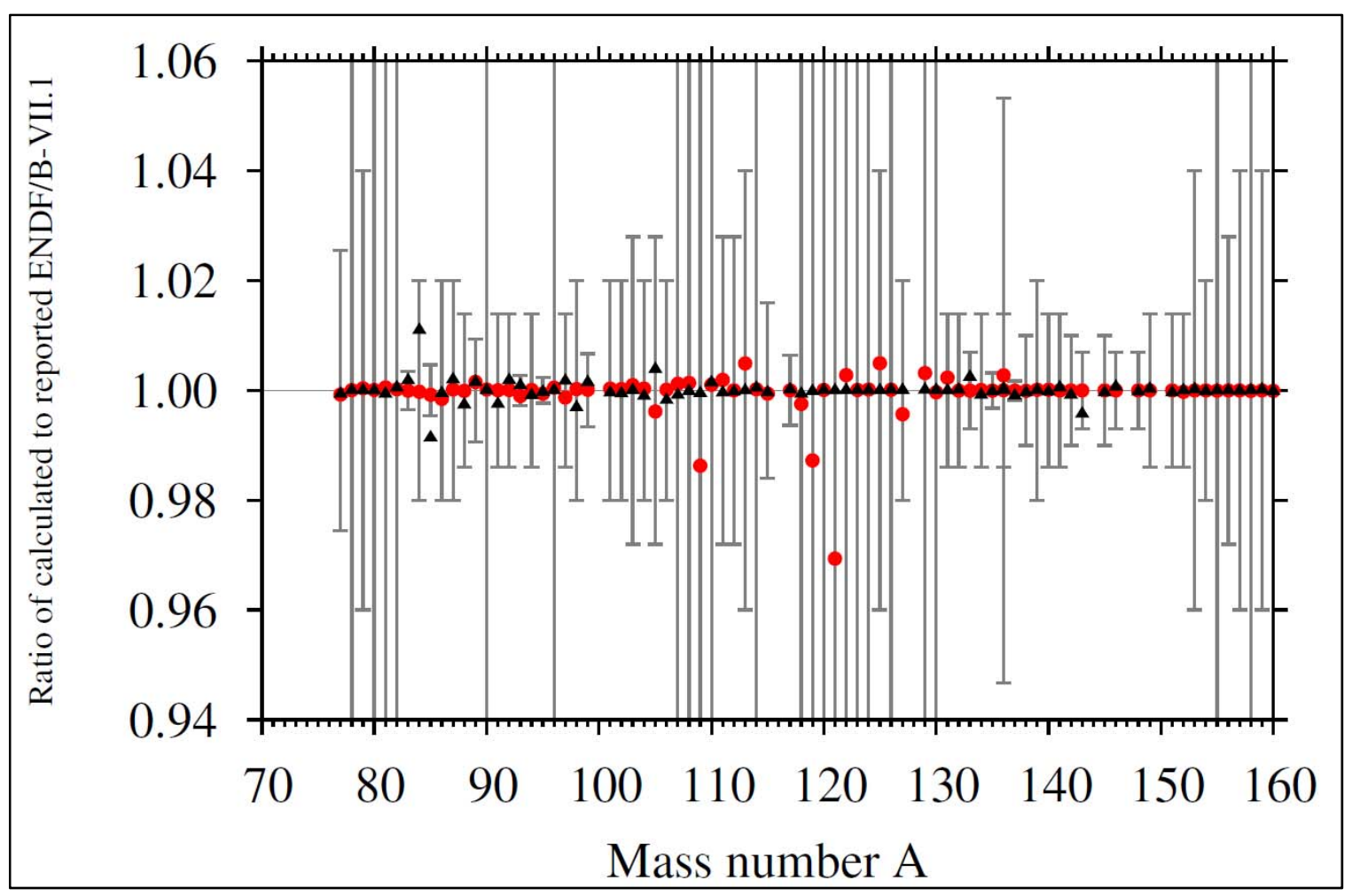

Fig. 42. Ratio of calculated-to-reported ENDF/B-VII.1 cumulative yields for the ends of the mass chains for Pu-241 fissioned with thermal neutrons.

\subsection{XENON ISOTOPES}

Puncturing the cladding and removing all the gas within the plenum of a fuel rod is the common method used to measure the xenon isotopes produced during irradiation. ${ }^{32}$ However, as pointed out in Section 4.1, the plenum gas is only a portion of the xenon produced, with the remainder bound in the fuel matrix within the rod. Also, the plenum contains a mixture of all gas released across the fuel length of the rod and is more representative of the hottest region in the fuel. The measured values are also often reported in atom ratio or the ratio of one xenon isotope to another. By the time the plenum gas can be sampled, the xenon concentrations consist of four primary stable xenon isotopes: ${ }^{131} \mathrm{Xe},{ }^{132} \mathrm{Xe},{ }^{134} \mathrm{Xe}$, and

${ }^{136} \mathrm{Xe}$. In most cases, the noble gas data are not provided in SFCOMPO; however, they often appear in the original reports, which have been examined for the data presented here. ${ }^{29,54-61}$

The figures in this section and in Section 4.4 (krypton isotopes) do not follow the standard format given for the other isotopic concentration figures found in this report. First, the data are reported in atom ratio. For xenon, the total xenon concentration is the sum of these four stable xenon isotopes. When values are reported with respect to a standard xenon isotope (e.g. $\left.{ }^{134} \mathrm{Xe}\right)$, the ratios would be combined to generate the respective isotope over the total xenon measured. The data are also plotted for each specific reactor rather than being grouped by reactor type. A generic PWR curve, however, is still generated for each figure.

Ongoing efforts are under way to quantify how well the models predict the xenon concentrations now that the nuclear data issue is resolved. In this report, the data are plotted and evaluated qualitatively (see Fig. 43, Fig. 44, Fig. 45, and Fig. 46). 


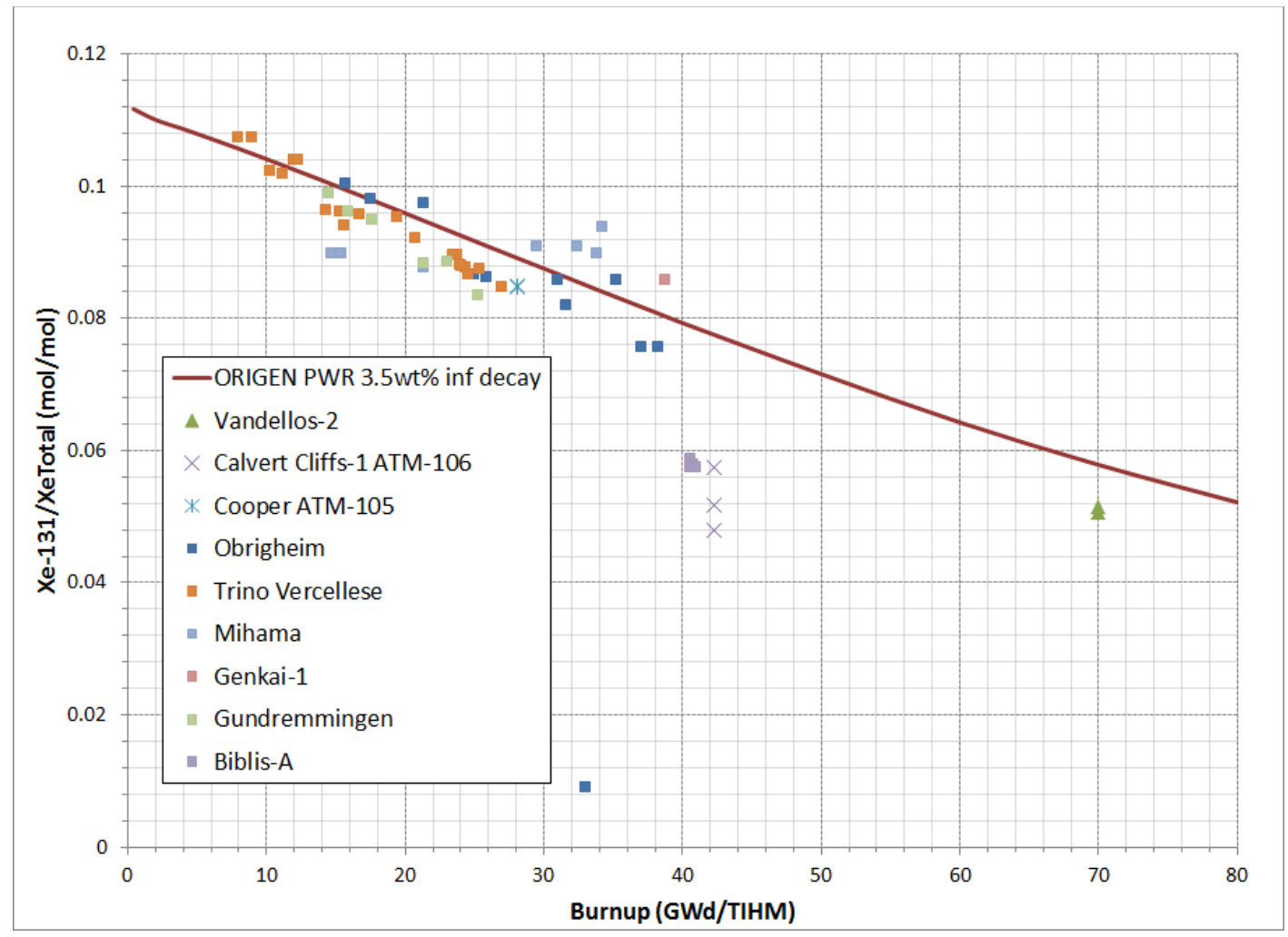

Fig. 43. Mole fraction Xe-131/total xenon.

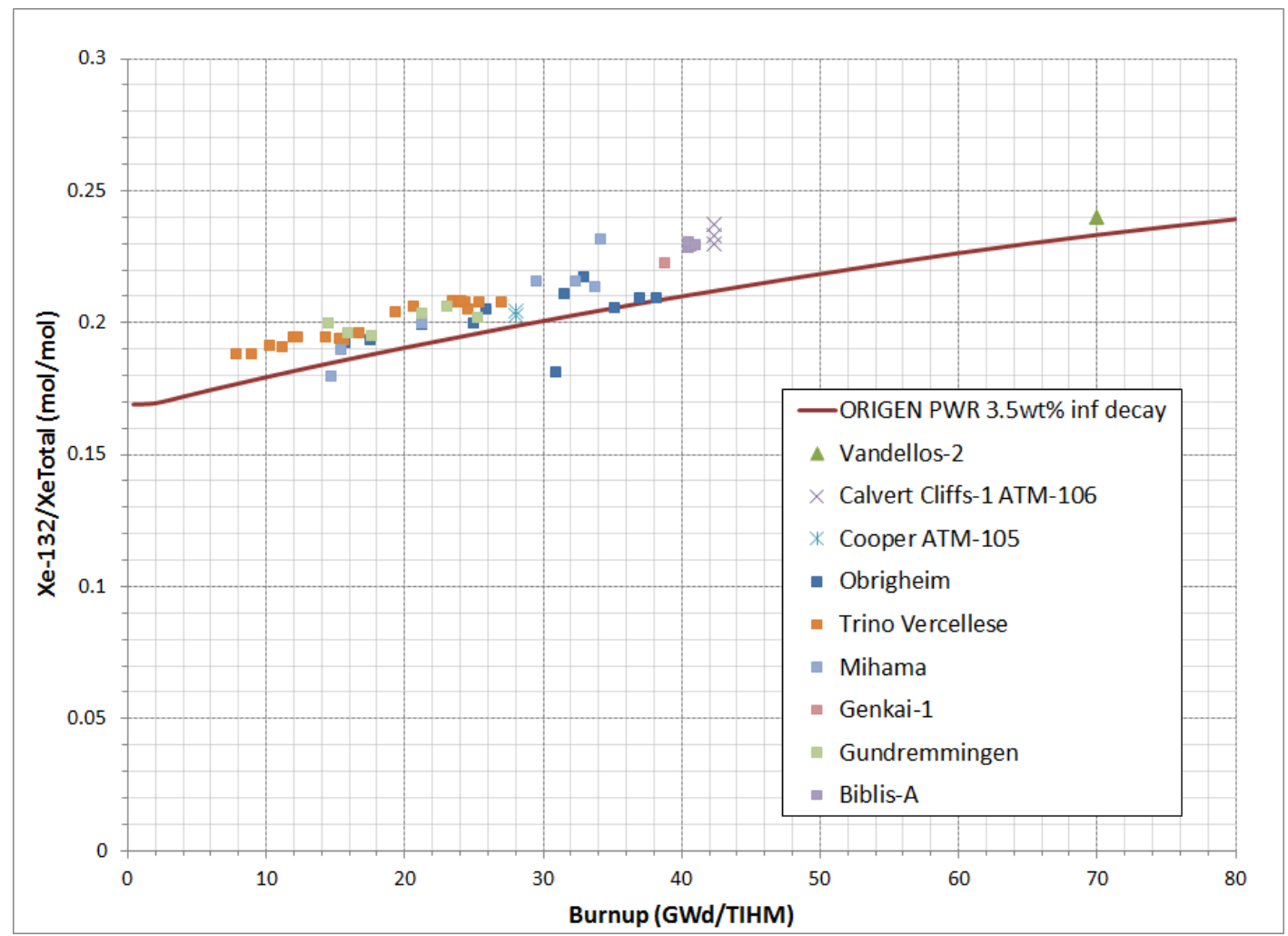

Fig. 44. Mole fraction Xe-132/total xenon. 


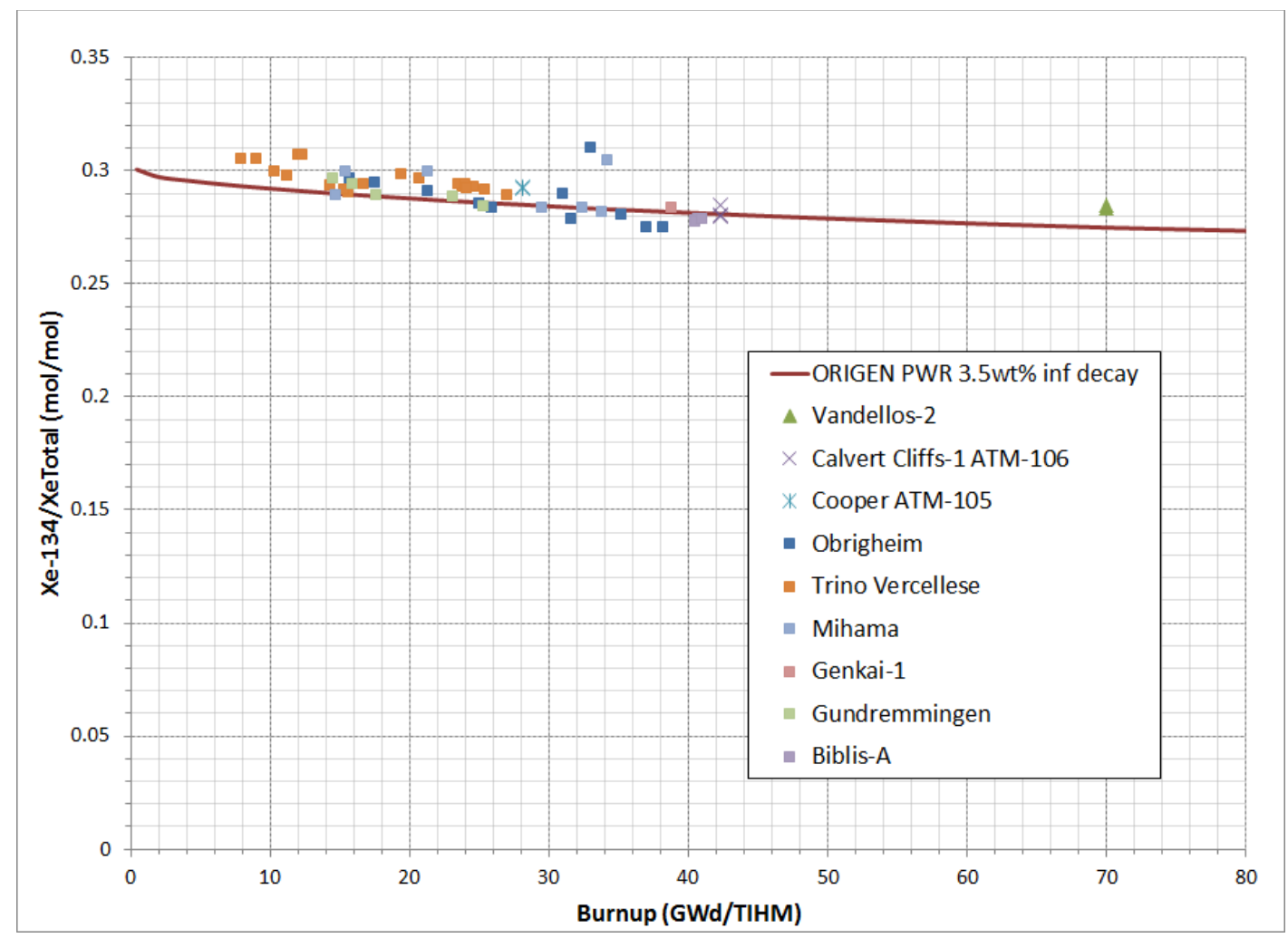

Fig. 45. Mole fraction Xe-134/total xenon.

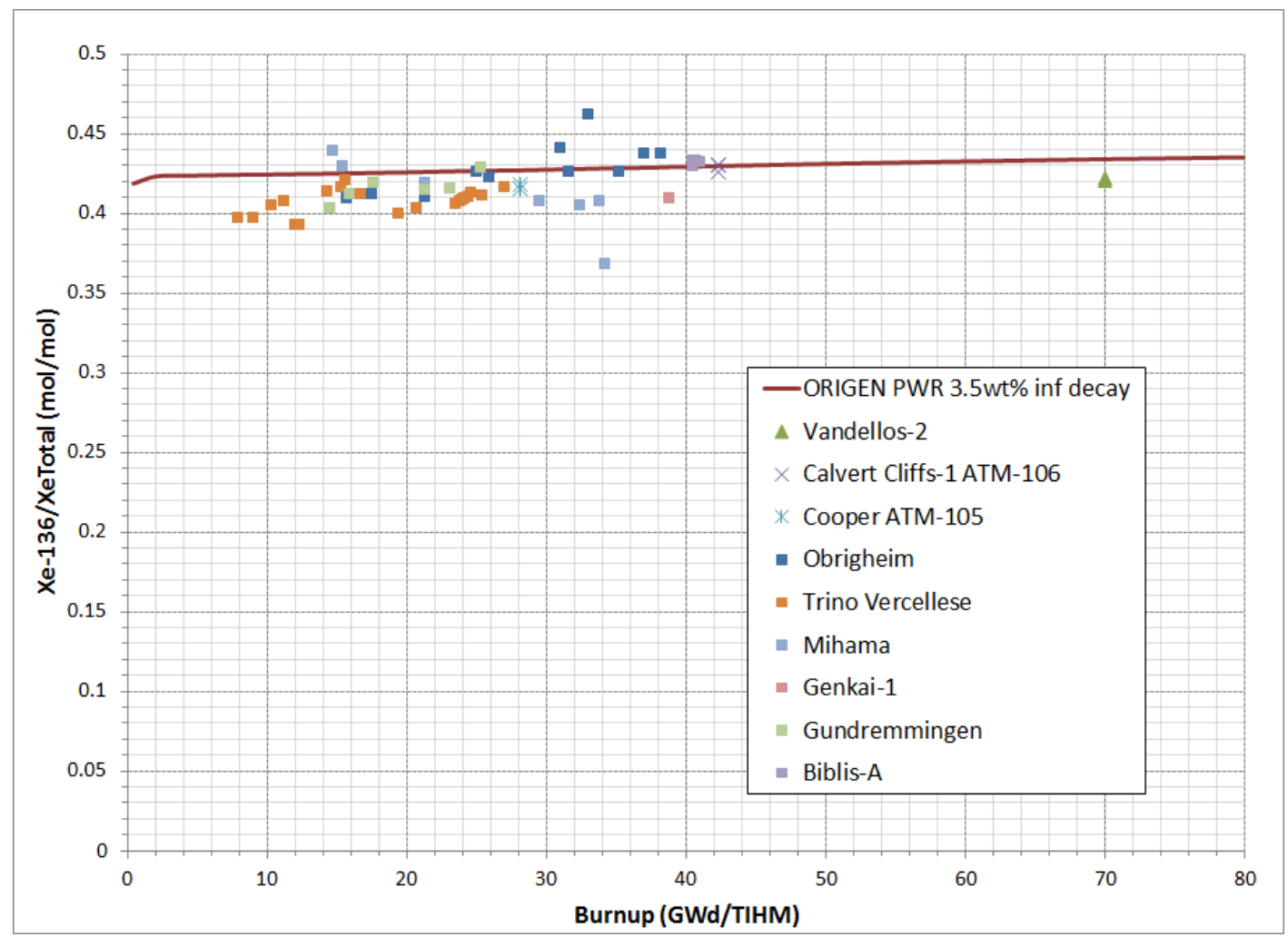

Fig. 46. Mole fraction Xe-136/total xenon. 


\subsection{KRYPTON ISOTOPES}

As in the xenon measurements, the krypton isotopes are primarily determined by puncture tests several years after the fuel is discharged. By the time the measurements are made, only five isotopes are easily detectable: ${ }^{82} \mathrm{Kr},{ }^{83} \mathrm{Kr},{ }^{84} \mathrm{Kr},{ }^{85} \mathrm{Kr}$, and ${ }^{86} \mathrm{Kr}$. However, the ${ }^{82} \mathrm{Kr}$ fraction is so small that it is often not reported due to the high uncertainty in the measurement. Unlike xenon, all the krypton isotopes are not stable. ${ }^{85} \mathrm{Kr}$ has a half-life of 10.76 years. Therefore, the reported atom ratios change over time as the ${ }^{85} \mathrm{Kr}$ decays away. In most cases, the measurement time for ${ }^{85} \mathrm{Kr}$ is reported. Due to the decay of ${ }^{85} \mathrm{Kr}$, some laboratories have reported some measurements as ratios of krypton stable isotopes. The scatter in the data shown in Fig. 47, Fig. 48, Fig. 49, and Fig. 50 may be due to differences in measurement times for which the experimental data were reported. As with the xenon isotopes, the krypton isotopic data are not found within SFCOMPO. The data were extracted from the IFPE and the original documents. ${ }^{29,54-61}$ Ongoing validation work will model each individual data point with its respective power history and decay time. Preliminary results not explicitly shown in this report indicate that the calculated radioactive ${ }^{85} \mathrm{Kr}$ concentrations range from within a few percent to approximately $10 \%$ of the measurement data after using the new consistent yield data.

Three ORIGEN curves were generated for ${ }^{85} \mathrm{Kr}$, as seen in Fig. 50, to show the impact of measurement time on the reported value.

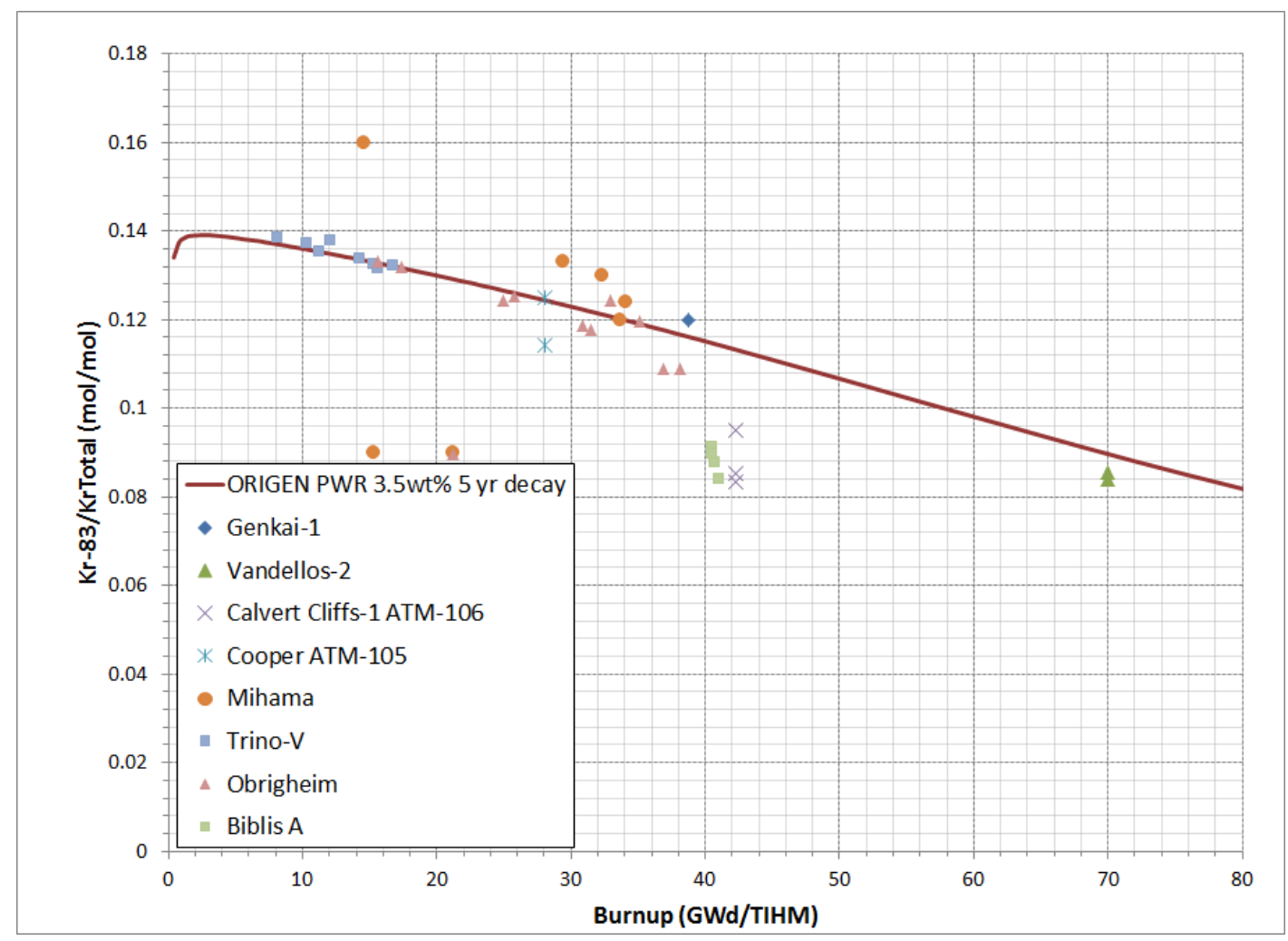

Fig. 47. Mole fraction Kr-83/total krypton. 


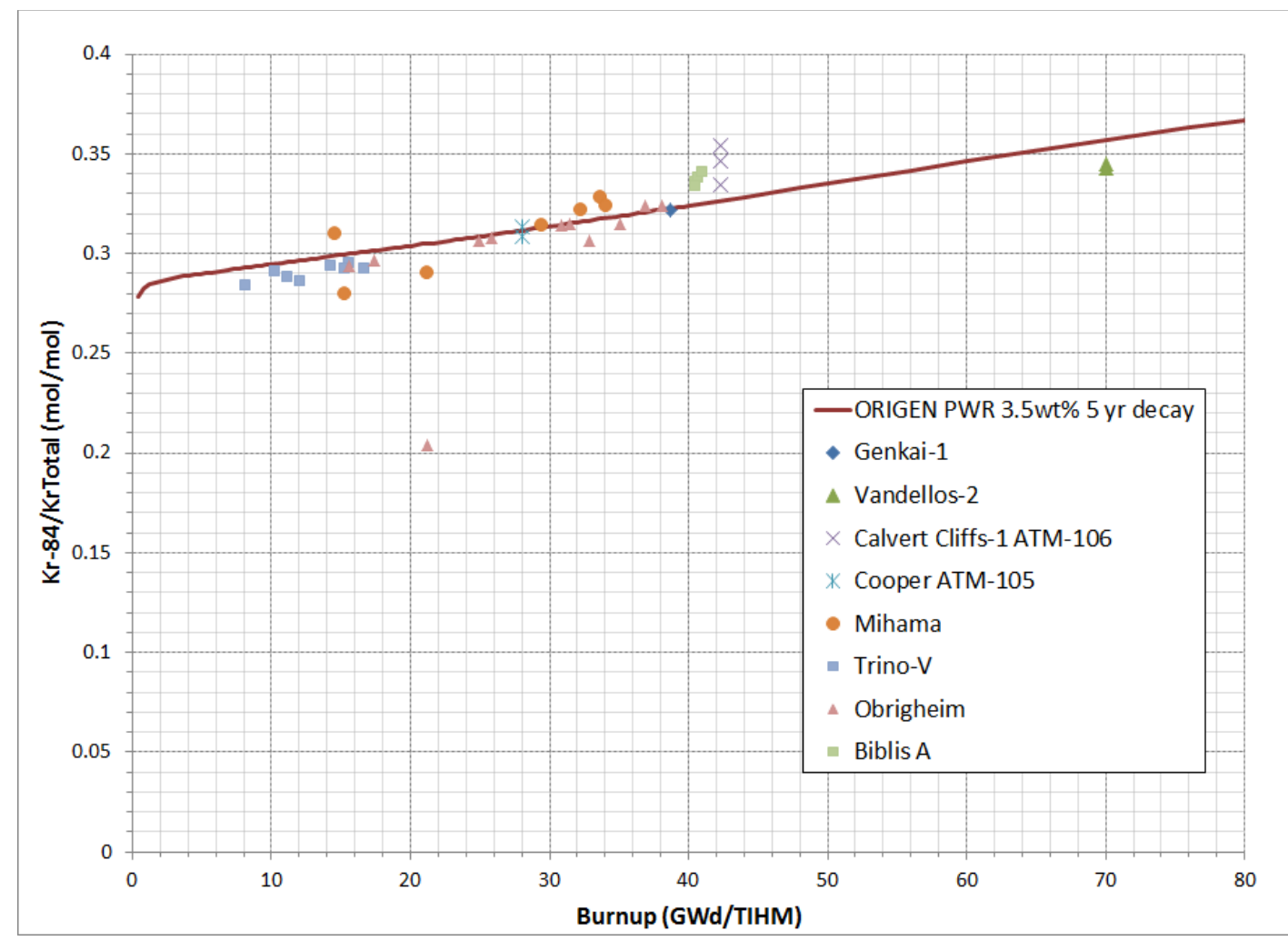

Fig. 48. Mole fraction Kr-84/total krypton.

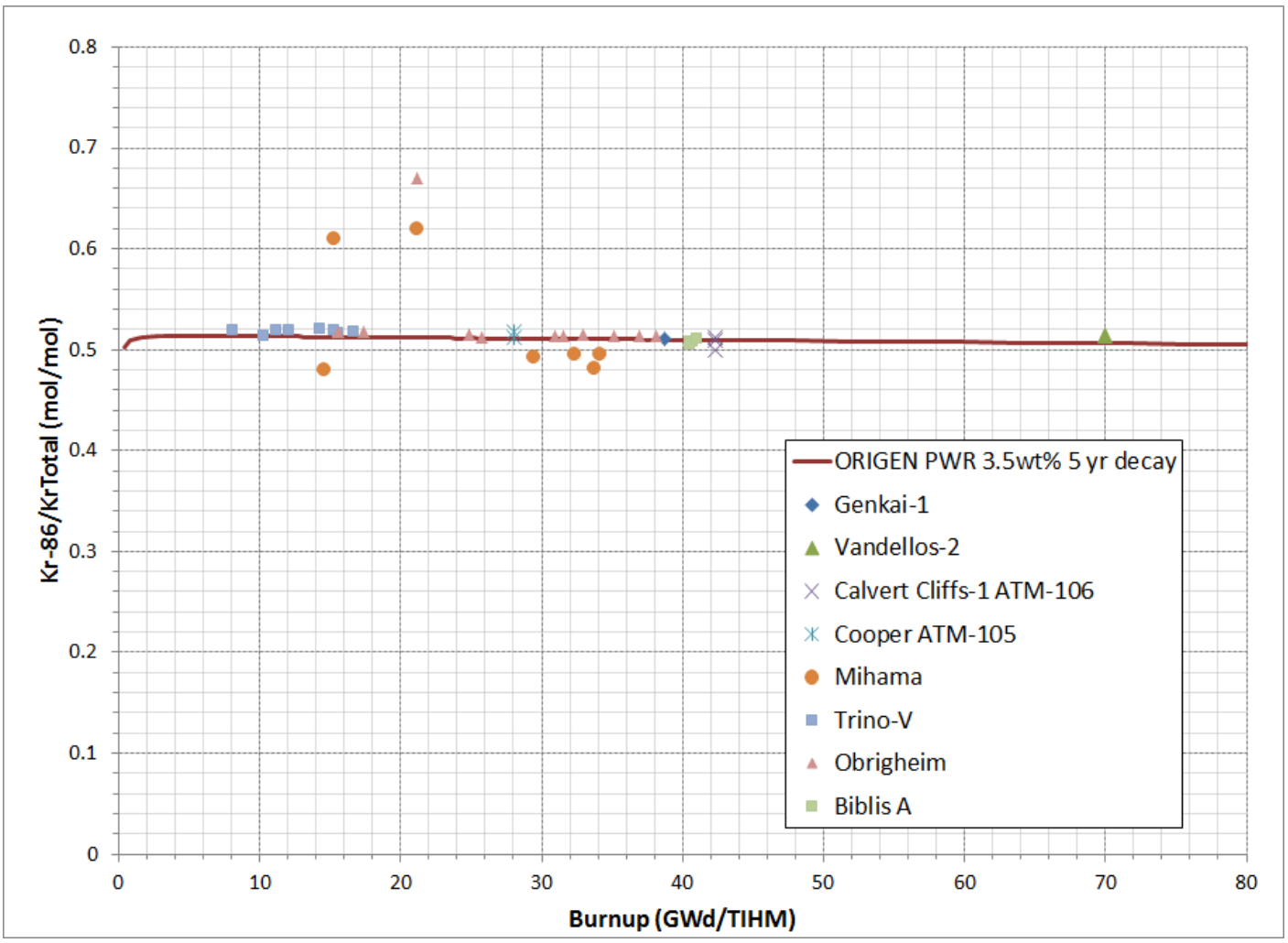

Fig. 49. Mole fraction Kr-86/total krypton. 


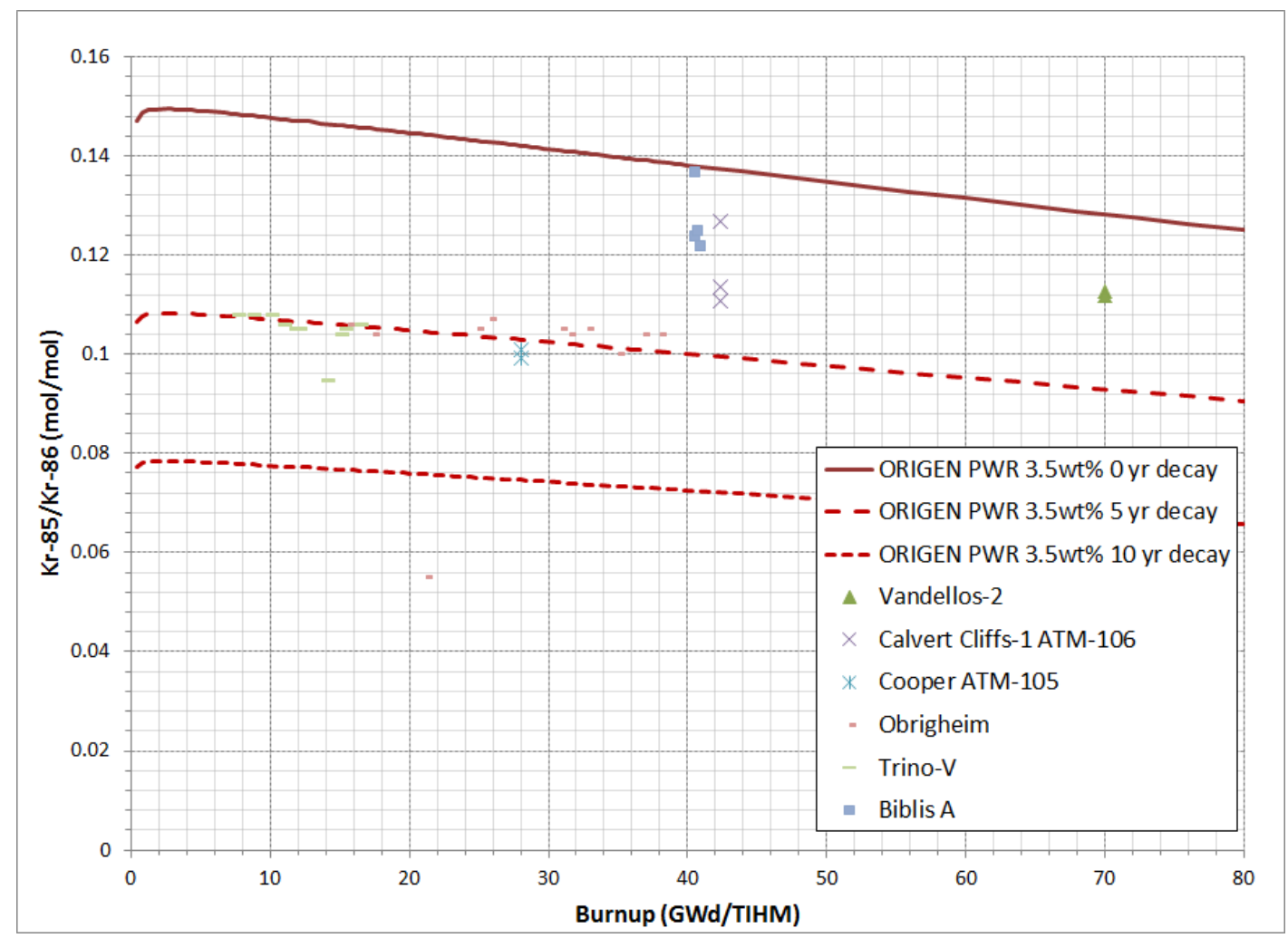

Fig. 50. Mole fraction Kr-85/Kr-86. 


\section{STABLE FISSON PRODUCTS}

This section provides an overview on the stable fission product isotopes other than the noble gases covered in Section 4. The neodymium isotopes are described separately, as they are the preferred isotope of determining burnup. The samarium isotopes are also described separately due to the abundance of stable isotopes that are generated. The remaining isotopes will be divided into either lighter or heavier fission products.

\subsection{OVERVIEW OF STABLE FISSION PRODUCT PRODUCTION}

The stable fission products are rarely produced directly from fission, as they primarily come from the decay of parent isotopes. ${ }^{32}$ Therefore, these isotopes may continue to build up even after the time of measurement, depending on the half-lives of their precursors. This trend will be seen for select isotopes in this section. Some of the isotopes covered in this section are not fission products in the purest sense, as they are not produced primarily from either a direct fission or the decay of a parent nuclide produced directly from fission, but are generated by neutron capture in nuclides which themselves have been produced directly from fission. These isotopes, such as ${ }^{142} \mathrm{Nd}$ and ${ }^{148} \mathrm{Sm}$, are often still categorized as fission products.

As seen in Fig. 51, the majority of the isotopes reported in this section fall in the heavier end of the spectrum (above mass number 120). This side of the spectrum is less sensitive to the fissioning isotope as compared to lighter isotopes. This insensitivity makes these isotopes good candidates for burnup measurement indicators, while the lighter isotopes give information on the relative contribution of fissionable actinides to the burnup.

Because the isotopes in this section are stable, they can only be measured by destructive analytical methods.

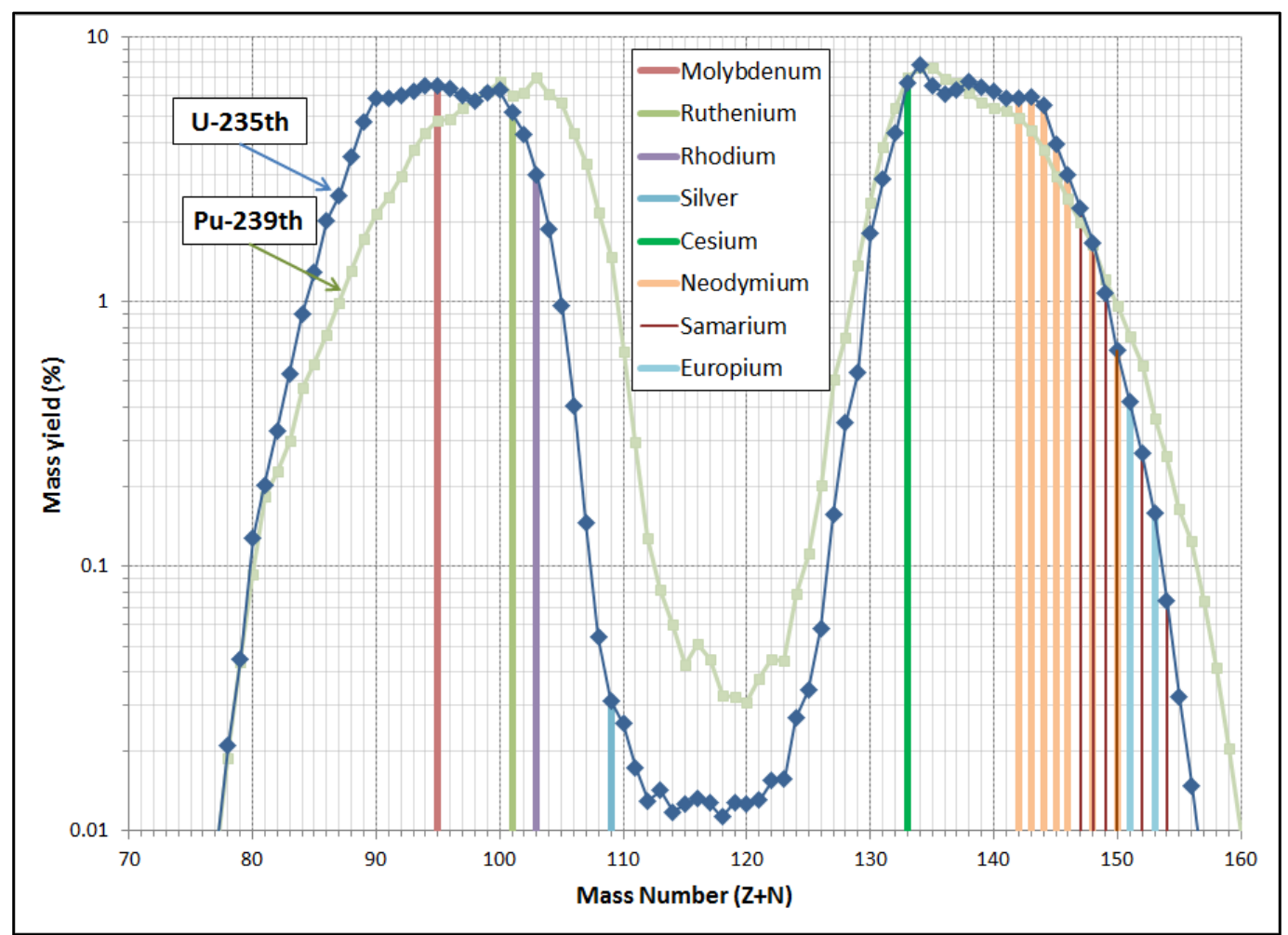

Fig. 51. Mass distribution of stable fission products from thermal fission of U-235 and Pu-239 covered in this section. 


\subsection{NEODYMIUM ISOTOPES}

Burnup of nuclear fuel is important for all aspects of fission product chemistry. Burnup's importance was one of the primary reasons that it was selected to be the abscissa in the concentration figures throughout this report. One method in determining the burnup of nuclear fuel is to accurately measure a fission product that meets the following criteria: ${ }^{32}$

1. stable or half-life must be sufficiently long to allow integration over the entire reactor operation,

2. nuclear data, such as cumulative fission yield, half-life and decay mode, need to be known very accurately,

3. limited migration in the fuel during operation,

4. unambiguous and accurate measurement, and

5. invariant to the fissioned nuclide (i.e., ${ }^{235} \mathrm{U}$ or ${ }^{239} \mathrm{Pu}$ ).

Many of the stable neodymium isotopes meet these criteria; the tight trend for all reactor types and enrichment as a function of burnup can be seen in Fig. 55 through Fig. $58 .{ }^{148} \mathrm{Nd}$ is primarily used as a burnup indicator because its thermal fission yield is similar for the major actinides ${ }^{235} \mathrm{U}$ and ${ }^{239} \mathrm{Pu}$ and its content varies linearly with burnup. ${ }^{32}$ However, other burnup monitors, such as ${ }^{146} \mathrm{Nd}$ or a combination of ${ }^{145} \mathrm{Nd}+{ }^{146} \mathrm{Nd}$, have been explored.

${ }^{142} \mathrm{Nd}$ is shielded in the mass chain by stable ${ }^{142} \mathrm{Ce}$. The buildup of this stable isotope comes from neutron capture in stable ${ }^{141} \mathrm{Pr}$, which becomes ${ }^{142} \mathrm{Pr}$, then beta-decays to ${ }^{142} \mathrm{Nd}$. The ${ }^{142} \mathrm{Nd}$ builds up approximately as a function of the square of the flux (or burnup), as seen in Fig. 52. This trend is common for nuclides that are shielded by stable isotopes in the mass chain. That is, multiple stable isotopes exist for a single mass chain, and the shielded isotope cannot be achieved by direct decay from fission product isotopes.

${ }^{143} \mathrm{Nd}$ and ${ }^{145} \mathrm{Nd}$ both have large thermal $(\mathrm{n}, \gamma)$ cross-sections; their production as a function of burnup concaves down at higher burnups, as seen in Fig. 53 and Fig. 55, respectively. ${ }^{143} \mathrm{Nd}$ also has a few precursors with a little more than one day half-lives. Therefore, this nuclide will continue to build up for a few days after irradiation. This continual buildup is more notable with ${ }^{144} \mathrm{Nd}$ due to the 285 day half-life of its precursor, ${ }^{144} \mathrm{Ce}$. The buildup of ${ }^{144} \mathrm{Nd}$ over time can be seen in Fig. $54 .{ }^{150} \mathrm{Nd}$ is actually not stable but has a very long half-life of $1.1 \times 10^{19}$ years. 


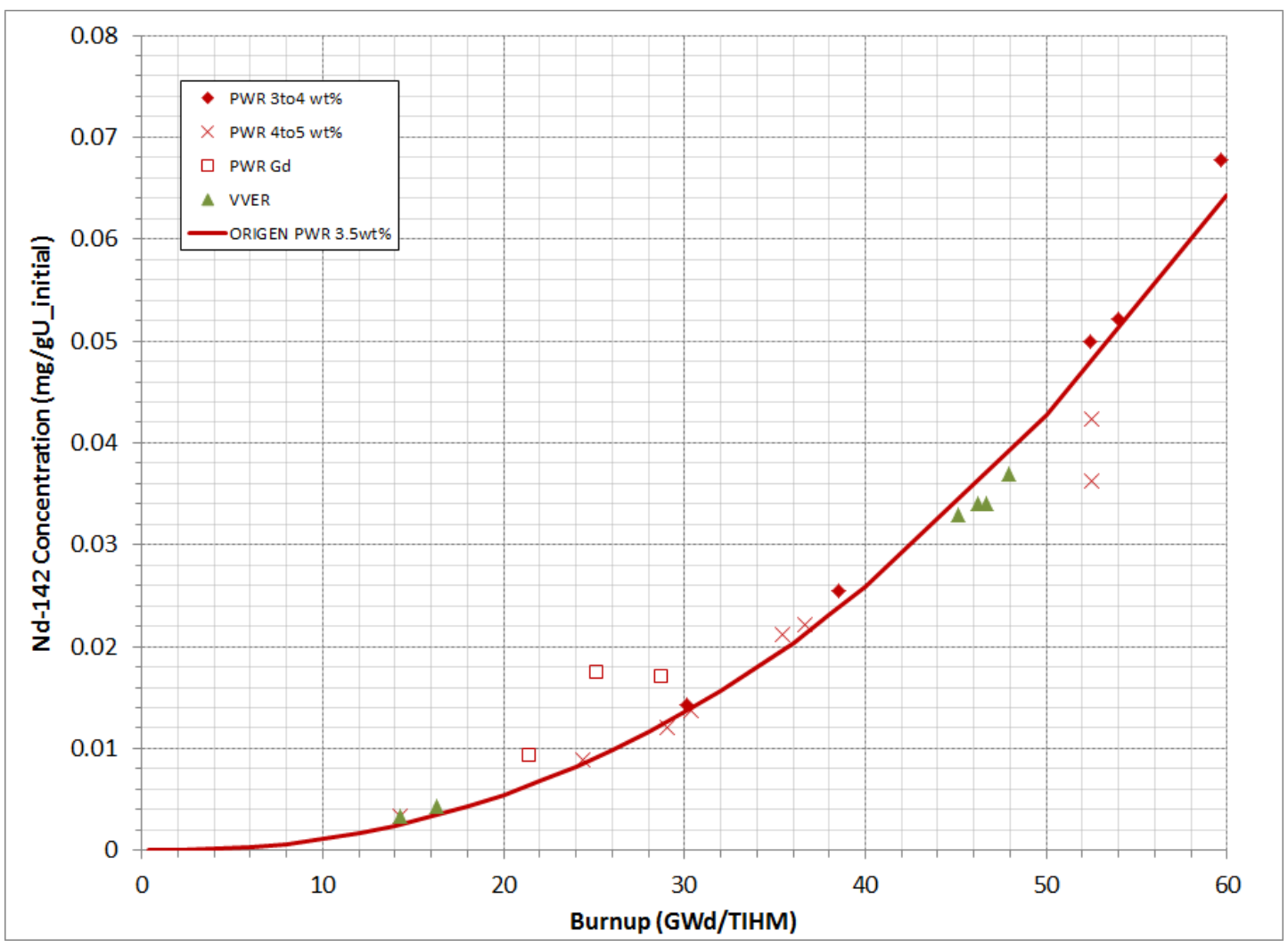

Fig. 52. Nd-142 concentration as a function of burnup.

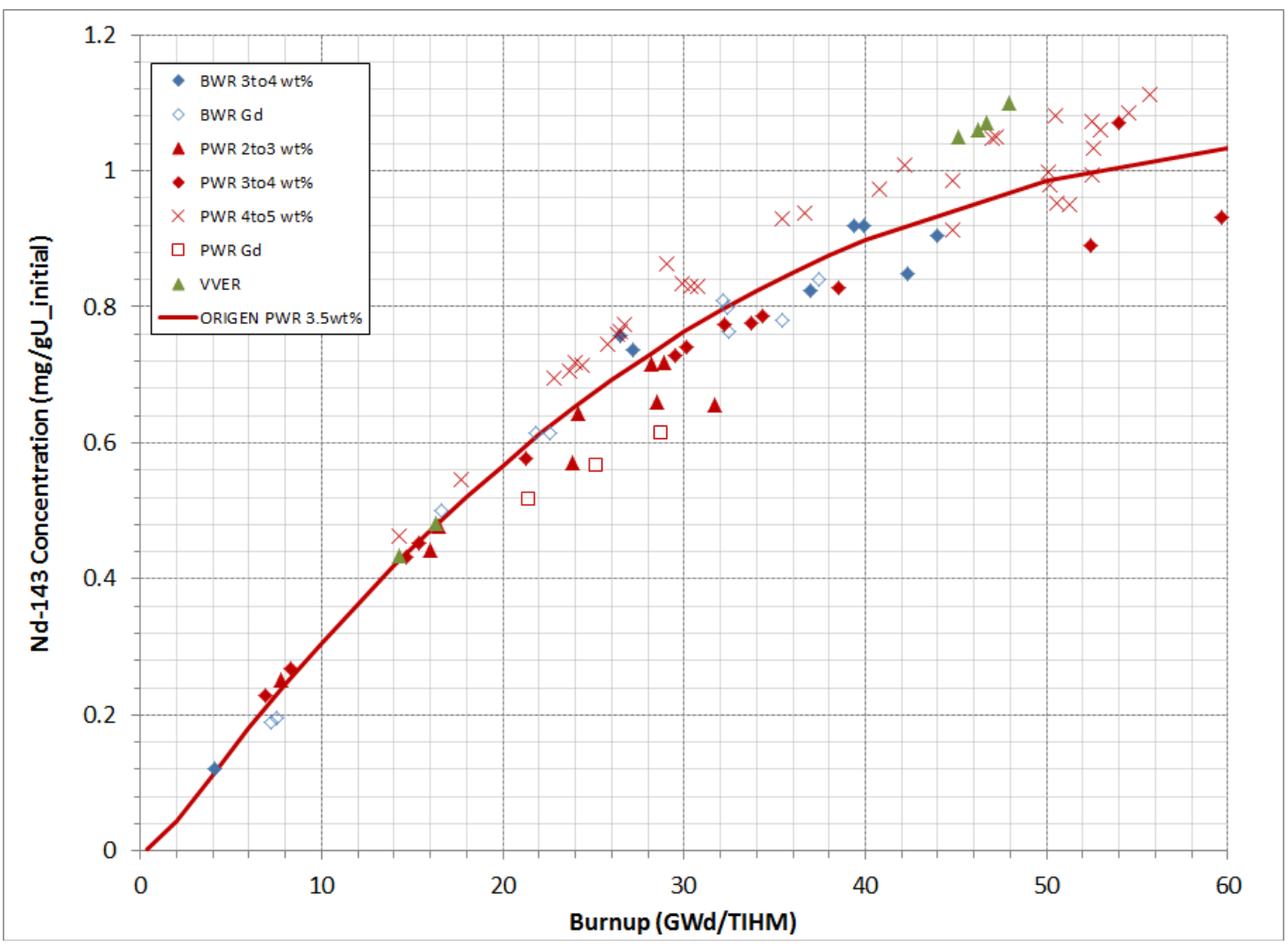

Fig. 53. Nd-143 concentration as a function of burnup. 


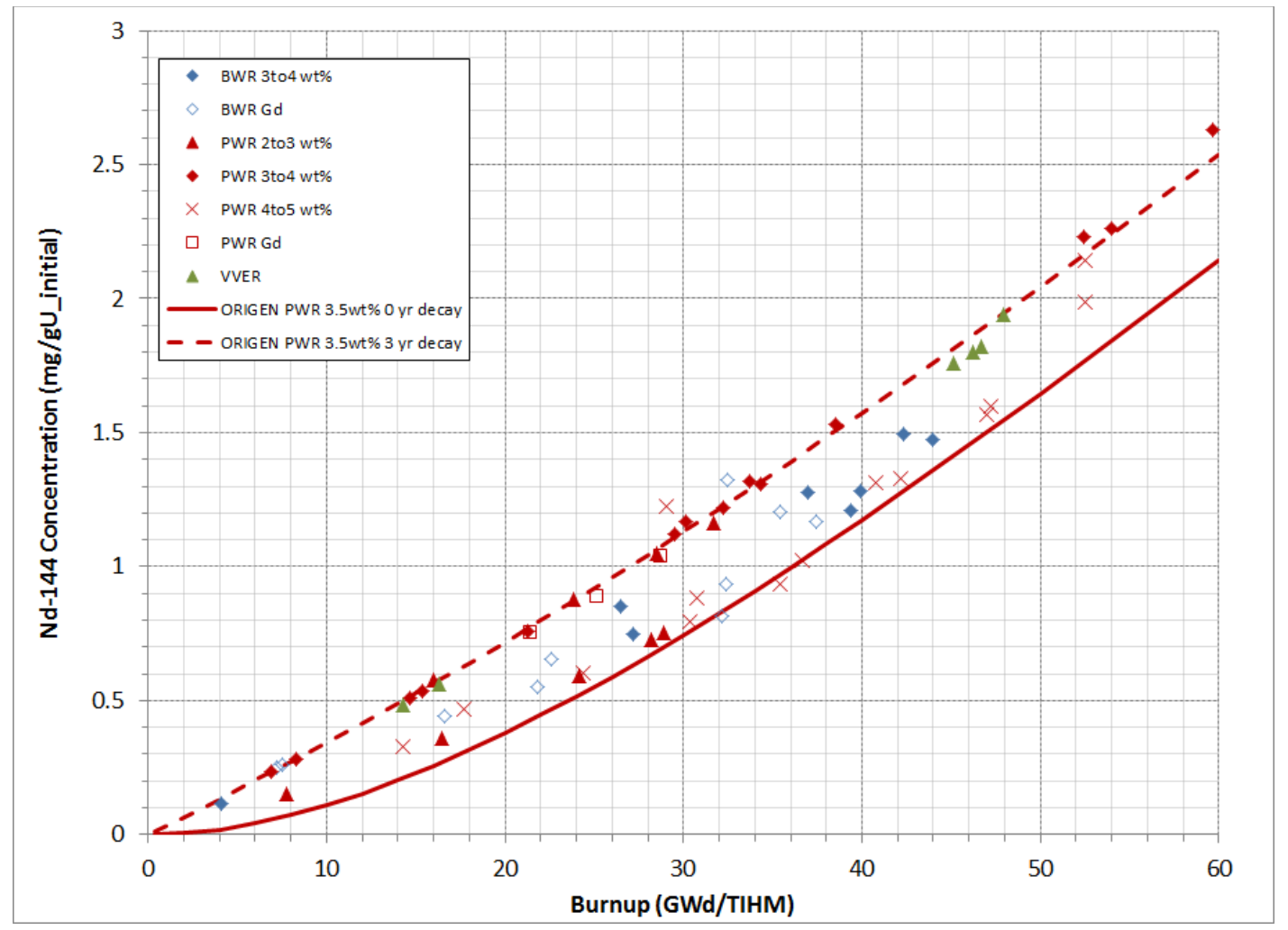

Fig. 54. Nd-144 concentration as a function of burnup.

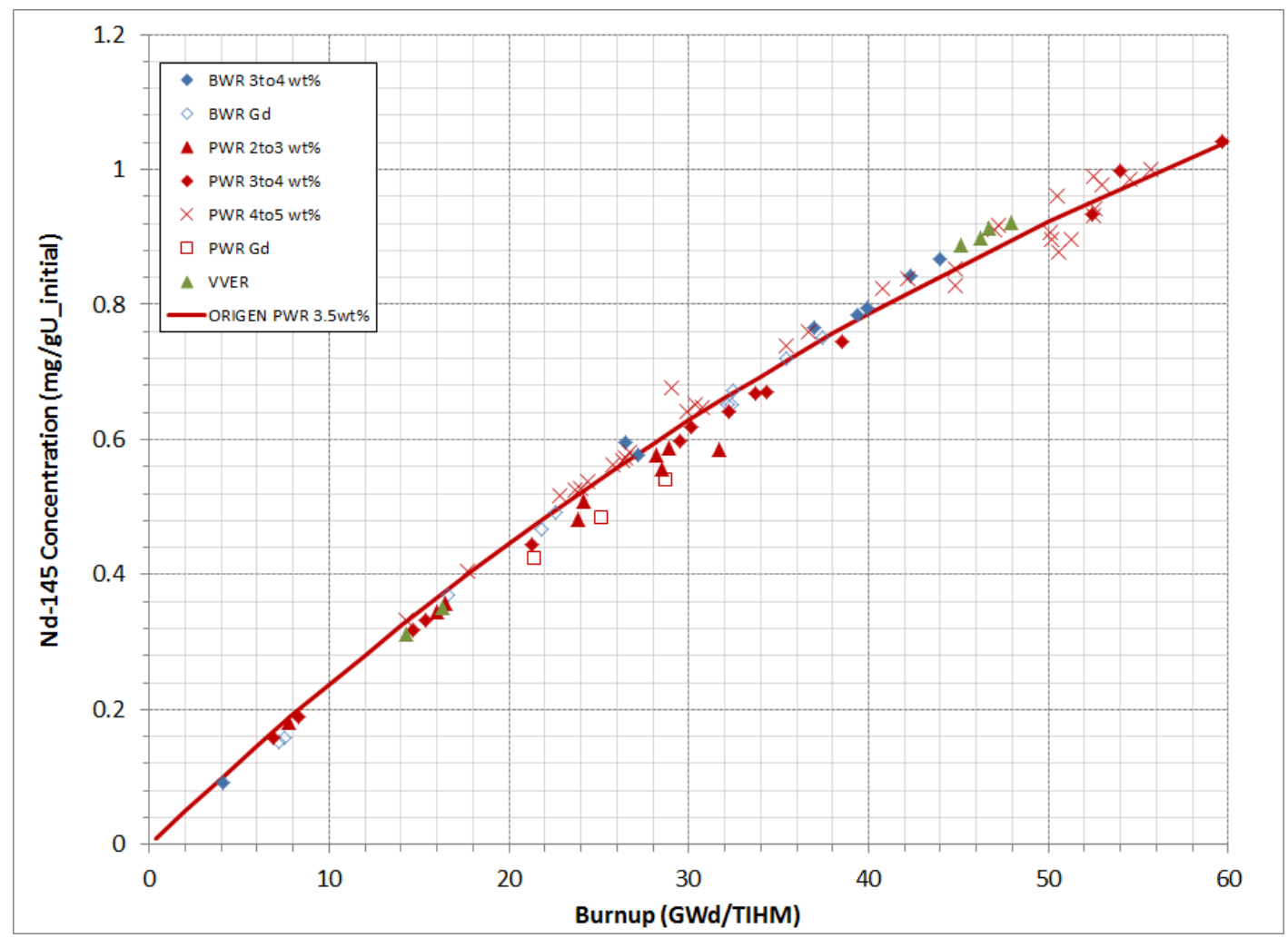

Fig. 55. Nd-145 concentration as a function of burnup. 


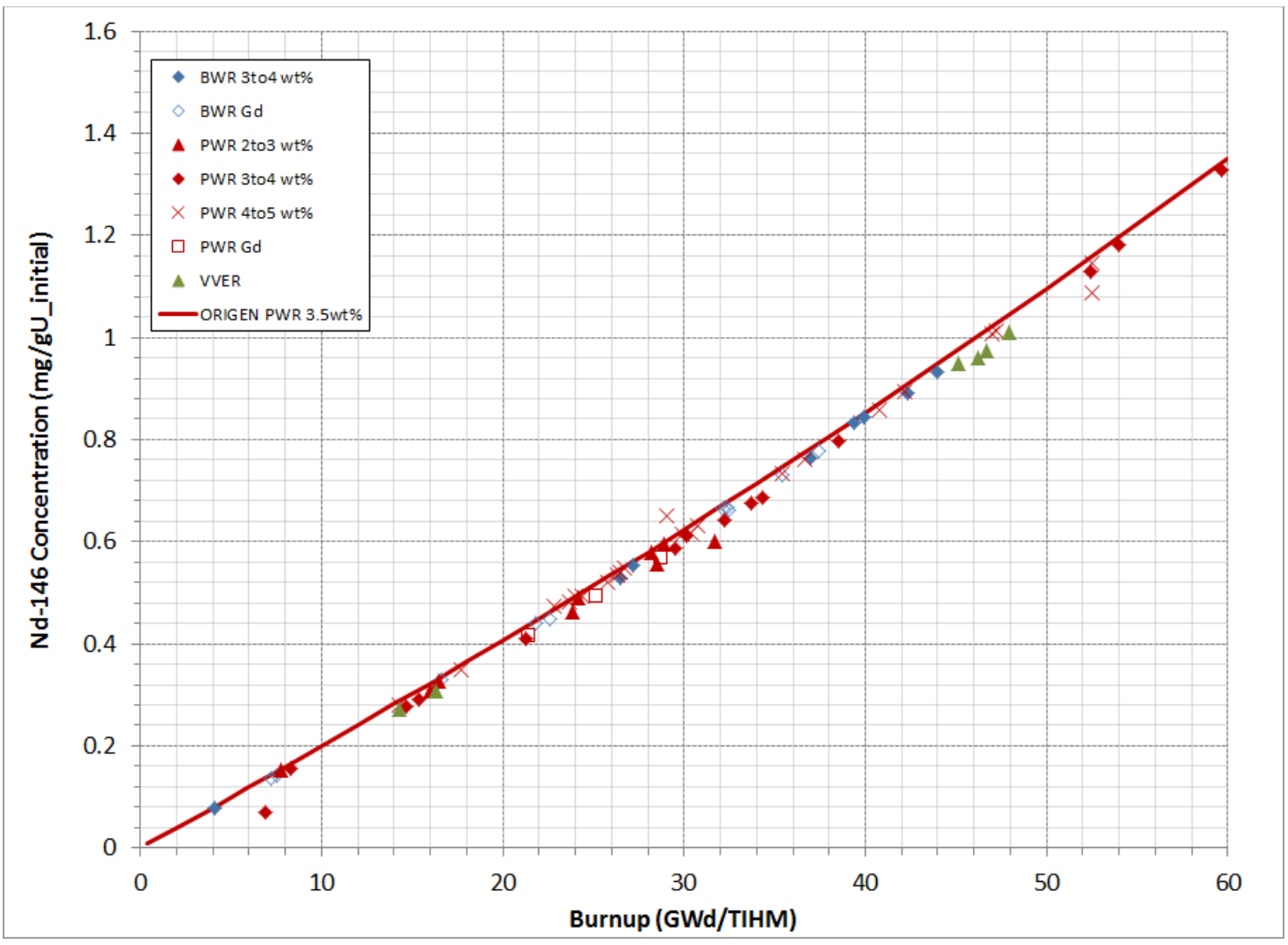

Fig. 56. Nd-146 concentration as a function of burnup.

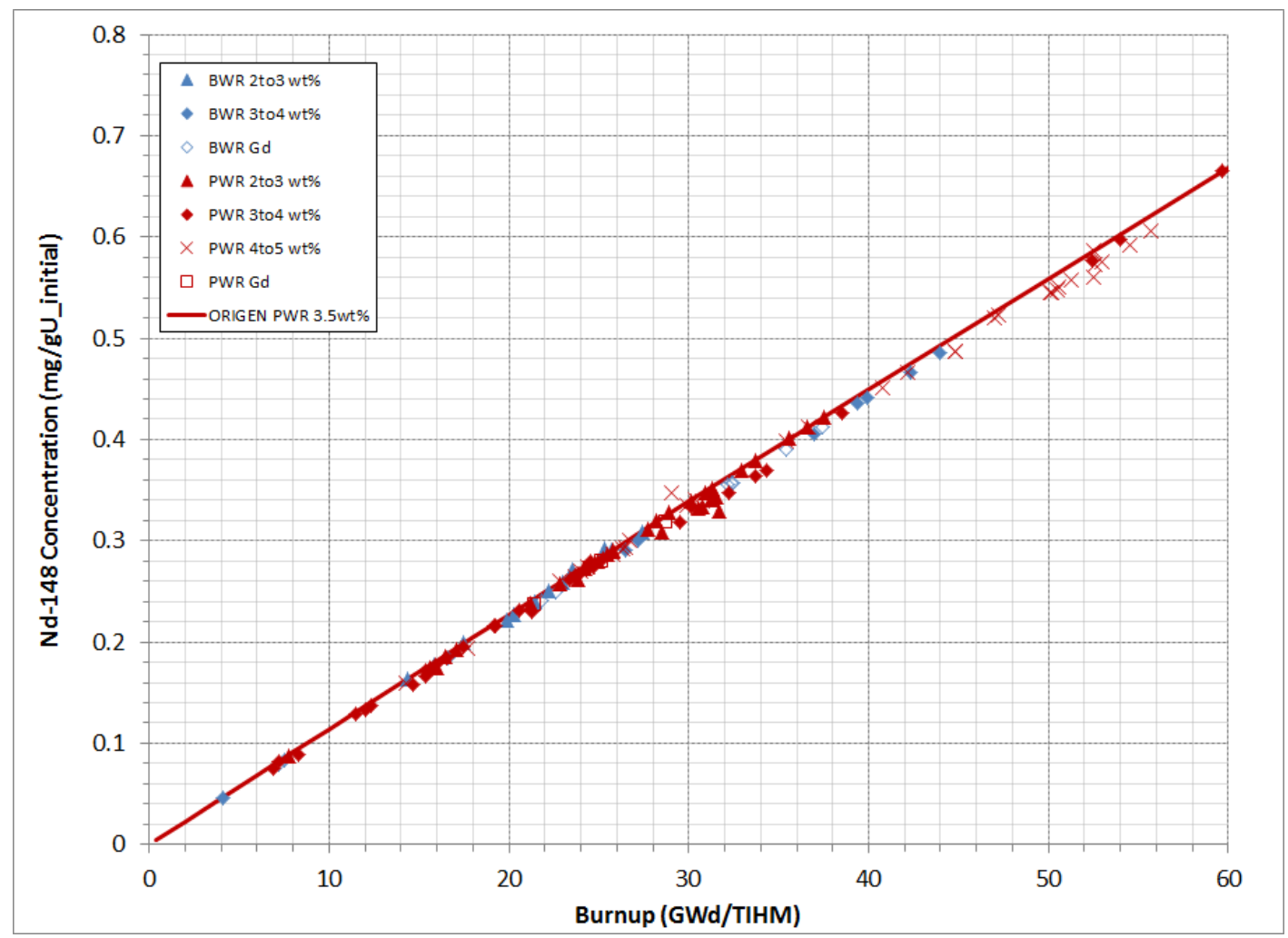

Fig. 57. Nd-148 concentration as a function of burnup. 


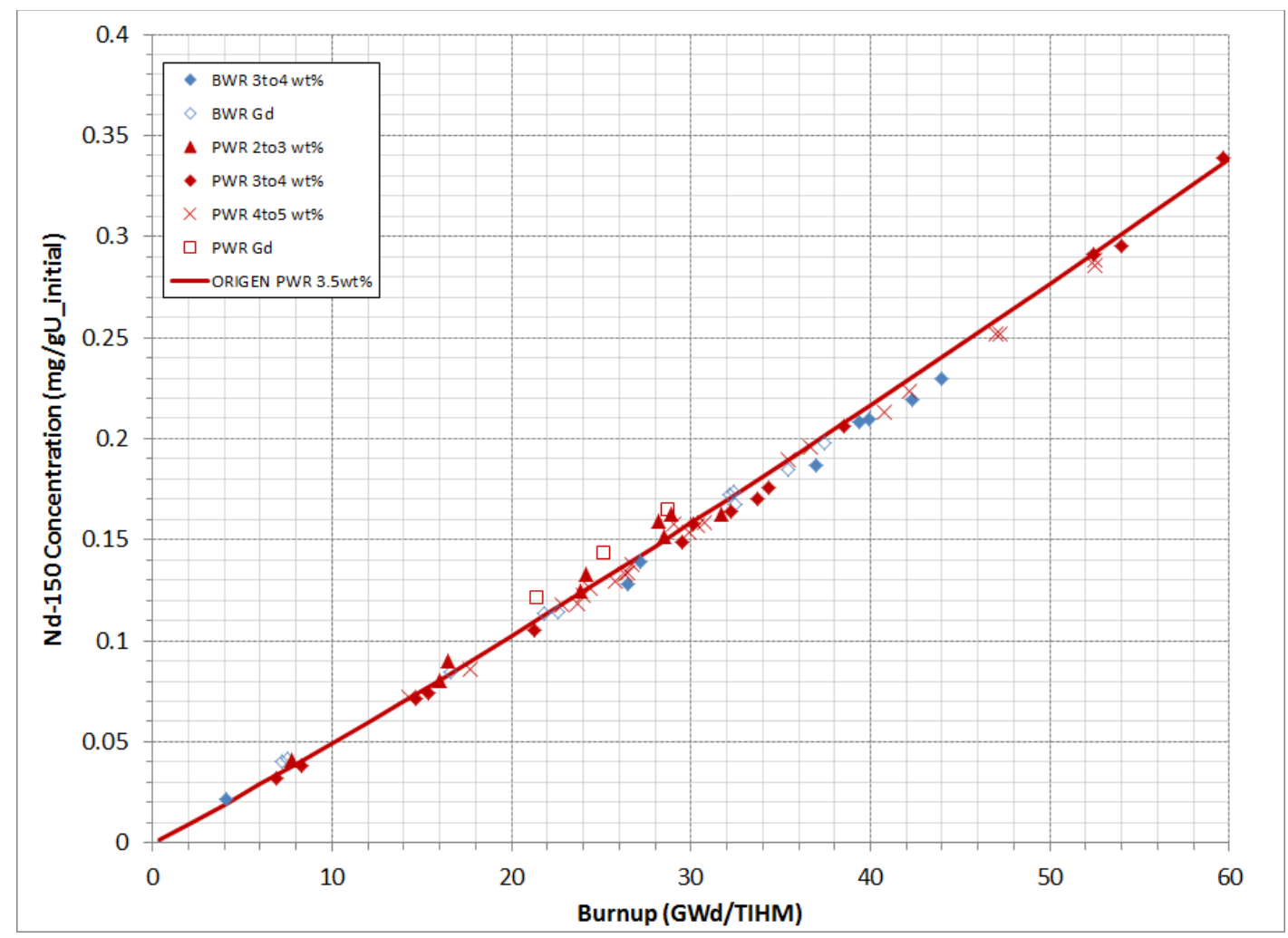

Fig. 58. Nd-150 concentration as a function of burnup.

\subsection{SAMARIUM ISOTOPES}

The samarium isotopes, especially ${ }^{149} \mathrm{Sm},{ }^{151} \mathrm{Sm}$ (see section 6.4 ), and ${ }^{152} \mathrm{Sm}$, have large absorption cross sections and are important to burnup credit calculations for criticality. The variations in isotopic content as a function of burnup for samarium isotopes are illustrated in Fig. 59-64. ${ }^{149} \mathrm{Sm}$ is one of the most important burnup credit isotopes due to its very high absorption cross section. Focus is placed on this isotope in reactor operation, especially near the end of core life, because of the negative reactivity it adds to the overall system. ${ }^{32}$ The ${ }^{148} \mathrm{Sm}$ and ${ }^{150} \mathrm{Sm}$ isotopes are both shielded by stable isotopes in their respective mass chains (see Fig. 60 and Fig. 62 ). ${ }^{148} \mathrm{Sm}$ trends approximately as the square of the burnup (or flux) as do many shielded isotopes. ${ }^{150} \mathrm{Sm}$, on the other hand, trends linearly with burnup due to the rather constant trend of ${ }^{149} \mathrm{Sm}$ with burnup (see Fig. 61). The constant trend of ${ }^{149} \mathrm{Sm}$ as a function of burnup is due to its very high absorption concentration mentioned above. The ${ }^{147} \mathrm{Sm}$ and ${ }^{149} \mathrm{Sm}$ isotopes both have long lived precursors and continue to have significant buildup after the end of the irradiation (see Fig. 59 and Fig. 61). 


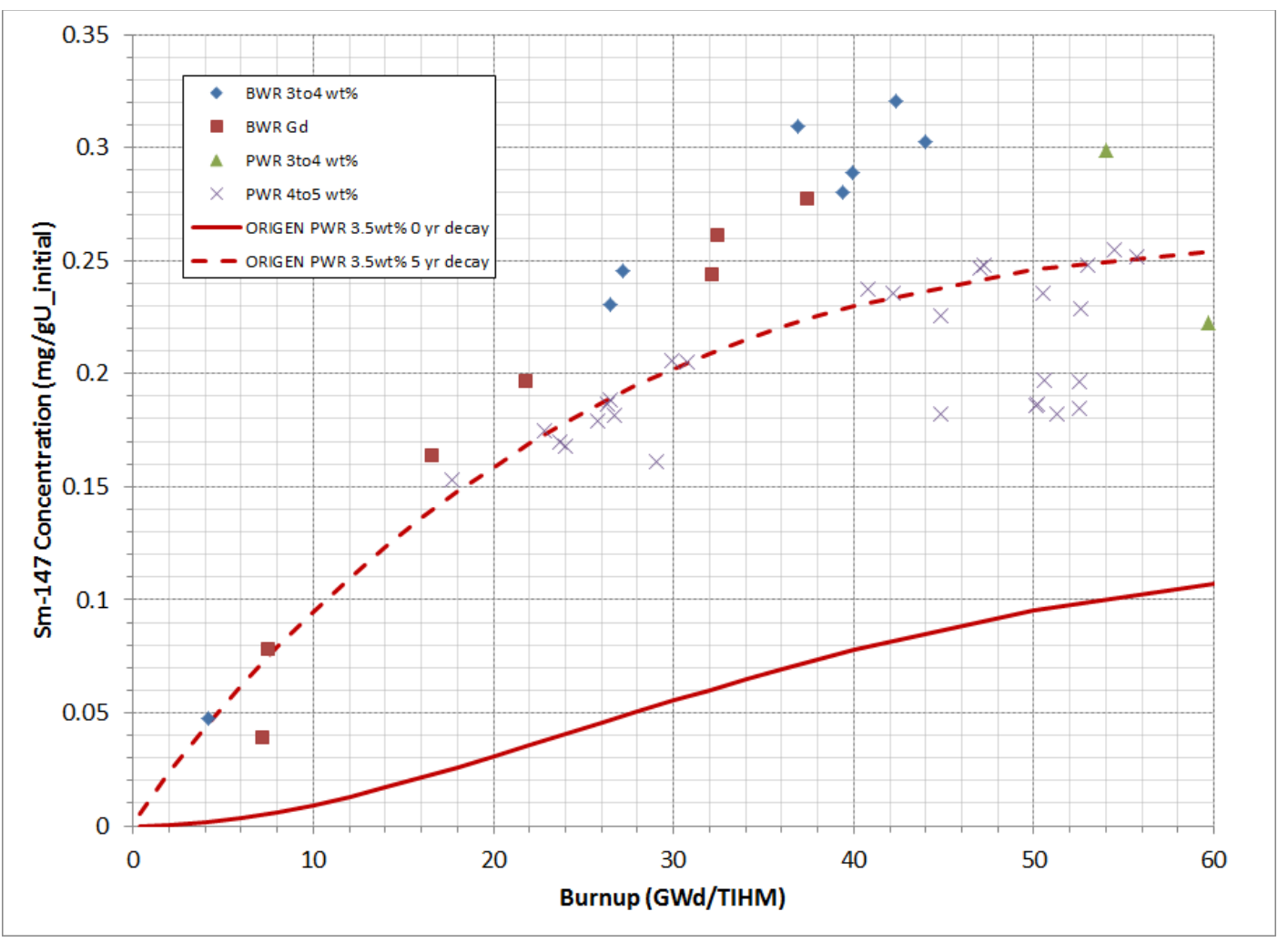

Fig. 59. Sm-147 concentration as a function of burnup.

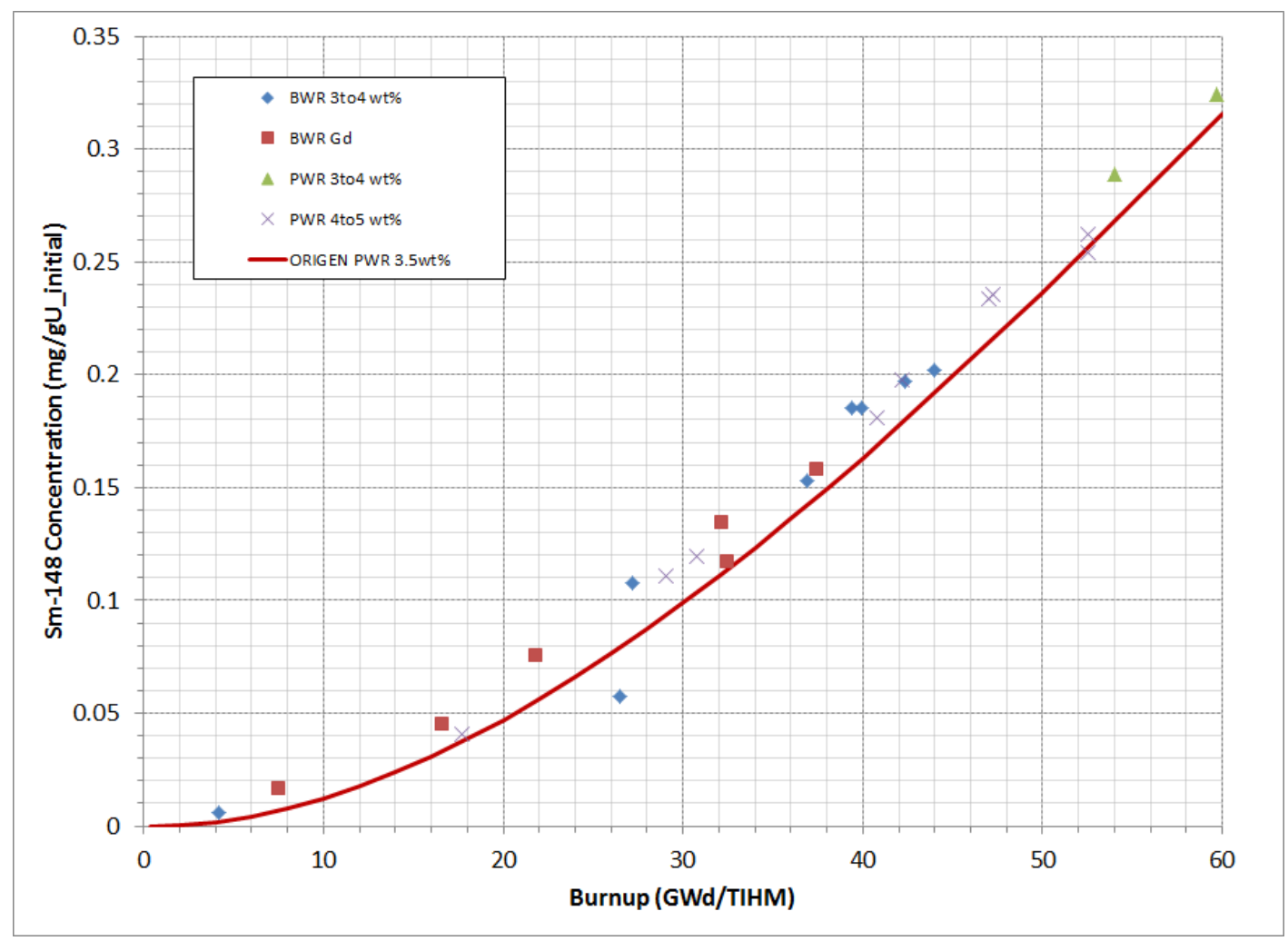

Fig. 60. Sm-148 concentration as a function of burnup. 


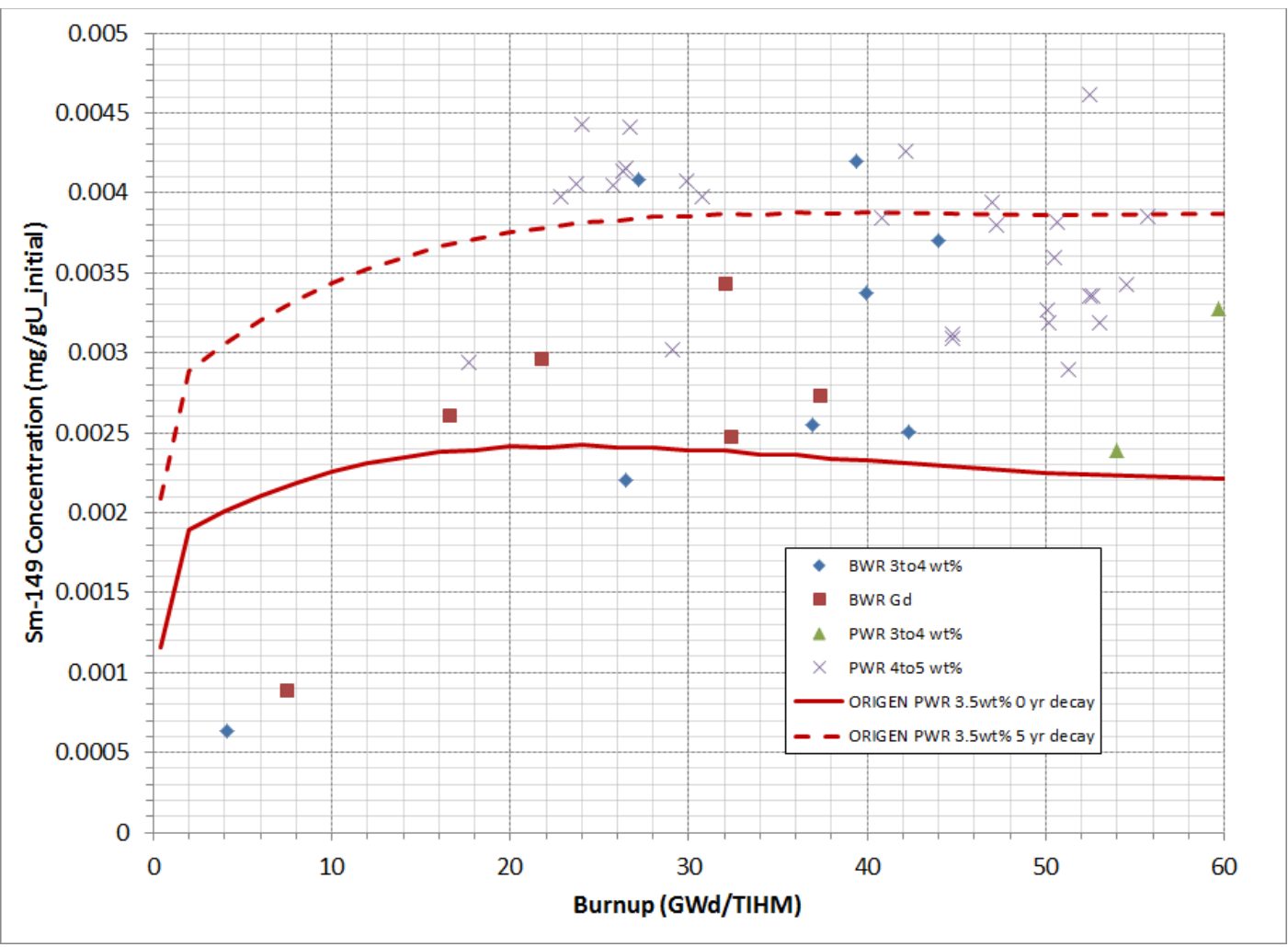

Fig. 61. Sm-149 concentration as a function of burnup.

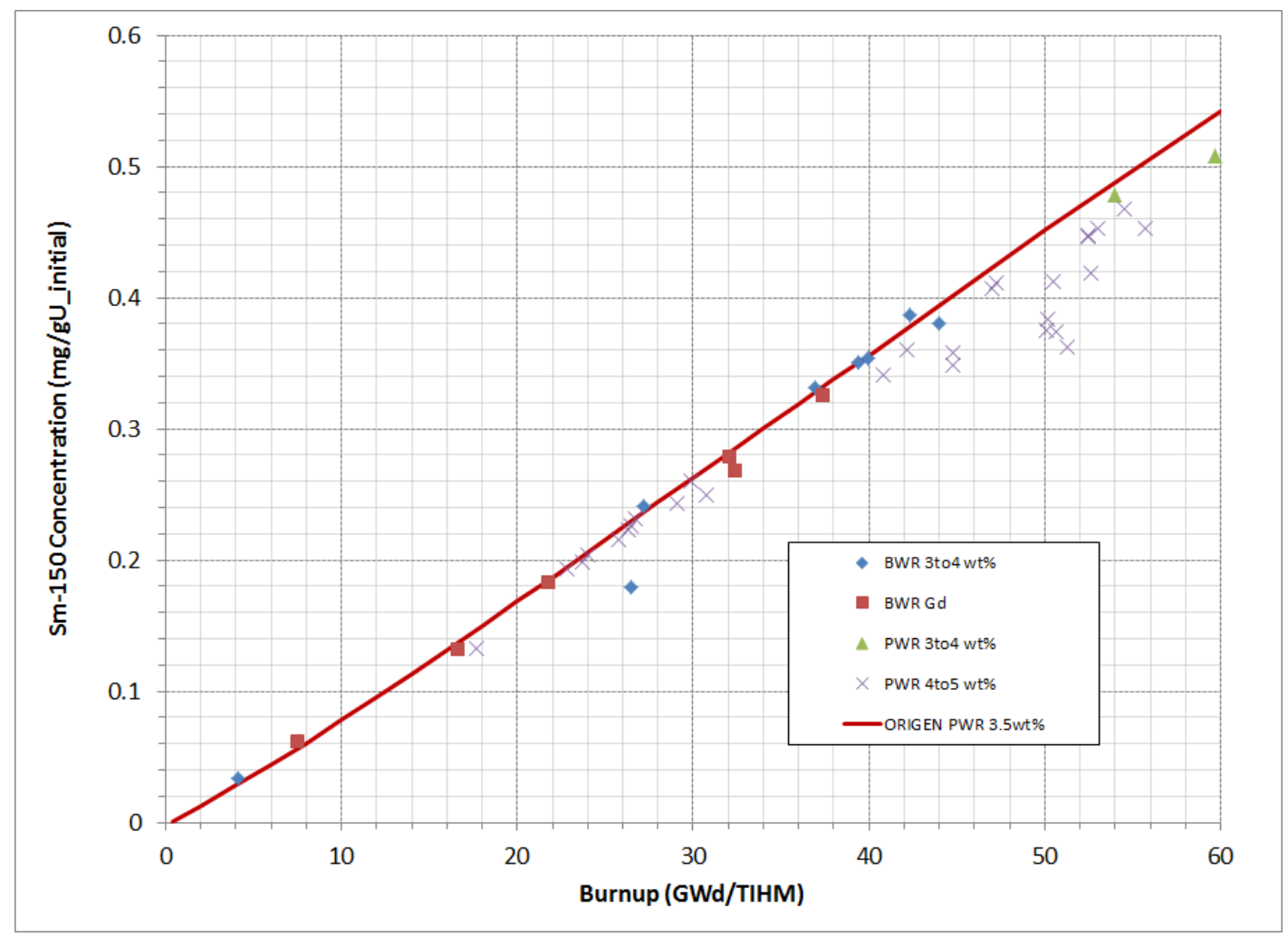

Fig. 62. Sm-150 concentration as a function of burnup. 


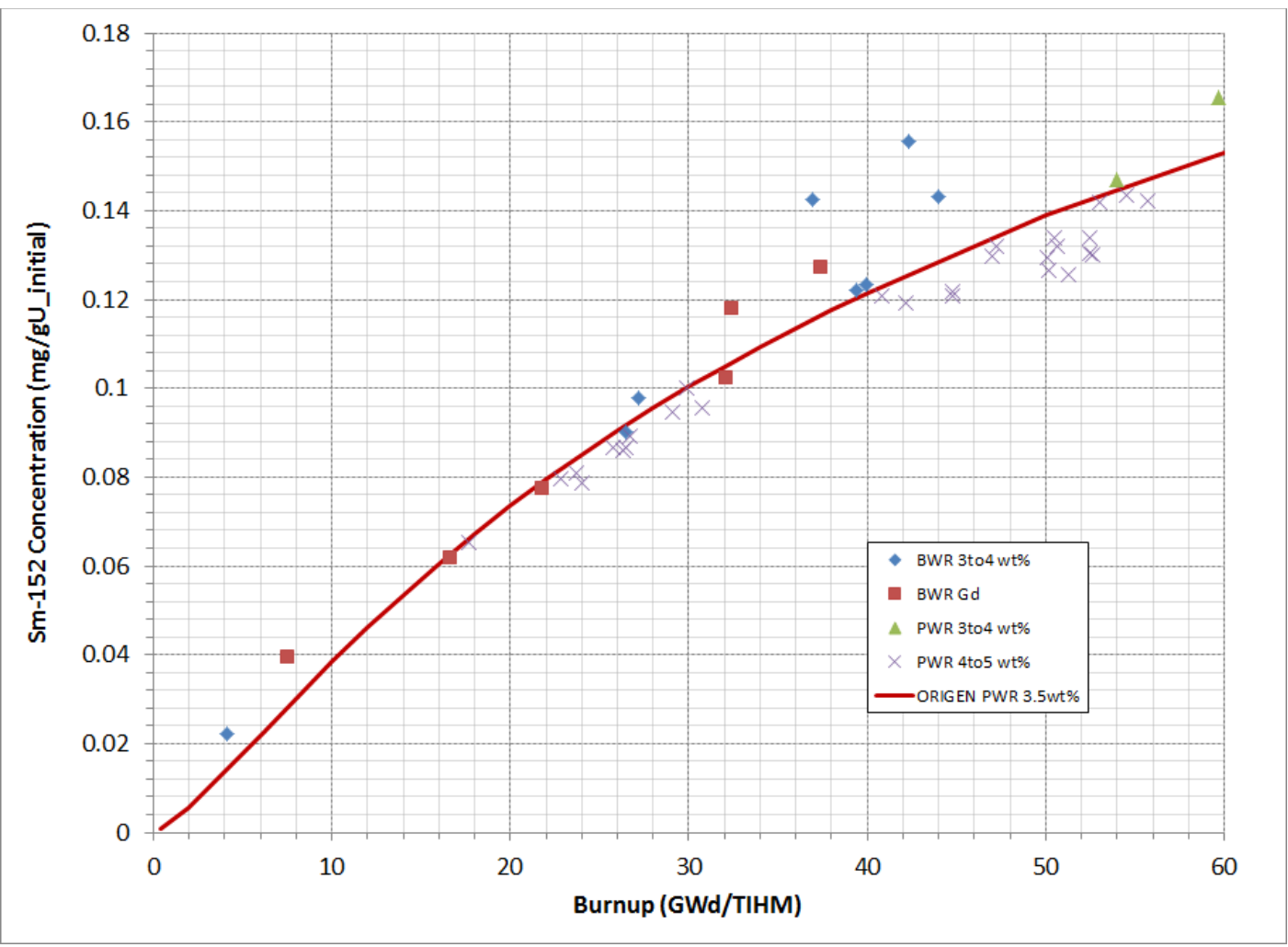

Fig. 63. Sm-152 concentration as a function of burnup.

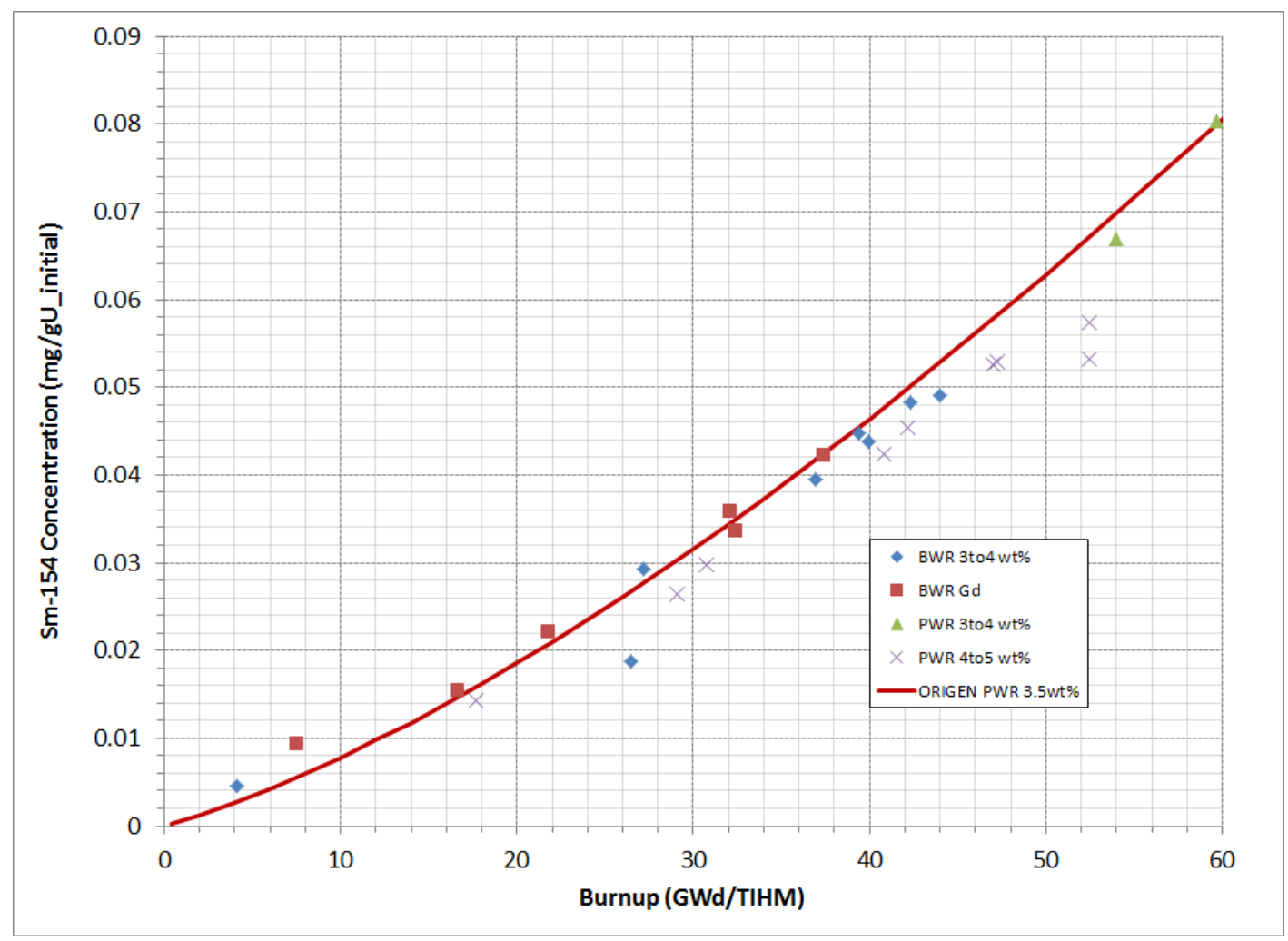

Fig. 64. Sm-154 concentration as a function of burnup. 


\subsection{LIGHT STABLE FISSION PRODUCTS}

Just like the stable krypton isotopes examined in Section $4.4,{ }^{95} \mathrm{Mo},{ }^{101} \mathrm{Ru}$, and ${ }^{103} \mathrm{Rh}$ are light stable fission products. More precisely, ${ }^{95} \mathrm{Mo},{ }^{101} \mathrm{Ru}$, and ${ }^{103} \mathrm{Rh}$ are the stable end points of their respective mass chains because all three rarely are formed directly from fission. The precursors to ${ }^{95} \mathrm{Mo}$ are ${ }^{95} \mathrm{Nb}$ and ${ }^{95} \mathrm{Zr}$, which have half-lives of 35 days and 64 days, respectively. Therefore, ${ }^{95}$ Mo continues to build up for several weeks after the end of irradiation (Fig. 65). ${ }^{101} \mathrm{Ru}$, on the other hand, has relatively short lived precursors and does not build up to any significant degree after irradiation (Fig. 66). ${ }^{103} \mathrm{Rh}$ will continue to build up slightly after irradiation due to the 39 day half-life of ${ }^{103} \mathrm{Ru} .{ }^{103} \mathrm{Rh}$ has the highest neutron capture cross section of the three- $150 \mathrm{~b}$, compared to $14 \mathrm{~b}$ for ${ }^{95} \mathrm{Mo}$ and $3 \mathrm{~b}$ for ${ }^{101} \mathrm{Ru}$. Therefore, the concentration trend of ${ }^{103} \mathrm{Rh}$ is more concave as a function of burnup (Fig. 67).

${ }^{109} \mathrm{Ag}$ is included in this section; however, it could be considered in the valley between the light and large fission fragments for fissioning of ${ }^{235} \mathrm{U}$ with thermal neutrons. However, the cumulative fission yield for ${ }^{109} \mathrm{Ag}$ from fissioning of ${ }^{239} \mathrm{Pu}$ with thermal neutrons is almost two orders of magnitude larger than from ${ }^{235} \mathrm{U}$. Therefore, the production of ${ }^{109} \mathrm{Ag}$ is very sensitive to which actinide is fissioning. As seen in Fig. 68, ORIGEN over-predicts the production of ${ }^{109} \mathrm{Ag}$. The discrepancy may be partly due to difficulties in performing the analytical measurements. Further examination in this deviation is needed.

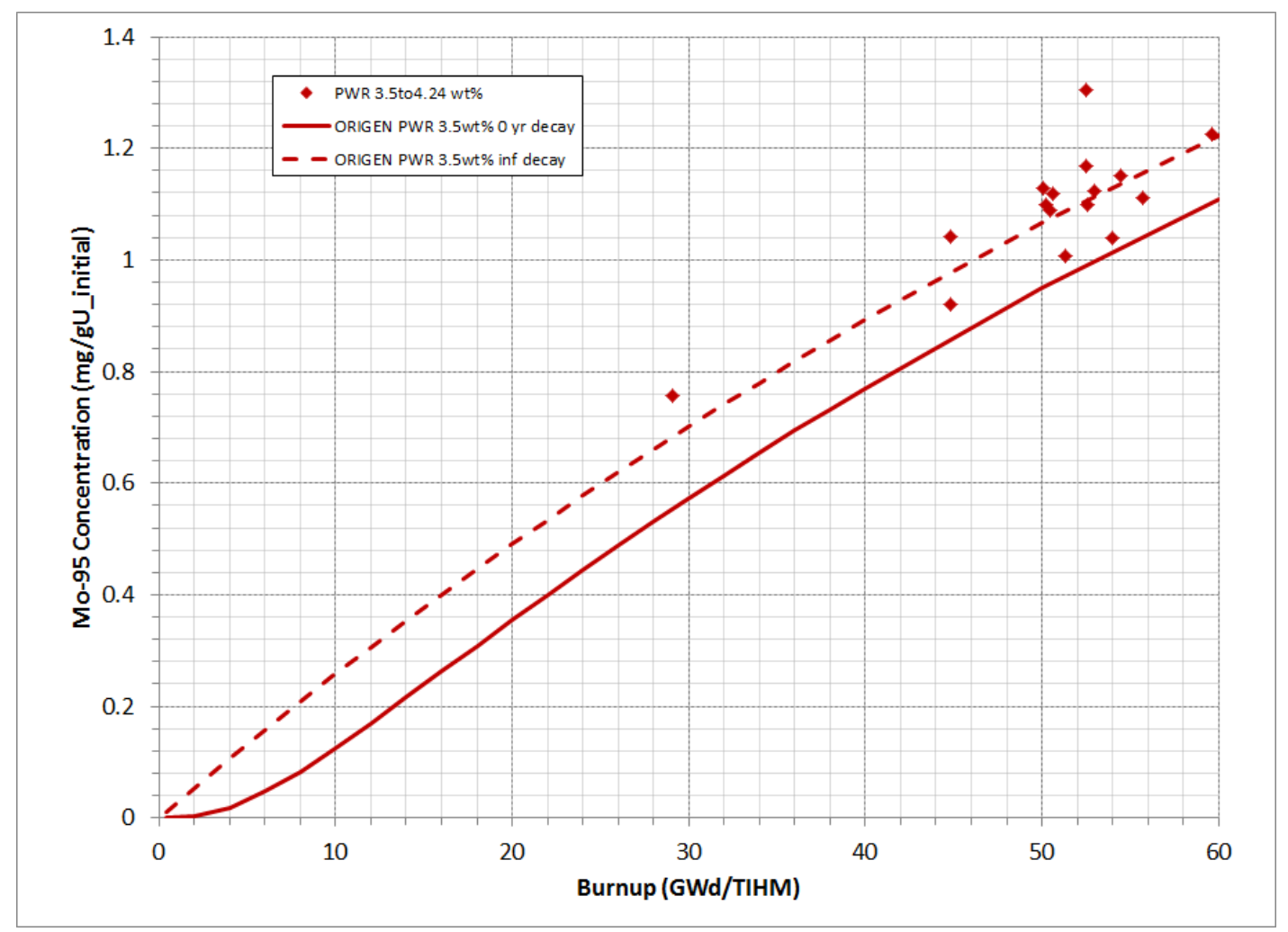

Fig. 65. Mo-95 concentration as a function of burnup. 


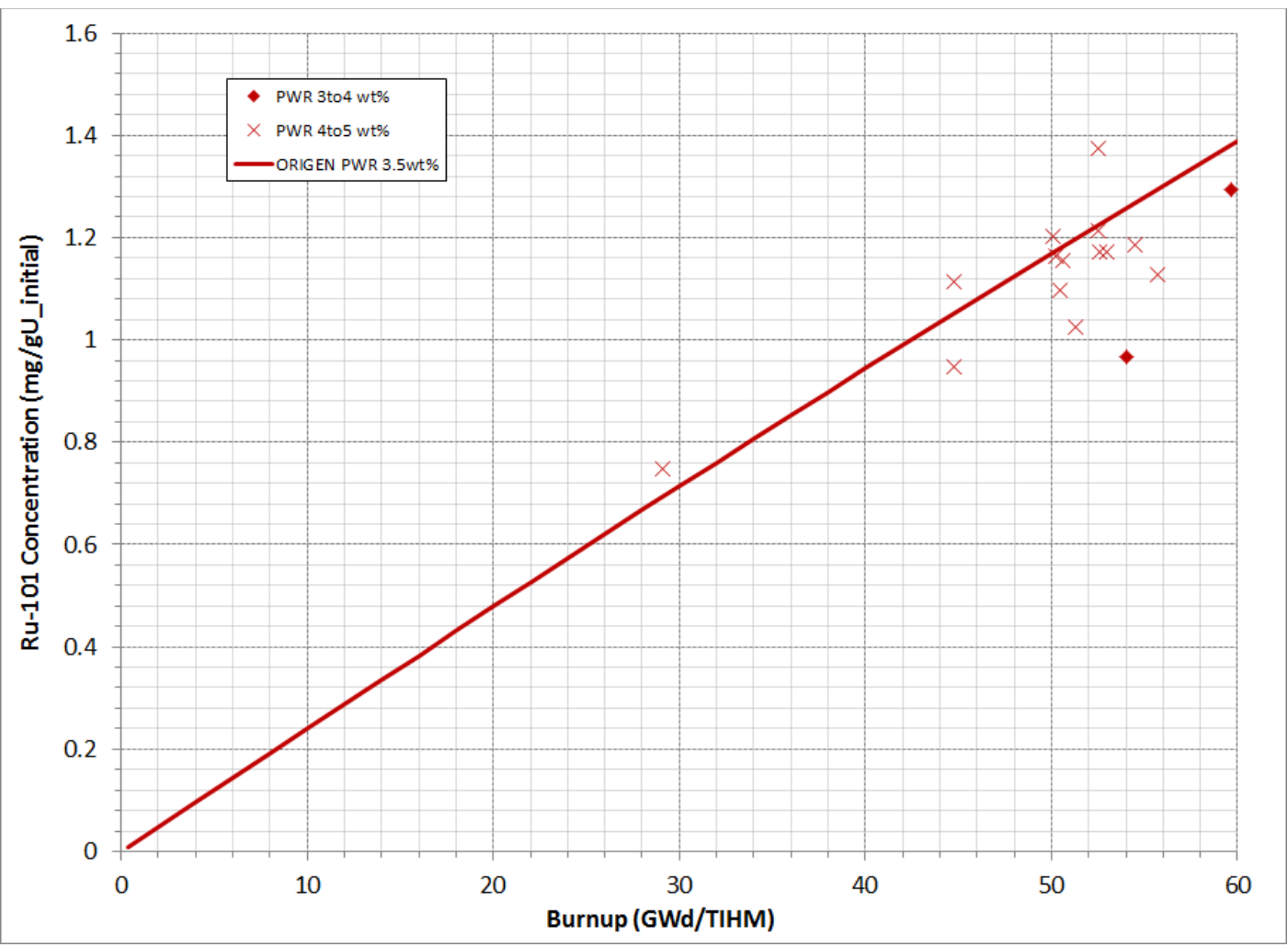

Fig. 66. Ru-101 concentration as a function of burnup.

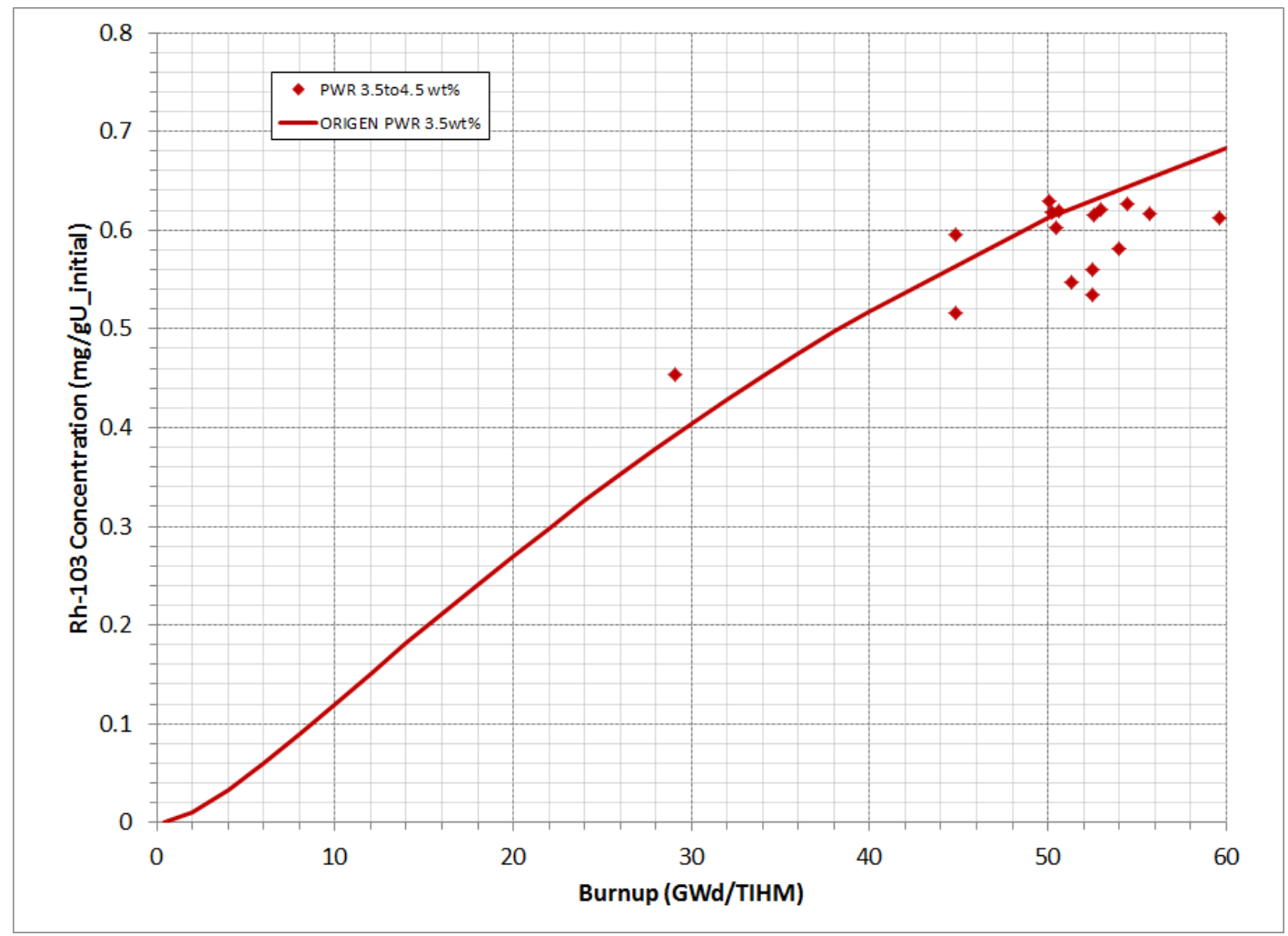

Fig. 67. Rh-103 concentration as a function of burnup. 


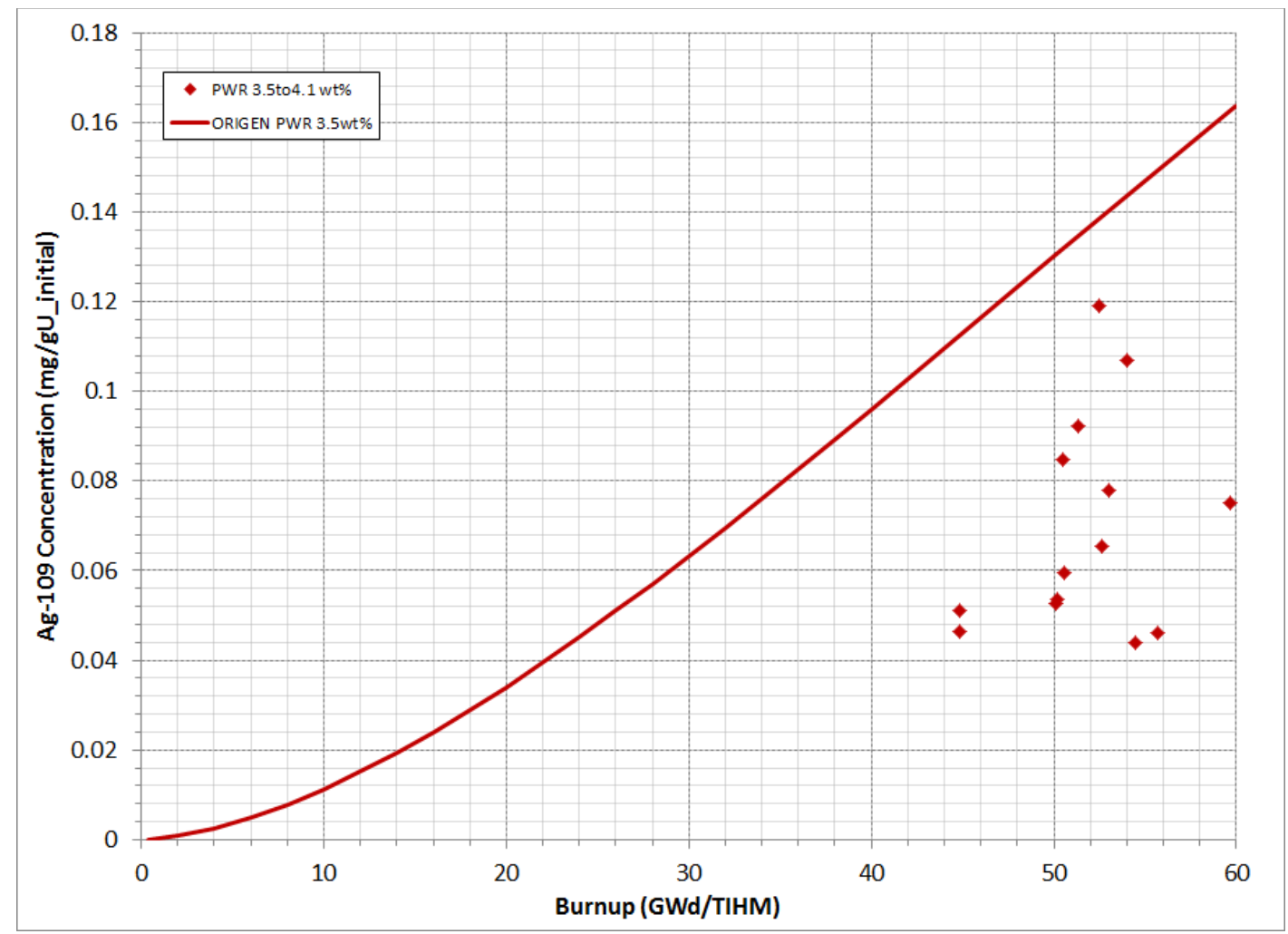

Fig. 68. Ag-109 concentration as a function of burnup.

\subsection{HEAVY STABLE FISSION PRODUCTS}

${ }^{133} \mathrm{Cs},{ }^{151} \mathrm{Eu}$, and ${ }^{153} \mathrm{Eu}$, like the stable neodymium and samarium isotopes, are heavy stable fission products that are the end points of their respective mass chains. The variations with burnup of these isotopes are illustrated in Figs. $69-71 .{ }^{133} \mathrm{Cs}$ and ${ }^{153} \mathrm{Eu}$ are often studied because they lead to the shielded ${ }^{134} \mathrm{Cs}$ and ${ }^{154} \mathrm{Eu}$, respectively, by neutron capture. As will be seen in Section 6.3, both of these isotopes have relatively long half-lives and $\beta$-decay to an excited nucleus that gives off a variety of gamma rays. ${ }^{151} \mathrm{Eu}$ is often measured because it is preceded by the long lived ${ }^{151} \mathrm{Sm}$ (half-life is 90 years). Due to the long half-life of ${ }^{151} \mathrm{Sm},{ }^{151} \mathrm{Eu}$ slowly builds up after irradiation by beta-decay of ${ }^{151} \mathrm{Sm}$, as seen in Fig. 70. 


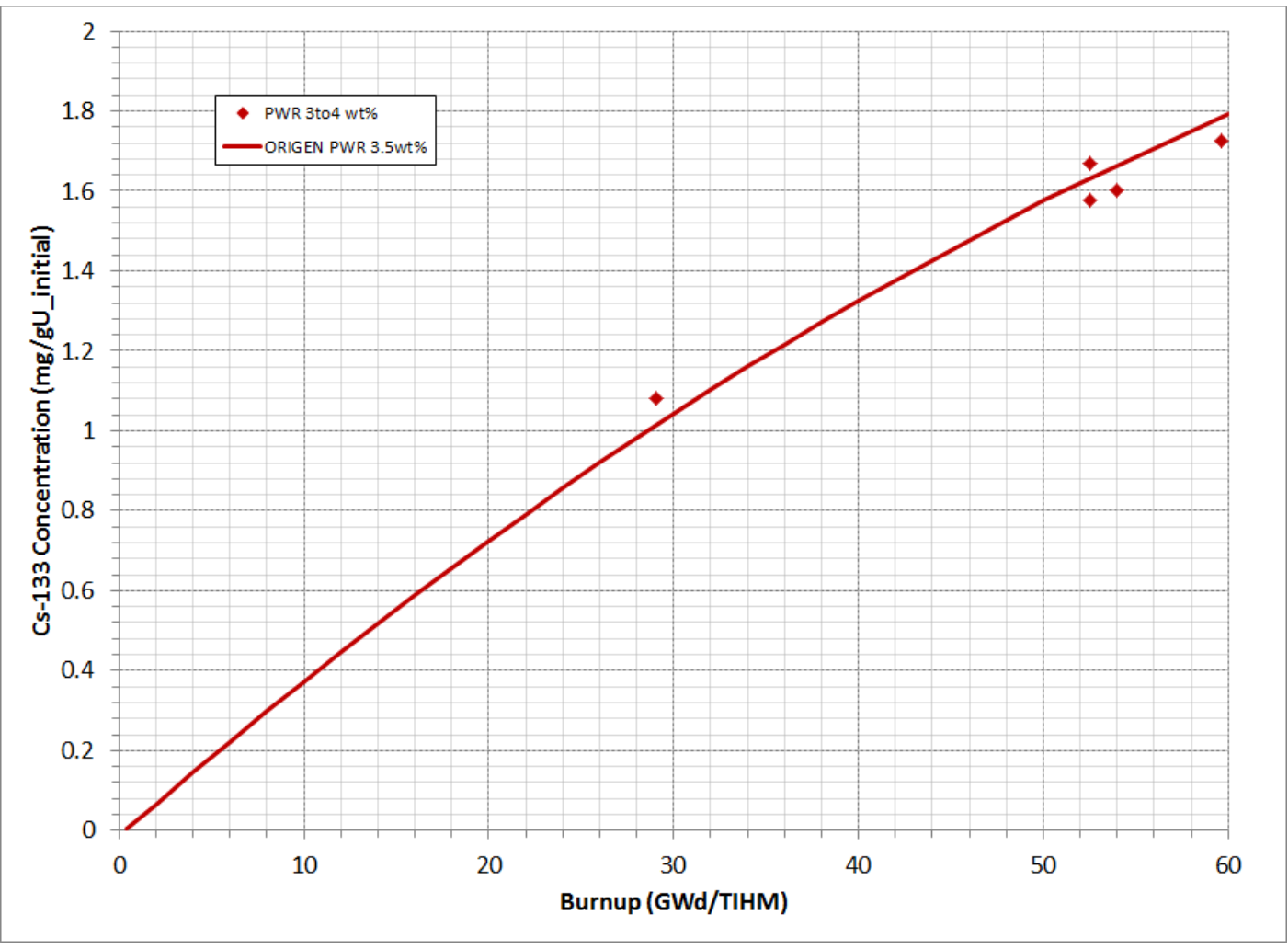

Fig. 69. Cs-133 concentration as a function of burnup.

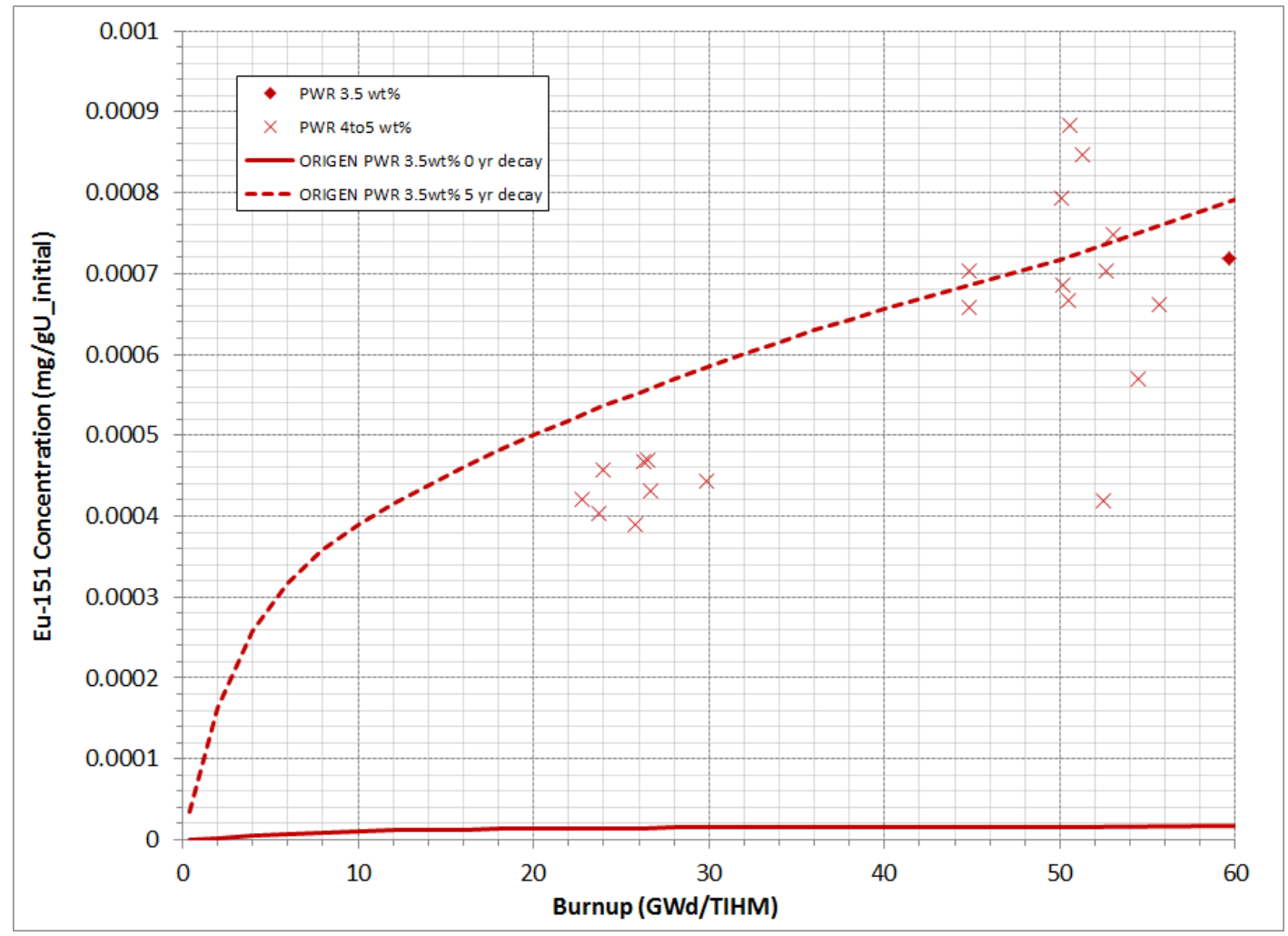

Fig. 70. Eu-151 concentration as a function of burnup. 


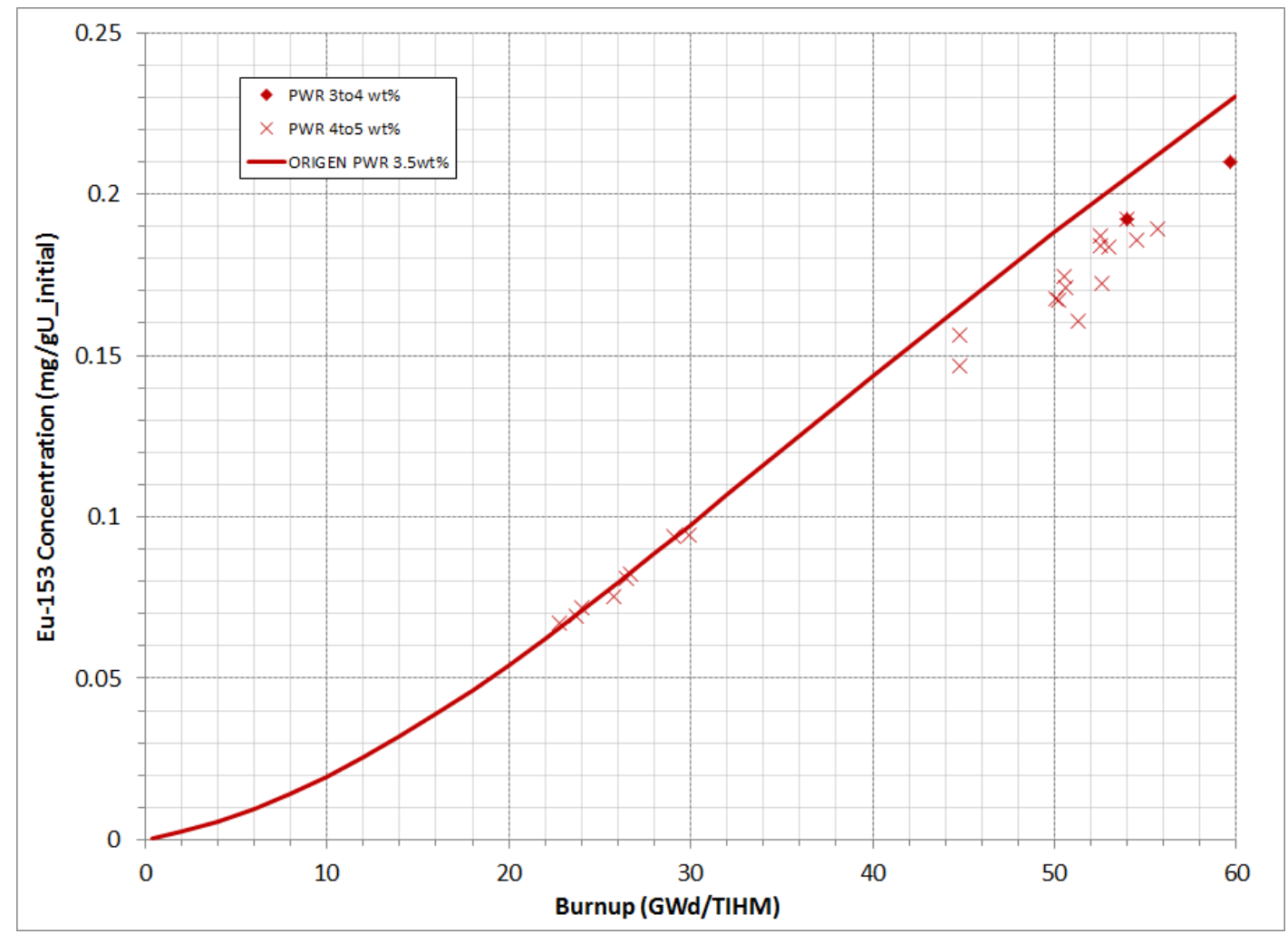

Fig. 71. Eu-153 concentration as a function of burnup.

\subsection{MODEL VALIDATION OF STABLE FISSION PRODUCTS}

The average calculated-to-experimental values for several stable fission products can be seen in Fig. 72 for $\mathrm{PWRs}^{27}$ and in Fig. 73 for BWRs. ${ }^{19}$ Only the neodymium and samarium isotopes are common between the two sets. According to Ilas et al., the samarium isotopes are much better estimated with SCALE 6.1/ENDF/B-VII than with SCALE 5.1/ENDF/B-V. ${ }^{27}$ This is evident when comparing the BWR results, which used ENDF/B-V, and the PWR results reported in Fig. 72, which used ENDF/B-VII. ${ }^{19}$

${ }^{101} \mathrm{Ru}$ and ${ }^{103} \mathrm{Rh}$ appear to be significantly underestimated; however, the quality of the data might be related to the challenges with chemically separating these elements in the measurement process. Not listed is ${ }^{109} \mathrm{Ag}$. This isotope has a $\mathrm{C} / \mathrm{E}$ equal to 1.773 . Separating out and obtaining a good silver measurement has challenged chemists in the past, as well. ${ }^{62}$

The models are obtaining very accurate neodymium isotope concentrations, confirming that the models are obtaining good agreement with the reported burnups of the samples. 


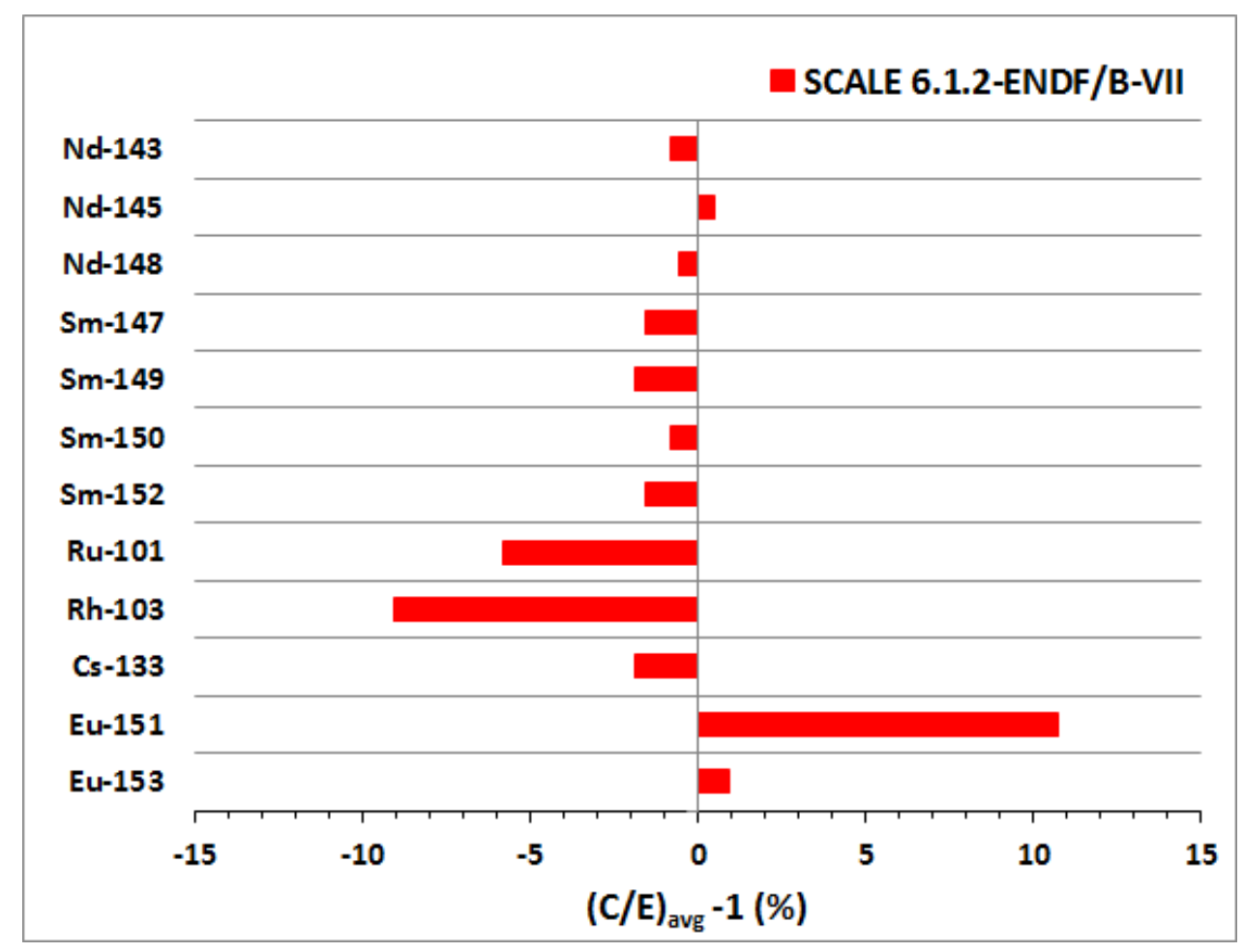

Fig. 72. Stable fission products C/E average for PWR simulation. ${ }^{27}$

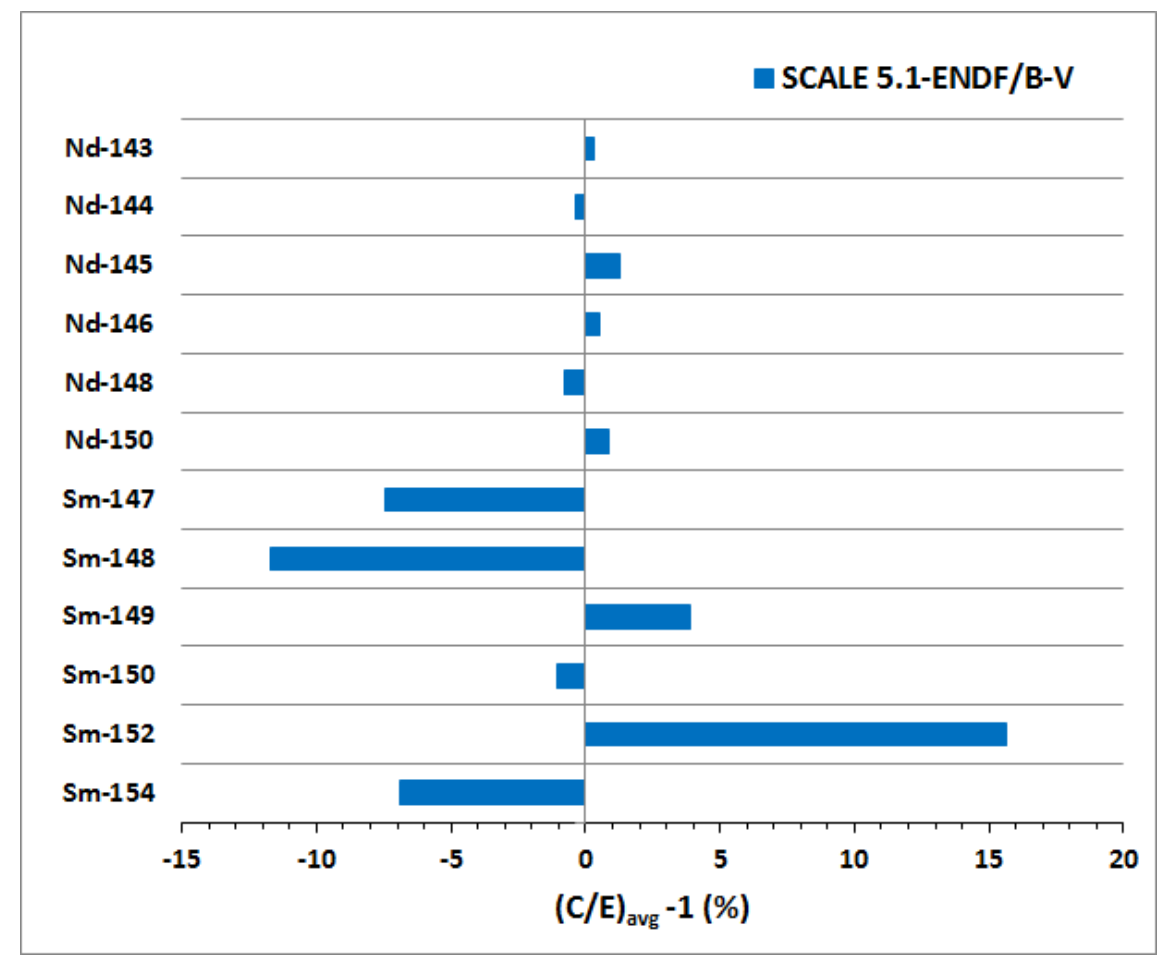

Fig. 73. Stable fission products C/E average for BWR simulation. ${ }^{19}$ 


\section{RADIOACTIVE FISSION PRODUCTS}

This section provides an overview on the radioactive fission isotopes other than the noble gases covered in Section 4. The fission products are grouped by half-life: (1) shorter than two years, (2) between two and ten years, (3) between ten and one hundred years, and (4) greater than one hundred years.

\subsection{OVERVIEW OF RADIOACTIVE FISSION PRODUCT PRODUCTION}

Unlike the stable fission products covered in Section 5, the radioactive fission products not only build up from precursor isotopes, but they also decay away due to their half-lives. Therefore, extra care must be taken in knowing how the data are presented. When reporting measurement data, laboratories may use different methods for reporting measured contents for these isotopes: some laboratories correct the measured data (i.e., back-calculation) to the end of irradiation time, while other laboratories report the measurement at the exact time of measurement. Some laboratories correct their data to some specific time between end of irradiation and measurement date. In this section, the presented data have been adjusted by the authors of this report to the end of irradiation when possible to enable more consistent comparisons.

The isotopes covered in this section are the fission products as seen in Fig. 74. Similar to Section 5, radionuclides that come from neutron-capture of direct fission products are also included within this section. Overall, the data do not come from a variety of reactor types. The majority of the data was obtained from PWRs and BWRs. Fission product data from the other reactor types are much needed.

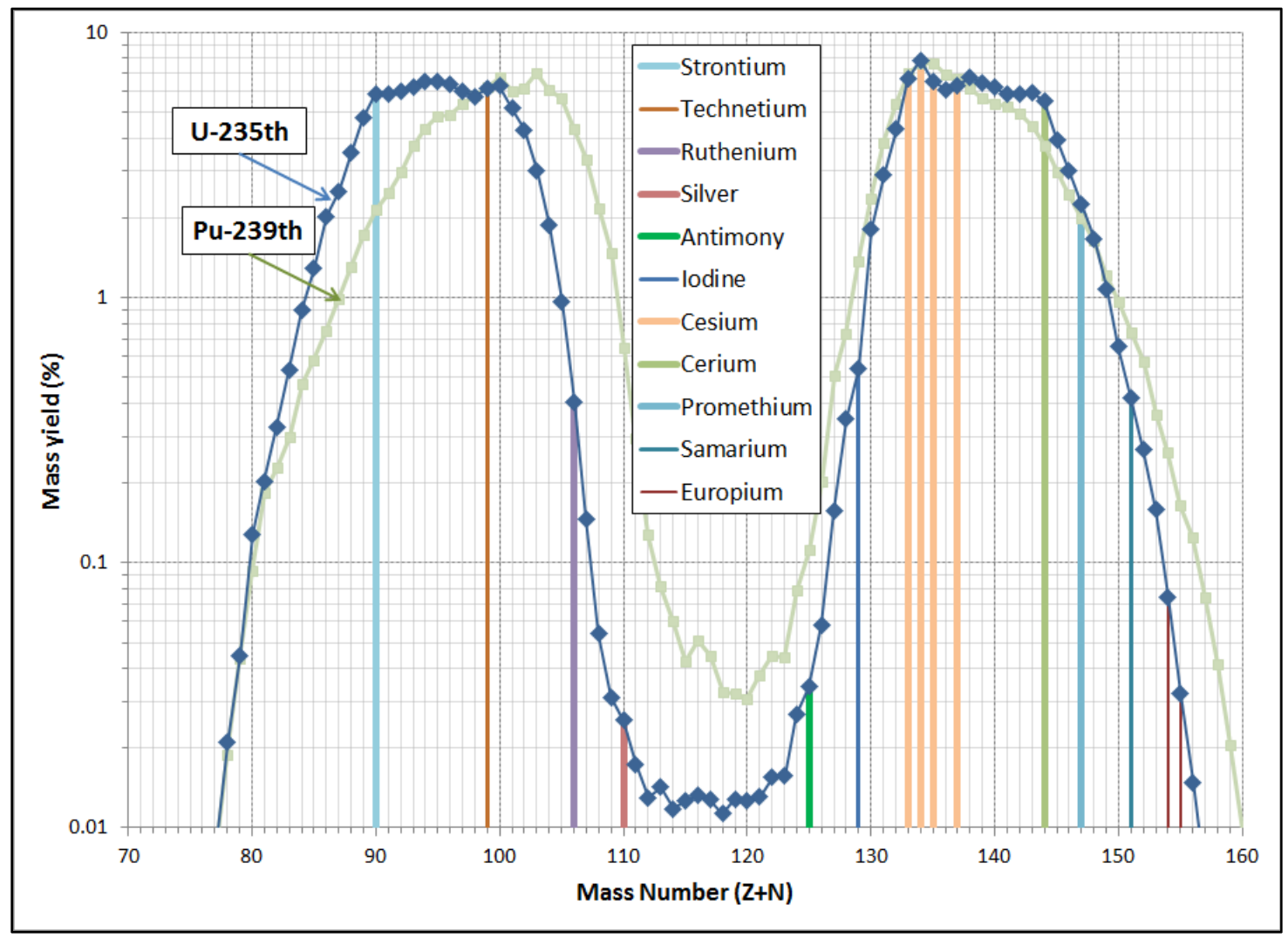

Fig. 74. Mass distribution of fission products from thermal fission of U-235 and Pu-239 covered in this section. 


\subsection{ISOTOPES WITH HALF-LIVES SHORTER THAN TWO YEARS}

The daughter products of ${ }^{110 \mathrm{~m}} \mathrm{Ag},{ }^{144} \mathrm{Ce}$, and ${ }^{106} \mathrm{Ru}$ are strong gamma-emitters that dominate the gamma spectrum of irradiated fuel for several years after discharge. ${ }^{32}$ The variations with burnup of these isotopes are illustrated in Figs. 75-77. The cumulative yield for ${ }^{144} \mathrm{Ce}$ from ${ }^{235} \mathrm{U}$ or ${ }^{239} \mathrm{Pu}$ by thermal neutrons is very similar. However, the cumulative yield for ${ }^{106} \mathrm{Ru}$ and ${ }^{110 \mathrm{~m}} \mathrm{Ag}$ from ${ }^{239} \mathrm{Pu}$ is more than 10 times larger than that from ${ }^{235} \mathrm{U}$. The deviations seen in the model and the measured results for ${ }^{144} \mathrm{Ce}$ need to be further examined (see Fig. 76). Also, the large scatter of the ${ }^{106} \mathrm{Ru}$ data needs to be explored (see Fig. 77).

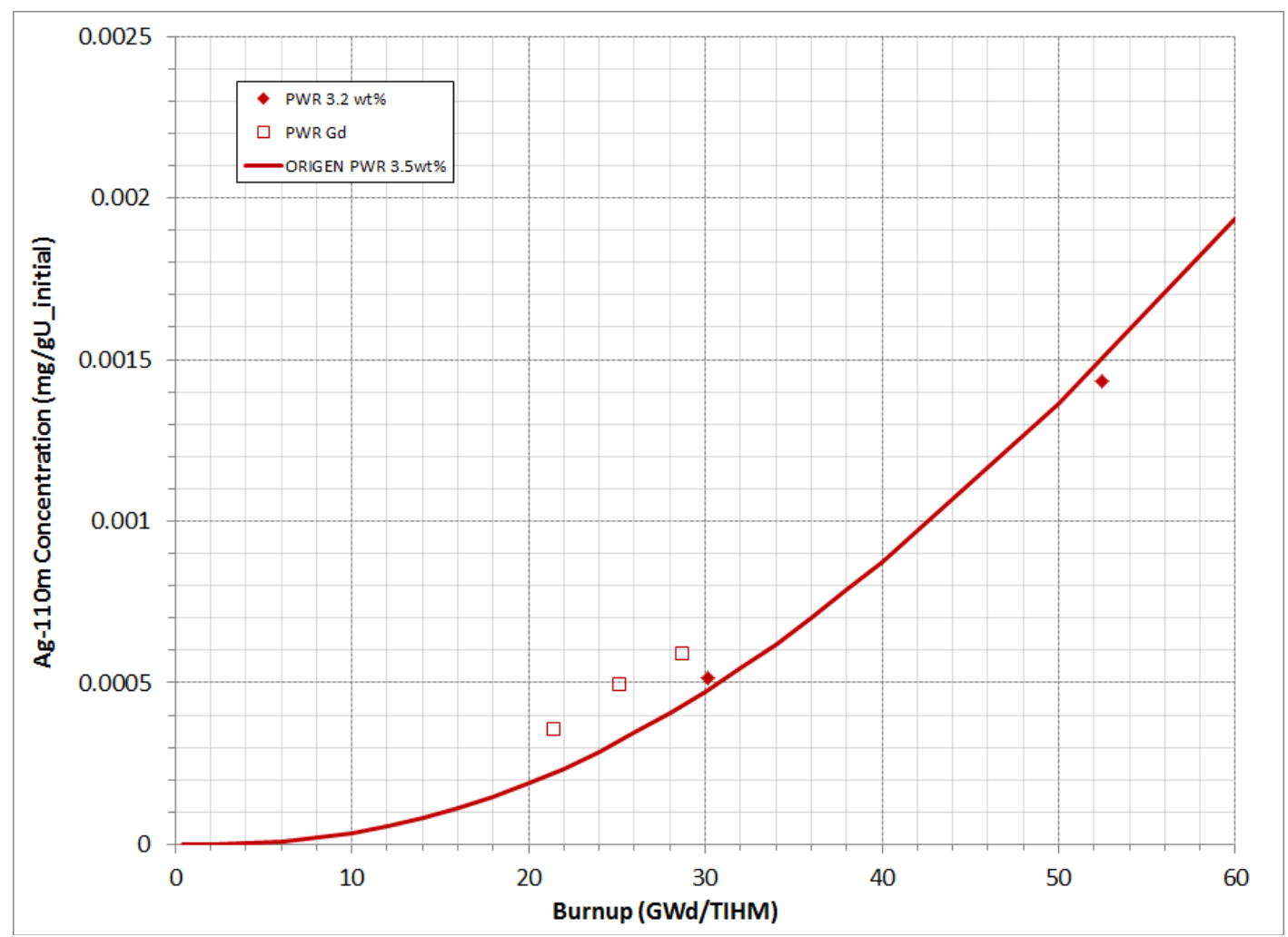

Fig. 75. Ag-110m concentration as a function of burnup. 


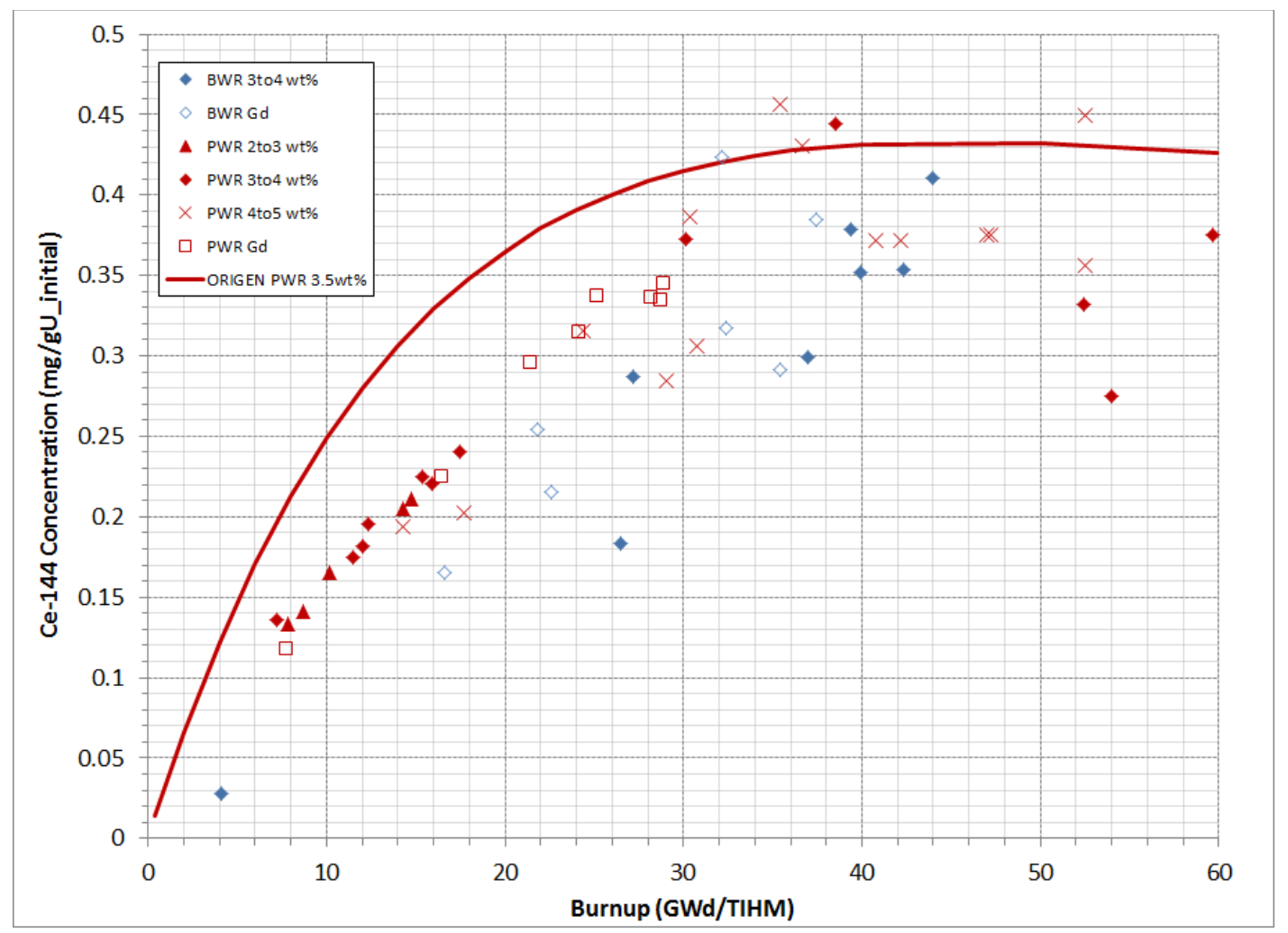

Fig. 76. Ce-144 concentration as a function of burnup.

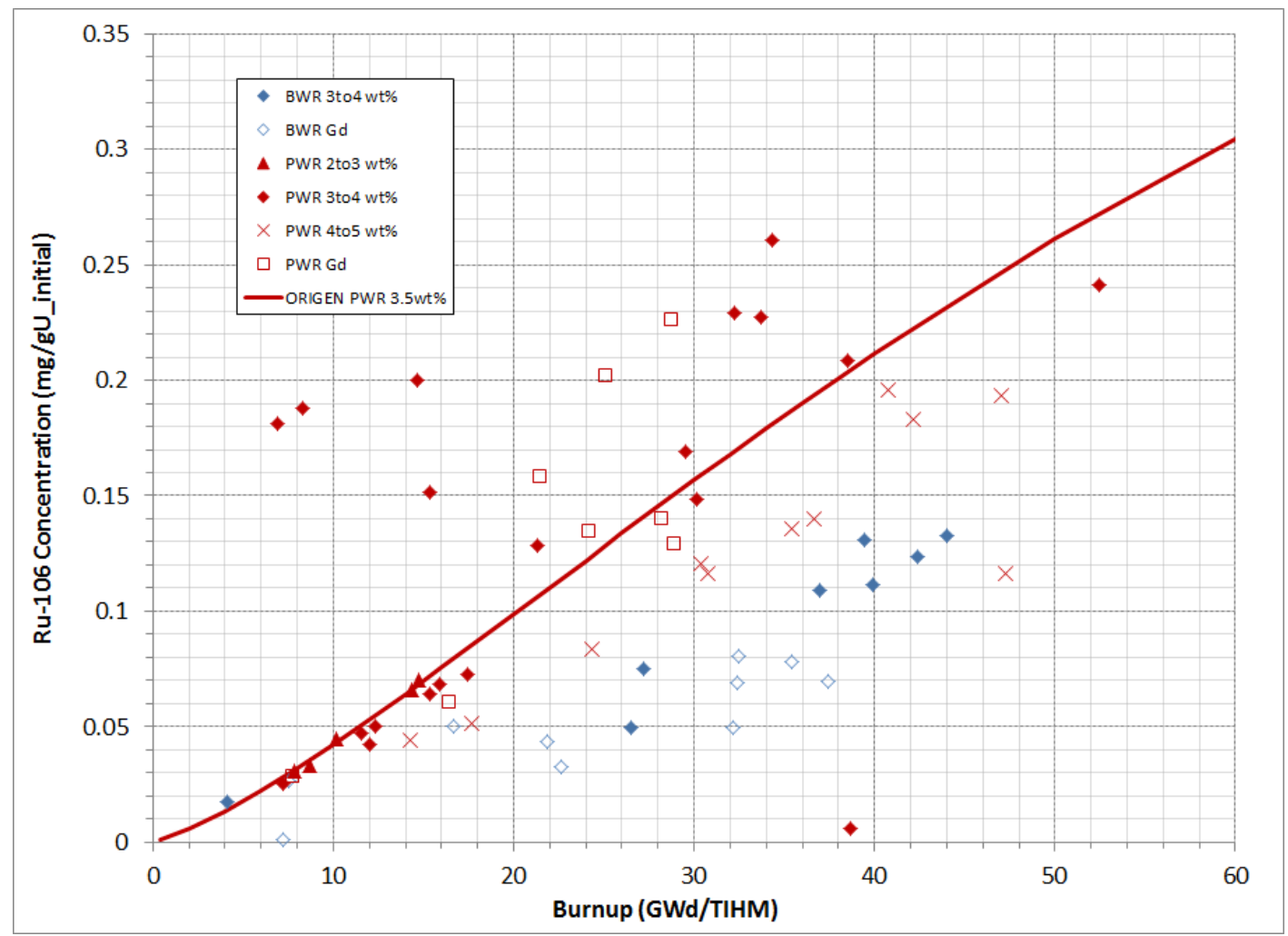

Fig. 77. Ru-106 concentration as a function of burnup. 


\subsection{ISOTOPES WITH HALF-LIVES BETWEEN TWO AND TEN YEARS}

${ }^{134} \mathrm{Cs}$ is shielded by stable ${ }^{134} \mathrm{Xe}$, so its production from fission is limited to its small independent fission yield. Instead, ${ }^{134} \mathrm{Cs}$ primarily comes from the neutron capture in stable ${ }^{133} \mathrm{Cs}$. The ${ }^{134} \mathrm{Cs}$ isotope $\beta$ decays to ${ }^{134} \mathrm{Ba}$ with a half-life of two years. Therefore, all the data shown in Fig. 78 have been backcalculated to the end of irradiation. As seen in Fig. 78, the concentration trend with burnup resembles the typically quadratic shape which is common to shielded isotopes. One challenge to modeling the radial distribution of ${ }^{134} \mathrm{Cs}$ in a fuel rod is due to the fact that ${ }^{133} \mathrm{Xe}$, which decays to ${ }^{133} \mathrm{Cs}$, has a 5.25 day halflife and can migrate in the fuel matrix. Thus, the ${ }^{134} \mathrm{Cs}$ distribution indicates to a certain degree the migration behavior of the fission product xenon in the fuel pellet. Due to the large number of high energy gamma rays coming off the excited ${ }^{134} \mathrm{Ba}$ nucleus, a nondestructive measurement of the ${ }^{134} \mathrm{Cs}$ concentration can be made.

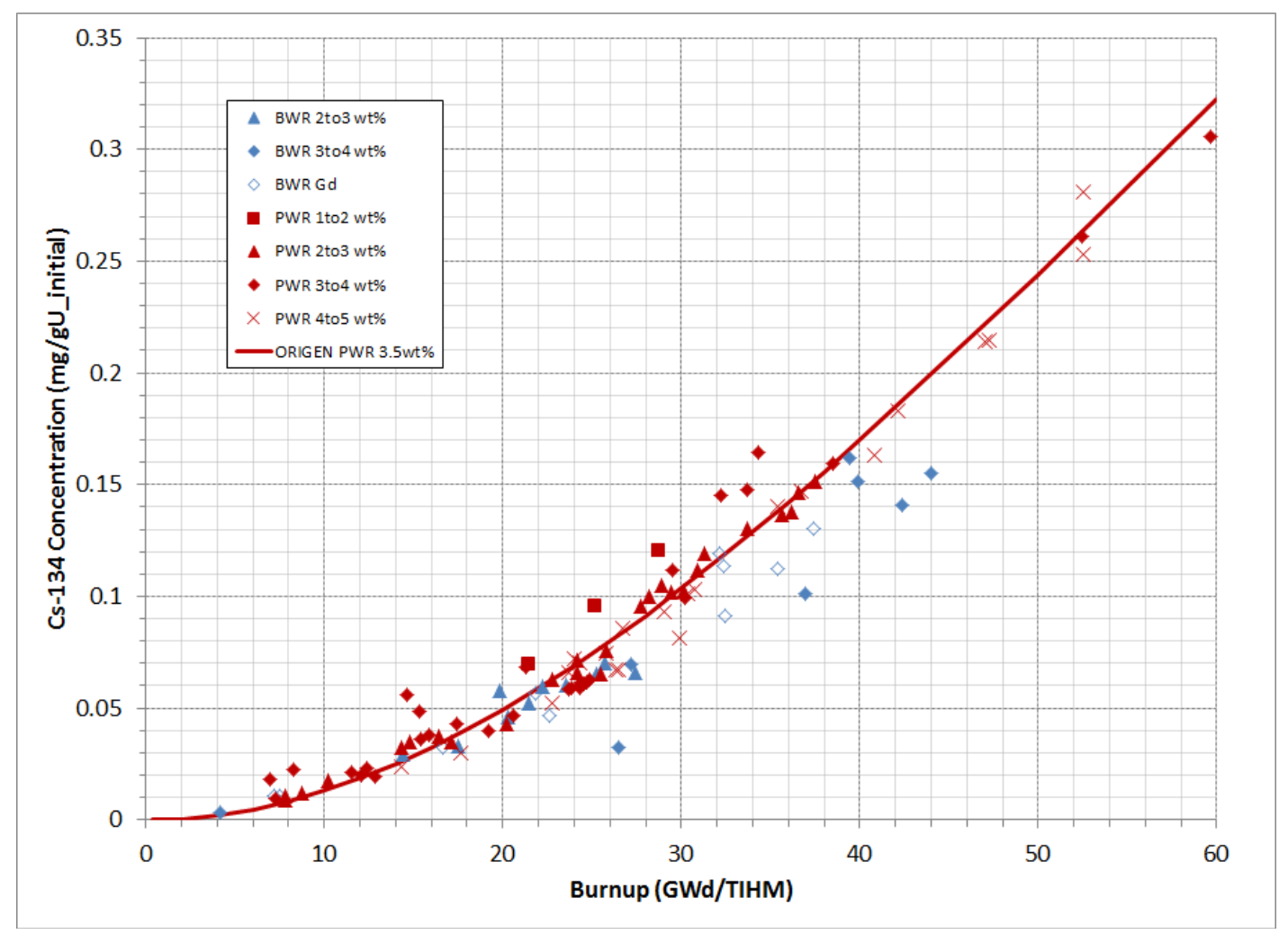

Fig. 78. Cs-134 concentration as a function of burnup.

${ }^{125} \mathrm{Sb}$ has a half-life of 2.7 years and $\beta$-decays to ${ }^{125 \mathrm{~m}} \mathrm{Te}$, which gives off a variety of gamma rays from the excited nucleus. The production of ${ }^{125} \mathrm{Sb}$ primarily comes from the fission of ${ }^{239} \mathrm{Pu}$. However, it is in the valley between the light and heavy fission products on the mass distribution of fission products (see Fig. 74). Therefore, a smaller quantity of ${ }^{125} \mathrm{Sb}$ is produced compared to the quantities for other significant gamma signature isotopes such as ${ }^{134} \mathrm{Cs},{ }^{137} \mathrm{Cs}$, and ${ }^{154} \mathrm{Eu}$. The variations with burnup of ${ }^{125} \mathrm{Sb},{ }^{147} \mathrm{Pm}$, and ${ }^{155} \mathrm{Eu}$ are shown in Figs. $79-81 .{ }^{147} \mathrm{Pm}$ is sometimes measured so that the data for its daughter ${ }^{147} \mathrm{Sm}$ can be decay corrected. When ${ }^{147} \mathrm{Pm}$ is not measured, ${ }^{147} \mathrm{Sm}$ is typically not decay corrected as can be seen by most of the cases in Fig. 59. 


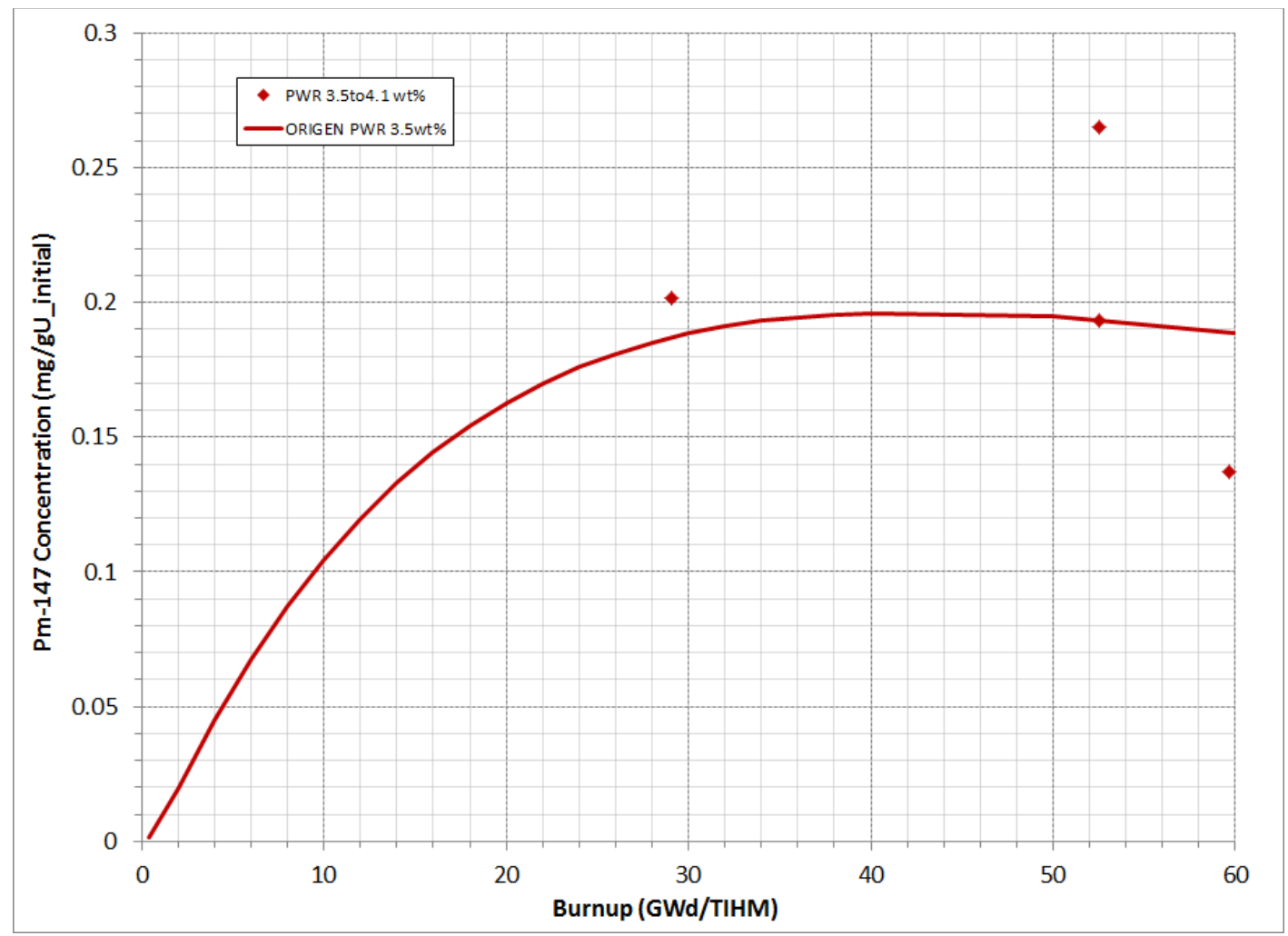

Fig. 79. Pm-147 concentration as a function of burnup.

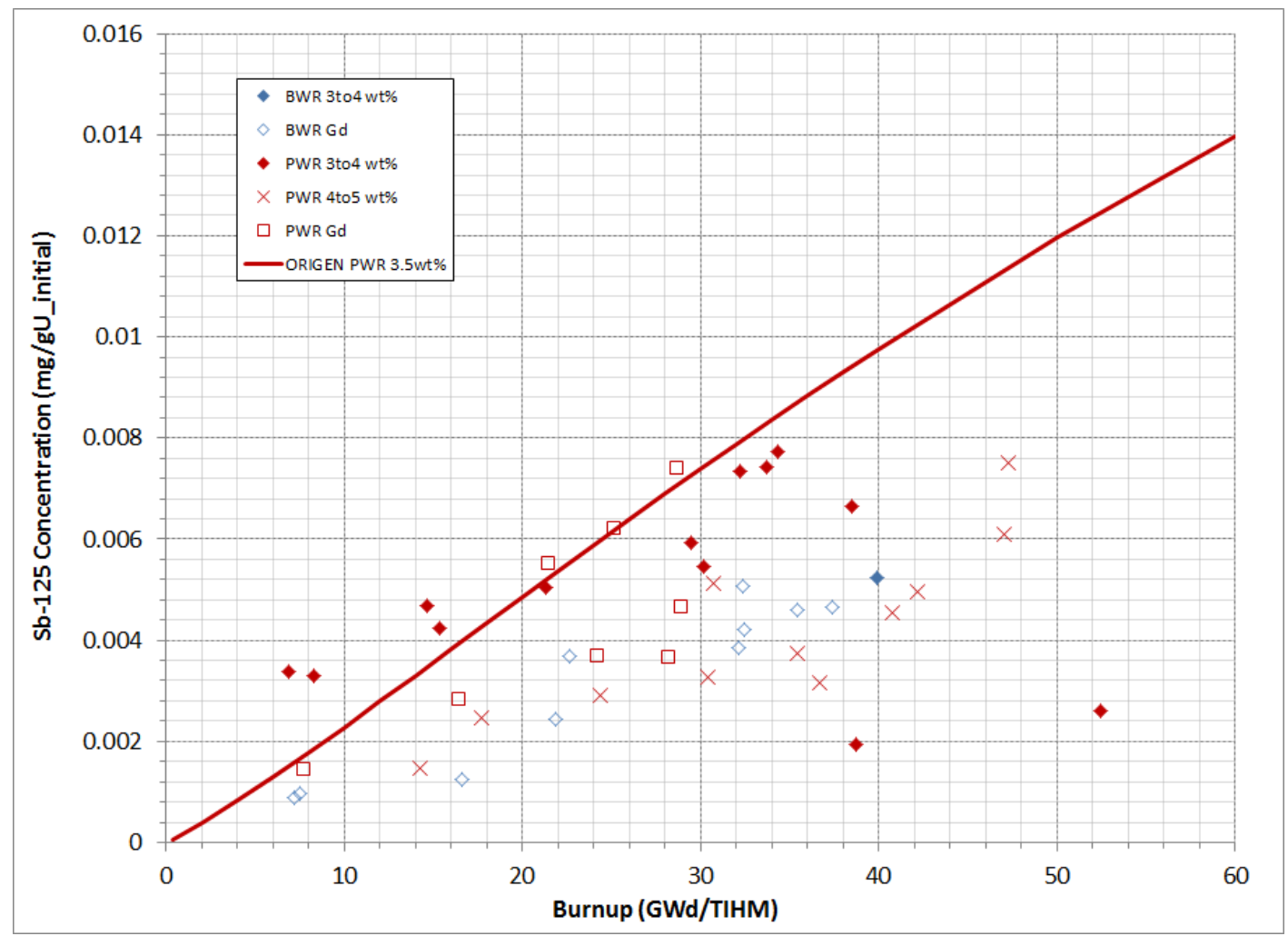

Fig. 80. Sb-125 concentration as a function of burnup. 


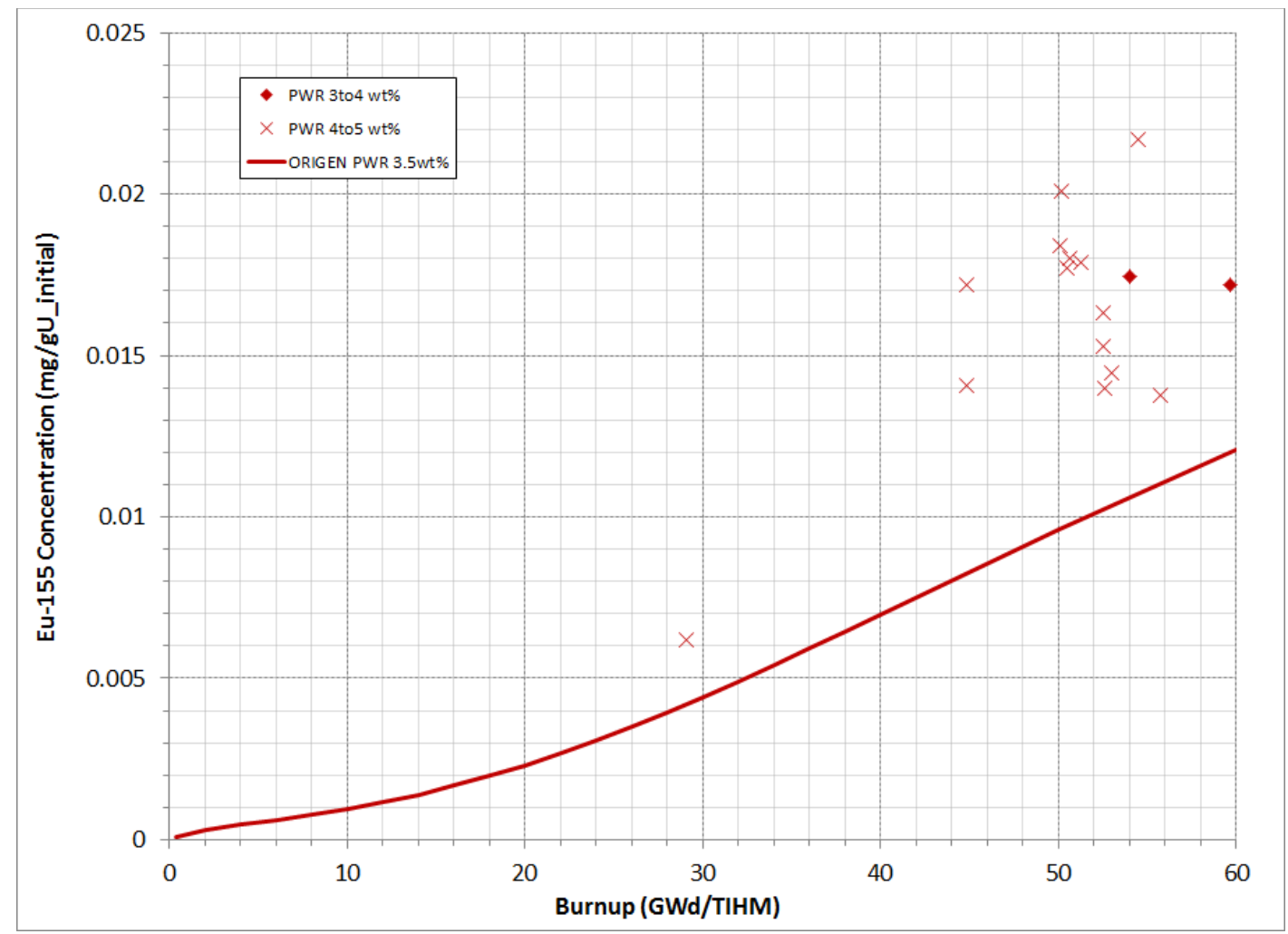

Fig. 81. Eu-155 concentration as a function of burnup.

${ }^{154} \mathrm{Eu}$ is formed by the neutron capture of ${ }^{153} \mathrm{Eu}$ and then further decays to stable ${ }^{154} \mathrm{Gd}$, with a half-life of 8.5 years. The excited nucleus of ${ }^{154} \mathrm{Gd}$ gives off a plethora of gamma rays that can be measured for long periods of time after irradiation. ${ }^{154} \mathrm{Eu}$ is also a shielded isotope; however, it has a large neutron capture cross section, creating a trend that is not as quadratic as for other shielded nuclei. While not clear in Fig. 82, the concentration of ${ }^{154} \mathrm{Eu}$ near the top half of BWR fuel has a larger value than equivalent burnups near the bottom half of the fuel. This effect is due to the spectral change in the neutron flux because of the increased void fraction of the water near the top of the assembly. The BWR data are extracted from Fig. 82 for samples taken from two rods and plotted separately in Fig. 83 to more clearly show the effect of moderator density. The arrows in Fig. 83 show the order of the samples from the bottom of the fuel rods to the top for two different rods. 


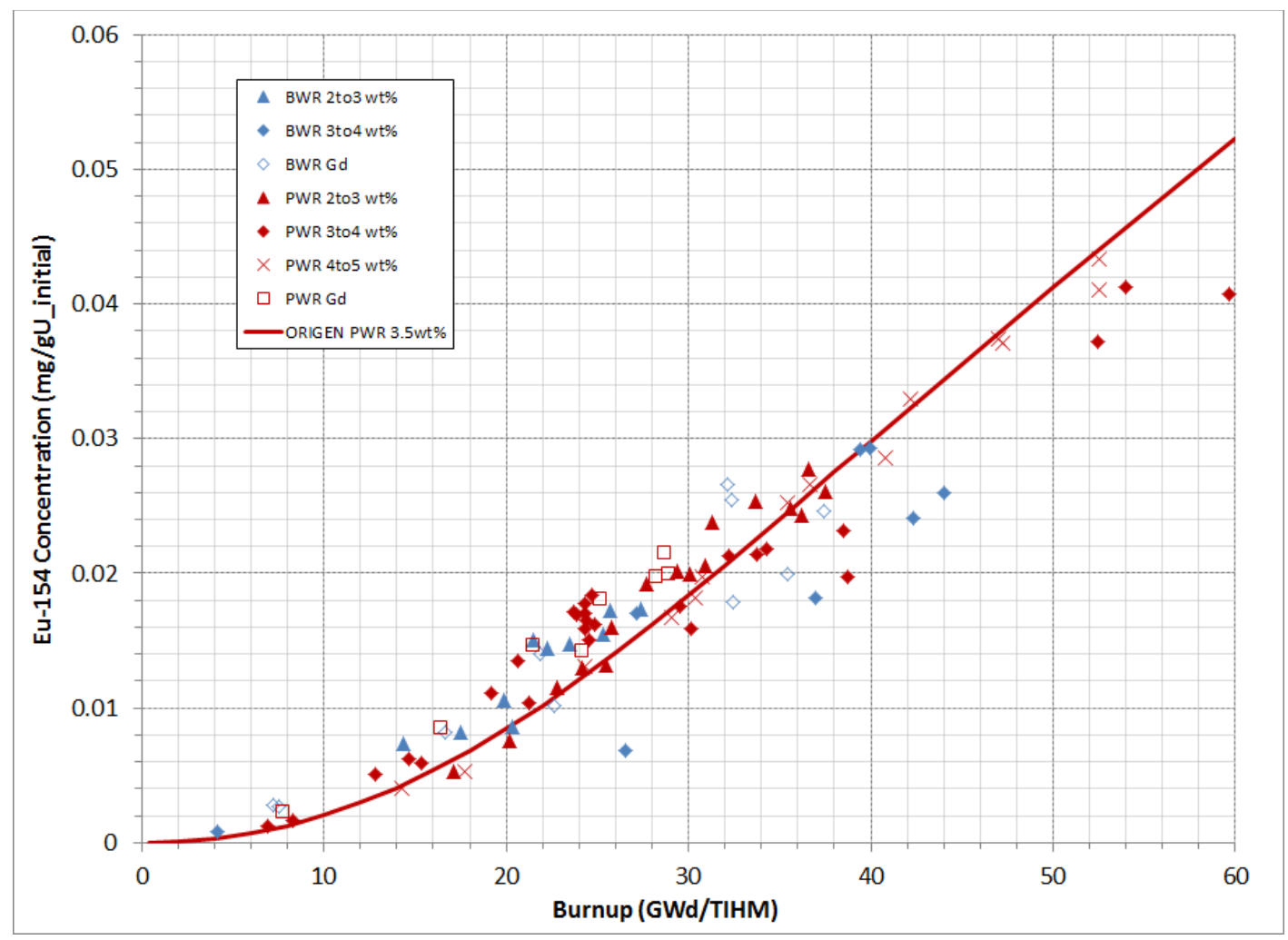

Fig. 82. Eu-154 concentration as a function of burnup.

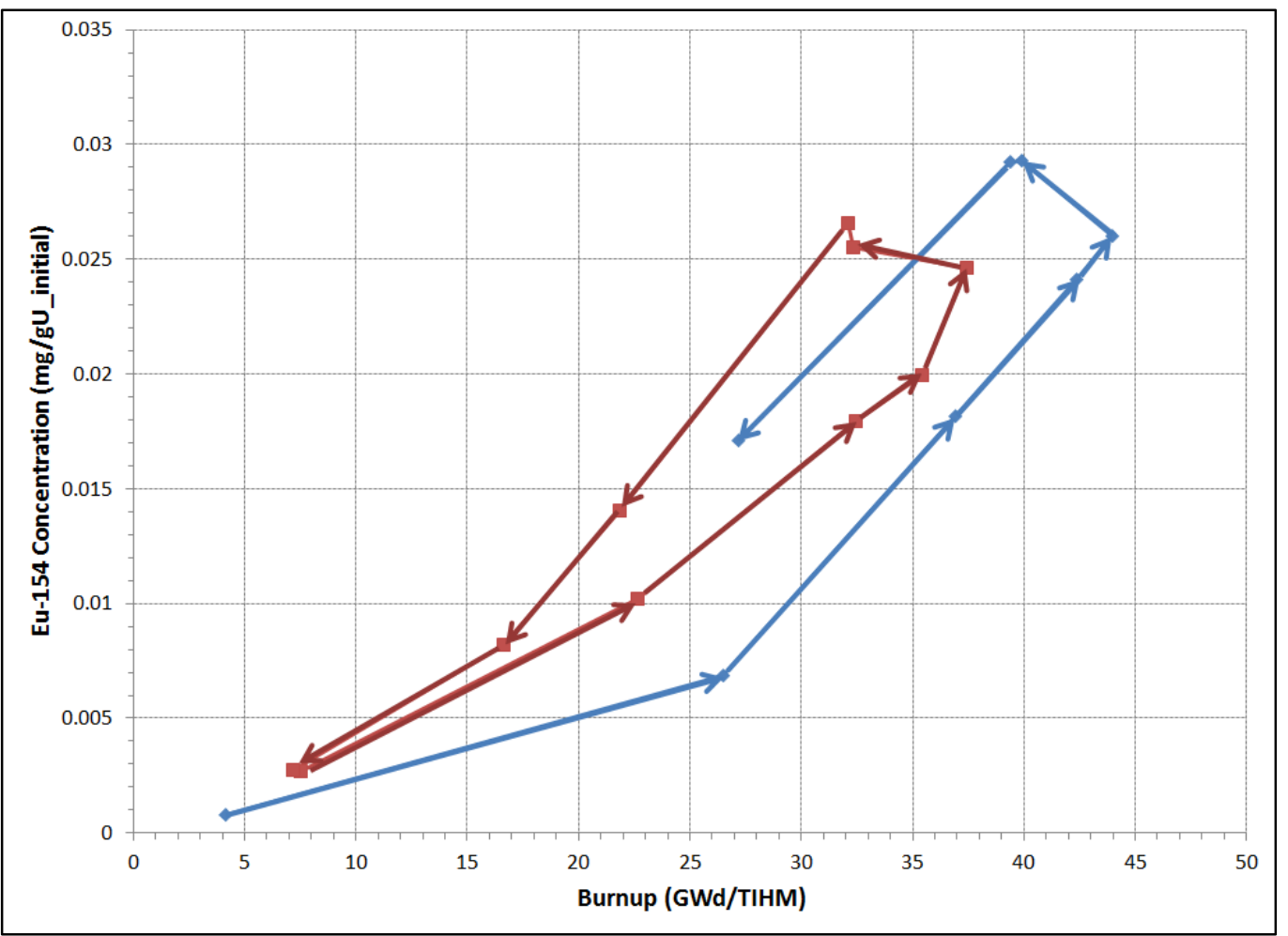

Fig. 83. The effect of a hardened spectrum on Eu-154 concentration in a BWR. 


\subsection{ISOTOPES WITH HALF-LIVES BETWEEN TEN AND ONE HUNDRED YEARS}

${ }^{90} \mathrm{Sr},{ }^{137} \mathrm{Cs}$, and ${ }^{151} \mathrm{Sm}$ have half-lives of 29,30 , and 90 years, respectively. The variations with burnup of these isotopes are illustrated in Figs. $84-86 .{ }^{90} \mathrm{Sr}$ and ${ }^{137} \mathrm{Cs}$ are produced with larger concentrations than ${ }^{151} \mathrm{Sm}$, and they play a significant role in the handling of irradiated fuel. ${ }^{90} \mathrm{Sr}$ decays by $\beta$-decay to stable ${ }^{90} \mathrm{Y} .{ }^{137} \mathrm{Cs}$ decays by $\beta$ decay to ${ }^{137 \mathrm{~m}} \mathrm{Ba}$, which gives off a signature single $661 \mathrm{keV}$ gamma ray. ${ }^{137} \mathrm{Cs}$ meets many of the criteria listed in determining burnup via the use of fission product burnup monitors given in Section 5.2. One advantage of using ${ }^{137} \mathrm{Cs}$ over ${ }^{148} \mathrm{Nd}$ as burnup indicator is the $661 \mathrm{keV}$ gamma ray associated with ${ }^{137} \mathrm{Cs}$; therefore, nondestructive measurements can be made of nuclear fuel to determine the concentration of ${ }^{137} \mathrm{Cs}$, which can then be used to infer the burnup, whereas, destructive measurements are required for determining the common burnup monitor, ${ }^{148} \mathrm{Nd}$.

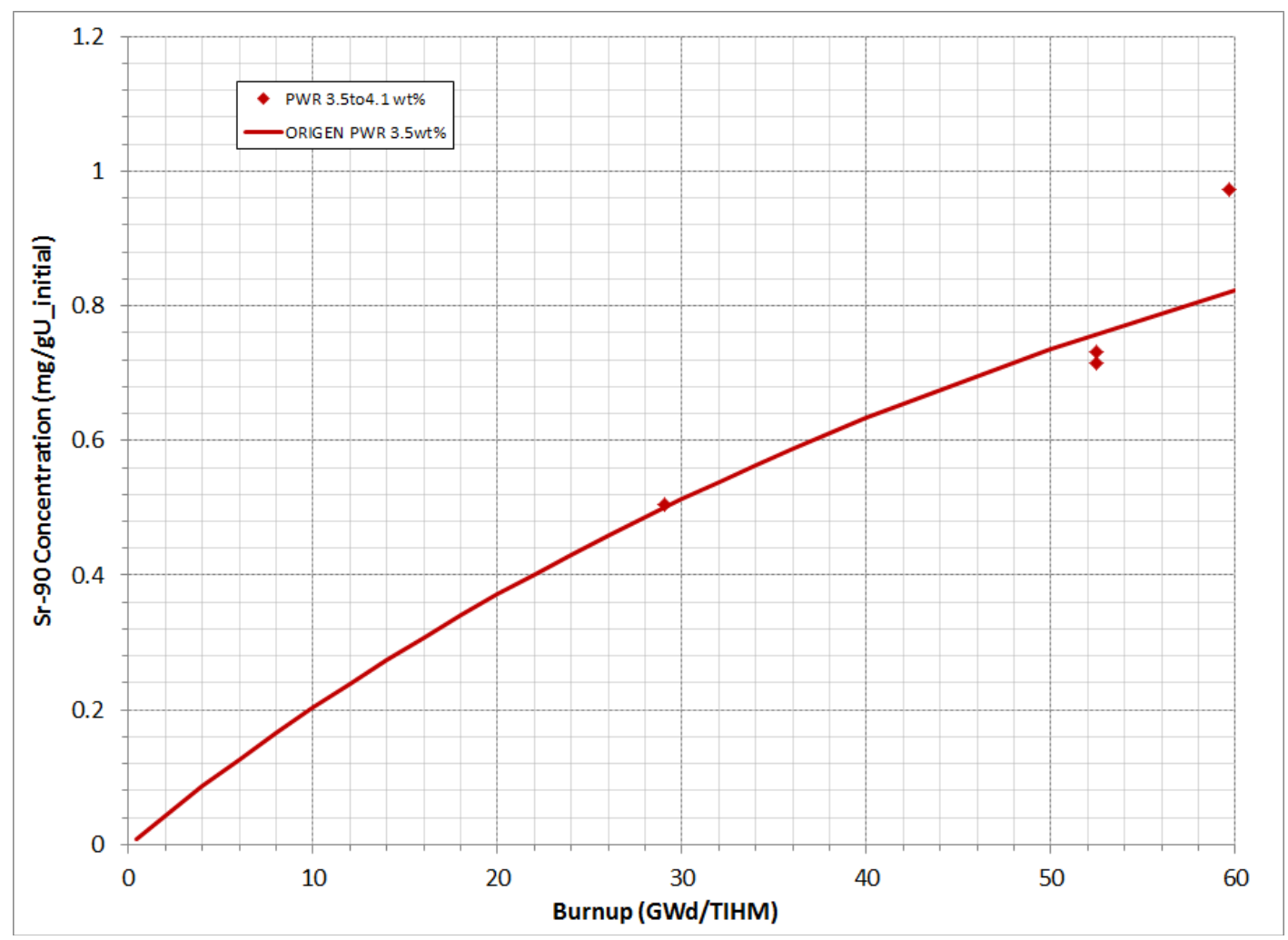

Fig. 84. Sr-90 concentration as a function of burnup. 


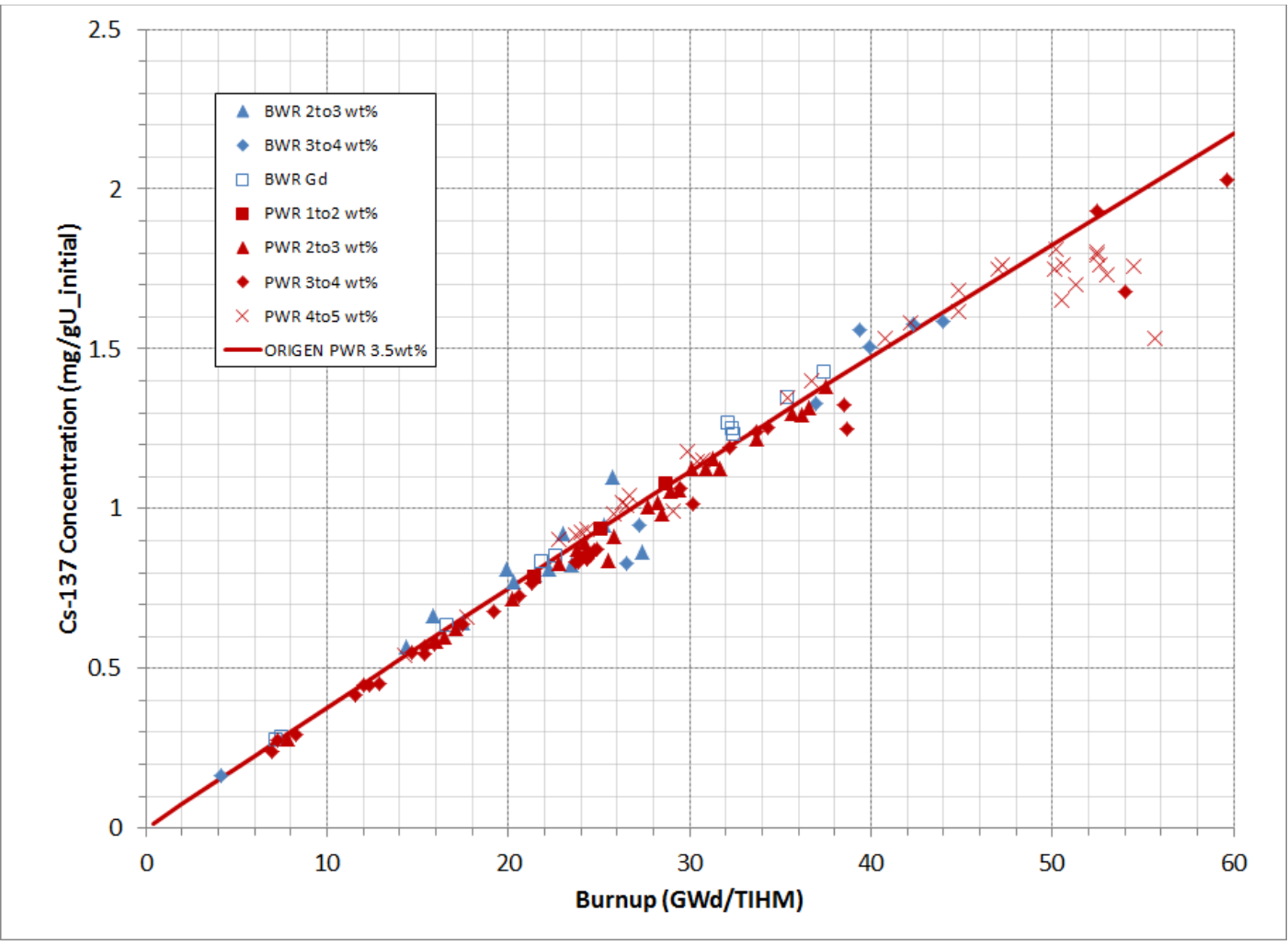

Fig. 85. Cs-137 concentration as a function of burnup.

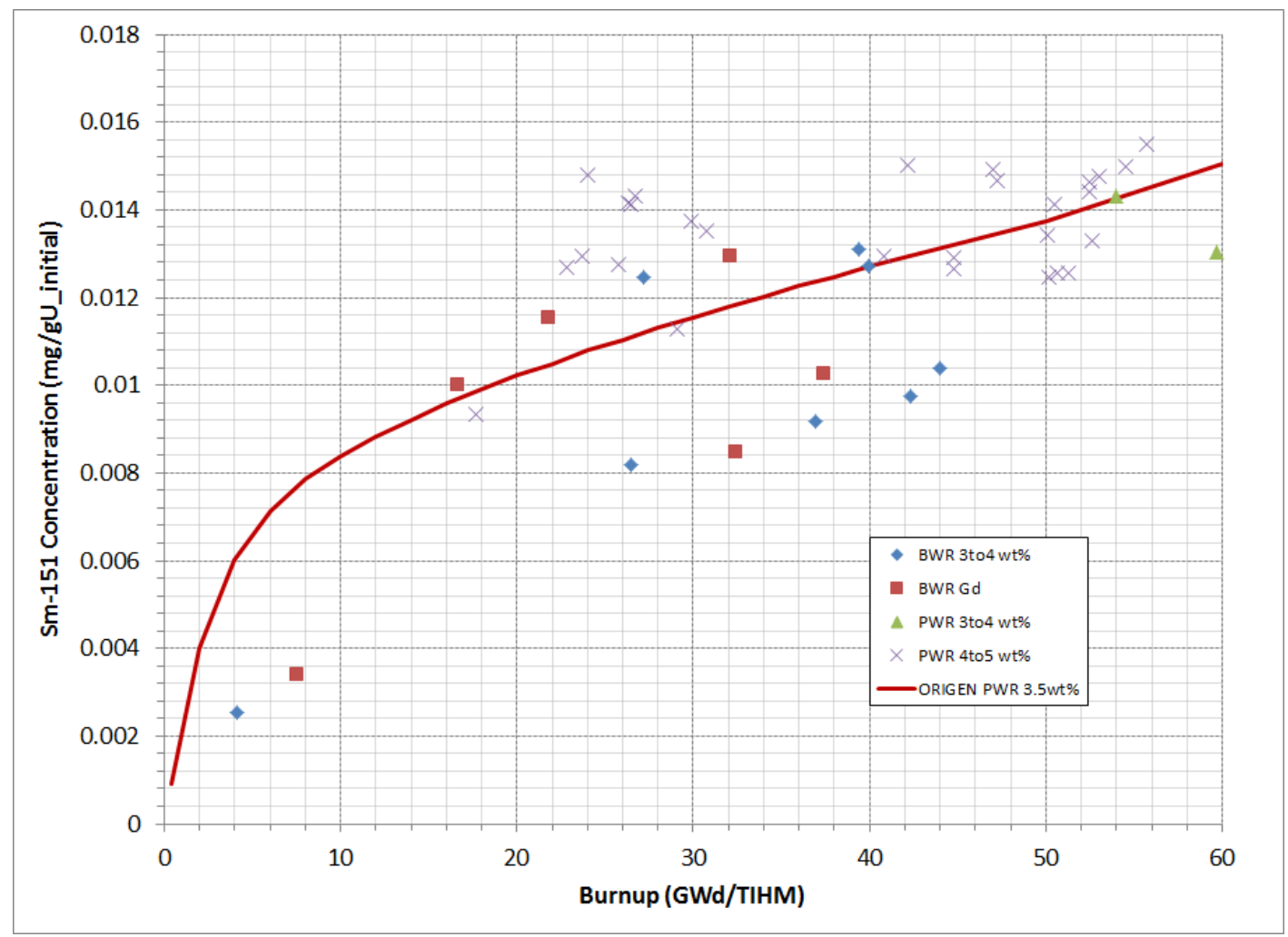

Fig. 86. Sm-151 concentration as a function of burnup. 


\subsection{ISOTOPES WITH HALF-LIVES GREATER THAN ONE HUNDRED YEARS}

${ }^{99} \mathrm{Tc},{ }^{135} \mathrm{Cs}$, and ${ }^{129} \mathrm{I}$ have half-lives of $2.11 \mathrm{E} 5 ; 2.3 \mathrm{E} 6$; and $1.57 \mathrm{E} 7$ years, respectively. Therefore, these isotopes receive a lot of focus on long-term storage of nuclear waste, especially ${ }^{99} \mathrm{Tc}$. The variations with burnup of these isotopes are illustrated in Figs. $87-89 .{ }^{135} \mathrm{Xe}$ is the precursor to ${ }^{135} \mathrm{Cs}$ and has a very large absorption cross section; therefore, a large amount of ${ }^{135} \mathrm{Xe}$ atoms will become ${ }^{136} \mathrm{Xe}$ rather than decaying to ${ }^{135} \mathrm{Cs} .{ }^{129} \mathrm{I}$ is volatile, and if it can escape the fuel matrix, it will migrate relatively easily through a reactor's system. ${ }^{32}$

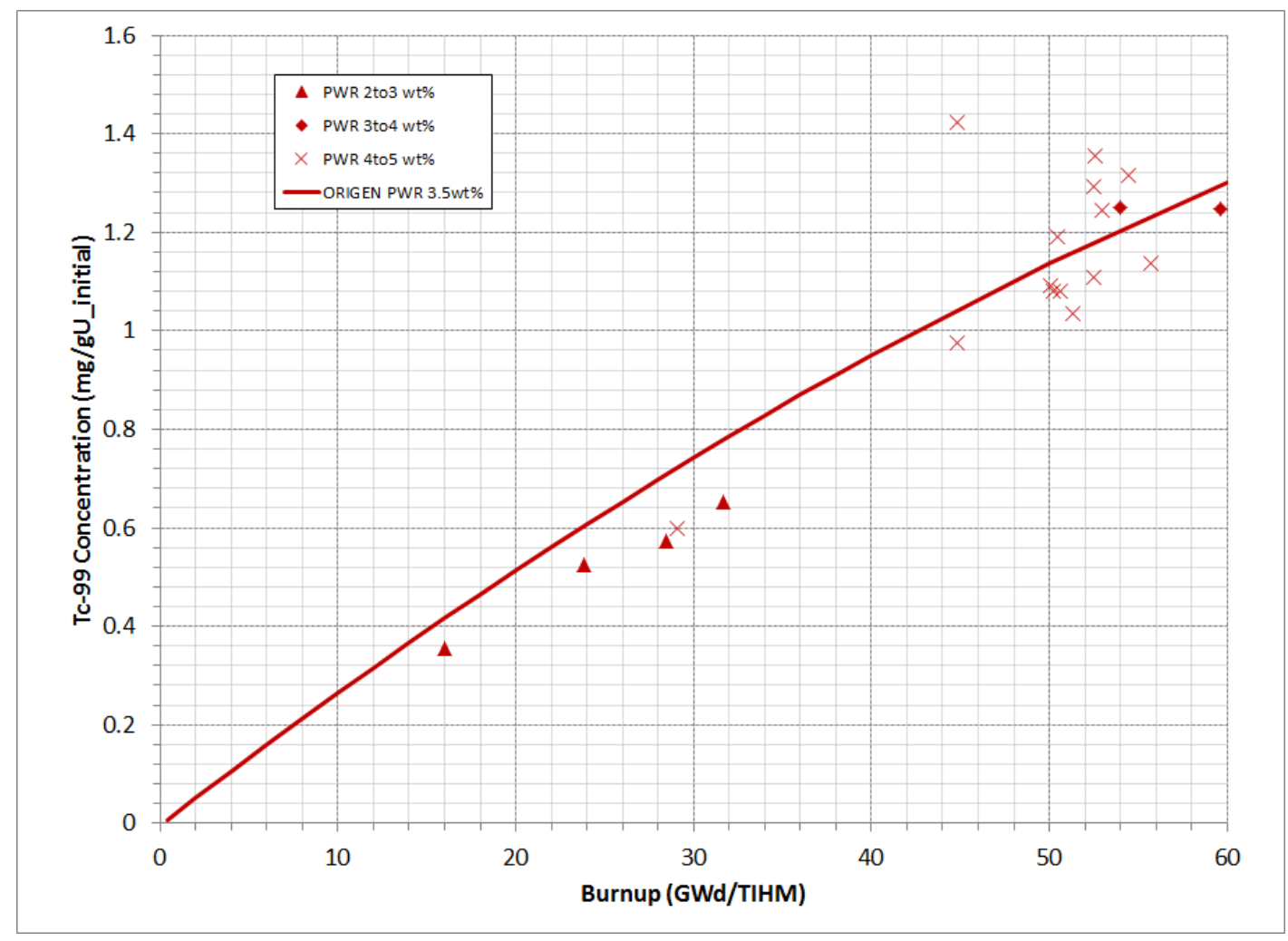

Fig. 87. Tc-99 concentration as a function of burnup. 


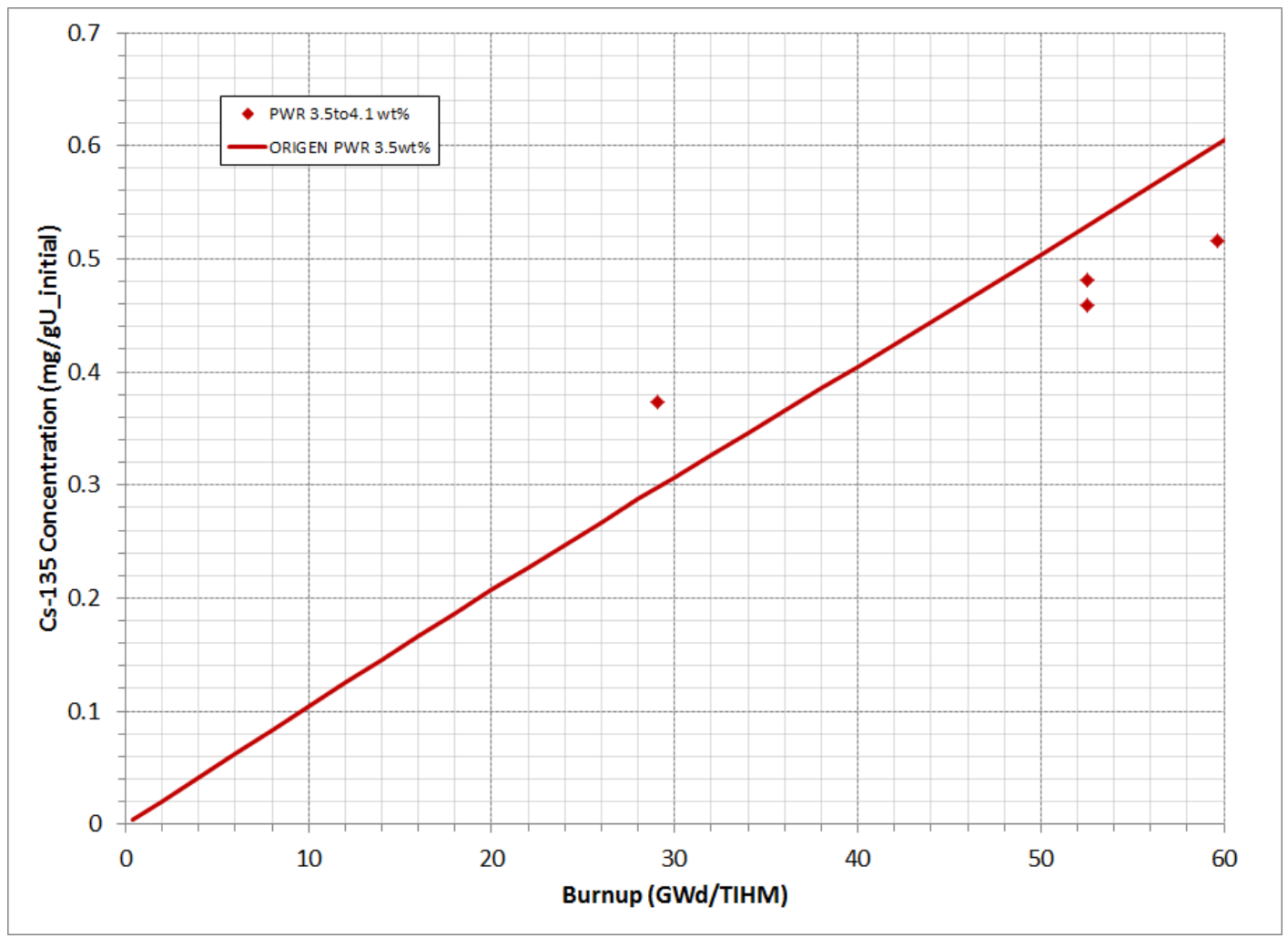

Fig. 88. Cs-135 concentration as a function of burnup.

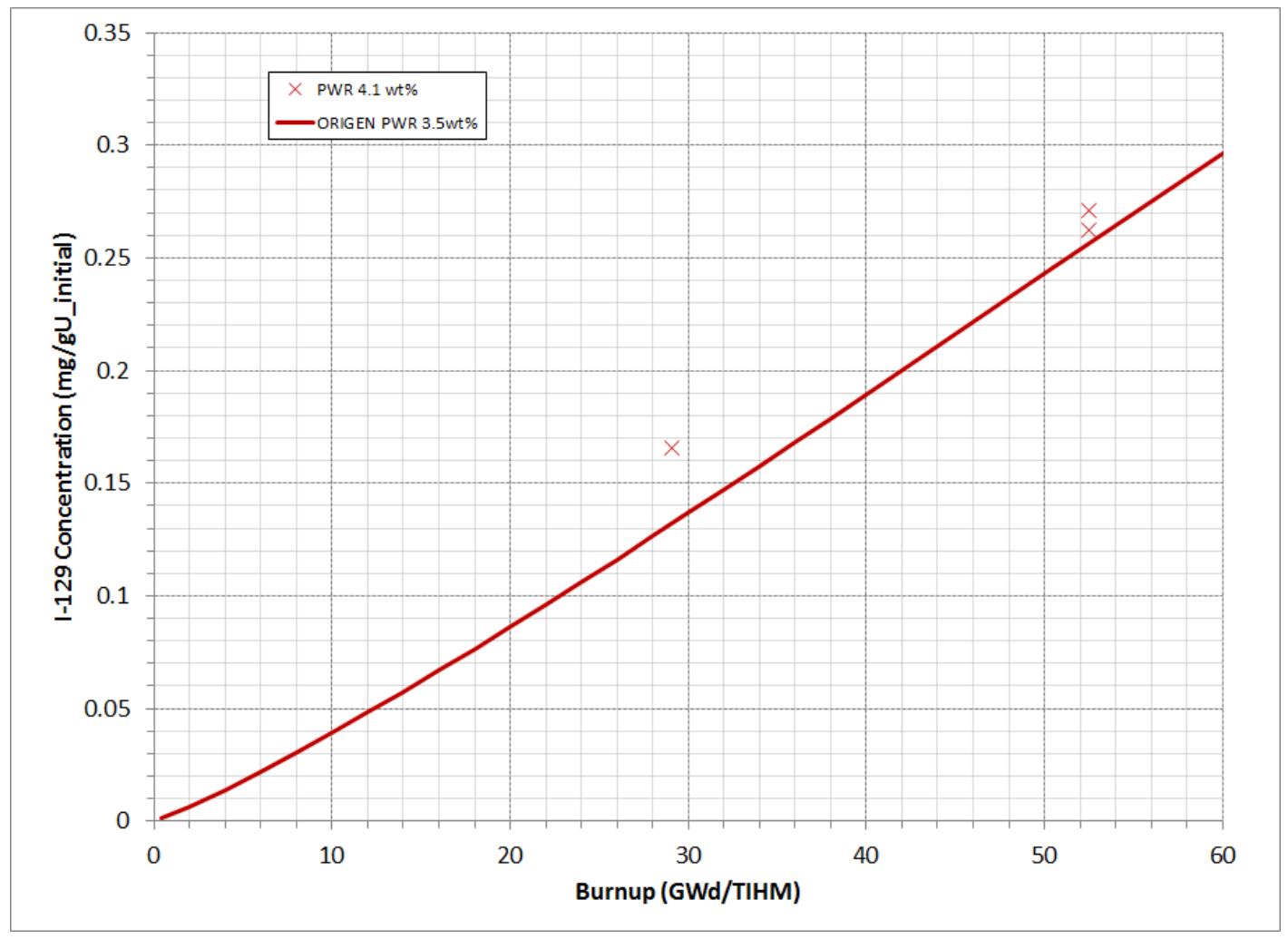

Fig. 89. I-129 concentration as a function of burnup. 


\subsection{MODEL VALIDATION OF RADIOACTIVE FISSION PRODUCTS}

The average calculated-to-experimental values for several radioactive fission products can be seen in Fig. 90 for PWRs ${ }^{27}$ and in Fig. 91 for BWRs. ${ }^{19}$ Due to its very large C/E value (on the order of 1.996 for the PWR data set), ${ }^{125} \mathrm{Sb}$ results are not included in the figures. In general, a larger uncertainty exists for modeling the radioactive fission products compared to either the actinides or the stable fission products. For both the PWR and BWR data, the models predict ${ }^{137} \mathrm{Cs}$ within a few percent of the measurement data. As seen in the work of Ilas et al. ${ }^{27}$ it is anticipated that the $\mathrm{C} / \mathrm{E}$ values for ${ }^{154} \mathrm{Eu}$ and ${ }^{134} \mathrm{Cs}$ would improve for the BWR analysis if they were modeled using the ENDF/B-VII library. However, it is not anticipated that the other isotopes would see much of an improvement. At the same time, many of the uncertainties for the PWR results trend in the opposite direction of the BWR results. Future efforts need to look into the cause of these different trends. For reactor types other than PWRs and BWRS, limited or no radioactive fission product data exist in the current data sets.

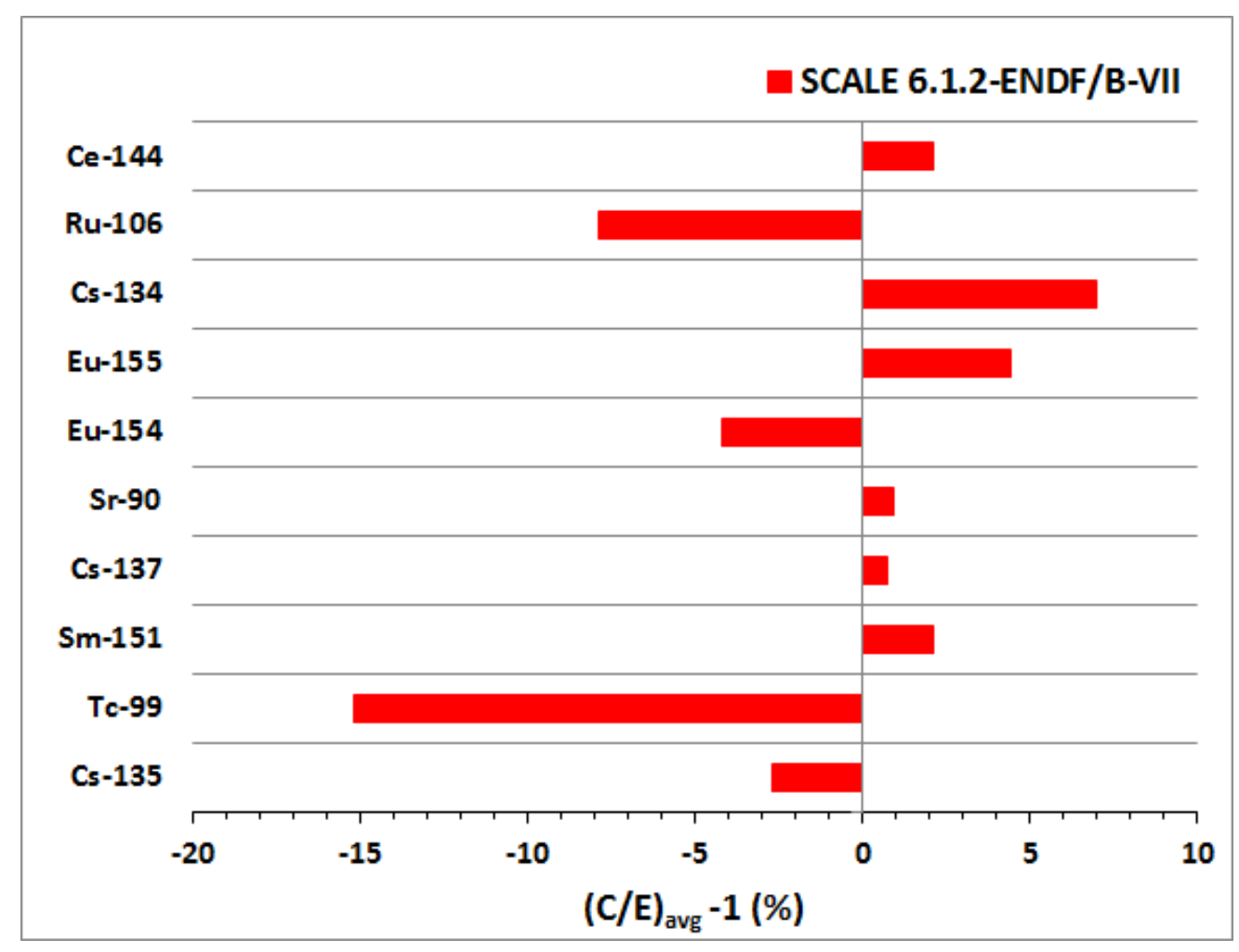

Fig. 90. Radioactive fission products C/E average for PWR simulation. ${ }^{27}$ 


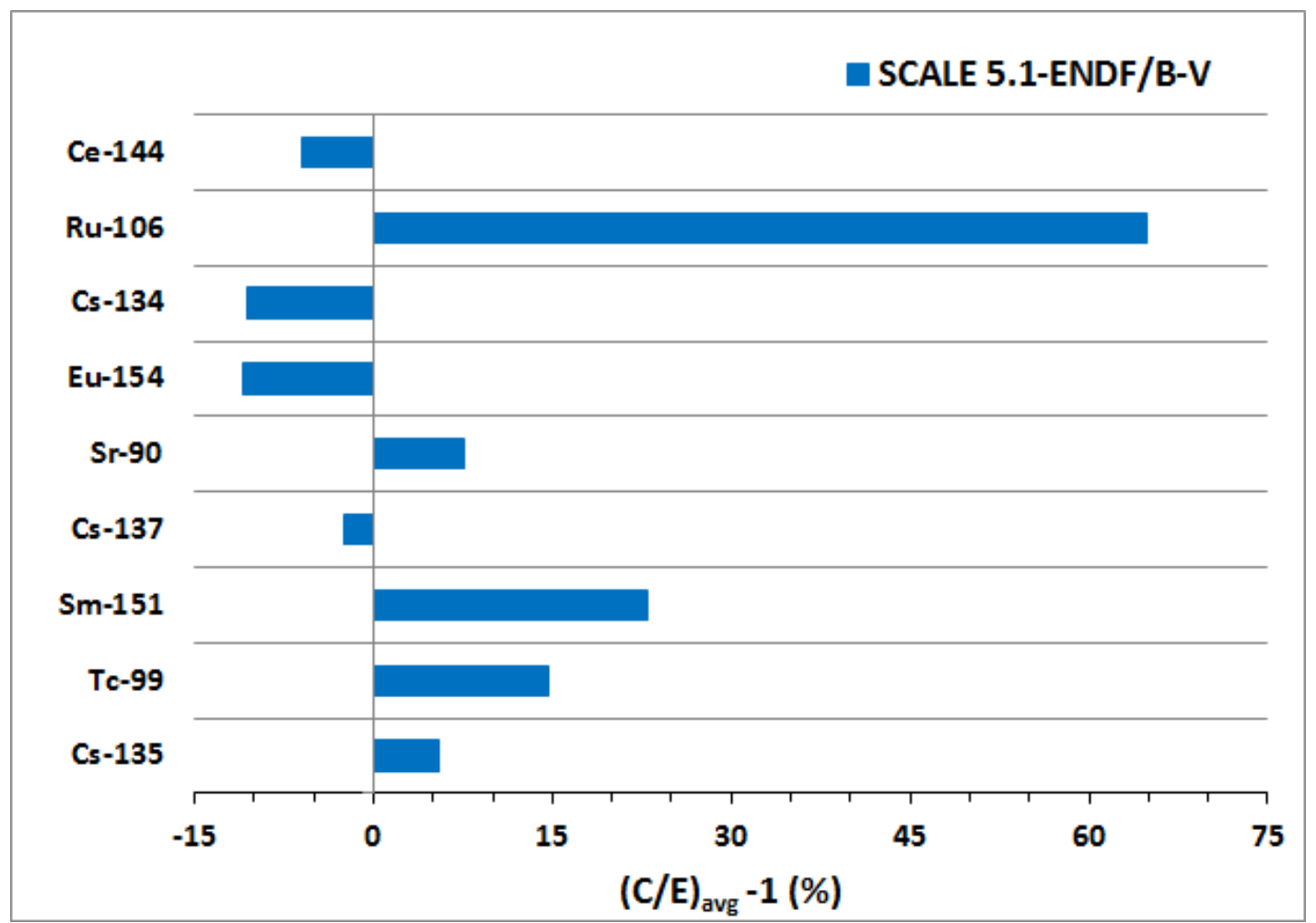

Fig. 91. Radioactive fission products C/E average for BWR simulation. ${ }^{19}$ 


\section{CONCLUSION}

Throughout this report, the diversity of isotopic data for a variety of reactor types was presented, and the current accuracy of depletion modeling was summarized. Special focus was given to the ORIGEN irradiation and decay simulation code in the SCALE nuclear systems modeling and simulation suite. While evaluating fission product noble gas data and comparing it to modeled predictions, an inconsistency was identified in the data on independent yields, cumulative yields, and decay schemes as available in ENDF/B-VII.1. The independent yield values were adjusted to be consistent and were implemented in the most recent beta release of SCALE.

In general, the major actinides were predicted within $5 \%$ of their measured values. The one exception was for the low-burnup Hanford B data, as noted in Reference 28. Future work should focus on understanding these large discrepancies and seeking out more well-qualified data that apply to this lowburnup regime. On average, the calculated values for ${ }^{234} \mathrm{U},{ }^{238} \mathrm{Pu}$, and ${ }^{241} \mathrm{Am}$ were within $10 \%$ of the experiment. Large improvements were seen for several of the curium isotopes when using improved cross section data found in ENDF/B-VII, compared to ENDF/B-V. The relatively large under prediction for ${ }^{242} \mathrm{Cm}$ needs further investigation.

After correcting the inconsistency identified in the fission yield data, the stable xenon and krypton fission products were predicted to within 5\% of the measurement. Preliminary results not explicitly shown in this report indicate that the calculated radioactive ${ }^{85} \mathrm{Kr}$ concentrations range from within a few percent to approximately $10 \%$ of the measurement data after using the new consistent yield data. This isotope was one of the largest impacted due to the legacy data issues. Due to complex migration of noble gases in fuel, more thorough investigation is needed to understand the ability of depletion codes to accurately calculate the noble gas concentrations.

The stable neodymium and samarium isotopes were predicted to within a few percent of the experimental data. Large improvements were seen in prediction for a few of the samarium isotopes when using the ENDF/B-VII libraries. Very accurate values were obtained for ${ }^{133} \mathrm{Cs}$ and ${ }^{153} \mathrm{Eu}$. The predicted values for the stable ruthenium and rhodium isotopes were within $10 \%$ of the measurement values. In general, a larger uncertainty exists for modeling the radioactive fission products compared to either the actinides or the stable fission products. The calculated data matched measurements of ${ }^{137} \mathrm{Cs}$ to within a few percent. On the other hand, calculated data deviated from measurements of ${ }^{106} \mathrm{Ru}$ and ${ }^{125} \mathrm{Sb}$ by $60 \%$ to $100 \%$, respectively.

In conclusion, while extensive work has been performed in validating the SCALE depletion tools, more validation studies are needed for reactors other than PWRs and BWRs. Specifically, more actinide data are needed for well characterized VVER, RBMK, CANDU, MAGNOX, and AGR reactor types. Actinide data are also needed for very low burnups to understand the current deviations observed in modeling the Hanford B experiments. Also, measured fission product data are, in general, very limited for reactors other than PWRs and BWRs. 


\section{REFERENCES}

1. Hermann, O.W., DeHart, M.D., Murphy, B.D., 1998. Evaluation of Measured LWR Spent Fuel Composition Data for Use in Code Validation End-User Manual. ORNL/M-6121.

2. Kurosawa, M., Naito, Y., Sakamoto, T., 1997. The Isotopic Composition Database System on Spent Fuels in Light Water Reactors (SFCOMPO). JAERI-Data/Code 96-036.

3. Mochizuki, H., Suyama, K., Nomura, Y., Okuno, H., 2001. Spent Fuel Composition Database System on WWW. JAERI-Data/Code 2001-020. (in Japanese)

4. SFCOMPO (Original) Database., 2001. http://www.oecd-nea.org/sfcompo

5. Suyama, K., Nouri, A., 2003. Improvements to SFCOMPO - A Database on Isotopic Composition of Spent Nuclear Fuel. Proceedings of the International Conference on Nuclear Criticality ICNC-2003, Tokai-Mura, Japan.

6. Michel-Sendis, F., Bossant, M., Soppera, N., Gauld, I., 2014. A New OECD/NEA Database of Nuclide Compositions of Spent Nuclear Fuel. PHYSOR 2014 - The Role of Reactor Physics Toward a Sustainable Future, The Westin Miyako, Kyoto, Japan.

7. Gauld, I., Sly, N., Michel-Sendis, F., 2014. OECD NEA Benchmark Database of Spent Nuclear Fuel Isotopic Compositions for World Reactor Designs. PHYSOR 2014 - The Role of Reactor Physics Toward a Sustainable Future, The Westin Miyako, Kyoto, Japan.

8. Tait, J.C., Gauld, I., Kerr, A.H., 1995. Validation of the ORIGEN-S code for predicting radionuclide inventories in used CANDU fuel. Journal of Nuclear Materials 223 (2), 109.

9. DeHart, M.D., Brady, M.C., Parks, C.V., 1996. OECD/NEA burnup credit calculational criticality benchmark phase I-B results. Technical Report ORNL/TM-6901, Oak Ridge National Laboratory.

10. Hermann, O.W., Bowman, S.M., Brady, M.C., Parks, C.V., 1996. Validation of the SCALE system for PWR spent fuel isotopic composition analyses. Technical Report ORNL/TM-12667, Oak Ridge National Laboratory.

11. Gauld, I.C., Ryman, J.C., 2000. Nuclide importance to criticality safety, decay heating, and source terms related to transport and interim storage of high-burnup LWR fuel. Technical Report NUREG/CR-76700, US Nuclear Regulatory Commission.

12. Ilas, G., Murphy, B.D., Gauld, I.C., 2007. Overview of ORIGEN-ARP and its Application to VVER and RBMK. CD Proceedings of American Nuclear Society, Washington, D.C.

13. Ilas, G., Gauld, I.C, 2008. Analysis of isotopic assay data from the MALIBU program. In: CD Proceedings of PHYSOR 2008.

14. Fensin, L.M., Hendricks, J.S., Anghaie, S., 2008. MCNPX 2.6 depletion method enhancements and testing. In: CD Proceedings of PHYSOR 2008.

15. Garcia-Herranz, N., Cabellos, O., Sanz, J., Juan, J., Kuijper, J.C., 2008. Propagation of statistical and nuclear data uncertainties in Monte Carlo burn-up calculations. Annals of Nuclear Energy 35 (4), 714.

16. Radulescu, G., Gauld, I.C., Ilas, G., 2009. Evaluation of PWR isotopic composition data. ANS Transactions 101, 688 .

17. Gauld, I.C., Radulescu, G., Ilas, G., 2009. SCALE validation experience using an expanded isotopic assay database for spent nuclear fuel. In: CD Proceedings of International BUC Workshop, Cordoba, Spain.

18. Ilas, G., Gauld, I.C., 2009. SCALE 6 analysis of isotopic assay benchmarks for PWR spent fuel. ANS Transactions 101, 691 .

19. Mertyurek, U., Francis, M.W., Gauld, I.C., 2010. SCALE 5 Analysis of BWR Spent Nuclear Fuel Isotopic Compositions for Safety Studies. Technical Report ORNL/TM-2010/286, Oak Ridge National Laboratory. 
20. Ilas, G., Gauld, I.C., Difilippo, F.C., Emmett, M.B., 2010. Analysis of experimental data for high burnup PWR spent fuel isotopic validation - Calvert Cliffs, Takahama, and Three Mile Island reactors. Technical Report NUREG/CR-6968, US Nuclear Regulatory Commission.

21. Ilas, G., Gauld, I.C., Murphy, B.D., 2010. Analysis of experimental data for high burnup PWR spent fuel isotopic validation - ARIANE and REBUS programs (UO2 fuel). Technical Report NUREG/CR-6969, US Nuclear Regulatory Commission.

22. Fensin, L.M., Hendricks, J.S., Anghaie, S., 2010. The enhancements and testing for the MCNPX 2.6.0 depletion capability. Nuclear Technology 170, 68 .

23. Radulescu, G., Gauld, I.C., Ilas, G., 2010. SCALE 5.1 Predictions of PWR Spent Nuclear Fuel Isotopic Compositions. Technical Report ORNL/TM-2010/44, Oak Ridge National Laboratory.

24. Gauld, I.C., Ilas, G., Radulescu, G., 2011. Uncertainties in Predicted Isotopic Compositions for High Burnup PWR Spent Nuclear Fuel. Technical Report NUREG/CR-7012, US Nuclear Regulatory Commission.

25. Ilas, G., Gauld, I.C., 2011. Analysis of Experimental Data for High Burnup PWR Spent Fuel Isotopic Validation-Vandellos II Reactor. Technical Report NUREG/CR-7013, US Nuclear Regulatory Commission.

26. Martinez, J.S., Cabellos, O., Diez, C.J., Gilfillan, F., Barbas, A., 2011. Isotopic prediction calculation methodologies: application to Vandellos-II reactor cycles 7-11. In: CD Proceedings of the International Conference on Mathematics and Computational Methods Applied to Nuclear Science and Engineering M\&C 2011.

27. Ilas, G., Gauld, I.C., Radulescu, G. 2012. Validation of new depletion capabilities and ENDF/BVII data libraries in SCALE. Annals of Nuclear Energy 46, 43-55.

28. Ilas, G., Gauld, I.C., Westfall, R.M., Pigni, M. 2014. Evaluation of Hanford B Reactor Experiments (PTA-069 and PTA-084) for Code and Data Benchmarking. Technical Report ORNL/TM-2014/53, Oak Ridge National Laboratory.

29. International Fuel Performance Experiments (IFPE) Database. 2012. https://www.oecdnea.org/science/wprs/fuel/ifpelst.html

30. Gauld, I.C., Radulescu, G., Ilas, G., Murphy, B.D., Williams, M.L., Wiarda, D., 2011. "Isotopic depletion and decay methods and analysis capabilities in SCALE", Nuclear Technology, vol.174, no.2, p.169.

31. Duderstadt, J. J., Hamilton, L.J., 1976. Nuclear Reactor Analysis, John Wiley \& Sons, New York.

32. Neeb, K. H., 1997. The Radiochemistry of Nuclear Power Plants with Light Water Reactors. Walter de Gruyter, Berlin.

33. Lin, C. C., 1996. Radiochemistry in Nuclear Power Reactors. National Academy Press, Washington, D.C.

34. Albright, D., Berkhout, F., Walker, W. 1992. World Inventory of Plutonium and Highly Enriched Uranium. Oxford University Press, New York.

35. Pearce, J. H., Sumerling, R., Hargreaves, R., 1983. Studies of the Radial Distribution of Pu, Xe and Cs in Irradiated Thermal-Reactor $\mathrm{UO}_{2}$ Fuel, using an Electron Probe Microanalyser. Journal of Nuclear Materials, Volume 116, pg. 1-9.

36. Table of Nuclides. http://atom.kaeri.re.kr. Nuclear Data Center, Korea Atomic Energy Research Institute (visited January 2014).

37. Soppera, N., Dupont, E., Bossant, M., 2012. JANIS Book of proton-induced cross sections: Comparison of evaluated and experimental data from ENDF/B-VII.1, JENDL/HE-2007, PADF2007, TENDL-2011 and EXFOR. OECD NEA Data Bank, AEN NEA, June.

38. Jessee, M.A., DeHart, M.D., 2011. NEWT: A New Transport Algorithm for Two-Dimensional Discrete-Ordinates Analysis in Non-Orthogonal Geometries, Oak Ridge National Laboratory, ORNL/TM-2005/39, Version 6.1, Sect F21.

39. Jessee, M.A., DeHart, M.D., 2011. TRITON: A Multipurpose Transport, Depletion, and Sensitivity and Uncertainty Analysis Module, Oak Ridge National Laboratory, ORNL/TM2005/39, Version 6.1, Sect T1. 
40. Olander, D. R., 1978. Fundamental Aspects of Nuclear Reactor Fuel Elements. Technical Information Center, U.S. Department of Energy.

41. Manzel, R., Sontheimer, F., Wurtz, R., 1984. The Radial Distribution of Fission Gases and Other Fission Products in Irradiated PWR Fuel. Journal of Nuclear Materials, Volume 126, 1984, pg. 132-143.

42. Kleykamp, H., 1985. The Chemical State of the Fission Products in Oxide Fuels. Journal of Nuclear Materials, Volume 131,pg. 221-246.

43. Ronchi, C., Walker, C. T., 1980. Determination of Xenon Concentrations in Nuclear Fuels by Microprobe Analysis. Journal of Physics D: Applied Physics, Volume 13, pg. 2175-2184.

44. Goll, W., Fuchs, H., Manzel, R., Schlemmer, F.U., 1993. Irradiation Behavior of $\mathrm{UO}_{2} / \mathrm{PuO}_{2}$ Fuel in Light Water Reactors. Nuclear Technology, Volume 102, April, pg. 29-46.

45. Lewis, W. B., MacEwan, J.R., Stevens, W. H., Hart, R.G., 1964. Fission-gas Behaviour in $\mathrm{UO}_{2}$ Fuel. Proceedings of the International Conference on the Peaceful Uses of Atomic Energy, Volume 11, pg. 405-413.

46. Notley, M. J. F., 1970. A Computer Program to Predict the Performance of $\mathrm{UO}_{2}$ Fuel Elements Irradiated at High Power Outputs to a Burnup of 10,000 MWd/MTU. Nuclear Applications \& Technology, Volume 9, August, pg. 195-204.

47. MacEwan, J. R., Bain, A. S., Notley, M. J. F., Jones, R. W., 1971. Irradiation Experience with Fuel for Power Reactors. Proceedings of the Fourth International Conference on the Peaceful Uses of Atomic Energy, Volume 10, pg. 239-256.

48. Notley, M. J. F., MacEwan, J. R., 1966. Stepwise Release of Fission Gas from $\mathrm{UO}_{2}$ Fuel. Nuclear Applications, Volume 2, December, pg. 477-480.

49. Uffelen, P. V., Konings, R. J. M., Vitanza, C., Tulenko, J., 2010. Chapter 13: Analysis of Reactor Fuel Rod Behavior. Handbook of Nuclear Engineering, Springer.

50. Lewis, W. B., 1966. Engineering for the Fission Gas in $\mathrm{UO}_{2}$ Fuel. Nuclear Applications, Volume 2, April, pg 171-181.

51. Notley, M. J. F., MacEwan, J. R., 1966. The Effect of $\mathrm{UO}_{2}$ Density on Fission Product Gas Release and Sheath Expansion. Nuclear Applications, Volume 2, April, pg. 117-122.

52. England, T.R., Rider, B. F., 1994. Evaluation and Compilation of Fission Product Yields 1993, Los Alamos National Laboratory, LA-UR-94-3106, ENDF-349, October.

53. Chadwick, M.B., 2011. ENDF/B-VII.1 Nuclear Data for Science and Technology: Cross Sections, Covariances, Fission Product Yields and Decay Data, Nuclear Data Sheets, Volume 112, Issue 12, December, pg 2887-2996.

54. Guenther, R. J., Blahnik, D.E., Campbell, T.K., Jenquin, U.P., Mendel, J.E., Thomas, L.E., Thornhill, C.K., 1991. Characterization of Spent Fuel Approved Testing Material - ATM-105, Pacific Northwest Laboratory, PNL-5109-105, December.

55. Zwicky, H. U., Low, J., Granfors, M., Alejano, C., Conde, J.M., Casado, C., Sabater, J., Lloret, M., Quecedo, M., Gago, J.A., 2010. Nuclide analysis in high burnup fuel samples irradiated in Vandellos 2, Journal of Nuclear Materials, Vol. 402, pg 60-73.

56. The Third Riso Fission Gas Project ANF Fuel, Riso, Riso-FGP3-ANF, September 1990.

57. Guenther, R. J., Blahnik, D.E., Campbell, T.K., Jenquin, U.P., Mendel, J.E., Thornhill, C.K., 1988. Characterization of Spent Fuel Approved Testing Material - ATM-106, Pacific Northwest Laboratory, PNL-5109-106, October.

58. Bresesti, A., Bresesti, M., Facchetti, S., 1972. Post-Irradiation Analysis of Trino-Vercellese Reactor Fuel Elements, EUR-4909, Joint Nuclear Research Centre Ispra and Karlsruhe Establishments.

59. Barbero, P., Bidoglio, G., Bresesti, M., 1977. Post-Irradiation Examination of the Fuel Discharged from the Trino Vercellese Reactor after the $2^{\text {nd }}$ Irradiation Cycle, EUR-5605, Joint Research Centre Ispra and Karlsruhe Establishments. 
60. Barbero, P., et al., 1980. Post Irradiation Analysis of the Obrigheim PWR Spent Fuel, EUR $6589 \mathrm{en}$, Commission of the European Communities, Joint Research Center, Ispra Establishment, Italy.

61. Post-Irradiation Analysis of the Gudremmingen BWR Spent Fuel, 1979. Nuclear Science and Technology, Commission of the European Communities, ISBN 92-825-1099-9.

62. Personal communication with Kevin Carney, Idaho National Laboratory (August 2014).

63. Wernsberger, B., Schlosser, C., 2004. Noble Gas monitoring within the international monitoring system of the comprehensive nuclear test-ban treaty, Radiation Physics and Chemistry. 71, 775779 .

64. Kalinowski, M.B., Pistner, C., 2006. Isotopic signature of atmospheric xenon released from light water reactors, Journal of Environmental Radioactivity. 88, 215-233. 
APPENDIX A. CORRECTING FISSION YIELD INCONSISTENCIES 



\section{APPENDIX A. CORRECTING FISSION YIELD INCONSISTENCIES}

\section{A.1 FORMALIZED FISSION YIELD DEFINITIONS}

The independent yield $I$ is the number of atoms of a fission product nuclide that is directly produced by a single fission after the emission of prompt neutrons but before the emission of delayed neutrons. The independent fission product yields can be calculated from the sum yield $Y$ and the fractional independent yield $f$ by the relation

$$
I(A, Z, M ; \vec{\eta})=Y(A ; \vec{\eta}) f(Z, A ; \vec{\eta}) R(A, Z, M ; \vec{\eta})
$$

where $R$ is the correction term for the isomeric yield ratio. Each independent yield is specified by the triplet $A, Z, M$, where $A$ is the mass number and $Z$ is the atomic number, while $M$ represents the isomeric state $\left(M=0\right.$ for the ground state, $M=1,2, \ldots$ for the $1^{\text {st }}, 2^{\text {nd }}, \ldots$ excited states). The quantity $\vec{\eta}=$ $\left\{A_{f}, Z_{f}, E_{n}\right\}$ refers to the mass and atomic number of the fissioning nucleus (denoted by $A_{f}$ and $Z_{f}$, respectively). For neutron-induced fission, the energy $E_{n}$ is positive and $A_{f}=A_{\text {target }}+1$ is the compound fissioning nucleus, while for spontaneous fission, $E_{n}=0$ and $A_{f}=A_{\text {target }}$ is the mass number of the fissioning nucleus. Omitting the variable $\vec{\eta}$, the unitary condition of the fractional yields,

and of the isomeric yield ratios,

$$
\sum_{Z} f(A, Z)=1 \quad \forall A,
$$

$$
\sum_{M} R(A, Z, M)=1 \quad \forall A, Z,
$$

implies the sum of all independent yields of mass number $A$ equals the sum yield $Y(A)$,

$$
\sum_{Z M} I(A, Z, M)=Y(A) \quad \forall A .
$$

We note that, with the exception of delayed neutron $(\beta n)$ emissions and the very few long-lived $\alpha$ decays, all fission products decay through isomeric transitions or $\beta^{ \pm}$modes for which the mass number $A$ is unaltered. Thus, to a very good approximation, the fission products can be considered as belonging to distinct mass chains and can be conveniently expressed by the equation above.

In addition, independent yield data must satisfy three conditions. First, the total yield must be normalized to 2 (two) fragments per fission

$$
\sum_{A Z M} I(A, Z, M)=2,
$$

where the index runs over each fission product yield. This condition is automatically fulfilled when the unitary conditions of the previous equations are satisfied and the total sum yield is constrained to

$$
\sum_{A} Y(A)=2
$$

where the index runs over each fission product with the same mass.

Second, the total mass must be the mass of the fissioning compound nucleus minus the average total number of nucleons $v$ emitted before and after fission, $A_{f}^{\prime}=A_{f}-v$, 
or equivalently,

$$
\sum_{A Z M} A I(A, Z, M)=A_{f}^{\prime}
$$

$$
\sum_{A Z} A Y(A)=A_{f}^{\prime} .
$$

For high-energy neutron induced fission, the quantity $v$ also needs to include the pre-fission neutrons since nucleons may be emitted before fission during de-excitation of a highly excited nucleus. For instance, above the threshold of first chance fission, there are two fissioning compound nuclei, $A_{f}$ and $A_{f}-1$. For excitation energy $E_{c} \lesssim 8 \mathrm{MeV}$ or for neutron incident energy $E_{n} \lesssim 2 \mathrm{MeV}$, it is a good approximation to assume $v$ as the average number of the prompt fission neutrons, $v_{F}$. nucleus

The third condition is placed on the total charge that must be the same as that of the fissioning

or equivalently,

$$
\sum_{A Z M} Z I(A, Z, M)=Z_{f}
$$

$$
\sum_{A Z} Z Y(A) f(A, Z)=Z_{f} .
$$

The cumulative yield $C$ of $A, Z, M$ is the total number of atoms of that nuclide produced over all time after one fission. If the nuclide is stable at the end of the chain, the cumulative yield is the total number of atoms remaining per fission. Therefore, the relation between independent and cumulative yields is

$$
C_{i}(\boldsymbol{I})=I_{i}+\sum_{j \in \boldsymbol{k}^{i}} C_{j}(\boldsymbol{I}) b_{i, j},
$$

where the index $i$ refers to each independent and cumulative yields identified by the triplet $A, Z, M$. The index $j$ refers to all possible decay modes $\left(\beta n, \beta^{-}\right.$, isomeric transition...) for the formation of the nucleus labeled by $i$. The index $j$ can be seen as running over the components of a vector $\boldsymbol{k}^{i}$ containing the pointers to specify the decaying nucleus identified by $j$ and the related fraction $b_{i, j}$ to the daughter nucleus $i$. The total number of nuclei decaying to the $i^{\text {th }}$ nucleus is given by the dimension of vector $\boldsymbol{k}^{i}$, i.e., $n_{i}=\operatorname{dim}\left(\boldsymbol{k}^{i}\right)$. In matrix notation, the vector of the cumulative yields can be written as

$$
\boldsymbol{C}=\boldsymbol{I} \boldsymbol{Q}^{\mathrm{T}},
$$

where the vector $I$ contains the independent fission product yields (FPYs) ordered accordingly to the elements of the lower triangular matrix $\boldsymbol{Q}$. In the simplest case where a set of nuclei in the ground state are decaying by $\beta^{-}$, the matrix elements of $\boldsymbol{Q}$ can be written as

$$
Q_{i, j}=\prod_{k=j}^{i-1} b_{k+1, k} .
$$

The relation between independent and cumulative yields can be seen as a system of coupled linear equations. The coupling among different equations depends on decay modes like $\beta n$ or $\alpha$-particle emissions, and the coefficients of the equations are defined by the branching ratios $b$. Therefore, the elements of the matrix $\boldsymbol{Q}$ coincide with the partial derivatives of the $i^{\text {th }}$ cumulative yield $C_{i}$ with respect to $j^{\text {th }}$ independent yield as

$$
\frac{\partial C_{i}(\boldsymbol{I})}{\partial I_{j}}=Q_{i j}
$$




\section{A.2 CORRECTION UTILIZING A BAYESIAN METHOD}

The methodology developed to adjust independent FPYs is based on a Bayesian technique. This method allows the entire statistical information of the cumulative FPY data (central values and uncertainties) to be included in the estimation of the related independent FPYs. In applying this method, the matrix $\boldsymbol{Q}$ was computed on the basis of the ENDF-B/VII.1 decay sub-library and arranged according to the list of independent and cumulative FPY used in the ORIGEN code. The evaluation starts with defining the quantities for the least squares condition,

$$
(\boldsymbol{\xi}-\boldsymbol{f}(\boldsymbol{I}))^{\mathrm{T}} \boldsymbol{P}^{-1}(\boldsymbol{\xi}-\boldsymbol{f}(\boldsymbol{I}))=\min .
$$

Here the (transpose) vector $\xi^{\mathrm{T}}=\left(\boldsymbol{\Lambda}, \zeta, 2, A_{f}^{\prime}, Z_{f}\right)^{\mathrm{T}}$ is the combined set of prior independent FPY estimates, $\boldsymbol{\Lambda}$, the cumulative FPY used as measured data, $\boldsymbol{\zeta}$, and the values of the constraints to be applied on the set of parameters $\boldsymbol{I}$. The corresponding (transpose) model vector is defined as $\boldsymbol{f}(\boldsymbol{I})^{\mathrm{T}}=$ $\left(\boldsymbol{I}, \boldsymbol{C}(\boldsymbol{I}), \sum_{k} I_{k}, \sum_{k} A_{k} I_{k}, \sum_{k} Z_{k} I_{k}\right)^{\mathrm{T}}$, while the input covariance matrix is accordingly arranged as

$$
\boldsymbol{P}=\left(\begin{array}{llll}
\boldsymbol{M} & & & \\
& \boldsymbol{D} & & \\
& & \sigma_{T}^{2} & \\
& & \sigma_{U}^{2} & \\
& & & \sigma_{V}^{2}
\end{array}\right)
$$

$\boldsymbol{M}$ is a diagonal covariance matrix of the prior independent FPYs whose elements are defined on the basis of the uncertainties found in ENDF/B-VII.1 library, likewise, the diagonal covariance matrix $\boldsymbol{D}$ which is associated with the cumulative yield vector $\zeta$. The three parameters, $\sigma_{T}, \sigma_{U}, \sigma_{V}$ are used to control the precision on the constraints. The updated covariance matrix $\boldsymbol{M}^{\prime}$ for the set of updated parameters $\boldsymbol{I}^{\prime}$ is found by the relation

$$
\boldsymbol{M}^{-1}=\boldsymbol{S}^{\mathrm{T}} \boldsymbol{P}^{-1} \boldsymbol{S}
$$

where $\boldsymbol{S}^{\mathrm{T}}=(\mathbb{I}, \boldsymbol{Q}, \mathbf{1}, \boldsymbol{A}, \boldsymbol{Z})^{\mathrm{T}}$ is the rectangular matrix associated with the sensitivities of the prior parameters defined by the identity matrix $\mathbb{I}$ and those ones of the cumulative FPY defined by $\boldsymbol{Q}$. The other three sensitivities are for the three constraints aforementioned. Namely, the $N$-dimensional vectors are defined as $\mathbf{1}^{\mathrm{T}}=\left\{1_{1}, \ldots, 1_{N}\right\}, \boldsymbol{A}^{\mathrm{T}}=\left\{A_{1}, \ldots, A_{N}\right\}$, and $\boldsymbol{Z}^{\mathrm{T}}=\left\{Z_{1}, \ldots, Z_{N}\right\}$ where each component of the vectors $\boldsymbol{A}$ and $\boldsymbol{Z}$, i.e., $A_{k}$ and $Z_{k}$, refers to the mass and charge number of the parameter $I_{k}$, respectively. Due to the simple form of the matrix $\boldsymbol{P}$, the updated covariance matrix can be written in explicit form as

$$
\boldsymbol{M}^{\boldsymbol{\prime}^{-1}}=\boldsymbol{M}^{-1}+\boldsymbol{Q}^{\mathrm{T}} \boldsymbol{D}^{-1} \boldsymbol{Q}+\left(\mathbf{1}^{\mathrm{T}} \otimes \mathbf{1}\right) \sigma_{T}^{-2}+\left(\boldsymbol{A}^{\mathrm{T}} \otimes \boldsymbol{A}\right) \sigma_{U}^{-2}+\left(\boldsymbol{Z}^{\mathrm{T}} \otimes \boldsymbol{Z}\right) \sigma_{V}^{-2}
$$

while the updated set of parameters is given by

$$
\boldsymbol{I}^{\prime}=\boldsymbol{I}+\boldsymbol{M}^{\prime} \boldsymbol{Q}^{\mathrm{T}} \boldsymbol{D}^{-1}(\boldsymbol{\zeta}-\boldsymbol{C}(\boldsymbol{I}))
$$

where the contribution of the matrices $\mathbb{I}, \mathbf{1}, \boldsymbol{A}, \boldsymbol{Z}$, namely,

$$
\boldsymbol{M}^{\prime}\left[\mathbb{I}^{\mathrm{T}}(\boldsymbol{I}-\boldsymbol{\Lambda})+\mathbf{1}^{\mathrm{T}} \sigma_{T}^{-2}\left(2-\sum_{k} I_{k}\right)+\boldsymbol{A}^{\mathrm{T}} \sigma_{U}^{-2}\left(A_{f}^{\prime}-\sum_{k} A_{k} I_{k}\right)+\boldsymbol{Z}^{\mathrm{T}} \sigma_{V}^{-2}\left(Z_{f}-\sum_{k} Z_{k} I_{k}\right)\right]
$$

is identically zero since we have chosen the vector of the prior parameter to coincide with the values found in ENDF/B-VII.1, namely, $\boldsymbol{\Lambda}=\mathbf{I}$, as well as the values of the three constraints. 